\title{
Dynamics of Social and Individual Preferences: Evidence from Madagascar
}

\author{
Thesis \\ in fulfillment of the \\ requirements for the degree of Dr. rer. pol \\ from the Faculty of Economics at \\ Georg-August-University Göttingen
}

submitted by

Viviana Alexandra Urueña Moyano

born on February 22, 1989 in Bogotá, Colombia

Göttingen, April 2021 
1. Referee: Prof. Marcela Ibañez Diaz, Ph.D.

2. Referee: Prof. Dr. Holger Rau

3. Referee: Prof. Dr. Francisco Alpízar Rodriguez

Date of submission: April 14, 2021 


\section{Declaration of Authorship \\ Versicherung gemäß Prüfungs- und Studienordnung für den Promozionsstudiengang "Wirtchaftswissenschaften" der Georg-August-Universität Göttingen}

Ich versichere,

1. dass ich die eingereichte Dissertation "Dynamics of Social and Individual Preferences: Evidence from Madagascar" selbstständig angefertigt habe und nicht die Hilfe Dritter in einer dem Prüfungsrecht und wissenschaftlicher Redlichkeit widersprechenden Weise in Anspruch genommen habe,

2. dass ich das Prüfungsrecht einschließlich der wissenschaftlichen Redlichkeit- hierzu gehört die strikte Beachtung des Zitiergebots, so dass die Übernahme fremden Gedankenguts in der Dissertation deutlich gekennzeichnet ist- beachtet habe,

3. dass beim vorliegenden Promotionsverfahren kein Vermittler gegen Entgelt eingeschaltet worden ist sowie im Zusammenhang mit dem Promotionsverfahren und seiner Vorbereitung.

- kein Entgelt gezahlt oder entgeltgleiche Leistungen erbracht worden sind.

- keine Dienste unentgeltlich in Anspruch genommen wurden, die dem Sinn und Zweck eines Prüfungsverfahrens widersprechen.

4. dass ich eine entsprechende Promotion nicht anderweitig beantragt und hierbei die eingereichte Dissertation oder Teile daraus vorgelegt habe.

Mir ist bekannt, dass Unwahrheiten hinsichtlich der vorstehenden Versicherung die Zulassung zur Promotionsprüfung ausschließen und im Falle eines späteren Bekanntwerdens die Promotionsprüfung für ungültig erklärt werden oder der Doktorgrad aberkannt werden kann.

April 14, 2021

Datum, Unterschrift 


\section{Overview of co-authors}

This dissertation includes four chapters that were written in joint work with co-authors, a general introduction, and a conclusion. In this section, I describe the contributions by each of the co-authors and myself.

1. The paper "Procedural Preferences in Competitive Environments: A field experiment in Madagascar" is co-authored with Prof. Marcela Ibañez Diaz PhD and Jun.-Prof. Dr. Gehard Riener. The experimental design and instruments were developed by Marcela Ibañez and Gerhard Riener. Viviana Urueña recruited the enumerators team in Madagascar and with Marcela Ibañez conducted the pilot of the experiment. After some changes, Viviana Urueña finished the data collection process. Viviana Urueña performed the data cleaning and analysis, initial literature review, and prepared the first draft of the paper. Marcela Ibañez contributed to the data analysis and improved the storyline of the paper. All three authors contributed to the final draft of the paper.

2. The two following chapters of this dissertation: "The costs of betrayal aversion: The case of vanilla production in Madagascar", and "It pays to be green: The role of persuasive communication to foster conservation", are joint work with Prof. Marcela Ibañez Diaz PhD and Jun.-Prof. Dr. Gehard Riener. All three authors jointly developed the research idea, experimental design and instruments. Viviana Urueña recruited the enumerators team in Madagascar and with Marcela Ibañez conducted the two rounds of pilots for the third paper. Viviana Urueña conducted the data collection, the literature review, conceptual framework, analyzed the data and prepared the first draft of the two papers. Marcela Ibañez contributed to the data analysis and improved the writing. Gehard Riener provided feedback during the writing process and provided helpful suggestions for the data analysis. All authors contributed to the final drafts.

The fieldwork for the three papers mentioned above was funded by the project 'Diversity Turn in Land Use Science'.

3. The paper "Can role models influence female's decision to participate in the labor market? Evidence from a field experiment" is co-authored with Christina Martini. Christina Martini and Viviana Urueña jointly developed the research idea, the experimental design and the instruments (video scripts, experimental instructions, post-experimental survey, and application forms). Viviana Urueña collected and cleaned the data. Christina Martini cleaned and analyzed the data and provided the initial literature review. Viviana Urueña contributed to the data analysis and the literature review. Both authors wrote the final draft of the paper. 
The data collection for this study was possible from the funding provided by the project 'Diversity Turn in Land Use Science' and the 'GlobalFood' Program.

April 14, 2021

Datum, Unterschrift 


\section{Acknowledgements}

This dissertation was written as part of the research project "Diversity Turn in Land use Science: The importance of social diversity for sustainable land use innovations using the example of vanilla farming in Madagascar", financed by the "Niedersächsisches Vorab" of Volkswagen Foundation. I gratefully acknowledge the financial support that was given to make this dissertation possible.

I wish to express my sincere appreciation to Prof. Marcela Ibañez $\mathrm{PhD}$, my first supervisor or "Doktormutter", for her guidance during the PhD program. I thank her for trusting me with this amazing project and for her constant support both in Germany and Madagascar. Her constructive and encouraging feedback greatly enriched this work. I also would like to thank Prof. Dr. Holger Rau, my second supervisor, for giving very detailed and helpful comments, which substantially improved this dissertation. I also thank Prof. Dr. Francisco Alpízar for taking part in my research committee. I wish to show my gratitude to my co-author Prof. Dr. Gehard Riener for his interest in developing joint research projects and for his helpful comments and contributions along the process.

I want to thank Hendrik Hänke and Yvonne Franke for facilitating my fieldwork in Madagascar and for the great and helpful seminars organized as part of the Diversity Turn certification program. I thank all professors involved in the project for their feedback in my research projects. I am immensely grateful to Diversity Turn PhD Team for their support and company during fieldwork and crystallize the word 'interdisciplinarity'. I leave with new perspectives, methods and interests cultivated during our constant exchange. I thank Kristina and Dominic for teaching me so much about agro-ecology and for their emotional and professional support. To Annemarie, I want to thank immensely for her kindness, for listening to me every time I needed it, and for making me smile even in the toughest times during my PhD. I thank Lloyd and Annette for sharing their knowledge with me. I thank Janna for each of our talks, which I appreciate very much. I thank her for giving me strength and hope in difficult times and helping me put everything into perspective. I also thank my malagasy colleagues Andry, Fulgence, Estelle, Marie Rolande, and Fanilo for enriching my knowledge about Madagascar and for their feedback on my papers. Special thanks to Fulgence and Marie Rolande for accepting to actively take part in one of my experiments. You are role models for the malagasy youth!

I would like to recognize the invaluable assistance that my team in Madagascar provided for this research. Without their dedication and hard work this dissertation would not have been possible: Parker, Jockline, Salma, Josie, Raissa, Marius, Elsa, Tatiana, Thorien, Angelico, Gatien, Ophelia, Willie, Crio, Jaclin, Jean Yves, Francisco, Vanessa, Mirina, and Richie (our great driver who brought us safe after every mission). I thank them for 'giving $110 \%$ ' each day of data collection and for teaching me so much about Madagascar. I also 
thank Evrard for his invaluable work, for taking care of me in the field, and for sharing his dream of the school garden with me, which I hope will help many families in SAVA. I also thank the team of Duke Lemur Center-SAVA, Dr. James Herrera, Laura De Ara, Lanto Andrianandrasana and Charlie Welch for their support in one of my research projects.

Special thanks to my chair, to the now 'old doctors' Kerstin, Guida and Sebastian from whom I learned during the early years of my Phd and take good memories with me. To the 'recent doctors' and office neighbors, Daniel and Pooja who filled my days with joy and a good chat. I thank my co-author, colleague, and friend (and now doctor) Tina, for her commitment and hard work in our joint paper, for her advice and guidance. It was a pleasure working together with her. I also thank Tatiana for taking the time to read my papers, for her comments, her company, friendship, and support during the last years. I thank Dr. Alexia Gaudeul for her interest and feedback on my work.

I also acknowledge the support of very special people I got to know during the $\mathrm{PhD}$ and from whom I learned greatly. I am incredibly grateful to Cansin for her unconditional help and for her insightful comments and suggestions on my papers. She is one of the persons I trust the most, and I am very fortunate to have her in my life. Thousand thanks for encouraging me every time I needed it. I want to thank Max for the great discussions we had about our research ideas and experimental designs, and for his valuable comments and feedback that helped me improve this dissertation. I also thank Raphael for providing detailed and constructive feedback that enhanced the quality of my papers, clarifying doubts, and for having many interesting chats about academia and life.

Juan Felipe R., Juan Felipe O., Angela, and Lorena, my classmates and friends from many years who have been accompanying me along each of my milestones, I thank them very much for their constant encouragement, emotional support, and interest on my research.

I am indebted to Jan, who knows this dissertation upside down. I am thankful for his time and patience, for his very detailed and helpful comments on this dissertation, and for his unconditional support and understanding. Jan arranged and offered me the best working place in our house during the lockdowns so I could focus on the writing of this dissertation and I will always be grateful for that.

A la familia Werner gracias por todo su cariño que ha sido fundamental durante mi tiempo en Alemania. Carmen, gracias a ti por compartir cada uno de mis logros. Por último, quiero agradecer a mi familia por su apoyo y amor incondicional. Gracias a ustedes he logrado cumplir cada uno de mis propósitos. A mi papá, gracias por darme una palabra de aliento cada vez que la necesito, por enseñarme a ser perseverante y disciplinada. Mamá, gracias por todo el amor que me das, por recordarme que todo tiene solución (excepto una cosa) y por enseñarme a disfrutar cada momento de la vida, incluso los más difíciles. A mis hermanas, gracias por su amor, paciencia y comprensión.

There are many other people I do not mention but who also played an important role during my $\mathrm{PhD}$ and who know they were part of this process in many different ways. To you, thank you very much for being there and for your support in the last years. 
"The call to action is not just for academic economists - it is for all of us who want a better, saner, more humane world. Economics is too important to be left to economists."

Abhijit Banerjee and Esther Duflo,

Good Economics for Hard Times: Better Answers to Our Biggest Problems 


\section{Contents}

$\begin{array}{ll}\text { Acknowledgments } & \text { ix }\end{array}$

List of Tables $\quad$ xvii

List of Figures $\quad$ xix

List of Acronyms $\quad$ xxi

1 General Introduction 1

1.1 Thesis Overview . . . . . . . . . . . . . . . . . 3

1.1.1 Chapters 2 and 3: Procedural preferences and betrayal aversion . . . 3

1.1.2 Chapter 4: Charitable giving for the environment . . . . . . . . 6

1.1.3 Chapter 5: Aspirations, competition and labor market . . . . . . . 7

1.2 Thesis Contributions . . . . . . . . . . . . . . . . . . 9

1.3 Thesis Limitations . . . . . . . . . . . . . . . . . . . . . . . . 11

2 Procedural Preferences in Competitive Environments 13

2.1 Introduction . . . . . . . . . . . . . . . . . . . . . . 15

2.2 Experimental Design and Procedures . . . . . . . . . . . . . . . . . 18

2.2.1 General Structure . . . . . . . . . . . . . . . . . . . . 18

2.2 .2 Treatments . . . . . . . . . . . . . . . . . 20

2.2 .3 Hypotheses . . . . . . . . . . . . . . . . . . . . . 21

2.2 .4 Procedures . . . . . . . . . . . . . . . . . 22

2.3 Results . . . . . . . . . . . . . . . . . . . . . . . 23

2.3.1 Descriptive statistics and randomization checks . . . . . . . . . 23

2.3.2 Selection of options in the unfair procedures . . . . . . . . . . . . . 24

2.3.3 Factors affecting the exploitation of advantages . . . . . . . . . . 25

2.3.4 Altruism, Trust and Trustworthiness . . . . . . . . . . . . . . 27

2.3.5 Treatment effects on other-regarding behaviors . . . . . . . . . . 28

2.4 Discussion . . . . . . . . . . . . . . . . . . . . . . . 30

2.5 Conclusion . . . . . . . . . . . . . . . . . . . . . . 31

2.6 Appendices . . . . . . . . . . . . . . . . . . . . 34

2.6.1 Appendix A - Tables . . . . . . . . . . . . . . . . 34

2.6.2 Appendix B — Experimental Instructions and Survey . . . . . . . . 39 
3 The costs of betrayal aversion:

$\begin{array}{ll}\text { The case of vanilla production in Madagascar } & 61\end{array}$

3.1 Introduction . . . . . . . . . . . . . . . . . . . . . . 63

3.2 Conceptual Framework . . . . . . . . . . . . . . . . . . . . . . 65

3.3 Local Context . . . . . . . . . . . . . . . . . . . . . . . . . . 67

3.4 Experimental design . . . . . . . . . . . . . . . . . . . . . . . . 69

3.4.1 Betrayal aversion elicitation . . . . . . . . . . . . . . 69

3.4 .2 Inequality aversion . . . . . . . . . . . . . . . . . . 70

3.4 .3 Baseline Survey . . . . . . . . . . . . . . . . . . . . . . . . 71

3.4.4 Experimental Procedure . . . . . . . . . . . . . . . . . 72

3.5 Results . . . . . . . . . . . . . . . . . . . . . . 73

3.5.1 Sample characteristics . . . . . . . . . . . . . . . 73

3.5.2 Betrayal attitude of farmers . . . . . . . . . . . . . . . . 77

3.5.3 Betrayal attitudes and decision-making . . . . . . . . . . . . . 81

3.5.4 Exploratory analysis . . . . . . . . . . . . . . . . . . 83

3.6 Robustness checks . . . . . . . . . . . . . . . . . . . . . 85

3.7 Discussion and Conclusion . . . . . . . . . . . . . . . . . . . . 86

3.8 Appendices . . . . . . . . . . . . . . . . . . . . . . 89

3.8.1 Appendix A — Tables . . . . . . . . . . . . . . . . 89

3.8.2 Appendix B — Figures . . . . . . . . . . . . . . . . . . . . 93

3.8.3 Appendix C — Experimental Instructions and Surveys . . . . . . . . 97

4 "It pays to be green": The role of persuasive communication $\begin{array}{ll}\text { to foster conservation } & 145\end{array}$

4.1 Introduction . . . . . . . . . . . . . . . . . . . . . . . . . 147

4.2 Conceptual framework and hypothesis . . . . . . . . . . . . . . . . . . 150

4.3 Context . . . . . . . . . . . . . . . . . . . . . . . . . 152

4.4 Experimental Design and Procedures _. . . . . . . . . . . . . . . 154

4.4.1 Experimental Design . . . . . . . . . . . . . . . . . . . 154

$4.4 .2 \quad$ Experimental Procedures _. . . . . . . . . . . . . . . . 159

4.5 Results . . . . . . . . . . . . . . . . . . . . . . 161

4.5.1 Summary statistics . . . . . . . . . . . . . . . . . . 161

4.5.2 Effort provision: Extensive and intensive margins . . . . . . . . . . 163

4.5.3 Environmental concerns and giving . . . . . . . . . . . . . 166

4.5.4 Additional analysis . . . . . . . . . . . . . . . . . . . . . . 169

4.6 Conclusions and Discussion . . . . . . . . . . . . . . . . . . . . 172

4.7 Appendices . . . . . . . . . . . . . . . . . . . . . . 173

4.7.1 Appendix A — Selection . . . . . . . . . . . . . . . 173

4.7.2 Appendix B — Audios . . . . . . . . . . . . . . . . . . . . 174

4.7.3 Appendix C — Example green and blue bookmarks . . . . . . . . 175

4.7.4 Appendix D - Regression analysis . . . . . . . . . . . . . . . . 175

4.7.5 Appendix E — Instructions . . . . . . . . . . . . . . . 177 
5 Can role models influence female's decision

$\begin{array}{ll}\text { to participate in the labor market? } & 195\end{array}$

5.1 Introduction . . . . . . . . . . . . . . . . . . . . . . 197

5.2 Field Setting . . . . . . . . . . . . . . . . . . . 200

5.3 Experimental Design . . . . . . . . . . . . . . . . . . . . . . 201

5.3.1 Experimental Procedures . . . . . . . . . . . . . . . . 208

5.4 Hypotheses . . . . . . . . . . . . . . . . . . . . . . . . . 210

5.5 Empirical Strategy . . . . . . . . . . . . . . . . . . . . . . . . . 212

5.6 Results . . . . . . . . . . . . . . . . . . . . . . . . . 212

5.6.1 Descriptive Statistics and Randomization Checks . . . . . . . . . . . 212

5.6.2 Treatment Effects on Applications . . . . . . . . . . . . . . . . . 213

5.6.3 Role Model Assessment . . . . . . . . . . . . . . . . . . . . . . . . 217

5.7 Exploratory Analysis . . . . . . . . . . . . . . . . . . . . . . . 218

5.7.1 Descriptive Statistics of Mechanism Variables . . . . . . . . . . . . 218

5.7.2 Treatment Effects on Mechanism Variables . . . . . . . . . . . . . 219

5.7.3 Can the Mechanism Variables Explain Behavior in the Field Experi-

ment? . . . . . . . . . . . . . . . . . 222

5.8 Discussion and Conclusion . . . . . . . . . . . . . . . . . . . . 223

5.9 Appendices . . . . . . . . . . . . . . . . . . . . . 227

5.9 .1 Appendix A - Tables . . . . . . . . . . . . . . 227

5.9.2 Appendix B - Experimental Instructions and Survey . . . . . . . . 231

5.9.3 Appendix C — Video Scripts . . . . . . . . . . . . . . . . . . 264

$\begin{array}{ll}\text { Bibliography } & 290\end{array}$ 


\section{List of Tables}

2.1 Matching Pennies Game . . . . . . . . . . . . . . . . . . . . . . 19

2.2 Treatment Description . . . . . . . . . . . . . . . . 20

2.3 Determinants Anti-Social behavior . . . . . . . . . . . . . . 27

2.4 Treatment effects on other-regarding behaviors . . . . . . . . . . 30

2.A1 Socioeconomic Characteristics by Treatment . . . . . . . . . . . . . 34

2.A2 Socioeconomic Characteristics by Role . . . . . . . . . . . . . . . 35

2.A3 Decision in the Second Stage by Player A . . . . . . . . . . . . . . 36

2.A4 Determinants Anti-Social behavior . . . . . . . . . . . . . 37

2.A5 Orthogonality Table . . . . . . . . . . . . . . . . . 38

2.A6 Multiple Hypothesis Testing _ . . . . . . . . . . . . . . . . . 38

2.B1 Examples Control questions Activity Green . . . . . . . . . . . . . . . . . 41

2.B2 Activity White . . . . . . . . . . . . . . . . . . 48

3.1 Game payoffs . . . . . . . . . . . . . . . . . . . 71

3.2 Overview of participants by visit . . . . . . . . . . . . 73

3.3 Sample Characteristics . . . . . . . . . . . . . . . . 76

3.4 Determinants Betrayal Attitudes . . . . . . . . . . . . . . 80

3.A1 Other studies: Betrayal aversion coefficients and individual types . . . . . 89

3.A2 Determinants Betrayal Aversion _. . . . . . . . . . . . . . 90

3.A3 Regression Coefficients . . . . . . . . . . . . . . . . . . . 91

3.A4 Regression Coefficients High and Low Victimization . . . . . . . . . . . . 91

3.A5 Orthogonality Table by order of Social Risk game . . . . . . . . . . . . 92

3.A6 Regression Coefficients Order of the Games . . . . . . . . . . . . . . . 92

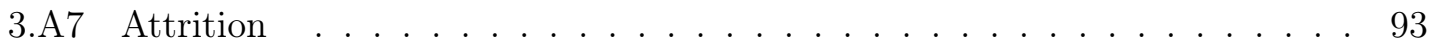

3.C1 Earnings Table Activity Triangle . . . . . . . . . . . . . . . . . 100

3.C2 Decision Sheet Activity Triangle . . . . . . . . . . . . . . . . . . . . . 100

3.C3 Earnings Table Activity Circle . . . . . . . . . . . . . . . . . . . . 102

3.C4 Decision Sheet Activity Circle . . . . . . . . . . . . . . . . . . . 102

4.1 Treatment groups . . . . . . . . . . . . . . . . . . . 157

4.2 Orthogonality Table . . . . . . . . . . . . . . . . . . . . . . 162

4.3 Treatment effects on effort (Full sample, OLS and Tobit models) . . . . . . . 165

4.4 Treatment effects: Subsample analysis by type (Panel: OLS and Tobit models) 168

4.5 Treatments and education level (Panel: OLS and Tobit models) . . . . . . . . 170

4.6 Donations to each generation . . . . . . . . . . . . . . . . 170 
4.7 Treatments and intergenerational altruism (Panel: OLS and Tobit models) . . 171

4.A1 Village types and sample size . . . . . . . . . . . . . . . . . 173

4.D1 Treatment effects on effort (Full sample, OLS and Tobit models) . . . . . . . . 176

4.D2 Multiple Hypothesis Testing . . . . . . . . . . . . . . . . . . . . . . . 176

5.1 Treatment Effects on Applications . . . . . . . . . . . . . . . . 215

5.2 Rating of the Role Model . . . . . . . . . . . . . . . . . . . . . 218

5.3 Mechanism Variables in the Placebo Group . . . . . . . . . . . . . . . . . 219

5.4 Treatment Effects on Performance and Competitive Preferences . . . . . . 221

5.5 Treatment Effects on Aspirations and Beliefs . . . . . . . . . . . . . . . . 222

5.6 Relation of Mechanism Variables to Complete Application . . . . . . . . . 223

5.A1 Summary Statistics . . . . . . . . . . . . . . . . . . . . 227

5.A2 Treatment Effects on Applications: Probit Model . . . . . . . . . . . . . . 228

5.A3 Multinomial Logit Complete Applications . . . . . . . . . . . . . . . . . . 229

5.A4 Aspirations in the Placebo Group by gender . . . . . . . . . . . . . . . . 230

5.A5 Multiple Hypothesis Testing . . . . . . . . . . . . . . . . . . 230 


\section{List of Figures}

$2.1 \quad$ Structure of Experimental Session _ . . . . . . . . . . . . . . . 20

2.2 Study region . . . . . . . . . . . . . . . . . . . . . . . 23

2.3 Share of Players A Exploiting the Advantage . . . . . . . . . . . . . 25

2.4 Evolution of other regarding behaviors across treatments . . . . . . . . . 28

2.B1 Payment Activity Green . . . . . . . . . . . . . . . . . . . . . . 40

2.B2 Decision sheet Activity Green . . . . . . . . . . . . . . . . . . . . 42

2.B3 Decision sheet Activity Blue Person B - 2,000 ariary . . . . . . . . . . . . 44

2.B4 Decision sheet Activity Blue Person A . . . . . . . . . . . . . . 46

2.B5 Decision sheets Activity Blue Person B . . . . . . . . . . . . . . 47

2.B6 Example Activity White T1 - Person D . . . . . . . . . . . . . . . . . 49

2.B7 Decision sheets Activity White T1 - Person D . . . . . . . . . . . . . . 50

2.B8 Example Activity White T2 - Person D . . . . . . . . . . . . . 51

2.B9 Decision sheets Activity White T2 - Person D . . . . . . . . . . . . . . 52

2.B10 Decision sheet Activity Green . . . . . . . . . . . . . . . 53

2.B11 Decision sheet Activity Blue Person A . . . . . . . . . . . . . . 54

2.B12 Decision sheets Activity Blue Person B . . . . . . . . . . . . . . . 55

3.1 Sequence of Experimental Session and Follow-up Surveys . . . . . . . . . . 69

$3.2 \quad$ Betrayal Aversion Elicitation . . . . . . . . . . . . . . . . . . . . 70

3.3 Distribution of MAPs . . . . . . . . . . . . . . . . . . . . 77

3.4 Distribution Betrayal Aversion Coefficient . . . . . . . . . . . . . 78

3.5 Relation between betrayal aversion attitudes and outcome variables . . . . 82

3.6 Analysis comparing Victimization levels . . . . . . . . . . . . . . . . 84

3.7 Analysis on game played first . . . . . . . . . . . . . . . . 86

3.B1 SAVA region in Madagascar . . . . . . . . . . . . . . . . . 93

3.B2 Social Risk Game . . . . . . . . . . . . . . . . . . . . . . . . . . 94

3.B3 Nature Risk Game . . . . . . . . . . . . . . . . . . . . . . . . . . . . 95

3.B4 Price development of green vanilla harvest $2017 \ldots \ldots$. . . . . . . . . . 95

3.B5 Analysis comparing New and Old Vanilla Farmers . . . . . . . . . . . . . . 96

3.C1 Earnings table example - Activity Green . . . . . . . . . . . . . . . . . . . 104

3.C2 Distribution of groups DELEGATES B - Activity Green . . . . . . . . . . 105

3.C3 Decision sheet - Activity Green . . . . . . . . . . . . . . . . . . 107

3.C4 Earnings Table Activity Green B1 . . . . . . . . . . . . . . . . . . . . 108

3.C5 Earnings Table Activity Green B0 . . . . . . . . . . . . . . . . . . . . 109 
3.C6 Earnings Table Activity Green B9 . . . . . . . . . . . . . . . . . . . . . 109

3.C7 Earnings table example - Activity White . . . . . . . . . . . . . . . 112

3.C8 Distribution of groups DELEGATES B - Activity White . . . . . . . . . . 113

3.C9 Decision sheet - Activity White . . . . . . . . . . . . . . . . 115

3.C10 Earnings Table Activity White B1 . . . . . . . . . . . . . . 116

3.C11 Earnings Table Activity White B0 . . . . . . . . . . . . . . . 117

3.C12 Earnings Table Activity White B9 . . . . . . . . . . . . . . . . . . 117

3.C13 Earnings table - Activity Orange . . . . . . . . . . . . . . . . . . . . 119

3.C14 Decision Sheet Activity Orange . . . . . . . . . . . . . . . . . . . . 120

$4.1 \quad$ Experimental sequence _. . . . . . . . . . . . . . . . . . . . 154

4.2 Average number of green bookmarks by treatment All scenarios, $N=670 \quad 163$

4.3 Average contributions by Scenario . . . . . . . . . . . . . . . . . . 166

4.A1 Household selection . . . . . . . . . . . . . . . . . . . 173

4.C1 Bookmarks . . . . . . . . . . . . . . . . . . 175

$5.1 \quad$ Experimental Sequence . . . . . . . . . . . . . . . . . . . . . . 202

5.2 Example Task . . . . . . . . . . . . . . . . . . 206

5.3 Study Region . . . . . . . . . . . . . . . . . . . . . . . . . . 210

5.4 Complete Applications by Gender and Type of Position in each Treatment 214

5.5 Predictive Margins Multinomial Logit: Complete Applications for each

Position . . . . . . . . . . . . . . . . . . . . . 217

5.B1 Education scale . . . . . . . . . . . . . . . . . . . 235

5. B2 Income scale . . . . . . . . . . . . . . . . . . . . . 235

5. B3 Social Status ladder . . . . . . . . . . . . . . . . . . . 236

5.B4 Asset scale . . . . . . . . . . . . . . . . . . . . . 237 


\section{List of Acronyms}

$\begin{array}{ll}\text { BA } & \text { Betrayal Aversion } \\ \text { CAF } & \text { Charities Aid Foundation } \\ \text { CV } & \text { Curriculum Vitae } \\ \text { DG } & \text { Dictator Game } \\ \text { DLC } & \text { Duke Lemur Center } \\ \text { FMG } & \text { Malagasy franc or 'Franc Malagache' } \\ \text { GPA } & \text { Grade Point Average } \\ \text { GSE } & \text { Generalized Self-Efficacy } \\ \text { HDI } & \text { Human Development Index } \\ \text { ILO } & \text { International Labour Organization } \\ \text { IPBES } & \text { Intergovernmental Science-Policy Platform on Biodiversity and Ecosystem Services } \\ \text { MAP } & \text { Minimum Acceptable Probability } \\ \text { NGO } & \text { Non-Governmental Organization } \\ \text { OLS } & \text { Ordinary Least Squares Estimation/Regression } \\ \text { PPP } & \text { Purchasing Power Parity } \\ \text { SAVA } & \text { Sambava-Antalaha-Vohemar-Andapa Region (Madagascar) } \\ \text { SDGs } & \text { Sustainable Development Goals } \\ \text { SE } & \text { Self-Efficacy } \\ \text { STEM } & \text { Science, Technology, Engineering, and Mathematics } \\ \text { TG } & \text { Trust Game (Sent) } \\ \text { TG-R } & \text { Trust Game (Returned) } \\ \text { UNESCO } & \text { United Nations Educational, Scientific and Cultural Organization } \\ \text { UNFPA } & \text { United Nations Population Fund } \\ \text { UNICEF } & \text { United Nations Children's Fund } \\ \text { USD } & \text { US-Dollar } \\ \text { WEIRD } & \text { Western, Educated,Industrialized, Rich and Democratic } \\ \text { WWF } & \text { World Wide Fund for Nature } \\ & \end{array}$




\section{Chapter 1}

\section{General Introduction}

"How selfish soever man may be supposed, there are evidently some principles in his nature, which interest him in the fortunes of others, and render their happiness necessary to him, though he derives nothing from it except the pleasure of seeing it." Adam Smith, The Theory of Moral Sentiments

When individuals decide whether to take risks, compete with others, or save money, preferences influence their decision-making. While individual preferences have been at the center of the economic theory, social preferences were for centuries ignored in the modeling of decision-making (e.g Sen, 1977; Bowles, 1998; Fehr \& Fischbacher, 2002; Bowles, 2008). Economists started to consider and include social preferences in the individual utility maximization function until the mist 1990s. Since then, the image of the purely self-interested money-maximizer individual has become obsolete. Through economic experiments, behavioral scientists have shown that individuals do not only care about their well-being, but also about others' welfare (Henrich et al., 2001; Fehr \& Fischbacher, 2002). Examples of social or other-regarding preferences are ubiquitous in everyday life. ${ }^{1}$ When individuals trust their doctors, donate to charities, dislike unfairness or inequalities, they reflect such preferences. The most common forms of social preferences are reciprocity, trust, altruism, fairness, and inequality aversion. These preferences have been extensively studied in the literature and while they are difficult to measure, survey questions and incentivized

\footnotetext{
${ }^{1}$ In the remainder of the thesis, I will be using the terms social and other-regarding as synonymous.
} 
economic games have allowed economists to elicit these unobservable characteristics. The most common games used in experimental economics are the "dictator game", the "trust or investment game", the "ultimatum game", and the "public goods game". In this dissertation, variances of some of these games were implemented to measure social preferences.

Ideally, one would like to have universal preferences in order to anticipate behavioral responses to policy interventions or shocks. Yet, individual and social preferences cannot be taken as 'one size fits all'. Several studies have shown that preferences are heterogeneous across multiple socioeconomic characteristics (e.g Henrich et al., 2001; Gneezy et al., 2009; Falk et al., 2018). Moreover, empirical evidence has also shown that preferences are dynamic and can change over an individual's lifetime (Cobo-Reyes et al., 2020), or after individuals are exposed to shocks (e.g Castillo \& Carter, 2011), or can be shaped with the use of interventions such as social information strategies (e.g Meier et al., 2020; Schier, 2020). However, while most empirical research focuses on measuring preferences' dynamics and heterogeneity, few research studies show how they influence economic and social outcomes. In particular, there is little evidence on how preferences can affect individual behavior outside of the laboratory.

This dissertation links individual and social preferences measured in the laboratory to individual characteristics, but most interestingly to real-world decision-making. Surprisingly, even when this topic is of great relevance, links between preferences and behaviors outside the laboratory are difficult to find in the experimental economics literature. One of the few examples is the recent work by Falk et al. (2018). The authors find that more altruistic people are more likely to have friends to help them in times of need, that time preferences are correlated to economic development, and that negative reciprocity is associated with more conflict at the country level.

The overarching motivation of this dissertation is to extend research on factors influencing preferences, and hence decision making, within the framework of an experiment and outside of the controlled setting. This thesis contributes to the economic literature by: (i) investigating how exposure to criminal environments affect social preferences and antisocial behavior (Chapter 2); (ii) examining how betrayal aversion affects investment decisions (Chapter 3); (iii) testing the effectiveness of persuasion messages to promote pro-environmental behavior; (iv) evaluating the effect of a role model intervention on female's participation in the labor market.

To contribute with the existing literature on preferences, we measure social and individual preferences with participants that do not belong to the standard Western, Educated, Industrialized, Rich and Democratic (WEIRD) subject pool. We conducted four field experiments in northeastern Madagascar, in the Sambava-Antalaha-VohemarAndapa (SAVA) region. Three of these experiments are with vanilla farmers and one is with high-school students.

Our research was conducted under the framework of the research project "Diversity Turn in Land use Science: The importance of social diversity for sustainable land use innovations 
using the example of vanilla farming in Madagascar". ${ }^{2}$ This project aimed to investigate the economic, social, and environmental effects of vertical integration in the vanilla sector. In particular, the focus of our work package was to study different behavioral aspects, such as trust, that can explain decision-making. In 2016 we visited the study region for an exploratory visit to collect qualitative information from different stakeholders. In this visit, many challenges for farmers and the overarching population became evident. Some of the conclusions from this visit were that in the study region, the vanilla boom leads to an increase in crime and has negative pressures on ecosystems and biodiversity. An additional challenge that came to our attention was that young students, especially women, might be experiencing an aspiration failure due to lack of opportunities, role models, and the existence of strong social norms. The chapters that are part of this dissertation aim to bridge research gaps and address some of these current challenges.

\subsection{Thesis Overview}

This dissertation presents four independent studies that advance experimental methods and evidence on social and individual preferences heterogeneity and dynamics. This dissertation examines the causes and consequences of antisocial behavior, investigates risk preferences, and explores policy options to promote environmental protection and reduce gender inequality in the labor market. To answer the different research questions, wellknown and innovative methods that combine economic games and surveys were conducted. Qualitative methods such as focus group discussions, participatory methods, and open interviews were used to complement the research. In the following sections, each of the chapters is briefly summarized.

\subsubsection{Chapters 2 and 3: Procedural preferences and betrayal aversion}

Trust facilitates economic activity. For example, we trust others when we buy online, go to the doctor, or lend money to family or friends. Trusting environments are as well fundamental for economies to grow (Zak \& Knack, 2001). However, deceptive behaviors are ubiquitous and may prevent the development of mutual trust and cooperation. For example, firms sabotage competitors using confidential information, engage in theft of trade secrets or use false representations of competitors' products or services. Similar examples can be drawn from individual interactions. Under deceptive scenarios, individuals might choose to avoid trusting others and assume the associated costs. What are the effects of theft, a form of deception, on antisocial behavior and prosocial preferences? How can betrayal aversion affect individuals' investment decisions? These questions are addressed in chapter 2 and 3. Our study region is a hotspot for crime, which has intensified given the recent spike of vanilla prices (Hänke et al., 2018; Neimark et al., 2019; Osterhoudt, 2020). Compared to

\footnotetext{
${ }^{2}$ For more information see: https://www.uni-goettingen.de/en/529181.html
} 
other cash crops, vanilla has the highest gross margin, increasing farmers' welfare (Komarek, 2010). Farmers dedicate their available land to cultivate mostly vanilla and rice, followed by a small share of other cash crops such as coffee and cloves, and other subsistence crops (Hänke et al., 2018; Fairtrade International, 2019). This low crop diversification causes farmers to be highly dependent and thus vulnerable to different shocks. Besides vanilla theft, the low state capacity, the weak rule of law, and low trust in local authorities are additional challenges of the region. Moreover, cyclones frequently hit the study region, which are a major threat for the plantations, the vanilla vines, and farmers' housing.

Given these context characteristics, the second and third chapters of this dissertation address the topic of deception, in the form of crop theft, which is an important challenge for farmers in Madagascar, and worldwide (e.g Schechter, 2007; Dyer, 2020). We explore how crop theft may affect farmers' preferences and its effects on their livelihoods. We use well-known experimental games to measure procedural preferences, other-regarding preferences, and risk and betrayal preferences in these two chapters.

The second chapter Procedural Preferences in Competitive Environments: A Field Experiment in Madagascar is joint work with Marcela Ibañez and Gerhard Riener. In this chapter, we study the likelihood that experiment participants exploit one of two types of unfair power advantages: spying or sabotaging. We test whether the decision to exploit the given advantage is associated with crime exposure. Moreover, to explore the consequences of deception on other-regarding preferences, we measure trust, trustworthiness, and altruism ex-ante and ex-post the unfair environment exposure. This allows us to measure and compare the evolution of other-regarding preferences under fair and unfair environments.

We conducted a lab-in-the-field experiment with 199 farmers where each participant was allocated into one of the treatment groups (Spy or Sabotage) or the control group. We measure other-regarding preferences using the standard methods in the experimental literature with slight modifications. We measure trustworthiness using a strategy method, and all participants play the role of dictator, trustor, and trustee. Our results show that more than half of the participants who were given the unfair power advantage do not exploit it. Besides, we find that participants who exploit one of the unfair advantages not only do it in their favor but also to benefit the counterpart. We find no evidence for procedural preferences as the same share of participants decide to spy or sabotage on their partner. Moreover, we show that the likelihood to exploit an advantageous position is positively correlated with crime exposure. Last, we find that unfair environments crowd out altruistic behavior but not trust or trustworthiness.

This chapter contributes to the economics literature on procedural preferences and the dynamics of other-regarding behaviors. Theoretical and empirical evidence shows that individuals have preferences not only for the material outcomes but also for the procedure that leads to them. This suggests that individuals exhibit procedural (fairness) preferences (Sen, 1997; Brandts \& Charness, 2003; G. Bolton et al., 2005; Gneezy, 2005; Chlaß \& Riener, 2015; Dold \& Khadjavi, 2017; Chlaß et al., 2019). Unlike ours, these studies do not compare 
different types of deceptive behaviors nor explore the social consequences when individuals are exposed to unfair environments. Moreover, an interesting feature of our experiment is that we can relate behaviors taken in the laboratory with experiences that participants have outside of it.

The third chapter The costs of betrayal aversion: The case of vanilla production in Madagascar is joint work with Marcela Ibañez and Gerhard Riener. In this chapter, we test whether attitudes towards betrayal can be associated with some of the production and commercialization inefficiencies present in the vanilla sector. We conducted a lab-in-the-field experiment with 760 vanilla farmers. We measured betrayal aversion using a within-subject design following the choice list elicitation method by Quercia (2016). We collected information on farmers' social characteristics and production and commercialization decisions using surveys at three different points in time. We also decompose the betrayal aversion measure into the different sources of risk (social and nature) and link them to some of the production and commercialization decisions that vanilla farmers make. In this experiment, we apply context-specific experimental settings using examples from participants' daily lives.

Surprisingly, we find that farmers are on average betrayal neutral and that betrayal attitudes are not related to the decisions farmers make concerning vanilla. Yet, we find heterogeneity in attitudes towards betrayal when exploring different levels of crime exposure. Individuals exposed to higher crime levels are more likely to be betrayal averse. Moreover, we find that farmers who are more reluctant to take social risks have less land allocated to vanilla and smaller vanilla plantations. These decisions have negative and sizable economic consequences on farmers' livelihoods.

The novelty of chapter 3 is that we provide experimental evidence on betrayal aversion preferences in farmers, a non-standard economic subject pool, and connect such attitudes to economic decision-making in the production and commercialization of vanilla. Previous studies have a pooled measure of betrayal aversion and have tried to predict such attitudes with a set of socioeconomic characteristics, but few can explain them. So far, studies have shown a gender difference towards betrayal attitudes, suggesting that women are more likely to be betrayal averse (e.g Bohnet et al., 2008; Aimone \& Houser, 2012; Quercia, 2016). We expand this empirical evidence by linking betrayal aversion to socioeconomic characteristics and relating whether such attitudes could explain some of the inefficiencies present in vanilla cultivation. From this, we further contribute to the agricultural economics literature as previous work has shown that production inefficiencies can be explained only by risk aversion or time preferences (e.g Liu \& Huang, 2013; Ruhinduka et al., 2020), leaving out in most cases the role of trust.

Overall, from a development perspective, exploring the association between deceptive behaviors and crime is relevant because, as shown, deceptive interactions generate less cooperative environments, which may reinforce existing poverty traps. The findings of both studies have important implications for initiatives that target crime reduction in the 
agricultural sector. In addition, with these two projects, we aim to show policymakers the relevance of using effective strategies that tackle different types of risks to reduce inefficiencies in the vanilla sector, increase social capital in the villages, and increase farmers' well-being.

\subsubsection{Chapter 4: Charitable giving for the environment}

The largest share of the world's surface has been altered by human activities (IPBES, 2018). Natural habitats are threatened by crop and grazing lands, housing, infrastructure, and industrial activities. Given that environmental conservation is intertwined with social and economic development, international and multinational organizations have included the topic of conservation in the world agenda. Although these initiatives are invaluable, there is also a need to engage the population in joint forces. Environmental degradation is especially alarming in some regions of the world, which is the case of Madagascar. Despite substantial investment in conservation and environmental policies, deforestation and forest degradation rates continue to increase in the country (Waeber et al., 2016). In particular, our study region is both an important spot for biodiversity and economic activity. Besides the predominance of traditional practices like slash-and-burn agriculture, other human activities create pressure on the environment. ${ }^{3}$ From focus group discussions and qualitative interviews, we know that conservationists struggle to persuade the population to adopt sustainable practices. We believe that a potential reason is a communication mismatch between environmental institutions and the population. Since most conservationists communicate in the form of commands and motivate environmental protection to prevent the extinction of fauna and flora, the population feels that their traditions and livelihoods are not being considered. The question is how best to persuade the population? Which messages are effective in promoting pro-environmental behaviors? Do the mode and frame of the messages matter?

The fourth chapter "It pays to be green": The role of persuasive communication to foster conservation is joint work with Marcela Ibañez and Gerhard Riener. This study departs from two strands of literature. On the one hand, there is evidence showing that stories or fables can guide moral behavior. (e.g Vitz, 1990; Michalopoulos \& Meng Xue, 2021). On the other hand, the recent work by Bénabou et al. (2019) suggests that other forms might be more effective to drive individuals towards the desired behavior. The authors propose that imperatives are more effective than stories or narratives.

Based on this evidence, in this chapter, we test whether different message types can foster pro-environmental behavior within a controlled setting in a lab-in-the-field experiment. In particular, we study the impact on giving to a fundraising campaign after listening to moral narratives or imperatives messages that are embedded in an egoistic or non-egoistic frame. An important characteristic of our chosen cause is that it is environment-oriented, and thus donating is a form of environmental activism or pro-environmental behavior. We

\footnotetext{
${ }^{3}$ The slash-and-burn agriculture is a planting method in which forests are burned and cleared. This method is often used by farmers around the world as the tree ashes make the soil more fertile.
} 
explore two potential channels that can make messages more persuasive: guilt aversion and congruence.

In the experiment participants were randomly selected into five groups. In each group, they could listen to one of the following audio recorders for about one minute: Narrative Egoistic, Imperative Egoistic, Narrative Non-Egoistic, Imperative Non-Egoistic, or Control. After listening to the audio recorder, participants were presented with three different scenarios in which they could decide whether and how much effort to exert for the donation campaign. This effort is translated into a monetary payment allocated to an NGO. In the control group, 81 percent of participants contribute. This share significantly increases when participants listened to the Imperative Egoistic message. Participants in this treatment group also contribute on average more when compared to the control and the other treatment groups.

Chapter 4 explores the role of information provision in the form of messages for proenvironmental behavior. The narrative and imperative communication modes have recently started to be explored in the economic literature interested in driving prosocial and moral behavior (Bénabou et al., 2019; Hillenbrand \& Verrina, 2018). Yet, these studies do not compare the behavioral effects of transmitting imperatives or narratives, nor under egoistic or non-egoistic frames. Overall, finding ways to persuade the population towards proenvironmental behaviors is an interesting and relevant line of research, especially given that environmental conservation is one of the main concerns worldwide. Cost-effective interventions, for instance, the adoption of persuasive messages by NGOs or governmental institutions, might help the population to internalize the consequences of their behavior and adopt practices that are more friendly with the environment without threatening their livelihood income.

The novelty of chapter 4 lies in that it provides experimental evidence on the impact that different messages - which vary in mode and frame- have on pro-environmental behavior. By exploring the channels on which messages may be more effective, this paper contributes to the rich literature on persuasion (Mullainathan \& Shleifer, 2005a,b; Dellavigna \& Gentzkow, 2010; Allcott, 2011; Allcott \& Rogers, 2014; Ferraro \& Price, 2013). Moreover, this work makes important contributions to literature outside of economics. Our work adds empirical evidence to the environmental psychology literature that highlights the role of value-congruence communication for pro-environmental behavior (Schultz, 2001; Lindenberg \& Steg, 2007; Steg \& Vlek, 2009; De Dominicis et al., 2017). In addition, it adds to recent conservation literature exploring the effect of value-framing in encouraging pro-environmental behaviors (e.g Evans et al., 2013; Reddy et al., 2020).

\subsubsection{Chapter 5: Aspirations, competition and labor market}

Women worldwide are underrepresented in the formal labor market, earn lower wages, and hold fewer leadership positions than men (World Economic Forum, 2019). One reason that may explain this gender gap is the lack of successful female examples that can serve as reference points. These conditions are similar in our study region. The population that we 
study in this chapter are students in the last year of high school. We changed our research sample from the previous projects because, different from farmers, students are at the stage of forming their aspirations and setting goals that will allow them to overcome the poverty traps. We collected anecdotal evidence from principals and teachers from our region visits. They repetitively mentioned that female students do not aspire to continue their education or find a stable and secure job. This aspiration failure fed by the economic constraint students face, seems to be aggravated by the lack of resources students can count on the schools and social norms that drive young women to drop out of school to marry and begin motherhood at an early age. As a result, there is a lack of successful female examples that can motivate female students to pursue higher education and advance in their careers.

The fifth chapter of this dissertation Can role models influence female's decision to participate in the labor market? is joint work with Christina Martini. This paper aims to reduce the lack of successful examples by providing students with role models. In particular, we test whether role model videos can drive female students to apply for two type of jobs that we offered: assistant or coordinator. Moreover, we explore the mechanism through which role models influence behaviors. We test whether role model videos can positively influence individual preferences such as aspirations and willingness to enter into competition and a set of beliefs such as locus of control and self-efficacy. Based on the assessment of these different channels, we explore which of them could explain the effect of role model videos on behavior.

In this experiment we randomly assigned 336 students from public schools to watch one of three videos: female role model, a male role model, or a placebo video. After watching the video, we measured students' aspirations following the work by Bernard et al. (2014), and conducted a lab-in-the-eld experiment following the designs by Niederle \& Vesterlund (2007) and Carpenter et al. (2018) to measure inter-and intra- competitive preferences and performance. After collecting social characteristics and beliefs with a post-experimental survey, we informed students about the two job positions and explained the application requirements. Students had the opportunity to apply to only one of the jobs advertised. A week after the visit, students filled an application form.

Overall, we find that the female role model encourages students to apply to one of the positions offered. Yet, the male role model is successful in motivating female students to apply for the coordinator position. Surprisingly, we find no evidence that female students become more competitive after being exposed to one of the treatment videos. Yet, we do find evidence for a change in aspirations and self-efficacy beliefs. As potential mechanisms for the role model intervention, we find that aspirations and the current achievements can explain the decision to apply.

In the economics and psychology literature there is a vast literature on information provision and specifically on the use and effect of role model interventions (e.g Ray, 2006; Chong \& Ferrara, 2009; Jensen \& Oster, 2009; La Ferrara et al., 2012; Beaman et al., 2012; Bernard et al., 2014; Riley, 2018; Meier et al., 2020; Schier, 2020). In this chapter, we extend this 
line of research by exploring the role of individual aspirations on behavior in the labor market. The novelty of this experiment is twofold. First, we show the effect of a role model intervention on a set of individual preferences and beliefs. Second, we link individual preferences measured in the laboratory (aspirations and competition) to behaviors outside of the laboratory (apply to a job). With this project, we hope to inspire policymakers and school directors to use this type of cost-effective intervention to bring the youth forward and alleviate poverty. We further aim to contribute to the existing evidence and thereby assist policymakers in deciding on activities that can increase female labor market participation.

\subsection{Thesis Contributions}

Measuring preferences is important to understand individuals' behavior as they can affect the outcome of policy interventions. For instance, social preferences are rooted in norms and institutions; hence, having a better understanding of this type of preferences can increase the effectiveness of an intervention. Moreover, understanding and perhaps shaping social preferences can create positive externalities. For example, there is ample research showing that social preferences affect charitable giving (e.g Andreoni, 1990; Dellavigna et al., 2012), and are associated to a higher economic growth and development (e.g Knack \& Keefer, 1997; Algan \& Cahuc, 2010).

While it is difficult to universalize behaviors and predict with certainty the response of certain development interventions, preferences can still help explain different world phenomena. Gneezy et al. (2009) provide extensive literature showing gender differences in risk, other-regarding, and competitive preferences. These differences may explain the gender gap in labor market participation or educational attainment. Besides gender, other studies have focused on other individual characteristics such as age. For instance, Cobo-Reyes et al. (2020) conduct a cross-country experiment to study how social preferences evolved across age. They find evidence of an inverse 'U-shaped' relation between age and altruism.

Other studies have also shown that social preferences can change after individuals are exposed to an intervention or to an external shock. ${ }^{4}$ For example, Schier (2020) provides experimental evidence that female role models, in the form of information about successful females entering into competition, increases female's willingness to compete in a real-effort task. Similar evidence has been found by Meier et al. (2020). Moreover, Castillo \& Carter (2011), and Cassar et al. (2017) find that trust increases after a community suffers hardship after natural disasters. Likewise, Bellows \& Miguel (2009) and Voors et al. (2012) find that individuals experiencing violence become more engaged in community governance

\footnotetext{
${ }^{4}$ While the majority of economists suggest that social and individual behaviors are dynamic and responsive, others argue that they are rather stable over time. For instance, Nunn \& Wantchekon (2011) find a less dynamic trusting behavior, especially when it is situated at very low levels. The authors argue that the slave trade can partially explain the current low-trusting levels in Africa as this trait has been transmitted over generations. As shown by the authors, the slave trade created an environment of mistrust inside families and friends as people were sold by their own social network. A middle-point argument in regard to social behavior dynamics is given by Bornhorst et al. (2010). The authors find that the evolution of trust depends on its initial levels but that repeated interactions can change its development.
} 
and more altruistic, respectively. Cassar et al. (2013) argues that violence might increase participation in social meetings, but it erodes local trust.

Another important heterogeneity of social and individual preferences occur at the country level. The seminal works of Falk et al. (2018) and Henrich et al. (2001) are good examples of cross-country heterogeneity of individual and social preferences. However, behavioral scientists usually conduct laboratory experiments with, what they consider, standard economic agents (students) from WEIRD countries. This sample serves as a reference point of how other people around the world would behave under similar conditions.

This dissertation contributes to the literature on social and individual preferences by expanding the empirical evidence on preferences that have been little studied, in particular with non-standard subject pools and, in some cases, by linking such preferences with decision-making outside of the laboratory. Some of the experiments that are part of this dissertation use a between-within-subject design, which allows us to observe behavioral changes in each individual and explore a dynamic dimension of preferences.

Despite the extensive theoretical and empirical research, there are still many aspects of individual and social preferences that require further research, especially regarding its social and economic consequences. For instance, little is known on procedural preferences under unfair environments when comparing different deceptive behaviors. In addition, scant studies explore betrayal aversion attitudes in non-standard economic agents. Surprisingly, few studies have explored the consequences of procedural preferences and betrayal attitudes on decision-making. Chapters 2 and 3 advance on these two types of preferences.

Chapters 4 and 5 make an empirical contribution to information provision interventions. Information can be provided in two forms: quantitative or qualitative in the form of stories, fables, anecdotes, narratives, etc. (Haaland et al., 2020). We use information that relies on qualitative anecdotes, stories, or narratives. We do not use quantitative information given the low literacy levels of our sample. Because of the positive results that are found and the video and audio instruments developed to conduct the experiments, the studies implemented in Chapters 4 and 5 are a blueprint for scaling up policies.

Besides the specific contributions of each chapter mentioned above, the methods implemented in this dissertation contribute to the advance in experimental economics. We use well-known but also innovative games adapted to the rural development context conditions to allow for better comprehension. The adaptation of such games could be used by other scientists who face similar environments. Moreover, part of this dissertation includes the creation of audio and visual material that could be as well used for future research work and policy-making. Since all studies were conducted with non-WEIRD subject pools, we contribute to the literature on experimental economics. Besides, different policy recommendations and strategies can be drawn from our results. We hope that this dissertation serves as a resource for further understanding of social and individual preferences, their dynamics, and their linkages to decision-making. We want to inspire other researchers to provide a closer look into the different issues we approached. Also, to inspire and support those working on 
policy advice who want to improve people's livelihoods around the world.

\subsection{Thesis Limitations}

Taking our research to the field has several advantages such as understanding the behavior of non-standard subject pools, and linking decisions from within and outside the lab. Yet, when conducting field experiments, and in particular lab-in-the-field experiments, there are three main limitations that are usually discussed in the literature: (i) demand effects; (ii) biases in the report of sensitive information; and, (iii) validity.

We minimized the first two by including different features in our experiments. First, our experimental games are incentivized. Second, the procedures were double-blinded and the experimenter was not present during the experimental sessions. Third, the instructions have a neutral framing and hence there is no possibility that participants could foresee our expectations. In the experimental instructions, we were very careful in the provision of examples always using different values to avoid anchoring. Fourth, when possible, we randomized the order of the games. Fifth, we were very reiterative with the participants in telling them that there were not right or wrong answers and that the information provided will be anonymous. In each of the experiments we used identification numbers (id) to associate each participant with her corresponding answers. We further conducted different data checks to clean our databases. Last, we compare the information collected with other studies conducted in Madagascar and received feedback from stakeholders in the region.

Concerning validity, each of the chapters has its limitations. To conduct the data collection for chapters 2, 3, and 4, we randomly selected a number of villages from a database of 60 villages where the Diversity Turn Project has been working in the last years. Our study area is a representative sample of villages located up to $10 \mathrm{~km}$ away from primary, secondary, or tertiary roads. Villages that are located further from this criteria are, in general, very difficult to access given the bad infrastructure conditions. Hence, while we cannot claim that our sample is representative of the region, it represents villages that share similar characteristics. In addition, when possible, we use a stratified sample using village size. This, because from observational data, there are differences in market access, infrastructure, access to school, and other public services. To increase the validity of our estimates, the selection of participants at the village was made randomly and also the selection of participants into the different treatments and control groups.

Concerning chapter 5, we collected data of high school students from all public schools in the SAVA region. Yet, as students signed up for taking part in the experiment, one limitation of this study is selection bias. This is a shortcoming for all experimental studies conducted with student samples where students decide whether to take part or not in the experiment. We minimized this by randomizing participating students into the different treatments and control groups. 


\section{Chapter 2}

\section{Procedural Preferences in Competitive Environments: A Field Experiment in Madagascar}

This chapter is joint work with Marcela Ibañez (University of Göttingen) and Gerhard Riener (Heinrich Heine University Düsseldorf). We are grateful for the helpful comments and suggestions received from Alexia Gaudeul and the participants at the 6th Annual PhD Lab in the Field Workshop, and the PhD Summer School 'Advances in Behavioral Ethics'. This work is supported by the 'Niedersächsisches Vorab' of Volkswagen Foundation (grant number: 11-76251-99-35/13 - ZN3119). Special thanks to the Diversity Turn research group for their constant feedback and support in the field. We would like to thank all enumerators who participated in the data collection in Madagascar, and all the farmers who attended our experimental sessions. We would also like to thank all the local people involved in the project (village chiefs, drivers, cooks). 


\subsection{Introduction}

Unfair competition practices where individuals engage in deceptive behavior to win a competition can affect economic efficiency (Shleifer, 2004). ${ }^{1}$ However, situations in which one party exploits the power to take actions that harm competitors are ubiquitous in social contexts. For example, businesses lie to consumers through deceptive advertising, provide lower quality than promised, or make fraudulent offers. Firms also sabotage competitors using confidential information, engaging in theft of trade secrets, or using counterfeit products or services of competitors. Under which circumstances do individuals engage in unfair competition practices and what consequences these forms of misdeeds have to those exposed to them?

Recent empirical evidence has shown that individuals have preferences not only for the outcomes but also for the process that lead to those outcomes (Gneezy, 2005; Chlaß et al., 2019; Dold \& Khadjavi, 2017). We extend that line of research and consider preferences for procedural fairness in competitive environments. We test whether the propensity to select into unfair competition differs when the procedures used to deceive the competitor vary. We further analyze the ex-post effects of unfair competition on prosocial preferences.

The objective of this paper is threefold. First, we test whether individuals exploit their power to use information to unfairly leverage advantage over his competitor. We compare two forms of power advantage: the advantage to revise one's own decision, which we refer to as SPYing, and the advantage to overrule her competitor's decision which we refer to as SABotaging. Spying and SAbotaging have the same economic consequences in terms of outcomes in our design. Hence, on the one hand, individuals who follow utilitarian ethical principles and are consequentialists should judge both actions as equivalent. On the other hand, if individuals follow deontological ethical principles, in which the means might not justify the ends, SABOTAGING - constituting an infringement of personal decisions - is likely to be judged as less acceptable or bear higher moral concerns than SPYING-which constitutes a simple use of information for one's own advantage. ${ }^{2}$ We expect that individuals would be more likely to engage in egoistic exploitation in the treatment group SPYING than in SABOTAGing as the moral cost of exploitation is lower. ${ }^{3}$

Second, because exposure to previous opportunistic experiences can affect individuals' behavior (Houser et al., 2012), we explore the relation between previous crime experiences on egoistic exploitation of power. In light of the broken window theory (Wilson \& Kelling, 1982) and the cross-norm inhibition effect (Keizer et al., 2008), we hypothesize that crime victimization is positively related to the decision to exploit the given advantage.

\footnotetext{
${ }^{1}$ Under certain circumstances (i.e., all market agents can equally exploit an advantageous position), these practices can result profitable for markets and individuals' welfare. Shleifer (2004) provides an array of examples. However, this is unlikely as advantageous positions are not equally distributed.

${ }^{2}$ Schwieren \& Weichselbaumer (2010) make a similar claim comparing cheating versus sabotaging.

${ }^{3}$ In any of our treatment or control groups players know the identity of the matched partner, therefore the moral cost associated with the action taken by player with the advantage does not necessarily involve reputation concerns, although the actions were observed by the experimenter.
} 
Third, we study the consequences of exposure to unfair environments on pro-sociality. To analyze how the possibility to exploit or be affected by power advantages affects otherregarding behaviors, we measure altruism, trust, and trustworthiness before and after a rigged matching pennies game. We compare those measures with the decisions made in a fair competitive environment (CONTROL group), where no player has an advantage. Compared with a fair competitive environment, we expect that unfair competition will crowd-out ex-post pro-sociality, particularly when individuals have the opportunity to exploit a less acceptable form of power advantage.

Since unethical actions are hard to observe and procedures difficult to compare outside the laboratory, as well as its consequences, we designed an artefactual field experiment in Madagascar. ${ }^{4}$ In the experiment, half of the participants in the treatment groups were given one of the two power advantages which they could use in their favor when competing with another player. While previous studies have examined SPying and SAbotaging actions in the laboratory, there is little evidence with non-WEIRD samples. Moreover, scant research has shown how own experiences of crime shape ethical behaviors.

Our results show that only 39 percent of the participants used the power advantage and selected into unfair competition. However, in a situation where the standard neoclassical economic model predicts that individuals will deceive their competitors to be better-off at a zero economic cost (Becker, 1968), about one-third (36 percent) selected unfair procedures to benefit the other player. Contrary to our expectations, there are no significant differences in the share of individuals who exploit the advantage in the SABOTAGING treatment group than in the SPYing group. This suggests that the perceived moral cost of exploiting the given advantage is similar across both forms of unfair competitive environments. In line with our hypothesis, we find that the likelihood to exploit an advantageous position is positively correlated with both self-reported theft victimization and average theft reported by others at the village level. We observe that this is mostly driven by the condition in which individuals can engage in SPYING. This indicates that experiences in the field translate to behavior in the laboratory.

Finally, an individual-level analysis shows that exposure to unfair conditions partly crowds out pro-sociality compared to fair competitive environments. We find that altruism crowds out for participants who were given the advantage in the game. This can be explained by a moral-licensing effect triggered by the unfair competitive environment. Surprisingly, we do not observe strong (negative) behavioral changes in players who were not given the advantage suggesting that individuals internalize pre-existing norms of advantageous behaviors, probably because of the high crime incidence.

We extend the line of research that establishes that procedural concerns, in addition to outcomes, matter in decision making (e.g. Sen, 1997; Chlaß et al., 2019). In previous laboratory experiments, individuals are given the opportunity to benefit themselves at the

\footnotetext{
${ }^{4}$ The definition of artefactual field experiment is taken from the terminology in Harrison \& List (2004). From now on, we will refer to it as the experiment.
} 
expense of another party by lying, spying or sabotaging (Brandts \& Charness, 2003; Gneezy, 2005; Harbring et al., 2007; Trautmann, 2009; Harbring \& Irlenbusch, 2011; Gino et al., 2013; Chlaß \& Riener, 2015; Dold \& Khadjavi, 2017; Chlaß et al., 2019). Most of these studies do not compare two different unethical behaviors but rather explore one scenario in which players can deceive others. On this line, our contribution to the literature on procedural preferences is two-fold. First, we extend the existing evidence by exploring two deceptive behaviors that have received little attention in the literature. Spying and Sabotaging are common practices in contexts where competition is salient, be it between firms or within a firm. For example, Carpenter et al. (2010) conduct a real-effort experiment in which they show that tournament payment schemes among co-workers incentive sabotage and reduce productivity. Further, Harbring et al. (2007) and Harbring \& Irlenbusch (2011), through a series of experiments, show that the prize spread, the revelation of the saboteur's identity, the framing of the activity, and whether communication is allowed, have an effect on the decision of an individual to sabotage. Spying can occur as well between and within firms (e.g: co-workers spying on each other), but we are not aware of studies evidencing the causes and consequences of this type of behavior. Surprisingly, spying and sabotaging have received less attention compared to other unethical behaviors such as lying. Second, by comparing the ex-ante and ex-post prosocial behavior of players who were not given an advantage, we consider how unfair procedures are judged in general, whether they are judged differently, and whether they have consequences in a setting outside of the game. This approach is new as usually procedural preferences are studied from the decision-maker's perspective but not from the victim. Different from the study of Brandts \& Charness (2003), in which the second player has the opportunity to retaliate under the framework of the game, we do not give this opportunity but rather observe whether giving the power advantage to half of the participants in the treatment and control groups affects the prosocial behavior of those who received no advantage.

Another line of research we add to is related to the factors influencing unethical behaviors. There is extensive research studying the drivers or determinants in the selection of anti-social behaviors (e.g. Jacobsen et al., 2017). Under competition settings there is evidence showing that such environments promote unethical behaviors (e.g. Schwieren \& Weichselbaumer, 2010; Carpenter et al., 2010; Charness et al., 2014). Going beyond the competition setting, we explore the socioeconomic characteristics that could further explain the decision to exploit the advantage in one's favor in the matching pennies game. In particular, we test the relation of such behaviors to criminal environments. Our results are in line with the broken window theory (Wilson \& Kelling, 1982) and with the cross-norm inhibition effect (Keizer et al., 2008). Further, experimental evidence has also shown that previous experiences of unfairness matter in selecting dishonest behaviors. For example, Houser et al. (2012) show that people are more likely to behave dishonestly after being treated unfairly in the laboratory.

Last, we add to the extensive literature studying how other-regarding behaviors evolve over time and what type of shocks can affect their trajectory (Bellows \& Miguel, 2009; Bornhorst 
et al., 2010; Voors et al., 2012; Cassar et al., 2017; Castillo \& Carter, 2011). Yet, none of these studies explore the behavioral response of individuals in environments where they do not have equal opportunities and where deceptive actions are allowed. Irlenbusch \& Ruchala (2008) show that competition fosters less cooperation among individuals and suggest that this could deteriorate when individuals have the chance to exert unethical behaviors, but there is no direct evidence. Further, G. Bolton et al. (2005) show that procedures that are perceived as unfair are less acceptable by individuals, but they do not link it to otherregarding behaviors. Given the importance of this topic for the well-functioning of markets and economic growth, it is surprising that no previous studies empirically investigate how other-regarding behaviors change after individuals are exposed to unfair environments. By analyzing the heterogeneous effects by player type, we explore the behavioral consequences of exposure to unfair environments by comparing it to a fair condition, which can be interpreted as the social costs that such environments generate.

The paper proceeds as follows. Section 2.2 presents the design and hypotheses. Section 2.3 presents the data and the results. Section 2.4 discusses the findings. Section 2.5 concludes.

\subsection{Experimental Design and Procedures}

\subsubsection{General Structure}

Participants are randomly and anonymously matched into pairs that remain fixed during the three-stage experiment.

Stage 1: In this stage, we obtain baseline measures of other-regarding preferences using the standard Dictator Game (DG) and Trust Game (TG). In the DG, the dictator is endowed with 10,000 ariary $\left(\approx 2.9 €^{5}\right)$ and can send multiples of 1,000 between $0-10,000$ ariary to the matching partner. The value sent to the partner is our measure of altruism. The trust game has the same structure of the investment game designed by Berg et al. (1995). The trustor is endowed with 5,000 ariary $(\approx 1.5 €)$ and can send multiples of 1,000 between $0-5,000$ ariary $(0$ to $\approx 1.5 €)$. This amount is doubled by the experimenter and is send to the trustee. Trustees are endowed as well with 5,000 ariary $(\approx 1.5 €)$ and decide how much they would return from each possible value between 2,000 and 10,000 that they could receive (0 was not included in the options). We apply the strategy method, meaning that each trustee makes a total of five different decisions. Hence, trustees decide how much to return for each possible amount sent by the trustor. Trustees are not constrained to return multiples of 1,000 , but they are offered an array of units $(200,500$, and 1,000$)$ that sum up the hypothetical amount received. The value sent by the trustor is our measure of trust. The value returned by the trustee is our measure of trustworthiness.

To obtain measures of pro-sociality for all participants, each participant plays both the roles

\footnotetext{
${ }^{5}$ The exchange rate at the time of the experiments was around 3,400 ariary equivalent to $1 €$
} 
of sender and receiver. At the end of the experimental session, participants are allocated to one of the two roles to determine their payments. To avoid income effects and changes in reciprocity, participants do not receive information on which role is assigned to them or their earnings until the end of the experimental session. We randomly vary the order in which the games are presented to avoid order effects.

Stage 2: In the second stage, subjects play a modified one-shot Matching Pennies Game. Participants are randomly selected into two-player types in this game: Player A and Player B. Each player chooses simultaneously one of two symbols: a circle or a triangle. ${ }^{6}$ If the symbols selected by the two participants in the group match -both circle or both triangle-, then Player A receives a high payment and Player B a low payment. If the symbols selected do not match, then Player B received a high payment and Player A a low payment (See Table 2.1). After both players make their decisions, Player A receives information about the game outcomes, and after that, Player B receives the information. This game represents a situation of fair competition. We explain the treatment variations implemented in Section 2.2.2.

Table 2.1: Matching Pennies Game

\begin{tabular}{ccc}
\hline Player A/Player B & Triangle & Circle \\
\hline Triangle & 4,$000 ; 1,000$ & 1,$000 ; 4,000$ \\
Circle & 1,$000 ; 4,000$ & 4,$000 ; 1,000$ \\
\hline Notes: Values in ariary. 4,000 ariary $\approx 1.2 €$, and 1,000 \\
$\approx 0.29 €$.
\end{tabular}
$\approx 0.29 €$

Stage 3: In this Stage, we measure other-regarding preferences using the same procedures as in Stage 1. Comparing the behavior in the DG and TG for the different treatments allows us to identify the impact of unfair competition on social preferences. ${ }^{7}$

While preparing the payments, we conduct a follow-up questionnaire to collect socioeconomic characteristics and information related to vanilla theft. Participants are aware from the beginning of the session that either Stage 1 or Stage 3 would be payment relevant and that one of the two games (DG or TG) would be randomly selected for payment. Earnings in Stage 2 are always payment relevant. Figure 2.1 summarizes the structure of the experiment.

\footnotetext{
${ }^{6}$ We select these two shapes as they are contextual neutral options and thus allows us to avoid a strong preference for one over the other. None of the figures give on its own a strategic advantage

${ }^{7}$ As there is some tendency to stick with previous decisions in these games, our test is conservative.
} 
Figure 2.1: Structure of Experimental Session

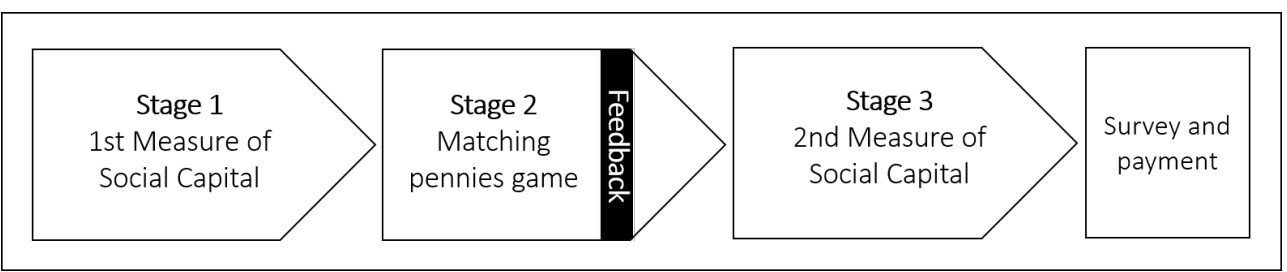

\subsubsection{Treatments}

In stage 2, we implement a between-subject design with two treatments and a control group that vary whether Player A can engage in unfair competition (or not) and, if so, the procedures that she can use to deceive their competitor (See Table 2.2). In the ConTrol group, both players receive the same information and decide simultaneously. In this group, none of the players can take advantage and it therefore represents a fair competitive environment.

Participants in the two treatment arms are exposed to a variant of that game that gives Player A the possibility to engage in unfair behavior. In this modified game, there is asymmetry of information, and Player A knows the outcome of the game before the outcome is payment relevant. Player A can therefore exploit this advantage by deceiving the competitor. Our treatment conditions randomly varied the procedure by which Player A could deceive the competitor. In treatment arm SPYING, Player A can deceive the competitor by revising her own decision (e.g. substitute a circle for a triangle or vice-versa). In the treatment SABotaging, Player A has the possibility to sabotage the competitor by overruling the competitor's decision.

In the treatment groups Spying and SAbotaging, Player A has the opportunity to select unfair competition. Yet, she can use this opportunity to her advantage or favor the competitor.

As we are interested in the impact that potentially exploitative environments have on prosocial behavior, Player B receives feedback on whether Player A engaged in deceptive behavior, the type of deceptive behavior used, and the earnings that each player receives. Player B receives feedback at the end of stage 2, where the outcomes of the game can no longer be modified. Since Player A decides on the final outcomes of the game, it is defined as the decisive player. Player B only receives information and does not have any strategic advantage; hence, it is defined as the passive player.

Table 2.2: Treatment Description

\begin{tabular}{cll}
\hline Treatment & \multicolumn{1}{c}{ Description } & Obs. \\
\hline \hline T0 & Control: Player A cannot change a decision (fair) & 66 \\
T1 & Spying: Player A can revise her decision (unfair) & 65 \\
T2 & SABOtaGing: Player A can overrule Player's B decision (unfair) & 68 \\
\hline
\end{tabular}




\subsubsection{Hypotheses}

Our study has two main objectives. First, to study the effect of the procedure on exploiting a power advantage, and second to study the effect of being exposed to an unfair environment on other-regarding preferences.

If an egoistic money maximizing individual can be better-off at a zero economic cost, then she will take advantage and use her power to engage in unfair procedures. Yet, theoretical and empirical studies suggest that individuals are guided not only by monetary interest but also hold moral principles (e.g. Benabou \& Tirole, 2006). Therefore they experience psychological costs when engaging in dishonest and fraudulent behavior (Benabou \& Tirole, 2006; Abbink \& Herrmann, 2011). Individuals may follow deontological ethical principles and are guided not only by the consequences of their acts but also by procedures that lead to the outcomes (Sen, 1997; Gneezy, 2005). When people consider whether or not to engage in unfair competition, they weigh the possible economic gain and how it is obtained. Abbink \& Herrmann (2011) show that people are more likely to behave nasty when the moral costs are lower. Infringement of decisions of others may be seen as more severe trespassing of moral conduct, and thus nastier, than just using the information provided to revise one's own decision. This derives our first hypothesis:

Hypothesis 1. Participants exploit the unfair advantage in their favor more often when they are given the power to revise their own decision (SPYING) than when they are given the power to overrule (SABOTAGING).

Different factors have been related to individuals that are likely to engage in unfair practices (Jacobsen et al., 2017). In our setting, criminality plays a central role in the lives of individuals. Criminal environments can drive dishonest behaviors through mainly two channels: 1) learning or imitation (Sutherland, 1960) and 2) cross-norm inhibition effect (Keizer et al., 2008). Since criminality usually occurs in secrecy, the second mechanism is more likely to drive individuals towards other anti-social behaviors. Houser et al. (2012) show that previous experiences of unfairness can trigger dishonesty in other unrelated situations. In our experimental design, individuals do not receive feedback on the outcomes they receive in stage 1 , yet, deceptive experiences in the real-world can be related to their behavior in the laboratory.

Vanilla theft is a risk farmers face every year when the harvest is about to get ready. 51 percent of the farmers participating in our experimental sessions reported being victims of theft in the harvest 2016. 25 percent reported having experienced theft more than once. Due to the high corruption and low trust in police, only 59 of the theft cases were notified to the local authorities. When asking farmers about the identity of the thieves, 40 percent of the victimized farmers affirmed that thieves are living in the same village. This goes in line with our anecdotal evidence. Vanilla plots are usually not easy to access; therefore, thieves need to know beforehand the location of the plots and the farmers' routines.

Following the empirical and anecdotal evidence, we derive our second hypothesis: 
Hypothesis 2. Experiences of criminality and victimization are positively correlated with the exploitation of unfair procedures.

Several studies show that other-regarding behaviors are not stable over time and that they depend on previous experiences (Bellows \& Miguel, 2009; Bornhorst et al., 2010; Voors et al., 2012; Cassar et al., 2017; Castillo \& Carter, 2011). The study by Bornhorst et al. (2010) shows that these behaviors depend on their initial levels and are malleable through repeated interactions. G. Bolton et al. (2005) and Trautmann (2009) show that procedures that are perceived as unfair are less acceptable by individuals. Building on this evidence, we expect that exposure to environments where unfair competition is possible will erode pro-social attitudes and generate distrust. Two mechanisms can be at play. First, individuals might be guided by reciprocity principles. Hence, being in a disadvantaged position under an unfair competitive environment might activate a negative reciprocity norm (Fehr \& Gächter, 1998), leading to a decrease in pro-sociality. Second, the rules of the game could as well help as a coordination mechanism. When the rules of the game allow dishonesty, this signals that this type of behavior is expected, and hence individuals learn to be less pro-social (Gino et al., 2013; Clot et al., 2014). Since Sabotaging might be a less acceptable form of taking advantage (Schwieren \& Weichselbaumer, 2010), the erosion of generosity and trust should be larger when such actions are allowed. Our third hypothesis is:

Hypothesis 3. Unfair procedures erode other-regarding behaviors compared to fair procedures. The erosion is larger in treatment SABOtaging than in treatment Spying.

\subsubsection{Procedures}

We conducted the experimental sessions in the district of Antalaha, Madagascar (see Figure 2.2). We randomly chose nine villages along three different roads connected to Antalaha City, one of the main centers of vanilla commercialization in northeastern Madagascar. Along the roads, each village is located at three different distances from the city: 30 minutes, 1 hour and 2 hours. For the selection of participants, the village chiefs provided us with lists of vanilla farmers. From each list we randomly selected 24 farmers and invited them to a workshop within the next week. The selection of participants was public to increase the legitimacy of the procedure. We did not invite participants from the same household. In total, 200 people participated in the experimental sessions. In each session, there were between 20 to 24 participants. All sessions were conducted between November and December 2016. Only one treatment was conducted in each village, which we randomly selected by taking the distance to Antalaha City as a reference. Hence, our two treatment arms and control group are present in each of the three roads. This allows us to reduce potential noise as we have all groups in each route and different distances from the main city. 
The instructions were given orally in the local language (Malagasy). The same instructions were used across all sessions and were translated from English to Malagasy and then back to English (see Appendix for the experimental instructions). Each of the games was explained before the participants had to make the decisions and communication among participants was not allowed. Visual material (posters and cards) was also used in each of the sessions to ensure that participants correctly understood the rules of the games. The experimental sessions lasted on average two and a half hours including the post-experimental survey. The farmers earned on average 8,941 ariary $(\approx 2.6 €)$, including a show up fee of 1,000 ariary $(\approx 0.3 €)$. We calibrated the earnings to the average daily wage of a vanilla farmer $(\approx 3 €)$. The payment was made individually and privately at the end of the experimental session.

Figure 2.2: Study region

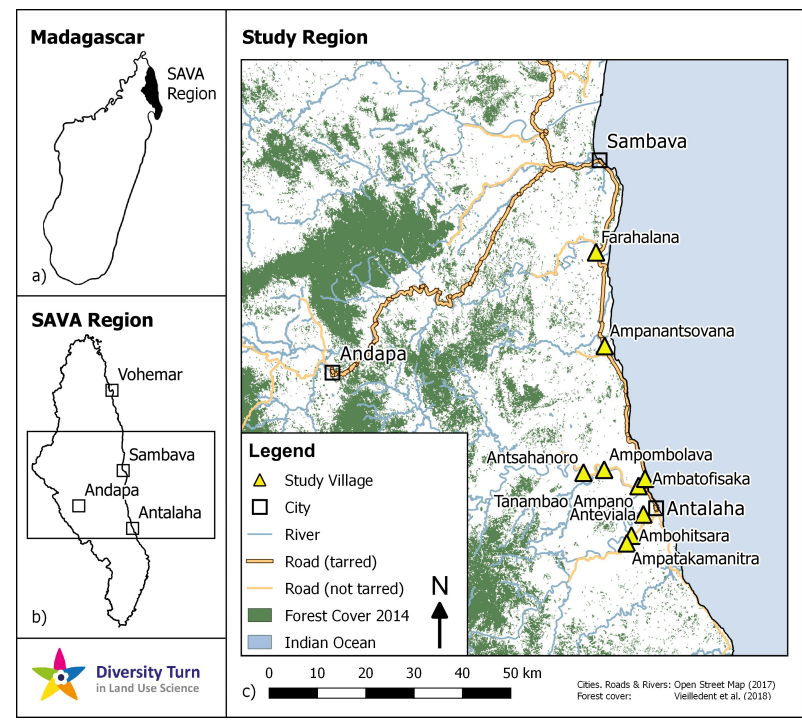

Source: Dominic Martin. PhD student, Diversity Turn Project. Map a) shows the location of the SAVA region in Madagascar. Map b) shows our study area within the SAVA region and, Map c) shows the the location of the villages visited. The 9 villages where we run the experiments are represented with yellow triangles.

\subsection{Results}

\subsubsection{Descriptive statistics and randomization checks}

In total, 200 vanilla farmers participated in the experiment, 66 in the CONTROL group, 65 in the treatment group SPYing, and 69 in the treatment group SABOTAGing. We removed one observation as this participant stated in the post-experimental questionnaire that she did not understand the instructions. This leaves us with a sample of 199 participants for the analysis. 
Table 2.A1 presents the socio-demographic characteristics of the vanilla farmers that participated in the experimental sessions by treatment. Participants are on average 50 years old, 69 percent are male, and 82 percent reported to be married. Participants have relatively low levels of education, with 62.3 percent having less than five years of schooling. A joint orthogonality test reveals that some observable characteristics are not balanced across the treatment groups, which we will account for in the analysis. We do not find significant differences between participants taking the role of Player A (decisive player) or Player B (passive player) in stage 2 (see Table 2.A2).

\subsubsection{Selection of options in the unfair procedures}

We first analyze the behavior of Player A (decisive player) in the matching pennies game. The selection of the figure is random. The probability of selecting a circle is not significantly different from 50 percent in any of the treatment conditions (see Table 2.A3, two-sided proportion test p-value $>0.1$ ). Roughly 50 percent of Players A obtained a high initial payoff. Once Players A have the opportunity to exploit the unfair competitive advantage, about 39 percent chose to do so. From those who changed their own or their competitor's decision, 64 percent exploited the opportunity to their advantage and obtain the high payment, and 36 percent used the opportunity to favor their competitor. Because of the decisions taken, we observe an increase in the fraction of Players A with high payoff from 50 to 57 percent at the end of the matching pennies game. Yet, this difference is not statistically significant (two-sided proportion test p-value $=0.31$ ). Table 2.A3 summarizes the outcomes and behavior in stage 2 of the experiment.

The fraction of Players A who exploit the advantage is not significantly different between the Spying and Sabotaging treatment groups. In the first treatment, 41 percent of Players A exploited the advantage, and in the second treatment, 38 percent (two-sided proportion test $\mathrm{p}$-value $=0.80$ ). This suggests that both procedures of unfair advantage are perceived as morally equivalent by Players A.

To understand how initial circumstances affect exploitation of advantage, Figure 2.3 presents the decision taken by Player A depending on whether she obtained the high initial payment in the matching pennies game or not. Not surprisingly, Players A are significantly more likely to exploit the advantage when they received the low payoff than when they received high payoff (one-sided proportion test, $\mathrm{p}$-value $=0.055$ ). Yet, while the neoclassical model predicts that individuals would exploit the situation to their advantage when the costs are zero, this is not the behavior we observe. Only about half of Players A (49 percent) who obtained a low initial payoff exploit their advantage to increase their earnings (a test of proportion indicates that this is significantly different from one, p-value $<0.01$ ), meaning that about the other half do not exploit the given advantage when being in the disadvantageous position. Figure 2.3 shows that 44 percent of Players A who received a low initial payoff in treatment SPYING exploit the given advantage versus 53 percent in treatment SABotaging. The proportion of participants who exploit their advantage is not 
significantly different between the two treatments (two-sided test of proportions, p-value $=0.611)$.

Result 1. Subjects who exploit the advantage to favor themselves do not reflect preferences regarding the procedures; therefore, our results reject Hypothesis 1.

Moreover, we observe that 29 percent of the decisive players who ended the first round of the matching pennies game with the high payoff behave altruistically by using their advantage to benefit the other player (t-test indicates that this is significantly different from zero, p-value $<0.01)$. As shown in Figure 2.3, when comparing the share of Players A that opt for the altruistic behavior across treatments, 36 and 24 percent respectively, we do not observe a significant difference (two-sided proportion test $\mathrm{p}$-value $=0.457$ )

We find that on average, participants respond to economic incentives and exploit the opportunities to their advantage. Yet, a substantial share of participants behaves altruistically by either not exploiting their advantage, keeping the low initial payoff (51 percent), or using it to forego the high initial payoff in favor of their competitors (29 percent).

Figure 2.3: Share of Players A Exploiting the Advantage

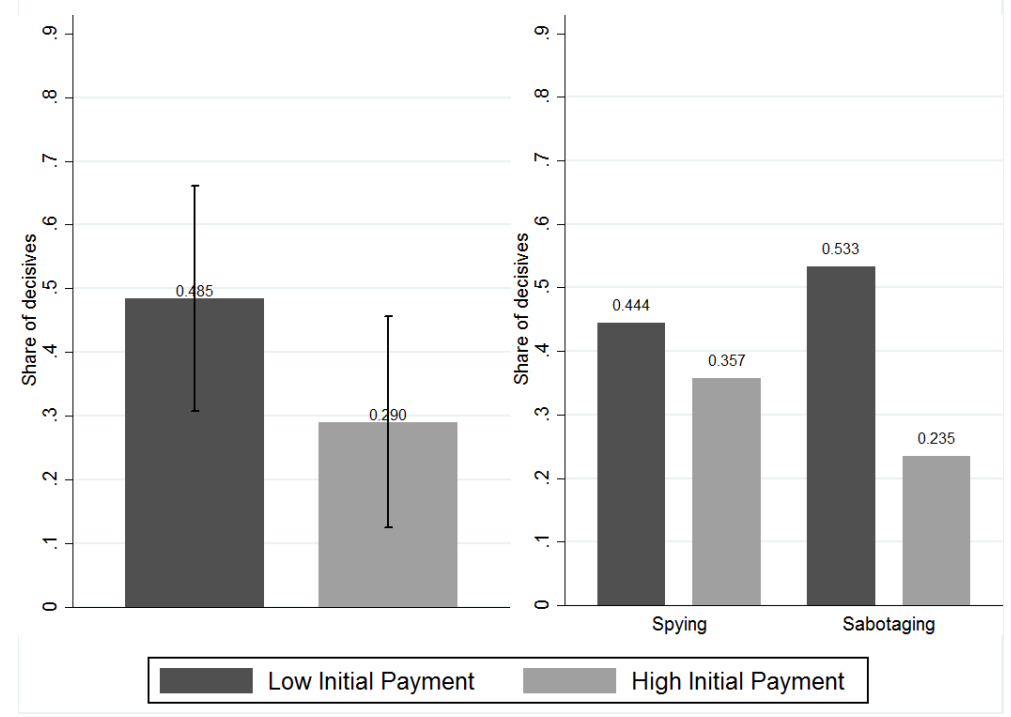

Notes: The figure presents the decision by Player A to exploit the advantage conditional on obtaining the high or low payoff in the matching pennies game. The left side of the figure pools the decisions across treatments, while the right side shows the decisions by treatment. Confidence intervals of $95 \%$.

\subsubsection{Factors affecting the exploitation of advantages}

We expand the analysis to examine the socioeconomic characteristics of Players A (decisives) who exploit advantages in their own favor by spying or sabotaging. We refer to this group of participants as 'Anti-social'. Table 2.3 reports the estimated coefficients of a 
linear probability model that predicts the likelihood to exhibit anti-social behavior. To establish the association between the perception of crime and anti-social behavior in the experiment, we use two measures: Self-reported crime victimization in the last vanilla harvest $^{8}$ (Victimization) and average theft reported by others in the village (Victimization $-i$ ) for the same period. We include socioeconomic characteristics and unbalanced variables (age, household size, ethnicity, and if participant sells her vanilla to a commissionaire) as controls. ${ }^{9}$ Since Players A made previous decisions in the DG and TG games, we control for the initial amount sent in DG as we are aware that previous good behaviors could self-license individuals to spy or sabotage more (Clot et al., 2014). Moreover, we control for the number of known people (friends and/or family members) that were present in the same session.

We find that average theft reported by others in the village (Victimization- $i$ ) is positively correlated with the likelihood to behave anti-socially in treatment SPYING (see columns 2 and 3). Similar findings are reported in Columns (4) and (5) when measuring crime as direct victimization in the last harvest. No such effect is observed for treatment SABOTAGing. The estimated average marginal effect implies that the share of decisive players who changed the outcome of the game to be better-off in treatment SPYING is $1.3 \mathrm{pp}$ higher when the decisive player lives in areas where crime perception increases by one unit (see Column 2). When adding socioeconomic controls, the likelihood for anti-social behavior decreases by $0.2 \mathrm{pp}$ (see Column 3). Living in a village that is perceived as more safe decreases the likelihood of anti-social behavior (see Table 2.A4 column 3). This finding is similar when controlling for self-reported victimization (see Table 2.A4 column 5).

We find some support for the behavioral validity of the experiment as personal experiences, like perceptions of criminal environments and direct victimization, are associated with the behavior taken in our experimental sessions. We do not find evidence that socioeconomic aspects such as age, gender, ethnicity, or household size are predictive for spying or sabotaging. This is in line with other studies (e.g Cappelen et al., 2013) that show no correlation between personal characteristics and dishonest behaviors.

Result 2. An increase in crime perception is positively and significantly correlated to the likelihood of a decisive participant taking advantage in the matching pennies game over their partner in treatment SPYING. Therefore, we partially fail to reject Hypothesis 2.

\footnotetext{
${ }^{8}$ This refers to participants being victims of vanilla theft in the last harvest March-August 2016

${ }^{9}$ Two highly-correlated covariates - number of children and household size - are unbalanced, therefore, we use only one of them in the estimations.
} 
Table 2.3: Determinants Anti-Social behavior

\begin{tabular}{lccccc}
\hline \hline & $(1)$ & $(2)$ & $(3)$ & $(4)$ & $(5)$ \\
& Model 1 & Model 2 & Model 3 & Model 4 & Model 5 \\
\hline SABOTAGING & -0.022 & 0.737 & 0.649 & $0.333^{*}$ & 0.266 \\
& $(0.179)$ & $(0.477)$ & $(0.560)$ & $(0.173)$ & $(0.201)$ \\
Victimization- $i$ & 0.005 & $0.013^{* *}$ & $0.011^{*}$ & & \\
& $(0.004)$ & $(0.005)$ & $(0.006)$ & & \\
Victimization & & & & $0.345^{* *}$ & $0.304^{* *}$ \\
& & & & $(0.140)$ & $(0.141)$ \\
SABOTAGING $\times$ Victimization- $-i$ & & $-0.015^{*}$ & -0.011 & & \\
& & $(0.008)$ & $(0.009)$ & & \\
SABOTAGING $\times$ Victimization & & & & $-0.563^{* *}$ & -0.384 \\
& & & & $(0.229)$ & $(0.238)$ \\
& $(0.381)$ & $(0.216)$ & $(0.435)$ & $(0.067)$ & $(0.302)$ \\
\hline Socioeconomic Controls & Yes & No & Yes & No & Yes \\
Observations & 64 & 64 & 64 & 64 & 64 \\
Adjusted $R^{2}$ & 0.017 & 0.036 & 0.025 & 0.062 & 0.036 \\
\hline \hline
\end{tabular}

Notes: Table presents the characteristics that can influence the decision of Players A to behave antisocial in the game, i.e: exploit the advantage on their favor. The coefficients are estimated using an OLS regression. Socioeconomic controls include: Safety village, Fraction sent in DG in stage 1, No. known people in session, Sells vanilla to a commissionaire, Male, Age in years, Household size, Betsimisaraka ethnicity. Robust standard errors in parentheses. ${ }^{*} p<0.1,{ }^{* *} p<0.05,{ }^{* * *} p<0.01$.

\subsubsection{Altruism, Trust and Trustworthiness}

The summary statistics for the decision in each stage of the game are presented in Table 2.A5. We find that in stage 1, participants sent on average 38 percent of their endowment in the DG and around 36 percent in the TG. On average, they returned 40 percent of the hypothetical amount received.

Average amounts sent in the DG are lower than commonly found in experiments with other non-college students (Castillo \& Carter, 2011) and in developing countries with middle-age individuals (Engel, 2011), where the equal split is common. Similarly, the average fraction sent in the TG is lower in comparison to what has been found in other African countries (Cardenas \& Carpenter, 2008; Johnson \& Mislin, 2011).

Participants seem to follow a reciprocity norm. There is a positive and significant correlation between the amount received and the amount returned in the trust game (Pearson correlation is 0.72 and 0.74 in stages 1 and 3 , with p-value $<0.001$ ).

There is a positive and significant correlation between altruism - proportion send in DGand trust - proportion send in the TG-(Pearson correlation is 0.15 and 0.33 in stage 1 and 3 ), and altruism and trustworthiness - proportion returned in TG-(Pearson correlation is 0.21 and 0.37 , in stage 1 and 3). Trustees send on average 82 percent of the initial investment, which evidences that trust does not pay-off for the trustor.

In the following subsection we present the treatment effects for the other-regarding-behaviors, altruism, trust, and trustworthiness. 


\subsubsection{Treatment effects on other-regarding behaviors}

Our third hypothesis is that exposure to unfair procedures crowds out ex-post pro-sociality. To examine this hypothesis we first compare participants' behavior in stages 1 and 3 across treatment and control groups. Figure 2.4 shows the differences in behavior when comparing the fractions sent or returned. ${ }^{10}$ On average, generosity decreases in the SABOTAGinG treatment compared to CONTROL, but there are no significant differences between the SPYing treatment and Control. We observe no significant differences in the average changes of trust and trustworthiness in the treatment groups compared to CONTROL.

Figure 2.4: Evolution of other regarding behaviors across treatments
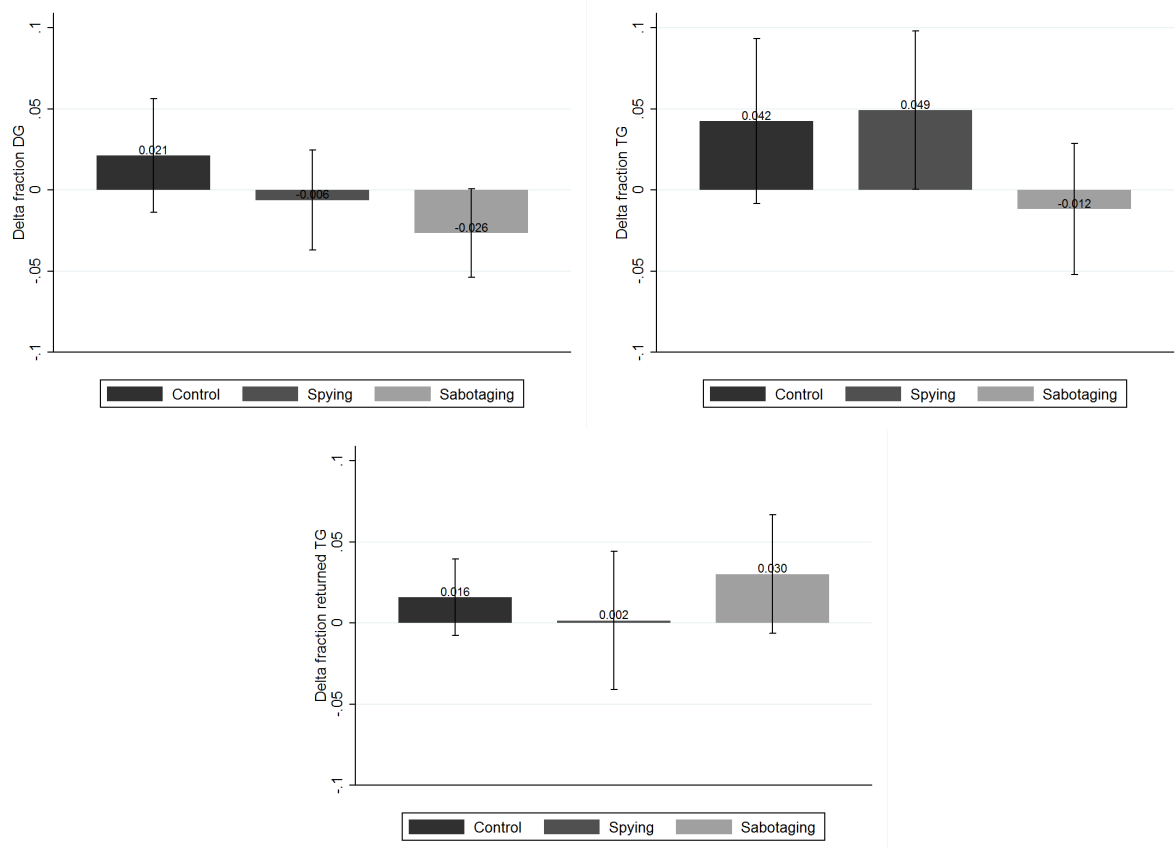

Notes: The figure presents the changes in other-regarding behaviors from stage 1 to stage 3 by treatment. The largest and significant change respect to the control condition is observed for altruism. Confidence intervals of $95 \%$.

To further explore these results and test the heterogeneous treatment effects on otherregarding behaviors by player type, we estimate independent linear regressions where the dependent variables $\Delta \mathrm{DG}$ and $\Delta \mathrm{TG}$ are the difference in the share of the endowment sent in stage 3 and stage 1 in the $\mathrm{DG}$ and $\mathrm{TG}$, respectively, while $\Delta \mathrm{TG}-\mathrm{R}$ is the change in the average share of the endowment (amount received) that was returned between stages 3 and 1 in the TG. The results are shown in Table 2.4.

Columns 1 and 2 present the estimates of the treatment effects on changes in altruism when excluding and including socioeconomic controls. The results show that, in comparison to a fair condition, altruism significantly decreases from stage 1 to stage 3 when participants can

\footnotetext{
${ }^{10}$ For trustworthiness we first calculate the share returned for each of the five hypothetical amounts received, then we average the shares, and last we calculate the difference between stages 3 and 1 .
} 
exploit their advantageous position. As shown in Column 2, the effect doubles in magnitude in treatment SABOTAGing (average decrease of $5.2 \mathrm{pp}$. in the share sent from stage 1 to stage 3) compared to treatment SPYING (average decrease of $2.6 \mathrm{pp}$ ). The pooled negative effects of SABOTAGing hold when correcting for multiple hypothesis testing (see Table 2.A6). Column 3 compares the effects on altruism for Players A (decisive players) and Players B (passive players). First, we observe that in comparison to Players B, Players A of the CONTROL group significantly increase (on average) the share of the endowment sent from stage 1 to stage 3. Second, in treatments Spying and SAbotaging, Players A significantly reduced the share they sent in comparison to Players A in the ConTrol group $(\mathrm{p}$-value $=0.016$ and $\mathrm{p}$-value $=0.02$, respectively $)$. There is also a significant decrease in the share that Players B sent from stage 1 to stage 3 in treatment SABOTAGING respect to Control group ( $\mathrm{p}$-value $=0.089$ ). We find no evidence for significant differences in the changes of giving behavior between Players A and B in the unfair conditions.

Columns 4 to 5 present the treatment effects on the evolution of trust excluding and including socioeconomic controls. First, we find no significant differences in the evolution of trust between treatments and the control group. Yet, a subgroup analysis reveals that the treatments have a distinct effect on Players A and B (decisive and passive players). In the TG, Players A sent on average a significantly higher share from stage 1 to stage 3 in the Control group with respect to Players B. Further, we find that Players A reduced the amount sent by $8.7 \mathrm{pp}$ from stage 1 to stage 3 in treatment SABOTAGING with respect to the Control condition ( $\mathrm{p}$-value $=0.095$ ). We do not observe significant differences in the trusting behavior of Players B.

Columns 7 and 8 reveal that overall there are no significant treatment effects for changes in trustworthiness. Yet, when conducting heterogeneous treatment effects by player, we find that Players A returned on average a larger share in the treatment SABOtAGing compared to Control group $(\mathrm{p}$-value $=0.030)$. Moreover, we find that in treatment SPYING Players A significantly increase on average the amount returned from stage 1 to stage 3 compared to Players B. This explains the significant effect of the interaction term for treatment Spying. Last, we find that Players B became less trustworthy in the SPYING treatment compared to Players B in the CONTROL group, yet the effect is weakly significant $(\mathrm{p}$-value $=0.091)$.

Result 3. Exposure to unfair procedures is associated with a crowding-out of altruism, while there are no such effects on trust and trustworthiness. The decrease in altruism is larger in the SABOTAGING condition. Therefore, we partially reject Hypothesis 3. 
Table 2.4: Treatment effects on other-regarding behaviors

\begin{tabular}{|c|c|c|c|c|c|c|c|c|c|}
\hline & \multicolumn{3}{|c|}{ Delta DG } & \multicolumn{3}{|c|}{ Delta TG } & \multicolumn{3}{|c|}{ Delta TG-R } \\
\hline & $(1)$ & (2) & (3) & (4) & (5) & (6) & $(7)$ & (8) & (9) \\
\hline SPYING & $\begin{array}{c}-0.027^{* * *} \\
(0.007)\end{array}$ & $\begin{array}{c}-0.026^{* *} \\
(0.011)\end{array}$ & $\begin{array}{c}0.001 \\
(0.020)\end{array}$ & $\begin{array}{c}0.007 \\
(0.046)\end{array}$ & $\begin{array}{c}0.009 \\
(0.056)\end{array}$ & $\begin{array}{c}0.036 \\
(0.054)\end{array}$ & $\begin{array}{l}-0.014 \\
(0.018)\end{array}$ & $\begin{array}{l}-0.012 \\
(0.017)\end{array}$ & $\begin{array}{l}-0.042^{*} \\
(0.022)\end{array}$ \\
\hline SABOTAGING & $\begin{array}{c}-0.047^{* * *} \\
(0.009)\end{array}$ & $\begin{array}{c}-0.052^{* * *} \\
(0.013)\end{array}$ & $\begin{array}{l}-0.036^{*} \\
(0.019)\end{array}$ & $\begin{array}{l}-0.053 \\
(0.043)\end{array}$ & $\begin{array}{l}-0.061 \\
(0.043)\end{array}$ & $\begin{array}{l}-0.037 \\
(0.052)\end{array}$ & $\begin{array}{c}0.015 \\
(0.012)\end{array}$ & $\begin{array}{c}0.025 \\
(0.018)\end{array}$ & $\begin{array}{c}0.003 \\
(0.027)\end{array}$ \\
\hline Decisive & $\begin{array}{l}0.023^{*} \\
(0.011)\end{array}$ & $\begin{array}{c}0.022 \\
(0.012)\end{array}$ & $\begin{array}{l}0.052^{* *} \\
(0.016)\end{array}$ & $\begin{array}{c}0.048 \\
(0.026)\end{array}$ & $\begin{array}{l}0.051^{*} \\
(0.024)\end{array}$ & $\begin{array}{c}0.086^{* * *} \\
(0.025)\end{array}$ & $\begin{array}{c}0.010 \\
(0.013)\end{array}$ & $\begin{array}{c}0.015 \\
(0.015)\end{array}$ & $\begin{array}{l}-0.019 \\
(0.015)\end{array}$ \\
\hline SPYING $\times$ Decisive & & & $\begin{array}{l}-0.057 \\
(0.030)\end{array}$ & & & $\begin{array}{c}-0.056 \\
(0.068)\end{array}$ & & & $\begin{array}{c}0.060^{* *} \\
(0.019)\end{array}$ \\
\hline Sabotaging $\times$ Decisive & & & $\begin{array}{l}-0.034 \\
(0.023)\end{array}$ & & & $\begin{array}{c}-0.051 \\
(0.045)\end{array}$ & & & $\begin{array}{c}0.046 \\
(0.029)\end{array}$ \\
\hline Socioeconomic Controls & No & Yes & Yes & No & Yes & Yes & No & Yes & Yes \\
\hline Observations & 199 & 199 & 199 & 199 & 199 & 199 & 199 & 199 & 199 \\
\hline
\end{tabular}

\subsection{Discussion}

In a game where subjects have the opportunity to exploit others through power advantages, we show that not all participants exploit the advantage to their favor, indicating moral concerns on how outcomes are achieved. This result is in line with the study by Harbring et al. (2007), in which around 40 percent of the players decide to sabotage their competitors, knowing beforehand that such actions would be revealed.

However, contrary to our hypothesis, we do not observe a significant difference in the share of individuals who exploit the advantage in treatment SPYING versus treatment SABOTAGing, suggesting that both procedures have similar moral costs. Except for the seminal works by Brandts \& Charness (2003) and Harbring et al. (2007), players usually do not receive information on the decisions taken by their competitors that led to the final outcomes. This could potentially explain why our results are at odds with our hypothesis, as both actions could be perceived as morally equal when individuals know that they will be revealed.

Moreover, we observe that about half of Players A decided not to exploit the given advantage when obtaining the low payoff in the matching pennies game. We attribute this to two main reasons: First, since luck determined the payoffs in the game, anti-social behaviors are harder to be morally justified compared to a situation in which individuals would have had to perform a task and compete (e.g Gravert, 2013). Therefore, Player A had a weak moral justification for opting for the unfair practice, reducing her incentives to do so. Second, since the experimenter could observe the behavior, individuals might still have image concerns even when anonymity was guaranteed. 
The nature of our design allows us to observe whether individuals also exploit the advantage to benefit her competitor. Similar to Chlaßs \& Riener (2015), we suggest that giving the decision rights to only one player might generate psychological costs. Therefore, the player might opt to use their advantage to rectify the "unfairness" or level the playing field by forgoing the high-payoff to benefit the competitor. Other potential reasons to explain this behavior are: individuals have purely altruistic motives (Becker, 1976) or impure altruistic motives in which they feel good by making their competitor better-off (Andreoni, 1990).

In the results, we evidence how living in criminal environments, and direct victimization is positively correlated with the decision to behave anti-social in treatment SPYING in the matching pennies game. This indicates the negative effects of crime on individual behavior. Yet, we are aware that we do not have adequate measures of criminality, as there are no public records in our study region. We thus acknowledge that other previous negative experiences outside the laboratory could potentially explain our empirical evidence on anti-social behaviors as well. It would be interesting and relevant to explore the causal effects of criminality on anti-social behaviors; however, this is outside the scope of the present research.

Last, we are interested in the evolution of other-regarding behaviors to explore the social costs associated to unfair environments. Our results show that altruism is the only prosocial behavior that decreases from stage 1 to stage 3 . We interpret our results by suggesting that trust and trustworthiness are conditional and strategic behaviors, while altruism is unconditional and therefore not strategic, making it more vulnerable when exposed to shocks (Cox, 2004). We explain the negative change of altruism on Players A as the result of a licensing effect. Since Players A had the opportunity to take advantage from stage 2 on, they used the opportunity in their favor. While it is striking that overall we do not observe strongly significant changes on Players B pro-sociality, we attribute this result to three potential reasons: First, most players do not exploit the given advantage; Second, the competitive context of the game might have neutralized positive or negative reciprocity as Players B could have anticipated egoistic behaviors (e.g. Rode, 2010); and third, exposure to unfair environments has been internalized as a social norm and therefore individuals are unlikely to retaliate under this type of environments. Given the low number of Players A that exploit the given advantage in their favor (16 anti-social players) we do not further explore the consequences in other-regarding behaviors for the corresponding victims.

\subsection{Conclusion}

In this paper we explore whether the procedure for taking advantage matters, what factors may influence the decision to exploit a given advantage, and whether being exposed to unfair procedures has an effect on other-regarding behaviors. We do so by conducting an artefactual field experiment in northeastern Madagascar with 199 vanilla farmers. In our experiment, participants are matched in pairs and engage in a fair or an unfair version 
of the matching pennies game. In the fair version (CONTROL group), the two players simultaneously decide between two options that determine their payoffs. Based on the decisions, one player receives a high payoff and the other one a low payoff. After decisions have been made, both players receive feedback on the choices and payoffs of the game. In the unfair version of the game, one of the players receives a power advantage: power to revise one's own decision (SPYING) or power to overrule the competitor's decision (SABOTAGinG). That player decides to exploit the advantage on her favor, to benefit her competitor, or not to use it. To explore changes in the prosocial behavior of individuals after being exposed to unfair procedures, we conducted a dictator and a trust game before and after the rigged matching pennies game and compare their behavior with decisions made by players in the fair competitive environment.

Contrary to our expectations, we find no significant differences in the share of players exploiting the given advantage in treatment group SPying compared to SABOTAGing. This result persists when players can use the advantage in their favor or benefit their competitor. Hence, we do not have evidence for procedural preferences for taking advantage, suggesting that individuals follow a consequentialist norm. Yet, it is important to clarify that not all participants who were given the advantage exploited it, indicating that in general, people do care about how outcomes are achieved. Our second main finding is that past theft experiences are positively correlated with the decision of individuals to exploit the advantage in their favor in the experiment. This finding indicates that experiences in the field translate to behavior in the laboratory.

Last, we find a negative and significant change in generosity when players are exposed to an unfair versus a fair competitive environment, but no significant change in trust and trustworthiness. The observed changes in altruism are significant for participants who obtained the unfair competitive advantage in the matching pennies game.

It is possible to translate the results obtained in Madagascar to other contexts, where individuals can exploit advantages in a market setting given the low state capacity and law enforcement, as well as high corruption. From our results, we show that theft is related to the decision to exploit a given advantage. Hence, since crime is an important challenge that many countries in the world face, especially in developing countries, our study provides further evidence on how these experiences can be translated into excuses to use opportunistic advantages to harm others. These actions can turn into a vicious circle that can end in low levels of pro-sociality, which might have negative consequences in economic growth in the long-run. 


\subsection{Appendices}

\subsubsection{Appendix A - Tables}

Table 2.A1: Socioeconomic Characteristics by Treatment

\begin{tabular}{|c|c|c|c|c|}
\hline & $\begin{array}{c}(1) \\
\text { Control }\end{array}$ & $\begin{array}{c}(2) \\
\text { SPYING }\end{array}$ & $\begin{array}{c}(3) \\
\text { SABOTAGING }\end{array}$ & $\begin{array}{c}(4) \\
\text { p-value }\end{array}$ \\
\hline Male & $\begin{array}{c}0.621 \\
(0.060)\end{array}$ & $\begin{array}{c}0.769 \\
(0.053)\end{array}$ & $\begin{array}{c}0.676 \\
(0.057)\end{array}$ & 0.183 \\
\hline Age in years & $\begin{array}{l}49.773 \\
(1.772)\end{array}$ & $\begin{array}{l}53.323 \\
(1.742)\end{array}$ & $\begin{array}{l}47.647 \\
(1.674)\end{array}$ & 0.067 \\
\hline Years of education & $\begin{array}{c}5.439 \\
(0.435)\end{array}$ & $\begin{array}{c}5.923 \\
(0.364)\end{array}$ & $\begin{array}{c}5.926 \\
(0.393)\end{array}$ & 0.612 \\
\hline Household size & $\begin{array}{c}4.879 \\
(0.240)\end{array}$ & $\begin{array}{c}5.723 \\
(0.334)\end{array}$ & $\begin{array}{c}4.426 \\
(0.223)\end{array}$ & 0.003 \\
\hline Number of children & $\begin{array}{c}3.545 \\
(0.259)\end{array}$ & $\begin{array}{c}4.923 \\
(0.467)\end{array}$ & $\begin{array}{c}3.559 \\
(0.265)\end{array}$ & 0.006 \\
\hline Married & $\begin{array}{c}0.818 \\
(0.048)\end{array}$ & $\begin{array}{c}0.815 \\
(0.048)\end{array}$ & $\begin{array}{c}0.838 \\
(0.045)\end{array}$ & 0.932 \\
\hline Betsimisaraka ethnicity & $\begin{array}{c}0.485 \\
(0.062)\end{array}$ & $\begin{array}{c}0.462 \\
(0.062)\end{array}$ & $\begin{array}{c}0.662 \\
(0.058)\end{array}$ & 0.039 \\
\hline No. known people in session & $\begin{array}{c}6.682 \\
(0.627)\end{array}$ & $\begin{array}{c}7.308 \\
(0.693)\end{array}$ & $\begin{array}{c}7.059 \\
(0.650)\end{array}$ & 0.797 \\
\hline Victimization & $\begin{array}{c}0.394 \\
(0.061)\end{array}$ & $\begin{array}{c}0.492 \\
(0.062)\end{array}$ & $\begin{array}{c}0.647 \\
(0.058)\end{array}$ & 0.012 \\
\hline Safety village & $\begin{array}{c}3.061 \\
(0.138)\end{array}$ & $\begin{array}{c}2.815 \\
(0.159)\end{array}$ & $\begin{array}{c}2.515 \\
(0.140)\end{array}$ & 0.031 \\
\hline Number of vanilla trees & $\begin{array}{l}600.485 \\
(98.431)\end{array}$ & $\begin{array}{c}706.462 \\
(198.759)\end{array}$ & $\begin{array}{c}778.088 \\
(233.066)\end{array}$ & 0.794 \\
\hline Kg. of green vanilla sold & $\begin{array}{l}13.288 \\
(3.387)\end{array}$ & $\begin{array}{l}16.638 \\
(2.922)\end{array}$ & $\begin{array}{l}13.706 \\
(4.438)\end{array}$ & 0.783 \\
\hline Sells vanilla to a commissionaire & $\begin{array}{c}0.379 \\
(0.060)\end{array}$ & $\begin{array}{c}0.477 \\
(0.062)\end{array}$ & $\begin{array}{c}0.588 \\
(0.060)\end{array}$ & 0.052 \\
\hline Sells vanilla to a collector & $\begin{array}{c}0.167 \\
(0.046)\end{array}$ & $\begin{array}{c}0.185 \\
(0.048)\end{array}$ & $\begin{array}{c}0.103 \\
(0.037)\end{array}$ & 0.385 \\
\hline Holded a credit in the past & $\begin{array}{c}0.106 \\
(0.038)\end{array}$ & $\begin{array}{c}0.092 \\
(0.036)\end{array}$ & $\begin{array}{c}0.118 \\
(0.039)\end{array}$ & 0.894 \\
\hline Holds a credit now & $\begin{array}{c}0.045 \\
(0.026)\end{array}$ & $\begin{array}{c}0.077 \\
(0.033)\end{array}$ & $\begin{array}{c}0.029 \\
(0.021)\end{array}$ & 0.449 \\
\hline$N$ & 66 & 65 & 68 & \\
\hline
\end{tabular}

Notes: The p-value corresponds to a joint orthogonality test that runs the F-test that the comparison groups (in this case the treatment arms) do not predict the balance variable. The variables are self-reported at the end of the experiment. Variables: Male: 1 if participant is male and 0 otherwise; Age in years: Age reported by participant; Years of education: Last year of education approved that participant reported; Household size: Number of people that lives in participant's house; Number of children: Number of children participant has; Married: 1 if participant reports to be married and 0 otherwise; Betsimisaraka ethnicity: 1 if participant is part of this ethnicity and 0 otherwise; No.known people in session: Number of friends or relatives taking part in the

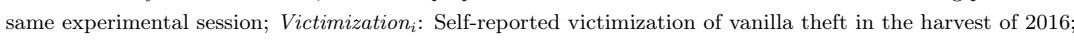
Safety village: takes values from 1 (strongly disagree) to 5 (strongly agree), participant had to rank the statement "In general, my village is very safe"; Number of vanilla trees: Number of vanilla trees participant owns; $K g$. of green vanilla sold: Number of green vanilla kilograms that participant sold in the harvest of 2016; Sells vanilla to a commissionaire: 1 if participant reported to have sold either green or black vanilla to a commissionaire and 0 otherwise. A commissionaire is a middle men that takes the vanilla from farmers to sell it in larger markets and brings profits afterwards, thus high levels of trust are required; Sells vanilla to a collector: 1 if participant reported to have sold either green or black vanilla to a collector and 0 otherwise. A collector is a middle men that buys the vanilla from farmers; Held a credit in the past: 1 if participant held a credit in the time previous to the experimental session and 0 otherwise; Holds a credit now: 1 if participant holds a credit at the moment of the experimental session and 0 otherwise. Standard errors in parentheses. 
Table 2.A2: Socioeconomic Characteristics by Role

\begin{tabular}{|c|c|c|c|}
\hline & $\begin{array}{c}(1) \\
\text { Passive }\end{array}$ & $\begin{array}{c}(2) \\
\text { Decisive }\end{array}$ & $\begin{array}{c}(3) \\
\text { p-value }\end{array}$ \\
\hline Male & $\begin{array}{c}0.676 \\
(0.047)\end{array}$ & $\begin{array}{c}0.701 \\
(0.047)\end{array}$ & 0.710 \\
\hline Age in years & $\begin{array}{l}49.941 \\
(1.419)\end{array}$ & $\begin{array}{l}50.485 \\
(1.436)\end{array}$ & 0.788 \\
\hline Years of education & $\begin{array}{c}5.794 \\
(0.294)\end{array}$ & $\begin{array}{c}5.732 \\
(0.357)\end{array}$ & 0.893 \\
\hline Household size & $\begin{array}{c}5.078 \\
(0.223)\end{array}$ & $\begin{array}{c}4.918 \\
(0.227)\end{array}$ & 0.614 \\
\hline Number of children & $\begin{array}{c}4.010 \\
(0.284)\end{array}$ & $\begin{array}{c}3.990 \\
(0.286)\end{array}$ & 0.960 \\
\hline Married & $\begin{array}{c}0.814 \\
(0.039)\end{array}$ & $\begin{array}{c}0.835 \\
(0.038)\end{array}$ & 0.695 \\
\hline Betsimisaraka ethnicity & $\begin{array}{c}0.490 \\
(0.050)\end{array}$ & $\begin{array}{c}0.588 \\
(0.050)\end{array}$ & 0.170 \\
\hline Number of vanilla trees & $\begin{array}{c}842.569 \\
(198.946)\end{array}$ & $\begin{array}{l}541.443 \\
(67.316)\end{array}$ & 0.162 \\
\hline $\mathrm{Kg}$. of green vanilla sold & $\begin{array}{l}12.691 \\
(2.561)\end{array}$ & $\begin{array}{l}16.454 \\
(3.383)\end{array}$ & 0.373 \\
\hline Victimization & $\begin{array}{c}0.510 \\
(0.050)\end{array}$ & $\begin{array}{c}0.515 \\
(0.051)\end{array}$ & 0.937 \\
\hline Holded a credit in the past & $\begin{array}{c}0.098 \\
(0.030)\end{array}$ & $\begin{array}{c}0.113 \\
(0.032)\end{array}$ & 0.726 \\
\hline Holds a credit now & $\begin{array}{c}0.039 \\
(0.019)\end{array}$ & $\begin{array}{c}0.062 \\
(0.025)\end{array}$ & 0.467 \\
\hline Sells vanilla to a commissionaire & $\begin{array}{c}0.451 \\
(0.050)\end{array}$ & $\begin{array}{c}0.515 \\
(0.051)\end{array}$ & 0.365 \\
\hline Sells vanilla to a collector & $\begin{array}{c}0.167 \\
(0.037)\end{array}$ & $\begin{array}{c}0.134 \\
(0.035)\end{array}$ & 0.522 \\
\hline$N$ & 102 & 97 & \\
\hline
\end{tabular}

Notes: The p-value corresponds to a joint orthogonality test that runs the F-test that the comparison groups (in this case the role of participant) do not predict the balance variable. Standard errors in parentheses. 
Table 2.A3: Decision in the Second Stage by Player A

\begin{tabular}{|c|c|c|c|c|c|}
\hline & $\begin{array}{c}(1) \\
\text { Control }\end{array}$ & $\begin{array}{c}(2) \\
\text { SPYING }\end{array}$ & $\begin{array}{c}(3) \\
\text { SABOTAGING }\end{array}$ & $\begin{array}{c}(4) \\
\text { Overall }\end{array}$ & $\begin{array}{c}(5) \\
\text { p-value }\end{array}$ \\
\hline \multicolumn{6}{|c|}{ Panel A: Player's A outcomes } \\
\hline Circle & $\begin{array}{c}0.636 \\
(0.085)\end{array}$ & $\begin{array}{c}0.375 \\
(0.087)\end{array}$ & $\begin{array}{c}0.563 \\
(0.089)\end{array}$ & $\begin{array}{c}0.526 \\
(0.051)\end{array}$ & 0.096 \\
\hline High Outcome S1 & $\begin{array}{c}0.545 \\
(0.088)\end{array}$ & $\begin{array}{c}0.438 \\
(0.089)\end{array}$ & $\begin{array}{c}0.531 \\
(0.090)\end{array}$ & $\begin{array}{c}0.505 \\
(0.051)\end{array}$ & 0.649 \\
\hline High Outcome S2 & $\begin{array}{c}0.545 \\
(0.088)\end{array}$ & $\begin{array}{c}0.531 \\
(0.090)\end{array}$ & $\begin{array}{c}0.656 \\
(0.085)\end{array}$ & $\begin{array}{c}0.577 \\
(0.050)\end{array}$ & 0.548 \\
\hline Exploit advantage & . & $\begin{array}{c}0.406 \\
(0.088)\end{array}$ & $\begin{array}{c}0.375 \\
(0.087)\end{array}$ & $\begin{array}{c}0.391 \\
(0.061)\end{array}$ & 0.802 \\
\hline \multicolumn{6}{|c|}{ Panel B: Exploit advantage by initial outcome } \\
\hline Low Payment & & $\begin{array}{c}0.444 \\
(0.121)\end{array}$ & $\begin{array}{c}0.533 \\
(0.133)\end{array}$ & $\begin{array}{c}0.485 \\
(0.088)\end{array}$ & 0.624 \\
\hline High Payment & & $\begin{array}{c}0.357 \\
(0.133)\end{array}$ & $\begin{array}{c}0.235 \\
(0.106)\end{array}$ & $\begin{array}{c}0.290 \\
(0.083)\end{array}$ & 0.474 \\
\hline Observations & 33 & 32 & 32 & 64 & \\
\hline
\end{tabular}

Notes: The p-value corresponds to a joint orthogonality test that runs the F-test that the comparison groups (in this case the treatment arms) do not predict the balance variable. Standard errors in parentheses. 
Table 2.A4: Determinants Anti-Social behavior

\begin{tabular}{|c|c|c|c|c|c|}
\hline & $\begin{array}{c}(1) \\
\text { Model } 1\end{array}$ & $\begin{array}{c}(2) \\
\text { Model } 2\end{array}$ & $\begin{array}{c}(3) \\
\text { Model } 3\end{array}$ & $\begin{array}{c}(4) \\
\text { Model } 4\end{array}$ & $\begin{array}{c}(5) \\
\text { Model } 5\end{array}$ \\
\hline SABOTAGING & $\begin{array}{c}-0.022 \\
(0.179)\end{array}$ & $\begin{array}{c}0.737 \\
(0.477)\end{array}$ & $\begin{array}{c}0.649 \\
(0.560)\end{array}$ & $\begin{array}{c}0.333^{*} \\
(0.173)\end{array}$ & $\begin{array}{c}0.266 \\
(0.201)\end{array}$ \\
\hline Victimization $-i$ & $\begin{array}{c}0.005 \\
(0.004)\end{array}$ & $\begin{array}{l}0.013^{* *} \\
(0.005)\end{array}$ & $\begin{array}{c}0.011^{*} \\
(0.006)\end{array}$ & & \\
\hline Victimization & & & & $\begin{array}{l}0.345^{* *} \\
(0.140)\end{array}$ & $\begin{array}{l}0.304^{* *} \\
(0.141)\end{array}$ \\
\hline SABOTAGING $\times$ Victimization $-i$ & & $\begin{array}{c}-0.015^{*} \\
(0.008)\end{array}$ & $\begin{array}{l}-0.011 \\
(0.009)\end{array}$ & & \\
\hline SABOTAGING $\times$ Victimization & & & & $\begin{array}{c}-0.563^{* *} \\
(0.229)\end{array}$ & $\begin{array}{c}-0.384 \\
(0.238)\end{array}$ \\
\hline Safety village & $\begin{array}{c}-0.111^{* *} \\
(0.047)\end{array}$ & & $\begin{array}{c}-0.095^{*} \\
(0.050)\end{array}$ & & $\begin{array}{c}-0.096^{*} \\
(0.048)\end{array}$ \\
\hline Fraction-sent Baseline DG & $\begin{array}{l}-0.367 \\
(0.447)\end{array}$ & & $\begin{array}{l}-0.268 \\
(0.450)\end{array}$ & & $\begin{array}{l}-0.259 \\
(0.431)\end{array}$ \\
\hline No. known people in session & $\begin{array}{c}0.006 \\
(0.009)\end{array}$ & & $\begin{array}{c}0.007 \\
(0.009)\end{array}$ & & $\begin{array}{c}0.008 \\
(0.010)\end{array}$ \\
\hline Sells vanilla to a commissionaire & $\begin{array}{l}-0.039 \\
(0.114)\end{array}$ & & $\begin{array}{l}-0.068 \\
(0.121)\end{array}$ & & $\begin{array}{l}-0.066 \\
(0.121)\end{array}$ \\
\hline Male & $\begin{array}{c}-0.004 \\
(0.130)\end{array}$ & & $\begin{array}{c}0.015 \\
(0.132)\end{array}$ & & $\begin{array}{c}-0.037 \\
(0.122)\end{array}$ \\
\hline Age in years & $\begin{array}{c}0.003 \\
(0.004)\end{array}$ & & $\begin{array}{c}0.003 \\
(0.004)\end{array}$ & & $\begin{array}{c}0.003 \\
(0.004)\end{array}$ \\
\hline Household size & $\begin{array}{c}0.026 \\
(0.032)\end{array}$ & & $\begin{array}{c}0.029 \\
(0.032)\end{array}$ & & $\begin{array}{c}0.019 \\
(0.033)\end{array}$ \\
\hline Betsimisaraka ethnicity & $\begin{array}{c}0.002 \\
(0.129) \\
(0.381)\end{array}$ & $(0.216)$ & $\begin{array}{c}-0.017 \\
(0.128) \\
(0.435)\end{array}$ & $(0.067)$ & $\begin{array}{c}-0.044 \\
(0.125) \\
(0.302)\end{array}$ \\
\hline $\begin{array}{l}\text { Observations } \\
\text { Adjusted } R^{2}\end{array}$ & $\begin{array}{c}64 \\
0.017\end{array}$ & $\begin{array}{c}64 \\
0.036\end{array}$ & $\begin{array}{c}64 \\
0.025\end{array}$ & $\begin{array}{c}64 \\
0.062\end{array}$ & $\begin{array}{c}64 \\
0.036\end{array}$ \\
\hline
\end{tabular}


Table 2.A5: Orthogonality Table

\begin{tabular}{|c|c|c|c|c|c|}
\hline & $\begin{array}{c}(1) \\
\text { Control }\end{array}$ & $\begin{array}{c}(2) \\
\text { SPYING }\end{array}$ & $\begin{array}{c}(3) \\
\text { SABOTAGING }\end{array}$ & $\begin{array}{c}(4) \\
\text { Overall }\end{array}$ & $\begin{array}{c}(5) \\
\text { p-value }\end{array}$ \\
\hline Baseline DG & $\begin{array}{c}0.356 \\
(0.015)\end{array}$ & $\begin{array}{c}0.400 \\
(0.016)\end{array}$ & $\begin{array}{c}0.390 \\
(0.013)\end{array}$ & $\begin{array}{c}0.382 \\
(0.008)\end{array}$ & 0.079 \\
\hline Ex-post DG & $\begin{array}{c}0.377 \\
(0.018)\end{array}$ & $\begin{array}{c}0.394 \\
(0.019)\end{array}$ & $\begin{array}{c}0.363 \\
(0.016)\end{array}$ & $\begin{array}{c}0.378 \\
(0.010)\end{array}$ & 0.474 \\
\hline$\Delta \mathrm{DG}$ & $\begin{array}{c}0.021 \\
(0.018)\end{array}$ & $\begin{array}{l}-0.006 \\
(0.016)\end{array}$ & $\begin{array}{l}-0.026 \\
(0.014)\end{array}$ & $\begin{array}{l}-0.004 \\
(0.009)\end{array}$ & 0.101 \\
\hline Baseline TG & $\begin{array}{c}0.364 \\
(0.024)\end{array}$ & $\begin{array}{c}0.329 \\
(0.022)\end{array}$ & $\begin{array}{c}0.394 \\
(0.018)\end{array}$ & $\begin{array}{c}0.363 \\
(0.013)\end{array}$ & 0.105 \\
\hline Ex-post TG & $\begin{array}{c}0.406 \\
(0.022)\end{array}$ & $\begin{array}{c}0.378 \\
(0.022)\end{array}$ & $\begin{array}{c}0.382 \\
(0.020)\end{array}$ & $\begin{array}{c}0.389 \\
(0.013)\end{array}$ & 0.626 \\
\hline$\Delta \mathrm{TG}$ & $\begin{array}{c}0.042 \\
(0.026)\end{array}$ & $\begin{array}{c}0.049 \\
(0.025)\end{array}$ & $\begin{array}{l}-0.012 \\
(0.020)\end{array}$ & $\begin{array}{c}0.026 \\
(0.014)\end{array}$ & 0.137 \\
\hline Ret. Baseline TG & $\begin{array}{c}0.404 \\
(0.018)\end{array}$ & $\begin{array}{c}0.421 \\
(0.020)\end{array}$ & $\begin{array}{c}0.388 \\
(0.017)\end{array}$ & $\begin{array}{c}0.404 \\
(0.011)\end{array}$ & 0.448 \\
\hline Ret. Ex-post TG & $\begin{array}{c}0.420 \\
(0.018)\end{array}$ & $\begin{array}{c}0.422 \\
(0.017)\end{array}$ & $\begin{array}{c}0.418 \\
(0.016)\end{array}$ & $\begin{array}{c}0.420 \\
(0.010)\end{array}$ & 0.985 \\
\hline$\Delta$ TG-R & $\begin{array}{c}0.016 \\
(0.012)\end{array}$ & $\begin{array}{c}0.002 \\
(0.022)\end{array}$ & $\begin{array}{c}0.030 \\
(0.019)\end{array}$ & $\begin{array}{c}0.016 \\
(0.010)\end{array}$ & 0.521 \\
\hline
\end{tabular}

Notes: The p-value corresponds to a joint orthogonality test that runs the F-test that the comparison groups (in this case the treatment arms) do not predict the balance variable. Standard errors in parentheses.

Table 2.A6: Multiple Hypothesis Testing

\begin{tabular}{|c|c|c|c|}
\hline Outcome variable & Treatment & p-value not adjusted & p-value adjusted (B-H) \\
\hline$\Delta \mathrm{DG}$ & SPYING vs. CONTROL & 0.045 & 0.1350 \\
\hline$\Delta \mathrm{DG}$ & SABOtaging vs. Control & 0.004 & 0.0240 \\
\hline$\Delta \mathrm{TG}$ & SPYing vs. CONTROL & 0.882 & 0.8820 \\
\hline$\Delta \mathrm{TG}$ & SABOtaging vs. Control & 0.200 & 0.3075 \\
\hline$\Delta \mathrm{TG}-\mathrm{R}$ & SPYING vs. CONTROL & 0.484 & 0.5808 \\
\hline$\Delta \mathrm{TG}-\mathrm{R}$ & Sabotaging vs. Control & 0.205 & 0.3075 \\
\hline
\end{tabular}

Notes: For the multiple hypothesis testing we use the Benjamini-Hochberg method as it has been shown to be less conservative, especially with low power samples, than the Bonferroni correction. 


\subsubsection{Appendix B - Experimental Instructions and Survey}

\section{Lab-in-the-field Instructions}

\section{Ladies and gentlemen, good morning and welcome!}

My name is Marius and these are my colleagues Viviana, Angelico, JeanYves, Tatiana, Vanessa, Jockline, and Nirina. We come in behalf of Georg-August University in Germany. We are doing in a study on Vanilla production in the Sava region. I want to thank you all for taking the time to come to this workshop. The results of the activities and questionnaires that we will be doing today will be very helpful for the research and will remain confidential. We appreciate your help.

This activity is done with different participants. To make sure that I do not forget any point of the explanation, I am going to read the instructions. Please pay attention.

If at any time you feel uncomfortable, you are free to leave the room whether we have started the activity or not. However, in that case you will earn no money. Maybe you might have heard about this activity before, yet what we will be doing today might be different. It is important that you pay attention to the explanation.

From now on, if you have questions, please raise your hand and we will come to you to clarify your questions. Please do not talk to the other participants in the workshop. This is very important. Please turn your mobile phone off as well.

\section{What are you doing today?}

This activity has five parts. After completing the workshop one activity will be paid for sure and in addition, one of the other four activities will be selected to be paid.

Each one of you will be paired with another participant from this room and form a group. During or after the activity you will not know who the other person in the group is. Also the other person will not know if you are in his or her group. Only one of us knows this but he/she will tell this to anybody.

You will soon receive a piece of paper. Please do not open it until I have finished explaining. 


\section{Activity Green 1 (DG-1)}

In each group one person will take the role $\mathrm{A}$ and the other the role $\mathrm{B}$.

Person in role A receives 10,000 ariary from us. Person in role B does not receive any payment. The task for Person A is to decide how many ariary he or she would like to send to Person B. Person A can send zero; 1,000; 2,000; up to 10,000 ariary.

The earnings for Person A will be 10,000 ariary minus the amount sent to Person B.

The earnings for Person B will be the amount sent by Person A.

(show poster "Payment Activity Green"). ${ }^{11}$

Figure 2.B1: Payment Activity Green

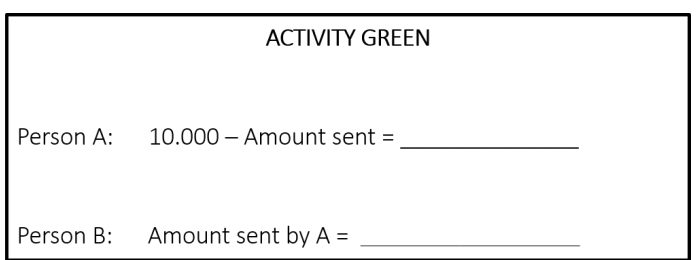

You will receive a piece of paper like this one (show decision sheet). This sheet has 10 bills of 1,000 ariary. Please mark how much you would like to send to Person B. If you mark the box with no bill it means you are sending zero ariary to Person B. Therefore Person A will receive 10,000 ariary and Person B would receive 0 ariary.

(show decision sheet "Activity Green")

Imagine that Person A wants to send 2,000 ariary to Person B. Then he or she has to mark 2 bills. (Mark 2 bills in the poster). Person A would receive 10,000 ariary minus 2,000 ariary equal to 8,000 ariary.

Let's see another example. Imagine that Person A wants to send 7,000 ariary to person B. Then we mark 7 bills. (Mark 7 bills in the poster). Then how much would Person B receive? How much person A would have at the end?

Now let me explain how the activity will work.

If this activity is selected for payment, at the end of the workshop we will select randomly who will be Person A and who Person B. But first all of you will all decide as if you were person A.

\footnotetext{
${ }^{11}$ Text in italics corresponds to the tasks for the instructor
} 


\section{Control Questions}

I would like to ask numbers $\mathrm{xx}, \mathrm{xx}$ to come to the front (pick the numbers randomly from the bag). We will do this activity together in case somebody has still questions. It is important that we do this because if you don?t understand the instructions then you will not be able to participate and earn some money. If after doing this you still want to ask something, please raise your hand and one of the assistants will come to you.

(Participants should go to the front and fill the table. Please ask the following questions while participants fill the table: how much Person B will receive? How much person A will keep?)

Table 2.B1: Examples Control questions Activity Green

\begin{tabular}{|c|c|c|}
\hline Amount sent by A & Person B receives & Person A keeps \\
\hline 3,000 & 3,000 & $10,000-3,000=7,000$ \\
\hline 6,000 & - & - \\
\hline 9,000 & - & - \\
\hline
\end{tabular}

Now we will start activity green. Please open the paper you received. 


\section{Decision Sheet Activity Green (DG)}

If you were selected to take the role of Person A, how much you would like to send to Person B?

There are no right or wrong answers. Once you have made a decision our enumerators will pass by collecting the papers.

Figure 2.B2: Decision sheet Activity Green

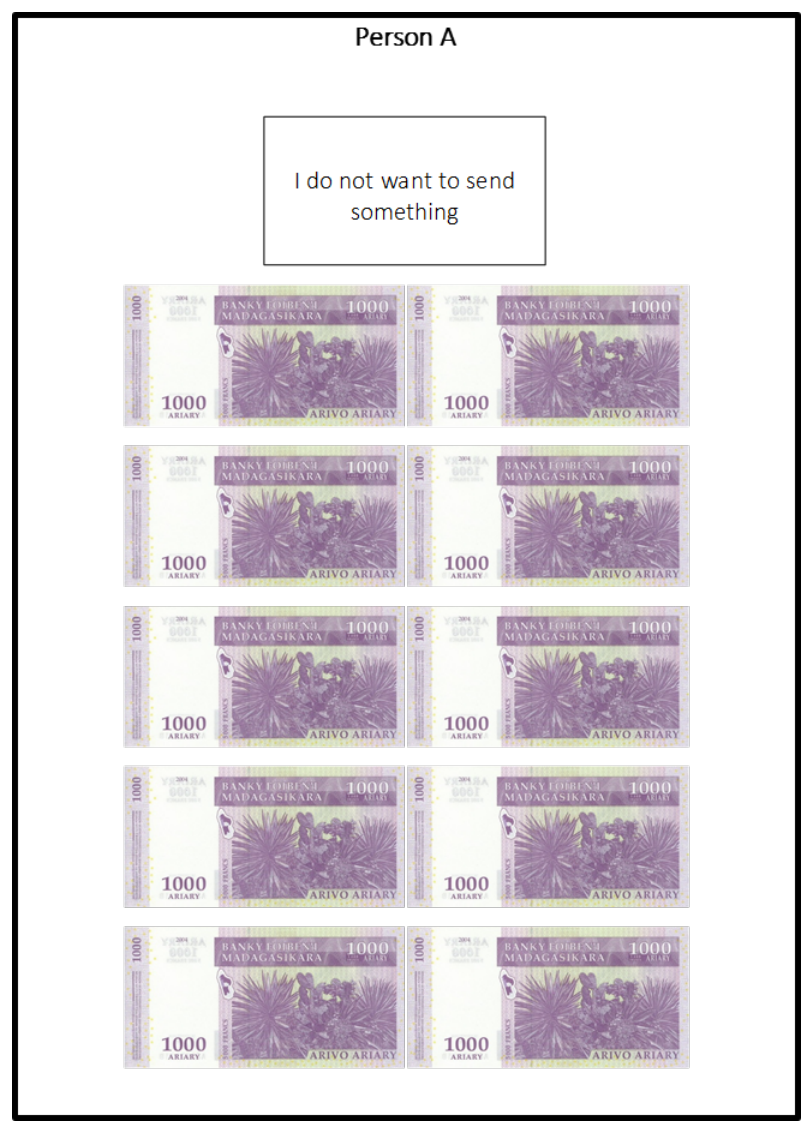




\section{Activity Blue 1 (TG-1)}

Again in this activity there are two roles. Person A and Person B.

Both A and B will receive 5,000 ariary. The task of Person A is to decide how much of the 5,000 ariary he or she wants to send to Person B. The amount sent to person B is multiplied by 2 and this will be the amount received by Person B.

For example if A sends zero ariary, B would receive zero ariary, but if A sends 1,000 ariary, B would receive $1,000 \times 2=2,000$ ariary.

If $\mathrm{A}$ sends 4,000 ariary, then $\mathrm{B}$ would receive $4,000 \times 2=8,000$ ariary.

The task of Person B is to decide how much of the money received he or she would like to return to Person A. The minimum that $\mathrm{B}$ can return is zero ariary, the maximum is the value received by $\mathrm{A}$. So, if person B received 2,000 ariary, he can send any amount between zero and 2,000 ariary but if B received 8,000 ariary, B can send any value between zero and 8,000 ariary. (show poster with the earnings of Person $A$ and B.)

The earning of Person A will be: 5,000 - Sent + Returned = Earnings A

The earnings for Person B will be: $5,000+$ Received $(\times 2)-$ Returned $=$ Earnings B

Let's see one example:

You will receive a piece of paper like this one (show Decision sheet Activity Green Person A). This sheet has one empty box and 5 bills of 1,000 ariary. Mark how much you would like to send to Person B. If you mark the box with no bill it means you are sending zero ariary to Person B. If Person A sends 5,000 ariary, this amount will be multiplied by two and Person B will receive 10,000 ariary.

Let us look another example:

Suppose that Person A wants to send 1,000 ariary. Then he or she would mark 1 bill. How much would A have at this point? $5,000-1,000=4,000$ ariary.

The amount sent by A multiplies by two and is received by $\mathrm{B}$. If $\mathrm{A}$ sends $1,000, \mathrm{~B}$ would receive $2 \times 1,000=2,000$ ariary.

How much person $\mathrm{B}$ has so far? 5,000 $+2,000=7,000$ ariary.

Now, the task for Person B is to decide how many of the units received he or she wants to sends back to Person A. Person B would receive a paper like this one (show Decision sheet Activity Green Person B-2,000 ariary). The task is to mark the value he or she would like to send back. 
Person B can send any zero, two hundred, 2,000 ariary, etc. In the example, if B received 2,000 ariary, he or she can send back zero, 200 ariary, 400 ariary, etc., up to 2,000 ariary. If person B marks the "I do not want to send something" box, this means that no money is sent back to Person A.

If Person B marks 2,000 ariary, person A would receive this amount.

Person B will not know how much person A passed him. Therefore, person B will receive five papers like this one (show Decision sheet Activity Green Person B - 2,000 ariary) with different values that Person $B$ could have sent. In each case, please decide how much you would like to send back. The final value to send back will depend on the decision of $\mathrm{A}$. (show decision sheets Activity Green Person B).

Figure 2.B3: Decision sheet Activity Blue Person B - 2,000 ariary

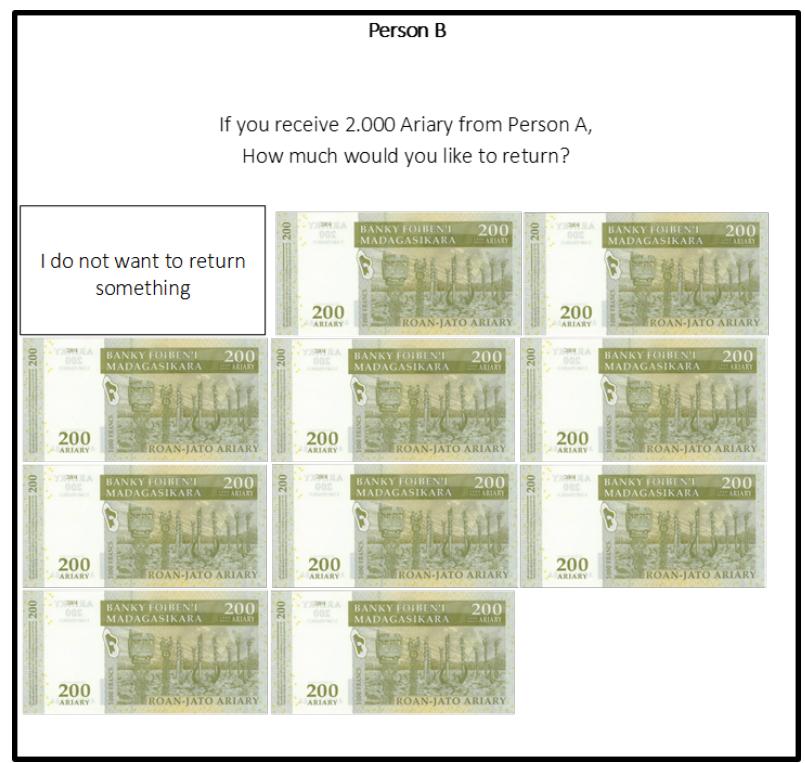

Let us suppose that A sends 1,000 ariary to B, and B wants to return 2,000 ariary.

How much would A earn? 5,000 - 1,000 +2,000 =6, 000 ariary.

How much would B earn? 5, $000+1,000 \times 2-2,000=5,000+2,000-2,000=5,000$ ariary.

Let's look at different examples (Write and draw it on the whiteboard):

If Person A sends 2,000 ariary, how much would Person B receive?

$2,000 \times 2=4,000$ ariary.

If out of those 4,000 ariary, Person B returns zero ariary, then what would be the payments of $\mathrm{A}$ and $\mathrm{B}$ ?

Person B would have a total of $5,000+4,000-0=9,000$ ariary.

Person A would receive: $5,000-2.000+0=3,000$ ariary. 


\section{Control Questions}

I would like to ask numbers $\mathrm{xx}, \mathrm{xx}$ to come to the front (pick the numbers randomly from the bag). We will do this activity together in case somebody has still questions. It is important that we do this because if you don't understand the instructions then you will not be able to participate and earn some money. If after doing this you still want to ask something, please raise your hand and one of the assistants will come to you.

(Participants should go to the front and fill the table. Please ask the following questions to the first participant and fill the table as he or she answers:)

If Person A would like to send Person B 2,000 ariary, how much he/she will need to mark in the papers? How much Person B will receive? (4,000 ariary). If Person B decides to return 1,000 ariary, how much Person A and Person B will get at the end?

Person A

$5,000-2,000=3,000$ ariary.

Person B

$5,000+2,000 \times 2-1,000=5,000+4,000-1,000=8,000$ ariary.

Now we will start the activity. First you will all be in the role of Person A and then all of you will be in the role of Person B. At the end of the workshop we will select randomly which of your decisions will be implemented for payment, if the one you took in the role of Person A or the one you took in the role of Person B. 


\section{Activity Blue 1 Person A (TG-A)}

Please open the paper marked TG1-A. Please decide how much you would like to send to Person B.

There are no right or wrong answers. Once you have made a decision our enumerators will pass by collecting the papers.

Figure 2.B4: Decision sheet Activity Blue Person A

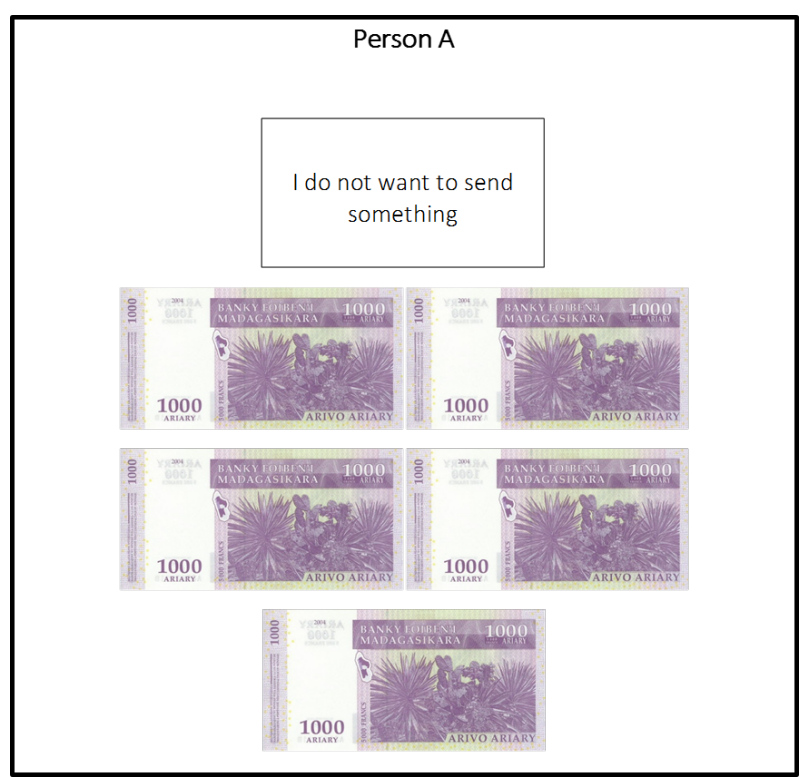




\section{Activity Blue 1 Person B (TG-B)}

Now, you will be in the role of Person B. Please open the paper marked TG1-B. Please decide how much you would like to return to Person A for all the 5 pages you have received.

There are no right or wrong answers. Once you have made a decision our enumerators will pass by collecting the papers.

Figure 2.B5: Decision sheets Activity Blue Person B
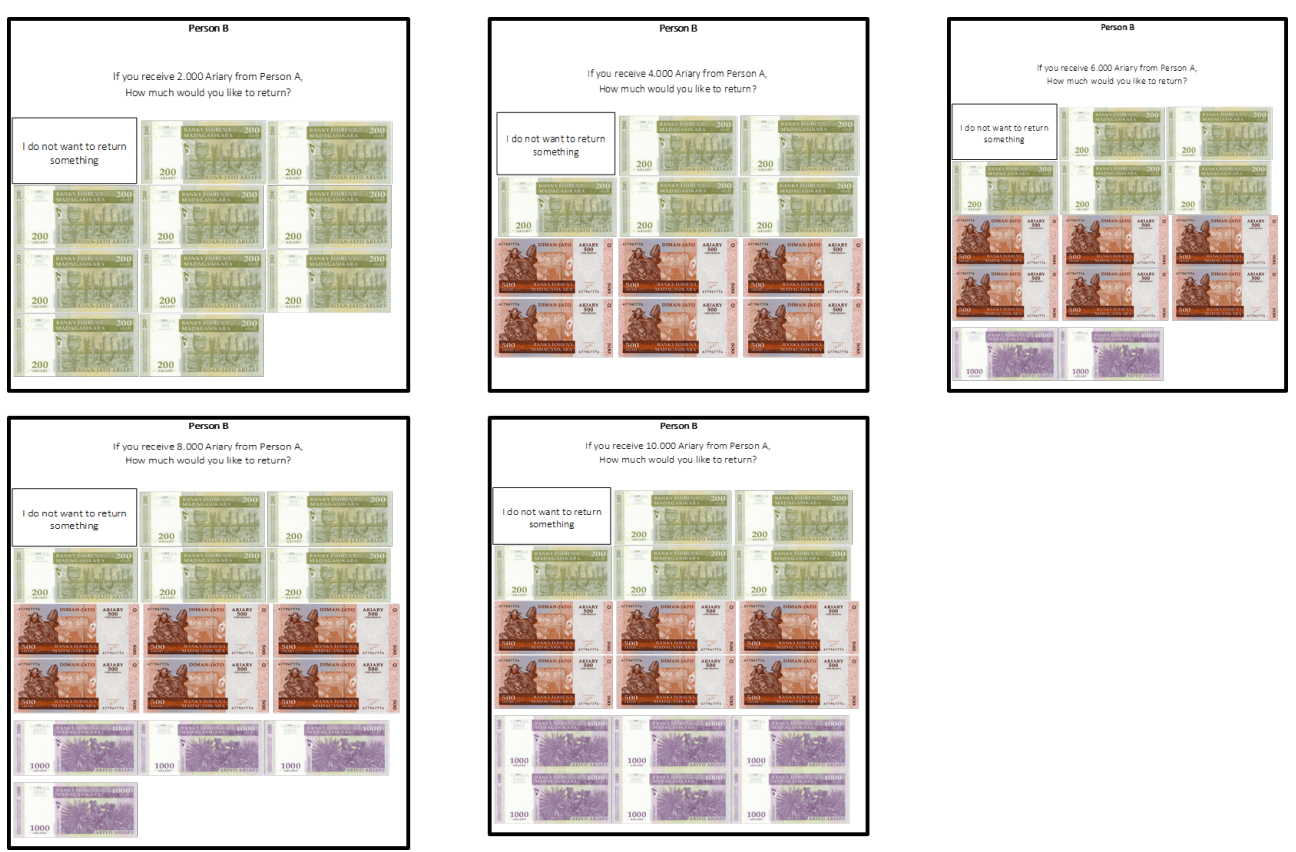


\section{Activity White}

In this part your group partner will remain fixed. One person in the group will take the role $\mathrm{P}$ and the other would take the role $\mathrm{D}$. Half of you will be person $\mathrm{P}$ and half of you will be person $\mathrm{D}$.

\section{The Possible Earnings}

In this activity $\mathrm{P}$ and $\mathrm{D}$ can choose between triangle or circle. Depending on their decisions, $\mathrm{P}$ and $\mathrm{D}$ will have different earnings. They are summarized here:

(show poster Activity White).

Table 2.B2: Activity White

\begin{tabular}{ccc}
\hline Player D/Player P & Triangle & Circle \\
\hline Triangle & 4000,1000 & 1000,4000 \\
Circle & 1000,4000 & 4000,1000 \\
\hline
\end{tabular}

(Read while showing the poster table)

If both $\mathrm{D}$ and $\mathrm{P}$ choose triangle, $\mathrm{D}$ receives 4,000 ariary and $\mathrm{P}$ receives 1,000 ariary.

If both $\mathrm{D}$ and $\mathrm{P}$ choose circle, $\mathrm{D}$ receives 4,000 ariary and $\mathrm{P}$ receives 1,000 ariary.

If you change these combinations of $\mathrm{P}$ and $\mathrm{D}$, then, $\mathrm{P}$ receives 4,000 ariary and $\mathrm{D}$ receives 1,000 ariary:

If $\mathrm{P}$ chooses circle and $\mathrm{D}$ chooses triangle, $\mathrm{P}$ receives 1,000 ariary and $\mathrm{D}$ receives 4,000 ariary.

If $\mathrm{P}$ chooses triangle and $\mathrm{D}$ chooses circle, $\mathrm{P}$ receives 1,000 ariary and $\mathrm{D}$ receives 4,000 ariary.

\section{Control Questions}

I would like to ask numbers $\mathrm{xxxx}, \mathrm{xxxx}$ (pick the numbers randomly from a bag) to come to the front. We want to make sure you understood the activity and that's why I would like to ask you some questions. If after doing this you still want to ask something, please raise your hand and one of the assistants will come to you.

(Participants should go to the front and choose in the table the right answer. Please ask the following questions to the participants)

1. If $\mathrm{P}$ selects Triangle and $\mathrm{D}$ selects Circle:

1.1. How much would $P$ receive?

1.2. How much would $\mathrm{D}$ receive?

2. If $\mathrm{P}$ selects Circle and D selects Circle: 
2.1. How much would $\mathrm{P}$ receive?

2.2. How much would $\mathrm{D}$ receive?

3. In which cases would $\mathrm{P}$ receive the highest payment?

4. In which cases would D receive the highest payment?

Now we are ready to start.

First Person $\mathbf{P}$ decides. Please Person D waits.

Person P, please decide between triangle or circle. There are no right or wrong answers. Once you have made a decision our enumerators will pass by collecting the papers.

Person D, please decide between triangle or circle. There are no right or wrong answers. Once you have made a decision our enumerators will pass by collecting the papers.

Break

\section{Treatment 0 (CONTROL)}

Person $\mathrm{P}$ and $\mathrm{D}$, please look at the results of this activity. In the paper our assistants are giving to you, you can see the decisions of Person P and D and the final earnings.

\section{T1 (SPYING)}

We will now inform Person D on the outcome. Person $\mathrm{P}$ does not receive this information and cannot react to it. Person D will receive the following paper:

Figure 2.B6: Example Activity White T1 - Person D

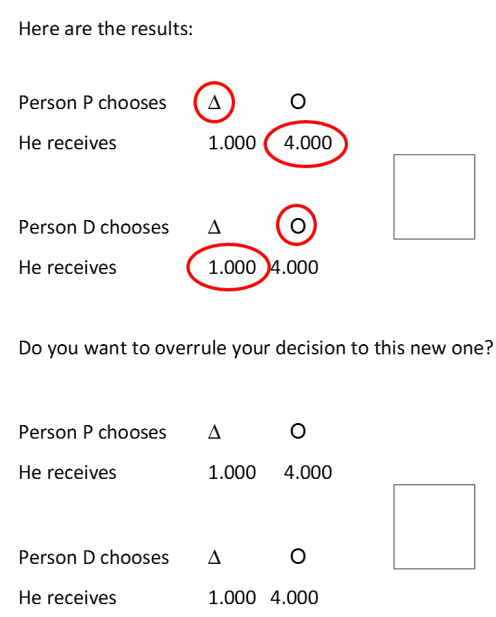


The first part shows the decisions from $\mathrm{P}$ and D. For example, $\mathrm{P}$ selected triangle and D selected circle. Therefore P earns 4,000 ariary and D earns 1,000 ariary.

Now the task for D is to select if he would like to overrule his own decision and select instead the following decision:

$\mathrm{P}$ selected triangle and earns 1,000 ariary

D selects now triangle and earns 4,000 ariary

Participant D is asked to fill in the right column which decision would prefer. Therefore in the right hand side, it can mark with $\mathrm{X}$ the preferred decision. If he marks the first row, it means that he did not overrule his decision. If he marks the decision on the second row, the old decision is overruled and the new one is implemented.

Let's look at an example. If Person $\mathrm{P}$ selects circle and person $\mathrm{D}$ selects triangle, then Person P receives 4,000 ariary and Person D receives 1,000 ariary. Person D will know this and therefore can overrule his decision and change the earnings. For example, Person D can change to circle, so Person P receives 1,000 ariary and D receives 4,000 ariary. If Person D does not change the decision the earnings are 4,000 ariary for Person $\mathrm{P}$ and 1,000 ariary for Person D. If D selects the old decision, would mark a cross in the first row. But if he selects the new payment would mark a cross in the second row.

Now we are ready to start.

Person D, please decide if you want to overrule your previous decision or not. Once you have made a decision our enumerators will pass by collecting the papers.

Figure 2.B7: Decision sheets Activity White T1 - Person D

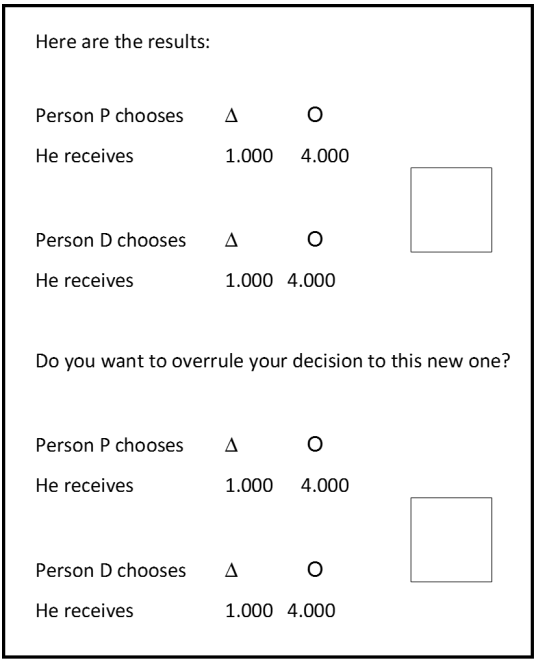

Now, Person $\mathrm{P}$ will receive the final results according to the decision of person D.

Person P, please have a look. 


\section{T2 (SABotaging)}

We will now inform Person D on the outcome. Person P does not receive this information and cannot react to it. Person D will receive the following paper:

Figure 2.B8: Example Activity White T2 - Person D

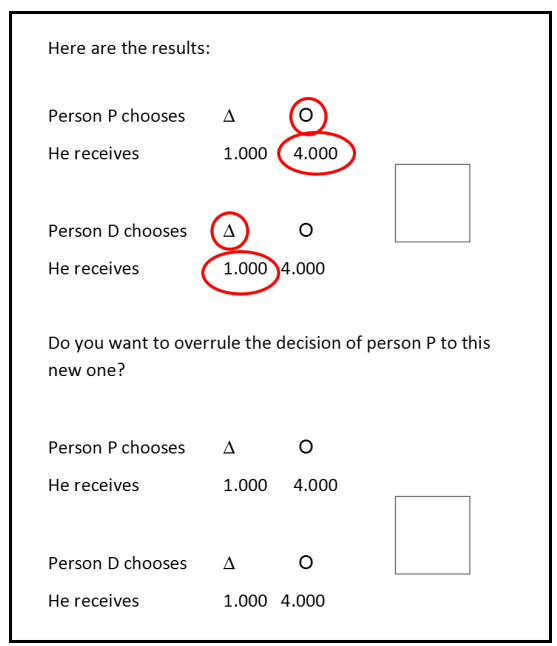

The first part shows the decisions from $\mathrm{P}$ and D. For example, $\mathrm{P}$ selected circle and D selected triangle. Therefore $\mathrm{P}$ earns 4,000 ariary and D earns 1,000 ariary.

Now the task for D is to select if he would like to overrule Person's P decision and select instead the following decision:

$\mathrm{P}$ selects now triangle and earns 1.000

D selected triangle and earns 4.000

Participant D is asked to fill in the right column which decision would prefer. Therefore in the right hand side, it can mark with $\mathrm{X}$ the preferred decision. If he marks the first row, it means that he did not overrule his decision. If he marks the decision on the second row, the old decision is overruled and the new one is implemented.

Let's look at an example. If Person P selects triangle and person D selects circle, then Person P receives 4,000 ariary and Person D receives 1,000 ariary. Person D will know this and therefore can overrule Person's P decision and change the earnings. For example, Person $\mathrm{D}$ can change the decision of Person $\mathrm{P}$ to circle, so that Person $\mathrm{P}$ receives 1,000 ariary and D receives 4,000 ariary. If Person D does not change the decision of Person $\mathrm{P}$, the earnings will be 4,000 for Person $\mathrm{P}$ and 1,000 for Person D. If D selects the old decision, would mark a cross in the first row. But if he selects the new payment would mark a cross in the second row.

Now we are ready to start. 
Person D, please decide if you want to overrule the decision of $\mathrm{P}$ or not. Once you have made a decision our enumerators will pass by collecting the papers.

Figure 2.B9: Decision sheets Activity White T2 - Person D

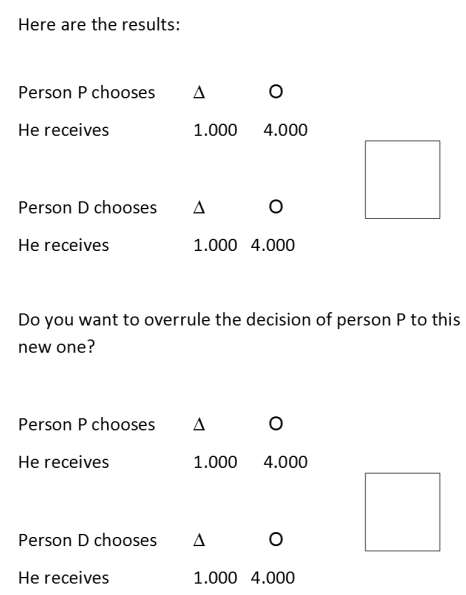

Now, Person $\mathrm{P}$ will receive the final results according to the decision of person D. Person P, please have a look. 


\section{Activity Green 2 (DG-2)}

Now that you are familiar with the GREEN activity, we will repeat it.

Like last time, at the end of the workshop we will select randomly who of you will take the role of Person A and who of you the role of Person B to implement the payments.

The person in role A receives 10,000 ariary from us. The person in role B does not receive any payment. The task for Person A is to decide how many ariary he or she would like to send to Person B. Person A can send zero; 1,000; 2,000; up to 10,000 ariary.

The earnings for Person A will be 10,000 ariary minus the amount sent to Person B. The earnings for Person B will be the amount sent by Person A.

Please open the paper you received.

If you were selected to take the role of Person A, how much you would like to send to Person B?

Remember that there are no right or wrong answers. Once you have made a decision our enumerators will pass by collecting the papers.

Figure 2.B10: Decision sheet Activity Green

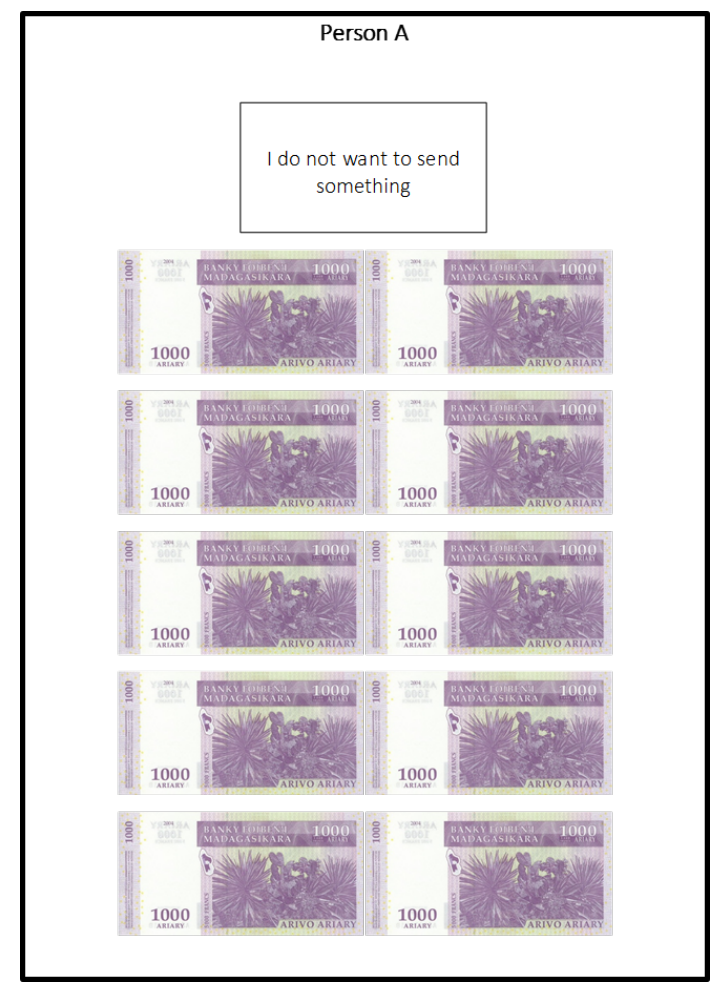




\section{Activity Blue 2 (TG-2)}

In this activity the groups remain fixed. Therefore, you are still paired with the same participant from the previous activity. Now we will repeat the BLUE activity that we did earlier.

Both A and B will receive 5,000 ariary. The task of Person A is to decide how much of the 5,000 ariary he or she wants to send to Person B. The amount sent to person B is multiplied by 2 and this will be the amount received by Person B.

For example if A sends zero ariary, B would receive zero ariary, but if A sends 1,000 ariary, $\mathrm{B}$ would receive $1,000 \times 2=2,000$ ariary. If $\mathrm{A}$ sends 4,000 ariary, then $\mathrm{B}$ would receive $4,000 \times 2=8,000$ ariary.

Like last time, at the end of the workshop we will select randomly who of you will be Person A and who of you will be Person B.

Please open the paper you received.

\section{Activity Blue 2 Person A (TG-A)}

Please open the paper marked TG2-A. Please decide how much you would like to send to Person B.

There are no right or wrong answers. Once you have made a decision our enumerators will pass by collecting the papers.

Figure 2.B11: Decision sheet Activity Blue Person A

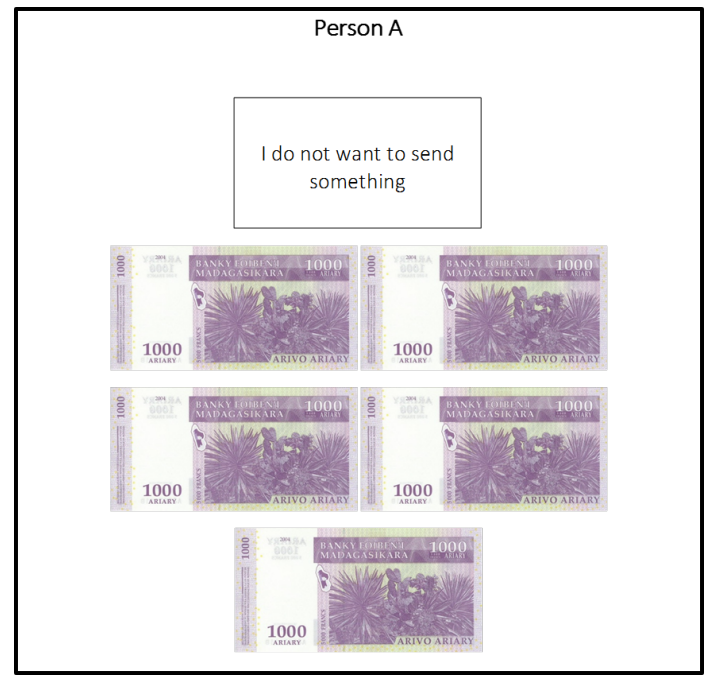




\section{Activity Blue 2 Person B (TG-B)}

Now, you will be in the role of Person B. Please open the paper marked TG2-B. Please decide how much you would like to return to Person A for all the 5 pages you have received.

There are no right or wrong answers. Once you have made a decision our enumerators will pass by collecting the papers.

Figure 2.B12: Decision sheets Activity Blue Person B
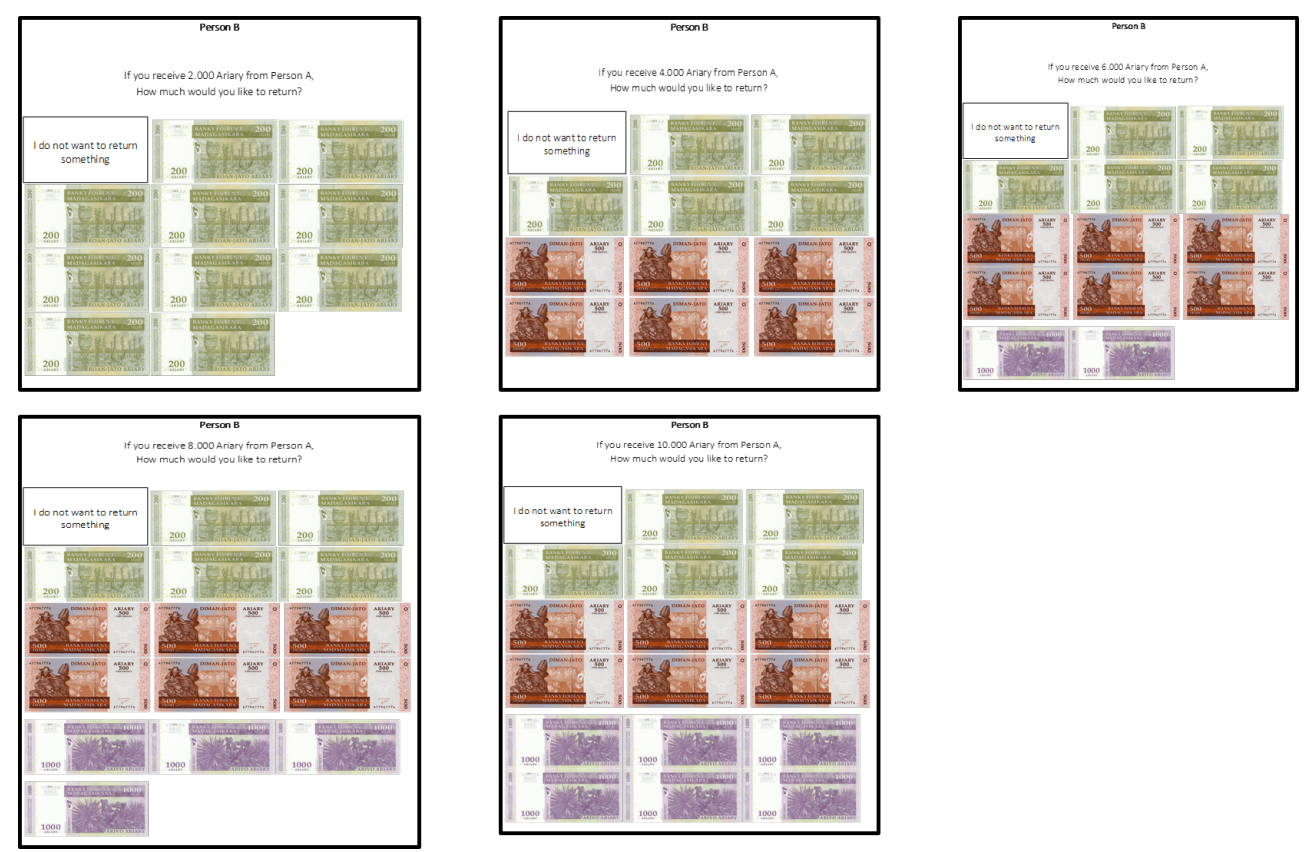


\section{End}

Now, one of you will take out one card of this bag. According to the name written in the card we will pay the earnings of that round. For example if the name "Blue" comes up, we will pay the total earnings of this activity, if the name "Green" comes up, then we will pay that round. In addition to that value, each of you will receive 1,000 ariary as a bonus for your assistance today. In the name of the University of Goettingen, I want to thank you very much for your time and collaboration today. Before you receive your earnings of today we will do a questionnaire. Please do not leave the room, our assistants will come to you as soon as possible. If some of you need to shortly go you can do it, but please come back soon to fill the questionnaire and receive your earnings of today. 


\section{Experimental Survey}

Participant No.

\section{Exit questionnaire Part 1: Attitudinal Questions}

(The questionnaires are done verbally to each of the participants. The coordinator with the help of the assistants will complete each of the forms.)

While we proceed with the calculation of the earnings of today, I would like to ask few questions about the workshop and yourself. The answers you will provide here are completely anonymous and will only be used for academic purposes.

\section{Questions regarding the workshop activity}

1. Did you have difficulties in answering one or more of the activities you did today?

$\square$ Yes

$\square$ No

$\square$ If yes, in which one(s)?

2. Did you understand the instructions of the activity?

$\square$ Yes

$\square$ No

3. How many people that were present today are:

Friends:

Relatives of you:

Now I will like to know your opinion about some issues. For the following sentences, please tell me how much you agree or disagree on them according to your personal opinions or believes. You can do this by choosing between: $1=$ strongly disagree, 2 $=$ disagree, $3=$ neither agree nor disagree, $4=$ agree, and $5=$ strongly agree. Please remember that the answers you give us are anonymous and will only be used for research purposes.

4. Generally speaking I trust most of the people in my village

\begin{tabular}{|c|c|c|c|c|}
\hline 1 & 2 & 3 & 4 & 5 \\
Strongly agree & Disagree & Neither agree nor disagree & Agree & Strongly agree \\
\hline
\end{tabular}


5. Generally speaking during harvest time is very difficult to trust other people

\begin{tabular}{|c|c|c|c|c|}
\hline 1 & 2 & 3 & 4 & 5 \\
Strongly agree & Disagree & Neither agree nor disagree & Agree & Strongly agree \\
\hline
\end{tabular}

6. I would be willing to lend my money to someone else in this village if they need it

\begin{tabular}{|c|c|c|c|c|}
\hline 1 & 2 & 3 & 4 & 5 \\
Strongly agree & Disagree & Neither agree nor disagree & Agree & Strongly agree \\
\hline
\end{tabular}

7. People have the moral obligation to share part of their resources with people that need it

\begin{tabular}{|c|c|c|c|c|}
\hline 1 & 2 & 3 & 4 & 5 \\
Strongly agree & Disagree & Neither agree nor disagree & Agree & Strongly agree \\
\hline
\end{tabular}

8. In general, my village is very safe

\begin{tabular}{|c|c|c|c|c|}
\hline 1 & 2 & 3 & 4 & 5 \\
Strongly agree & Disagree & Neither agree nor disagree & Agree & Strongly agree \\
\hline
\end{tabular}

\section{For the following questions please give the answer that adjusts more to your daily life}

9. How many times per year do you meet the people that buy your vanilla?

$$
\begin{array}{llllll}
1 & 2 & 3 & 4 & 5 & \text { more than } 5 \text { times }
\end{array}
$$

10. Has somebody stolen vanilla from you in the last harvest?

$\square$ Yes

No

(if yes, how many times?)

(if yes, did you filled a report?)

11. The people that stole your vanilla are from this village?

$\square$ Yes

No

12. If somebody gives you money to help you during difficult times, how much would you pay back?

Same as the other person gave me

More than what the other person gave me 
13. I always try to sell my vanilla to the person that offers me:

The highest price

To buy my vanilla every year

A normal but stable price and additional benefits for me and my family

14. If somebody that buys my vanilla every year suddenly reduces the price then I will:

Sell my vanilla to somebody else

Sell my vanilla to this person

Sell only part of my vanilla

\section{Exit questionnaire Part 2: Demographic Questions}

1. Gender: $\quad \square$ Female $\quad \square$ Male

2. Age:

3. Marital Status: $\quad \square$ Never Married $\quad \square$ Married $\quad \square$ Divorced $\quad \square$ Widow

4. What was the last year of education approved?

5. Which one is your ethnic group?

6. How many people live in your house?

7. How many children do you have?

8. Do you have at the moment a credit with a financial institution? $\quad \square$ Yes $\quad \square$ No

9. Have you asked for a credit before this time? $\square$ Yes $\square$ No

10. Your annual income (spaecified if in Franc malagache or ariary)

11. How many trees of vanilla do you own?

12. How many $\mathrm{kg}$ of green vanilla did you sell this year?

13. How many $\mathrm{kg}$ of cured vanilla did you sell this year?

14. How many kilos did you sell and for which price?

April - June price ariary (per $\mathrm{Kg})$

July price ariary (per $\mathrm{Kg}$ )

August price ariary (per $\mathrm{Kg})$

15. To whom you sell your products (Symrise, Exotic, Commissionaire, Cooperative, Collector)?

16. Name 


\section{Chapter 3}

\section{The costs of betrayal aversion: The case of vanilla production in Madagascar}

This chapter is joint work with Marcela Ibañez (University of Göttingen) and Gerhard Riener (Heinrich Heine University Düsseldorf). Special thanks to the Diversity Turn research group for their constant feedback and support in the field. We are grateful for the helpful comments and suggestions received from Holger Rau. All remaining errors are ours. Ana Maria Montañez and Marius Willmann provided great research assistance. This work is supported by the "Niedersächsisches Vorab" of Volkswagen Foundation, grant number: 11-76251-99-35/13 (ZN3119). We would like to thank all enumerators who took part in the data collection in Madagascar and all the farmers who attended our experimental sessions and accepted to participate in our baseline and follow-up surveys. We would also like to thank all the local people who supported us during the data collection (village chiefs, drivers, cooks, etc.). 


\subsection{Introduction}

Recent studies have shown that individuals behave more risk averse when the source of risk is another human being, rather than nature, a phenomenon known as betrayal aversion (Bohnet \& Zeckhauser, 2004; Bohnet et al., 2008; Fehr, 2009). Avoiding social risk to a larger extent than risk imposed by nature may have a considerable impact on production decisions due to negative externalities on social cohesion or trust within a society. Betrayal aversion can have particularly devastating welfare consequences in societies with weak institutions (Soares, 2015; Fafchamps \& Moser, 2003; Fafchamps \& Minten, 2009). However, evidence on betrayal aversion has been gathered in mainly educated subject pools in university laboratory settings. Moreover, little attention has been directed in measuring it in the field and linking it to personal experiences and economic decisions outside of the laboratory.

We fill this gap by providing evidence on betrayal aversion attitudes among farmers in rural areas in a country with weak institutions, Madagascar. While most theoretical and empirical evidence links farmers' production decisions to risk attitudes, this study considers the role of betrayal aversion. This extension is relevant as farmers often confront both natural - such as weather shocks and pests - and social risks - such as crop theft or exploitative market conditions- (Liu \& Huang, 2013). ${ }^{1}$

Avoiding social risk may have a larger impact on production decisions than natural risks with the same material consequences. Welch et al. (2005) propose that individuals make emotional investments by trusting others. Hence, if they anticipate negative emotions due to an expected breach of trust, they might seek ways to avoid the relation and face the economic consequences. For example, betrayal averse individuals can opt for less efficient but safer decisions like diverting resources in security and monitoring (Fehr, 2009) or decide not to engage in profitable economic relations (Aimone et al., 2015). Such actions add to the welfare costs of societies with fragile property rights (Besley \& Ghatak, 2010; Besley et al., 2015).

To examine whether betrayal aversion is related to productive investment, we conducted our study with farmers in Madagascar. This country and its farming sector constitute a particularly suitable environment. Madagascar ranks 122 out of 129 countries in the International Property Right Index ${ }^{2}$. In its agricultural sector, crop theft is a common source of strategic uncertainty. In the absence of a functioning institution, mob justice is often used (Neimark et al., 2019; Osterhoudt, 2020). Because of the price volatility, frequent theft episodes, and weather shocks, vanilla farming in Madagascar can be characterized as risky both in terms of natural and social risk. Hence, our study region is an interesting place to explore attitudes towards betrayal and its potential relation to decision-making. The negative consequences of theft on farmers' production decisions have been shown in other

\footnotetext{
${ }^{1}$ For instance, Liu \& Huang (2013) find that - after controlling for village characteristics - risk averse farmers adopt later new cotton technology and use more pesticide quantities which greatly reduce their income. One could argue that this could be solved with certain risk-sharing policies or insurance.

${ }^{2}$ This index measures the protection of property rights and tries to make it comparable across states. For more information see https://www.internationalpropertyrightsindex.org/
} 
contexts. In a farming context in Kenya, Dyer (2020) finds that fear of theft creates indirect costs to farmers by changing their production decisions. The author shows that providing private security helps farmers to increase profits. Moreover, Schechter (2007) shows that farmers in Paraguay, whose plantations are more vulnerable to theft, give surprisingly larger gifts on average to thieves and plant less stealable crops, reducing farmers' income and creating market inefficiencies. However, it is not clear if the changes in investments can be mediated by betrayal aversion.

To explore farmers' attitudes towards betrayal, its determinants, and its relation to realworld decision-making, we conducted a framed lab-in-the-field experiment ${ }^{3}$ in northeastern Madagascar with 760 vanilla farmers. We measure betrayal aversion using the choice list elicitation method introduced by Quercia (2016). This measure is less complex and easier to implement in settings where individuals have low schooling levels. We adopt the definition of Bohnet \& Zeckhauser (2004) to characterize betrayal aversion and consider that an individual is betrayal averse if the minimum acceptable probability (MAP) at which subjects trust someone is higher than the MAP at which they would confront a risk from nature. To examine the relationship of betrayal aversion with production and commercialization decisions, we conducted a post-experimental questionnaire and two follow-up surveys 30 and 45 days after the experiment.

We find significant heterogeneity in attitudes towards betrayal. Moreover, we find that individuals exposed to crime in previous years display a higher degree of betrayal aversion. In particular, Victimization- $i$ - measured as past experiences of theft reported by others in the village in 2017 - is positively correlated with the unwillingness to take social risks (MAP social). We do not find a significant correlation with the MAP nature. Linking our measure of betrayal aversion to production decisions, we find that one standard deviation increase in the MAP social is related to a decrease in the share of vanilla plantations (2 percentage points) and smaller vanilla plots $(0.06 \mathrm{Ha})$. Since vanilla constitutes the most significant source of annual income for most farmers, these decisions can significantly reduce their income. However, other productive decisions such as the choice of harvest, preparation, labor paid, and guarding cannot be associated with our measures of risk and betrayal aversion. Yet, our results should be taken with caution as they are not robust when adjusting for multiple hypothesis testing.

Our paper contributes to two strands of literature. First, it adds to the literature on betrayal aversion (Bohnet \& Zeckhauser, 2004; Bohnet et al., 2008) by providing field evidence on the heterogeneity of betrayal aversion preferences. We find that most of the subjects are betrayal neutral. Several reasons can explain our contrasting results to most of the previous literature. First, our study region is frequently hit by cyclones; therefore, farmers face a high risk from nature, probably almost as high as crop theft. As a consequence, they might confront different sources of risks in a similar way. A second reason, following Koppel et al. (2017), is that in most previous betrayal aversion studies, trustees were usually sitting

\footnotetext{
${ }^{3}$ The definition of framed field experiment is taken from the terminology in Harrison \& List (2004). From this point on, we will refer to it as the experiment.
} 
in the same room with the trustors, making individuals more susceptible to sentiments of betrayal. In our experiment, decision-makers did not have contact, and the decisions were taken at different points in time. A third reason-proposed in the work by Fetchenhauer \& Dunning (2012) - is that people behave as betrayal averse when they have the opportunity to decide whether or not to enter the trust game hypothetically. Yet, once they are taking part in the game - as in our experiment - they are less betrayal averse to avoid signaling distrust to the matched person.

Second, we add to the literature in agricultural economics by exploring the role of betrayal aversion and different sources of risk on production decisions. While the negative effect of criminality has been discussed in recent works by Dyer (2020) and Schechter (2007), the authors do not link farmers' production decisions to betrayal but only to risk attitudes. The consequences of risk preferences on pre-and post-harvest decisions have been previously studied (e.g Liu \& Huang, 2013; Ruhinduka et al., 2020), yet these studies do not disentangle the sources of risk that influence such decisions. Our paper extends the literature mentioned above by showing that betrayal aversion is an important psychological factor, which may hinder production efficiency in developing countries.

Our findings have significant implications for initiatives that aim at reducing crime in the agricultural sector. Providing watchmen (Dyer, 2020) may pay double dividends compared to an equally costly policy that reduces disaster risk by the same objective amount. This strategy also has implications on the interpretation of the effectiveness of reducing social risk through increased property security. Increasing trust may also increase farmers' investments in productive assets such as time and land Groenewald \& Bulte (2013).

The paper proceeds as follows. Section 3.2 presents the conceptual framework and the hypothesis. Section 3.3 presents the field context, and Section 3.4 describes the experimental design and procedures. Section 3.5 presents the results, and Section Section 3.6 the robustness checks. Section 3.7 discusses and concludes.

\subsection{Conceptual Framework}

Experimental literature documents the relationship between individuals' behavior in the trust game and risk preferences (Ben-Ner \& Putterman, 2001; D. S. Karlan, 2005; Schechter, 2007). These studies show that risk averse individuals are less likely to trust, or trust, on average less. Other studies have shown that risk attitudes cannot entirely predict trusting behaviors (Eckel \& Wilson, 2004; Ashraf et al., 2006; Houser et al., 2010). One of the reasons is that a risky situation departs from a state uncertainty - outcome does not depend on another individual - while trust happens in environments of strategic uncertainty - outcome depends on the decisions others take (Houser et al., 2010).

If risk attitudes alone can predict trust behavior, then the source of risk should not matter in the strategy individuals take when deciding to trust or not (Eckel \& Wilson, 2004). Yet, the seminal work by Bohnet \& Zeckhauser (2004) showed that individuals required an additional 
risk premium when they confront a counterpart in a trust game than when confronting nature that represented the same risk. This result lends itself to the interpretation that there are different attitudes towards risk when they are exposed to a "social risk" or "asocial or natural risk". This difference can be explained as the compensation individuals need to bear the costs of trust betrayal. Hence, trusting decisions cannot be only determined by risk attitudes but also by the emotions individuals have towards betrayal (Fehr, 2009).

The measurement of betrayal aversion compares the "minimum acceptable probability" (MAP) that an individual requires for obtaining a high outcome before assuming a risk between the Social RISK and the NATURE RIsK games (see Equation 4.1). Hence, the betrayal aversion measure captures the premium individuals require in the SocIAL RISK condition compared with the NATURE Risk condition. Most of the studies use a betweensubject design as they argue that people tend to anchor on the first game presented (Bohnet et al., 2008). We use a within-subject design, as we are interested in obtaining an individual measure of betrayal aversion. To avoid anchoring effects, we randomly vary the order in which the games are presented; therefore, we can control for this in our subsequent analysis. Moreover, as we use a choice list elicitation, the MAPs are calculated by taking the middle point between the last probability for which the participants chose the risky option and the first one when they chose the safe option. This calculation follows the design by Quercia (2016). Based on the result of the individual betrayal aversion coefficient, individuals can be classified into three different types: Betrayal Averse $\left(B A_{i}>0\right)$, Betrayal Lover $\left(B A_{i}<0\right)$, and Betrayal Neutral $\left(B A_{i}=0\right)$.

$$
B A_{i}=M A P_{S R i}-M A P_{N R i}
$$

The majority of studies have shown that individuals are likely to be betrayal averse (Bohnet \& Zeckhauser, 2004; Bohnet et al., 2008; Aimone \& Houser, 2012; Cubitt et al., 2017; Quercia, 2016). Yet, these results come from a student sample which might not be align with the risks that people confront in everyday life. For example, farmers worldwide face different risks from social and asocial factors, e.g., pests, theft, natural disasters, deceptive market partners, etc. Theft of crops or cattle is one challenge that farmers, especially in developing countries, confront (Fafchamps \& Moser, 2003; Schechter, 2007; Dyer, 2020). As a consequence, individuals suffer a monetary cost when they are victimized, but they also undergo a psychological cost from being cheated, which should be higher in situations where members of the social network are involved. Hence, based on the empirical and anecdotal evidence, we believe that farmers request an additional risk premium to trust in the Social Risk than in the Nature Risk. This derives our first hypothesis:

Hypothesis 1. Farmers are on average betrayal averse and request an additional premium to take social risks.

There is theoretical and empirical evidence linking farmers' production decisions and risk attitudes. For instance, Liu \& Huang (2013) found that after controlling for village characteristics, risk averse farmers adopt later new cotton technology and use more pesticide 
quantities which greatly reduces their income. In addition, the work by Ruhinduka et al. (2020) links risk preferences to postharvest choices and found that risk-averse farmers are less likely to process and store paddy rice, reducing their future income. However, as mentioned above, farmers are not only exposed to natural risks, but also to social risks. Hence, certain decisions can be attributed to emotions towards betrayal.

Dyer (2020) shows that crime generates market failures as it reduces the incentives to optimize certain agricultural practices. Moreover, Groenewald \& Bulte (2013) find that farmers that trust less in others are less likely to invest in productive assets such as time and land. Farmers in Madagascar heavily weigh safety when their subsistence income depends on others (Laney \& Turner, 2015). Because of this, farmers might deviate from optimal production and commercialization practices and reduce their earnings. Since no studies link the effects of betrayal to production decisions, there is no evidence of whether farmers incur extra costs to blind themselves towards social risks. Yet, given that betrayal causes additional psychological costs, we believe that betrayal averse farmers are less productive than farmers who do not suffer from betrayal costs. This derives our second hypothesis:

Hypothesis 2. More betrayal averse farmers are less productive than farmers who perceive low betrayal costs

\subsection{Local Context}

We conducted our study with vanilla farmers in Madagascar, one of the world's largest exporters of natural vanilla. Vanilla is cultivated mainly in the north-eastern part of the country, the Sambava-Andapa-Vohemar-Antalaha (henceforth SAVA) region (see Figure 3.B1). Farmers cultivate mostly vanilla and rice, followed by a small share of other cash crops such as coffee and cloves and subsistence crops (Hänke et al., 2018; Fairtrade International, 2019).

One of the largest risks that farmers confront is the increase of crop theft (Neimark et al., 2019; Osterhoudt, 2020). Green vanilla is a high-value crop that is highly visible and easy to transport. It must stay about seven months on the plantation for optimal ripeness, even when about two months after pollination, it has reached its full size and weight (Havkin-Frenkel \& Belanger, 2018). ${ }^{4}$ Moreover, to reach its dark color and aroma, farmers have to prepare the vanilla outside of their houses, a process that takes about two to three months after harvest. Because of its characteristics, vanilla is an attractive and relatively easy target for thieves. Besides crop theft, farmers face other risks such as extreme weather shocks. Cyclones frequently hit the region some years even twice, flooding the plantations and destroying the vanilla vines and farmers' housing (M. Brown, 2009). The consequences of cyclones have a high impact on the population, as it causes crop and income losses, exacerbating food insecurity and poverty (M. Brown, 2009; Hänke et al., 2018).

\footnotetext{
2018).

${ }^{4}$ Vanilla reaches its optimum degree of ripeness nine months after pollination (Havkin-Frenkel \& Belanger,
} 
In response to the risk of theft, farmers might decrease productive investments. For instance, they might decrease the size of the vanilla plantations, harvest the beans earlier, and sell them without processing. Alternatively, they might incur additional costs to protect their plantations. We focus on production and commercialization decisions associated with betrayal aversion attitudes. In particular, we consider (i) Share of land cultivated with vanilla; (ii) Average size of vanilla plantations; (iii) Month of vanilla harvest in 2017; whether the farmer (iv) Harvest the vanilla before the official market opening in 2018; if the (v) Farmer prepared the green vanilla in $2017^{5}$; if the (vi) Farmer prepared the green vanilla in 2018; (vii) Share of paid labor compared to total labor; and whether the (viii) Farmer guards the vanilla plantations.

Early vanilla harvesting is one of the biggest challenges in the SAVA region (Cadot et al., 2009). This practice threatens the quality of the vanilla from Madagascar (Havkin-Frenkel \& Belanger, 2018) and decreases farmers' income as farm gate prices are lower before the official market opening. Moreover, the output price farmers obtain from vanilla depends on whether they sell it right after harvest (green vanilla) or if they harvest and cure it (black vanilla). On the technology side, the curing process increases production time and costs. It also increases social risks as the farmer brings the vanilla to their house for storage, which increases their exposure to theft at home - especially because the vanilla releases an aroma during the curing process, making it more salient. Deciding not to prepare vanilla means that farmers are losing an income opportunity as prices can be as eight times as high. Moreover, the early harvest practice and the decision to sell green reduces farmers' opportunities for vertical integration, closing thus an important window to improve their livelihoods (Hänke et al., 2018). One of the main reasons that explain the early harvest practice and the unwillingness to sell black vanilla is fear of theft (Hänke et al., 2018), which constitutes a social risk. Because of this, such decisions can be exacerbated by betrayal aversion attitudes.

We further study how much land dedicated to vanilla the farmer has, as fear of theft can deter farmers from having more and larger plantations. Fewer and smaller plantations translate into lower yields and hence into lower income. Moreover, we consider how much labor farmers hire as it requires high levels of trust from the people in the village. In this case, betrayal aversion attitudes could deter farmers from hiring the labor required for the vanilla production, making it less efficient. Last, we consider guarding as it implies an extra cost for the farmer or his family.

Given that Madagascar is one of the poorest nations in the world that highly relies on the agricultural sector (World Bank, 2019), exploring this topic is highly relevant from a development perspective. Yet, the lessons learned from Madagascar can be applied to other regions around the world where farmers confront similar risks.

\footnotetext{
${ }^{5}$ In this process, vanilla develops its quality which is measured by its vanillin content. To reach the dark color and aroma, farmers have to use a combination of "sweating" and "drying" processes that last about 2-3 months. Green beans are first dipped into near-boiling water, boxed to keep them warm, and then exposed to daily sunlight to dry. See Havkin-Frenkel \& Belanger (2018) for a detailed explanation on vanilla preparation.
} 


\subsection{Experimental design}

To measure farmers' degree of betrayal aversion and analyze its predictive power to explain production and commercialization decisions, we conducted one experimental session and individual interviews with farmers and two follow-up surveys 30 and 45 days after the day of the experiment. In these surveys, we track participants' harvesting and market behavior before and after the official opening of the vanilla market. We collected the data between May and July 2018 (see Figure 3.1). The experimental instructions and questionnaires can be found in Appendix C.

Figure 3.1: Sequence of Experimental Session and Follow-up Surveys

\begin{tabular}{|c|c|c|}
$\begin{array}{c}\text { Visit 1: } \\
\text { Experiment \& Baseline Survey } \\
\text { (May - June) } \\
\mathrm{N}=760\end{array}$ & $\begin{array}{c}\text { Visit 2: } \\
\text { Follow-up 1 Survey } \\
\text { (June - July) } \\
\mathrm{N}=703\end{array}$ \\
\cline { 2 - 4 } & $\begin{array}{c}\text { Visit 3: } \\
\text { Follow-up 2 Survey } \\
\text { (July) } \\
\mathrm{N}=710\end{array}$ \\
\hline
\end{tabular}

\subsubsection{Betrayal aversion elicitation}

To measure betrayal aversion, we follow the methods described in Quercia (2016). Participants confront two sets of scenarios: a secure low payoff scenario and a risky payoff with a higher expected payment scenario. They have to choose according to which scenario their payment will be determined. The scenarios vary whether participants confront a SocIAL Risk or NATURE Risk. Under the Social Risk, participants are confronted with the distribution of actual decisions by participants living in urban areas, whereas under the NATURE Risk a random device determines the payoffs.

The scenarios are introduced using a vignette. Participants take the role of a seller who needs to hire a delegate to sell a hypothetical product (pineapple) in the market. Participants can choose between the safe Delegate $A$ who pays a 4,000 ariary $(\approx 1 €)$, and the risky Delegate $B$ that - with a prespecified probability - pays either 9,000 ariary or 1,000 ariary.

In each scenario (Social Risk and NATURE RISK), participants take 11 decisions that vary the probability of receiving the high payment between 0 and 100 percent in 10 percentage point intervals. This decision is implemented using the strategy method, and at the end, one of the decisions is selected for payment with equal probability. The procedure allows to elicit two "minimum acceptable probabilities": MAP Social and MAP Nature. Given the low level of education of the participants, we expressed probabilities as frequencies varying the number of delegates who offer the different payments (see Figures 3.B2 and 3.B3 in the Appendix).

Both the Social Risk and the NATURE RISK vignettes have identical payoff structures (see Figure 3.2). However, whereas in the NATURE Risk a random device determines the 
payment, in the SOCIAL Risk, participants confront other participants who decide whether to pay the low or high payment. The vignette presents these risks due to weather conditions that change transportation costs or delegates who decide to offer a lower payment to the farmer. We randomized the order of the games to control for order effects.

Figure 3.2: Betrayal Aversion Elicitation

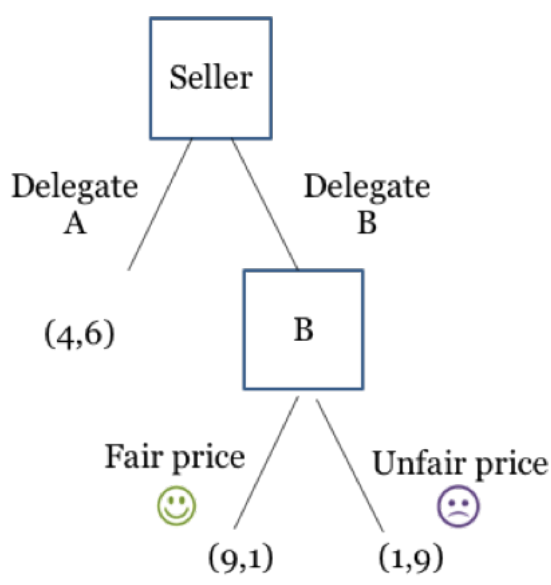

Activity 1 Social Risk Game

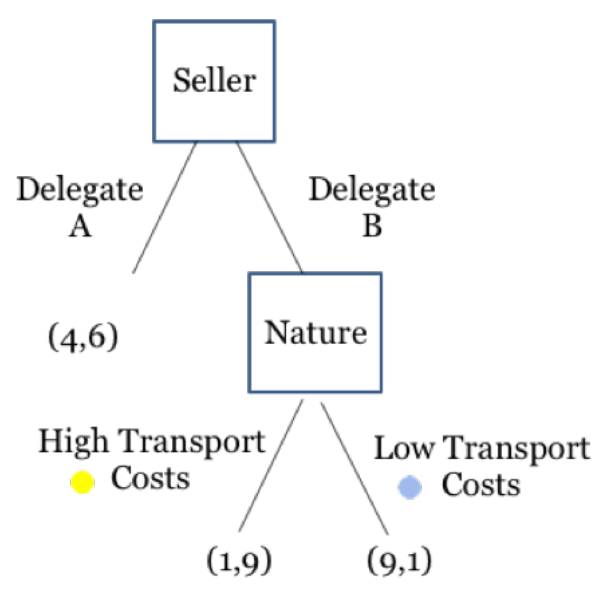

Activity 2 Lottery Risk Game

The Delegates are participants in three different cities who took part in two modified dictator games. In the first dictator game, they had to decide how to distribute 10,000 ariary between themselves and the sellers. They were allowed to decide whether to send the seller 1,000 or 9,000 ariary. In the second dictator game, the distribution was determined by a random device. The task of the delegate was to select a ball from a bag containing blue and yellow balls. If the yellow ball was selected, the delegate faced high transportation costs and thus returned the low amount to the seller. The seller received 1,000 ariary, while the delegate kept the rest. However, if the blue ball was selected, then the delegate faced low transportation costs and returned the high amount to the seller (9,000 ariary). Half of the delegates were randomly selected into the group of Delegates $A$ and received a payment of 6,000 ariary. This procedure was communicated beforehand to the participants. Participants made the decisions under anonymity and knew that the decisions bear monetary consequences. In the analysis, we focus only on the sellers' decisions, i.e., the farmer participants.

\subsubsection{Inequality aversion}

Since the sellers knew the payoff distribution in the betrayal aversion measure, one could argue that inequality aversion (Fehr \& Schmidt, 1999) could affect the decisions taken in the Social and Natural Risk Game as there is an unequal distribution of earnings between sellers and delegates. This concern was raised by Bohnet \& Zeckhauser (2004), although they did not account for it, as in their setup, the measure of betrayal aversion comes from 
a between-subject design elicitation.

To measure inequality aversion, we use a similar structure as the voting game in Bolton $\&$ Ockenfels (2006). Participants were divided into groups of three: Person A, Person $B$ and Person D. ${ }^{6}$ Each participant was asked to vote as if they were in the role of Person A, between two options that distribute 15,000 ariary $(\approx 3.85 €)^{7}$ in two different ways (see Table 3.1 for the payoff distribution). Simultaneously, each participant voted for either Option 1, which represents an egalitarian distribution, or for Option 2, which represents a minority gain and a majority loss. The alternative with the majority of votes was implemented, and the corresponding payoffs were then distributed among the group members. Participants were kept behind the veil of ignorance. Before voting, participants did not know their role but were aware that each role in the group will be assigned randomly after they have made their decisions and that the payoffs will be implemented accordingly.

Table 3.1: Game payoffs

\begin{tabular}{cccc}
\hline & Person A & Person B & Person D \\
\hline \hline Option 1 & 5,000 & 5,000 & 5,000 \\
\hline Option 2 & 11,000 & 2,000 & 2,000 \\
\hline
\end{tabular}

\subsubsection{Baseline Survey}

After the decisions, subjects participated in the post-experimental baseline survey. The survey includes questions on attitudes and preferences (patience, general trust, trust during harvest time), production inputs (number of plantations and their characteristics, years of experience in farming vanilla, labor, walking distance from homes to plantations, and guarding activities), victimization (i.e., being a victim of theft in 2017 and 2018), financial security (savings, bank account, and off-farm income), production output (time of harvest, time of selling green and black vanilla, kilograms of green vanilla harvested and sold in 2017 and in the last month, kilograms of black vanilla sold in 2017 and in the last month, selling prices), and socioeconomic characteristics (sex, age, marital status, years of education, household size). We also asked farmers whether they are new to vanilla farming. This distinction is relevant, as new vanilla farmers are those with plantations no older than three years and therefore could not report data on production outputs. This, as vanilla vines have their first harvest three years after being planted.

In the baseline survey, we collected data of six out of our eight main outcome variables related to farmers' production and commercialization decisions that are part of our research question.

For the follow-up surveys, 30 and 45 days after the experimental sessions, we focus on production decisions (time of harvesting and selling, decision to prepare vanilla, number

\footnotetext{
${ }^{6}$ In Malagasy there is no letter C.

${ }^{7}$ To avoid efficiency concerns we kept the total amount distributed constant.
} 
of nights spent at plantations to guard), production output (kilograms of green vanilla harvested and sold, selling prices), and victimization. We decided to visit farmers two additional times to obtain information about the harvest and selling points, and the price farmers can receive across time. Since questions about harvesting and selling times are sensitive, we emphasized several times that the information provided in each of the surveys will remain confidential (see Appendix $\mathrm{C}$ for the complete survey set).

Some farmers answered the questions before the official opening of the vanilla market, which was on July 15, 2018, and some others after the market opening.

\subsubsection{Experimental Procedure}

Some vanilla farmers live in very remote areas difficult to access given the general lack of good infrastructure. Some are only reachable by pirogue - a traditional canoe - or several hours or days of walk. We sampled from a large database collected by the Diversity Turn Project $^{8}$ which includes information of all villages in the region located 10 kilometers away from the main road. Our first sample comprises a list of 60 villages that we split equally into five different types according to their population size (see Hänke et al. (2018) for the list). To select villages for participation in the experiment, we stratified based on village size. We contacted 25 villages in total, of which two refused to participate and one was not accessible at the time of the data collection. Therefore, a total of 22 villages took part in the experiment.

We visited each of the selected villages two weeks before starting with the data collection. In each village, we asked the chief for a list of vanilla farmers. From that list, we randomly picked 40 numbers and invited the selected farmers to the experiment. This procedure was done publicly in front of the village chief and another person of the village. If the person selected was not living in the village anymore or was deceased, we re-sampled without replacement.

We conducted two experimental sessions in each village on the same day, one in the morning and one in the afternoon. On average, 20 farmers participated in each of the sessions. A total of 788 vanilla farmers participated in the experiment and the baseline or post-experimental survey. We removed 28 observations from our sample: five farmers did not allow us to visit again, 20 farmers did not grow vanilla, two farmers did not provide full information about their plantations, and one farmer did not have plots. This leaves us with a total sample of 760 observations for the first part of the experiment.

To reduce attrition for the next two visits, we asked participants at the end of the experimental session for a contact phone number to reach them in the future. This helped the enumerators announce their visits to the villages in advanced and arranged times and places to meet with each participant. Yet, for the first and second follow-up we have an attrition of $\approx 7$ percent ( 57 and 50 participants, respectively). For those farmers who did

\footnotetext{
${ }^{8}$ For more information see: https://www.uni-goettingen.de/en/529181.html
} 
not take part in one or both follow-ups, we obtained a certificate from the village chief who confirmed that the person had an emergency or a especial situation on the day we were visiting the village and had to leave (16 and 3 participants for each follow-up, respectively), or that the participant migrated ( 1 person from total sample), or passed ( 1 person from total sample), or was nobody knew about his whereabouts (1 person from total sample). For the remaining 38 and 44 participants not taking part in the first or second follow-up, respectively, we do not have a written explanation that justifies their no participation, and it was not possible to find them at their homes. It is likely that these participants were at their fields during our visit and thus were not possible to reach via mobile phone due to lack of network connection. Due to safety reasons, we did not collect information on participants' field location, and therefore, we could not visit them there. We observe a total of 667 farmers in the three visits ( 87 percent of the total sample). Table 3.2 gives an overview of the number of participants by visit. In section 3.6 we check whether our measure of betrayal aversion or other socioeconomics can predict the likelihood of participating in both follow-ups or not.

Table 3.2: Overview of participants by visit

\begin{tabular}{lcc}
\hline Visit & No. participants & Attrition \\
\hline \hline Visit 1: Experiment and Baseline & 760 & \\
Visit 2: Follow-up 1 & 703 & $7.5 \%$ \\
Visit 3: Follow-up 2 & 710 & $6.6 \%$ \\
\hline Total observed in the 3 visits & 667 & \\
\hline
\end{tabular}

In the experimental sessions, participants earned on average 9,200 ariary $(\approx 2.36 €)$, including a 2,000 ariary show-up fee $(\approx 0.5 €)$. This value is comparable to what a person in the region would earn per day of work $(\approx 4 €)$. Each farmer received their earnings in a white envelope. For their participation in each of the follow-up surveys, farmers received a flat fee of 3,000 ariary $(\approx 0.77 €)$ as compensation for their time. The experiment and the post-experimental survey took approximately two hours in total. The two follow-ups lasted on average eleven and eight minutes, respectively.

\subsection{Results}

\subsubsection{Sample characteristics}

We start by describing the main characteristics of our sample. Farmers participating in the experiment are on average 47 years old, are mostly men (74 percent) and married (84 percent), have completed on average 5 years of education - which corresponds to primary school - have on average 1.3 vanilla plantations and 16 years of experience in vanilla farming. In addition, 34 percent of farmers in our sample are new vanilla farmers, which means 
that they could not harvest, sell, or experience theft of green vanilla since their plantations are not older than three years. Table 3.3 presents the socioeconomic, production, and victimization characteristics of our sample.

Farmers dedicate their available land to cultivate mostly vanilla and rice, followed by a small share of other cash crops such as coffee and cloves and other subsistence crops. The vanilla plantations from sampled farmers have an average size of 1.2 ha, representing about 60 percent of their land. The low crop diversification causes that farmers are highly vulnerable to shocks affecting their production. Moreover, in our sample and in the region, farmers are smallholders (Hänke et al., 2018; Fairtrade International, 2019).

From the information collected, 41 percent and 19 percent of farmers reported harvesting their green vanilla before the market opening in 2017 and 2018, respectively. ${ }^{9}$ The average price farmers received for green vanilla in the months previous to the opening of the vanilla market is lower in comparison to the price they could receive if they wait. This, especially until the opening of the vanilla market, which usually occurs between the last week of June and the first two weeks of July. For instance, farmers who were harvesting and selling their green vanilla in March 2017 -a time that coincides with the 'lean season'- received on average 60,000 ariary $(\approx 15 €)$ per kilogram. Yet, if they had waited until June, they could have received 2.2 times more money per kilogram of vanilla (see Figure 3.B4). The figure is similar for the 2018 harvest. The price of green vanilla two weeks before the market opening was around 80,000 ariary per kilogram $(\approx 20 €)$, and the price once the market opened (July 15 ) was initially around 100.000 ariary per kilogram $(\approx 25 €)$.

After green vanilla is harvested, it can be either sold as such or start the preparation process. More than half of our farmers indicate that they did not prepare green vanilla in the harvest of 2017 and 2018. A preference for selling green is the key reason for not processing, especially given the high prices at the time. From anecdotal evidence, we know that liquidity constraints are one of the main reasons for not preparing vanilla. An additional reason is that farmers incur a higher risk of theft if vanilla is kept at their homes for the preparation process (Hänke et al., 2018; Fairtrade International, 2019). Sample farmers harvested an average of 47 and 31 kilograms of vanilla in the harvests of 2017 and 2018, respectively. ${ }^{10}$ Moreover, a barrier for farmers is that their yield may not be enough for preparing vanilla. About 5 kilograms of green vanilla are needed to prepare 1 kilogram of black vanilla (Havkin-Frenkel \& Belanger, 2018).

Vanilla is a labor intensive crop with labor peaks during March to July and September to November. Similar to the findings by Komarek (2010) in Uganda, we find that households rely more on family labor than on hired labor for production activities. Only 30 percent of the total labor force that farmers use for different activities related to vanilla production

\footnotetext{
${ }^{9}$ Table 3.2 reports that 20 percent of farmers harvested the green vanilla before market opening. Yet, the sample size is reduced to 450 farmers due to attrition. We calculate the 19 percent from a total base of 484 old vanilla farmers from whom we have complete information about output variables.

${ }^{10}$ The information about harvest and selling from the harvest 2018 is incomplete as our data collection ended two weeks after the official market opened. We acknowledge that farmers kept harvesting and selling vanilla after this point.
} 
(wedding, pollination, guarding, harvesting, curing, selling, etc.) is hired labor, which means that most of the activities are performed by family members. In addition, women are less likely to be hired than men, which is also shown in the work by Komarek (2010). Wedding and guarding are the most labor intensive tasks and predominantly done by men. Women mainly participate in pollination activities. Our questionnaire did not include child labor, which is commonly used for farm work (Fairtrade International, 2019).

An important share of farmers experienced theft from their plantations, and it occurred more than once in the same harvest year. Theft is thus economically relevant. Based on the self-reported victimization, about a third (34 percent) of farmers in our sample with plantations older than three years were victims of green vanilla theft in 2017 at least once. This number decreased in 2018 by 6 percentage points, but the difference is not statistically significant (paired z-test, $\mathrm{z}=1.0516, \mathrm{p}$-value $=0.293$ ). Besides this measure, we calculated the average theft reported by others in the village (Victimization-i) for the same period. Moreover, in our baseline survey, 50 percent of farmers agree with the statement that their plot is in constant threat of theft. This percentage increases when we asked farmers about the risk of theft when leaving the plots unattended 80 percent agree that this is a high risk. Fear of theft also threatens farmers' well-being and increases their production costs. For instance, 70 percent of farmers reported to have stayed overnight at the plantations to guard the vanilla one month before the experimental session occurred, and 46 percent of them reported to have spent every night at their plantation. Even though the number of farmers reporting to stay every night at their plantations went down by 10 percentage points (25 percentage points), 30 days (45 days) after the experimental sessions, this shows the fear farmers face to leave their plantations unattended. Most farmers reported guarding their plantations either by themselves or with their families' help or by hiring a guardian. Almost half of the farmers reported guarding their plantations alone, and 9 percent hire a guardian. The average salary of a guardian is 11,000 ariary $(\approx 2.75 €)$ for a working day, which represents approximately 7 percent of the farm gate price for 1 kilogram of green vanilla just for one night. ${ }^{11}$ The use of fences ( 1 percent), traps ( 5 percent), dogs (1.6 percent), and guns (2.8 percent) is rare.

Regarding farmers' commercialization decisions, 60 percent reported selling their vanilla on the spot market in 2017, and 21 percent to have sold to an exporter or through an association. Only 10 percent sold to a middle man ('rabatteur' or 'commissionaire'). Reasons for this low share are that middlemen usually give lower prices or do not give cash-in-hand, which discourages farmers from selling vanilla to them. Anecdotal evidence suggests that farmers sell green vanilla to middlemen when they need liquidity and the official market opening is in the distant future.

${ }^{11}$ The farm gate price for 1 kilogram of green vanilla in 2018 was around 150,000 ariary $(\approx 38 €)$. 
Table 3.3: Sample Characteristics

\begin{tabular}{|c|c|c|c|c|c|}
\hline Variable & $\mathrm{N}$ & $\min$ & Mean & $\max$ & St.Dev \\
\hline \multicolumn{6}{|l|}{ Panel A: Socioeconomic variables } \\
\hline Female & 760 & 0 & 0.261 & 1 & 0.439 \\
\hline Age in years & 760 & 18 & 47.512 & 88 & 14.189 \\
\hline No. years of school completed & 760 & 0 & 5.783 & 15 & 3.150 \\
\hline Married & 760 & 0 & 0.837 & 1 & 0.370 \\
\hline Farmer saves money & 760 & 0 & 0.650 & 1 & 0.477 \\
\hline Farmer has a bank account & 760 & 0 & 0.234 & 1 & 0.424 \\
\hline Generates income from non-farming activities & 760 & 0 & 0.479 & 1 & 0.500 \\
\hline Catholic & 703 & 0 & 0.304 & 1 & 0.460 \\
\hline Protestant & 703 & 0 & 0.255 & 1 & 0.436 \\
\hline Betsimsaraka & 703 & 0 & 0.294 & 1 & 0.456 \\
\hline Tsimihety & 703 & 0 & 0.275 & 1 & 0.447 \\
\hline Patience level & 760 & 1 & 1.602 & 4 & 1.150 \\
\hline Total of male adults in $\mathrm{HH}$ & 760 & 0 & 0.433 & 10 & 0.856 \\
\hline \multicolumn{6}{|l|}{ Panel B: Production variables - input } \\
\hline Years of experience in farming vanilla & 760 & 0 & 16.022 & 73 & 13.701 \\
\hline New vanilla farmer & 760 & 0 & 0.343 & 1 & 0.475 \\
\hline Level of farming skills & 760 & 1 & 1.889 & 3 & 0.501 \\
\hline Share from total land with vanilla & 760 & 0.10 & 0.598 & 1 & 0.240 \\
\hline No. vanilla plantations farmer has & 760 & 1 & 1.326 & 4 & 0.600 \\
\hline Average size vanilla plantation (in $\mathrm{Ha}$ ) & 760 & 0.02 & 1.244 & 20 & 1.127 \\
\hline Labor force Male units (Family-unpaid) & 760 & 0 & 3.687 & 68 & 5.562 \\
\hline Labor force Female units (Family-unpaid) & 760 & 0 & 2.476 & 34 & 3.402 \\
\hline Labor force Male units (Hired) & 760 & 0 & 2.401 & 30 & 4.181 \\
\hline Labor force Female units (Hired) & 760 & 0 & 0.926 & 18 & 2.443 \\
\hline Spent every night at plantation in last 30 days & 760 & 0 & 0.462 & 1 & 0.499 \\
\hline Farmer guard the plantation(s) & 760 & 0 & 0.872 & 1 & 0.334 \\
\hline Farmer guards alone & 760 & 0 & 0.463 & 1 & 0.499 \\
\hline Farmer pays a guardian & 760 & 0 & 0.092 & 1 & 0.289 \\
\hline \multicolumn{6}{|l|}{ Panel $C$ : Production variables - output } \\
\hline Month of green vanilla harvest 2017 & 484 & 3 & 5.742 & 8 & 1.074 \\
\hline Green vanilla harvested in 2017 (kg) & 484 & 1 & 89.190 & 1,000 & 127.662 \\
\hline Month of green vanilla sells 2017 & 367 & 3 & 6.050 & 9 & 1.004 \\
\hline Green vanilla sold in 2017 (kg) & 367 & 1 & 46.649 & 600 & 55.942 \\
\hline Farmer prepared vanilla in 2017 & 484 & 0 & 0.413 & 1 & 0.493 \\
\hline Harvested vanilla before market opening 2018 & 464 & 0 & 0.196 & 1 & 0.397 \\
\hline Green vanilla harvested in $2018(\mathrm{~kg})$ (Total) & 499 & 0 & 30.124 & 500 & 61.256 \\
\hline Green vanilla sold in 2018 (kg) (Total) & 499 & 0 & 1.858 & 100 & 8.844 \\
\hline Farmer plans to prepare vanilla in 2018 & 499 & 0 & 0.479 & 1 & 0.500 \\
\hline Farmer prepare vanilla in 2018 & 467 & 0 & 0.381 & 1 & 0.486 \\
\hline \multicolumn{6}{|l|}{ Panel D: Social capital } \\
\hline Trust people in the village & 760 & 1 & 2.711 & 5 & 0.958 \\
\hline Level of cooperation within village & 760 & 1 & 1.679 & 5 & 0.849 \\
\hline Farmer is member of an association & 703 & 0 & 0.286 & 1 & 0.452 \\
\hline \multicolumn{6}{|l|}{ Panel E: Victimization variables } \\
\hline Victim of green vanilla theft in 2017 & 499 & 0 & 0.343 & 1 & 0.475 \\
\hline Victimization $-i 2017$ & 760 & 0.05 & 0.222 & 0.46 & 0.093 \\
\hline Victim of green vanilla theft in 2018 & 499 & 0 & 0.283 & 1 & 0.451 \\
\hline Victimization-i 2018 & 760 & 0 & 0.184 & 0.486 & 0.118 \\
\hline Plot threat of theft & 760 & 1 & 3.089 & 5 & 1.169 \\
\hline High risk of theft if plot has no supervision & 760 & 1 & 3.895 & 5 & 1.067 \\
\hline High risk of theft if plot has supervision & 760 & 1 & 2.571 & 5 & 1.015 \\
\hline \multicolumn{6}{|c|}{$\begin{array}{l}\text { Notes: Data was collected at three different points in time: after the experiment, } 15 \text { days and } 30 \text { days } \\
\text { after the experiment. "Total" refers to the sum of the information reported in the three visits. The } \\
\text { differences in the number of observations in Panel A is because in the Baseline survey ( } \mathrm{N}=760 \text { ) we did } \\
\text { not collect information on religion and ethnicity but during the first follow-up ( } \mathrm{N}=703) \text {. The sample size } \\
\text { in Panel C corresponds to farmers with plantations older than } 3 \text { years, as they are the only ones who } \\
\text { could report data on harvest and selling of vanilla ( } \mathrm{N}=499) \text {. The number of observations in harvesting } \\
\text { and selling in } 2017 \text { in Panel } \mathrm{C} \text { is reduced because we do not have output information of } 15 \text { observations } \\
\text { for this harvest. Also because some farmers do not sell green vanilla after harvest but prepare it and } \\
\text { sell after some weeks as black vanilla in the market. The variables on harvest, selling and preparation } \\
\text { of green vanilla in } 2018 \text { were collected before and during the first two weeks after the opening of the } \\
\text { official vanilla market. The reduction of the sample for the harvest in } 2018 \text { is because we are using } \\
\text { the information of the first follow-up only or from both follow-ups where we have an attrition of about } \\
7 \text { percent. The variables Trust people in the village, Level of cooperation within village Plot threat of theft, } \\
\text { High risk of theft if plot has no supervision, and High risk of theft if plot has supervision correspond to } \\
\text { statements farmers rate from } 1 \text { to } 5 \text {. } 1 \text { means 'Strongly disagree' and 5 'Strongly Aoree' }\end{array}$} \\
\hline
\end{tabular}




\subsubsection{Betrayal attitude of farmers}

The distributions of MAPs for the SOcIAL RISK and NATURE Risk are presented in Figure 3.3. The Wilcoxon signed-rank test does not reject the null hypothesis that the two measures follow the same distribution. There is a high positive correlation between both measures. The mean coefficient of risk aversion among the sample is -0.004 , which is not statistically different from zero (z-test, $\mathrm{p}$-value $=0.912$ ). This leads us to conclude that participants in our sample are on average betrayal neutral.

Figure 3.3: Distribution of MAPs

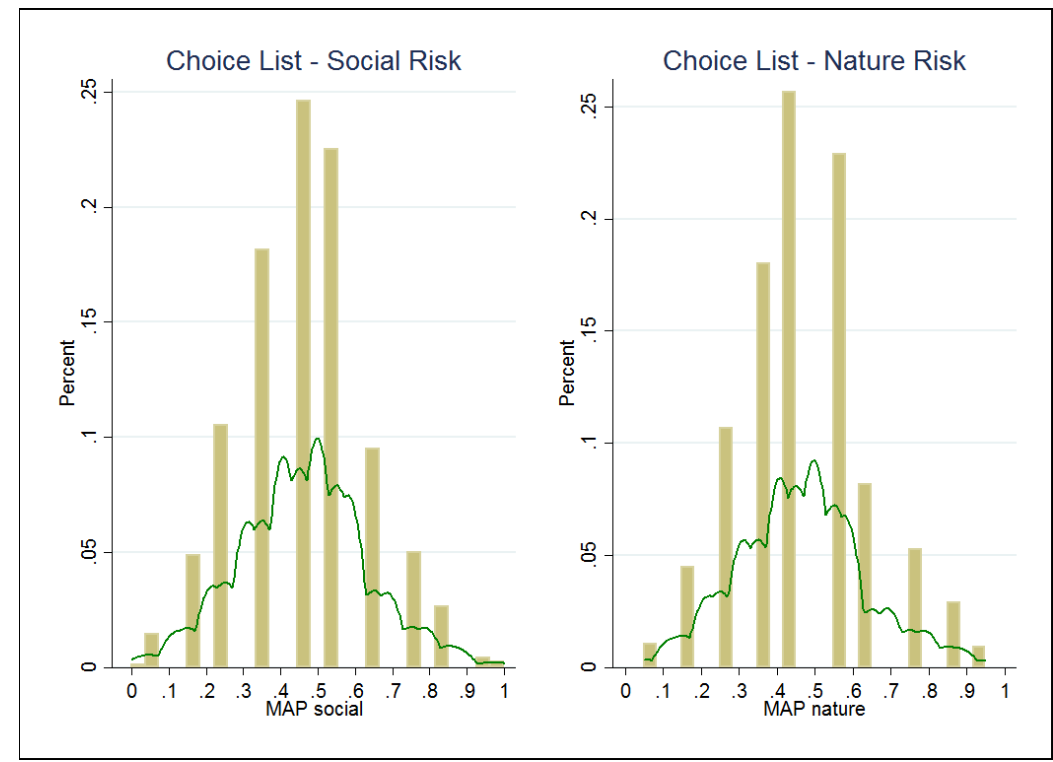

Notes: The figure presents the distributions and estimated kernel density functions of the MAPs for the Social Risk and NATURE Risk games.

However, there is a fair amount of heterogeneity as can be seen in Figure 3.4 that plots the distribution of the betrayal aversion coefficient, and the estimated kernel density function. Individuals located on the right side, with positive values, are classified as betrayal averse. Individuals on the left side, with negative values, are classified as betrayal seeking. Using these criteria, we find that the largest share of participants in our sample (40 percent) can be classified as betrayal neutral. The share of betrayal averse and betrayal loving individuals is about 30 percent for each.

Result 1. There is a large heterogeneity in the sample and participants display not only betrayal aversion but also betrayal seeking and betrayal neutral preferences. Therefore, we reject Hypothesis 1. 
Figure 3.4: Distribution Betrayal Aversion Coefficient

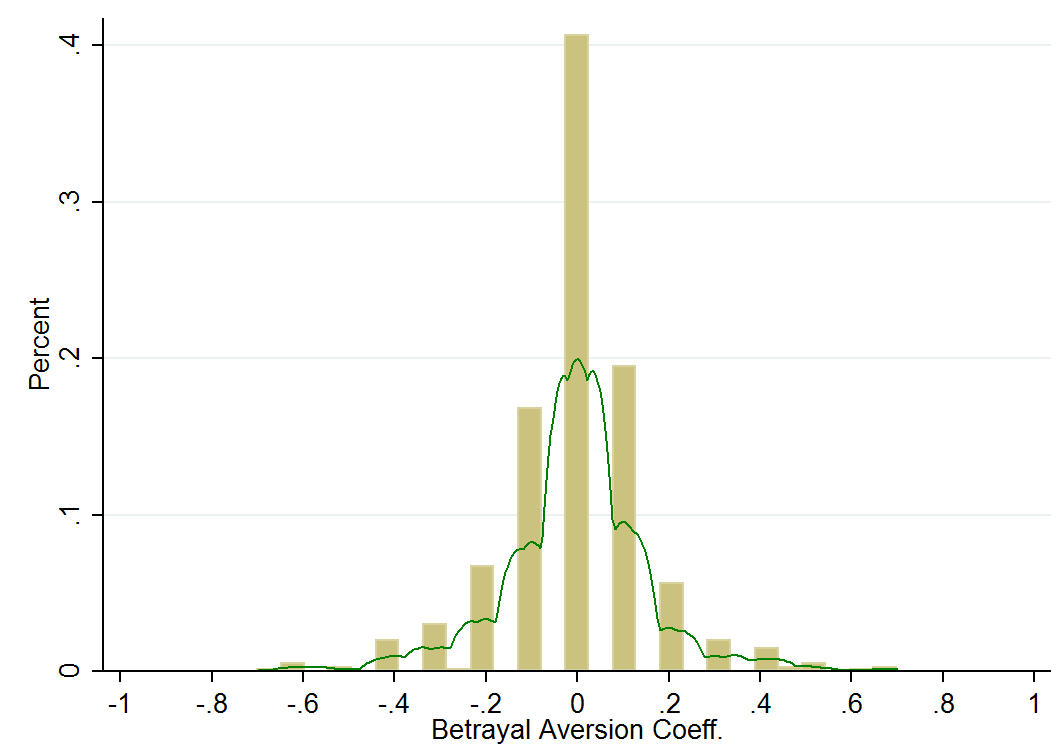

Notes: The figure presents the distribution and estimated kernel density function of the betrayal aversion coefficient. Based on this we find that 30 percent of participants are betrayal averse (coefficient $>0$ ), 30 percent betrayal seeking (coefficient $<0$ ), and 40 percent betrayal neutral (coefficient $=0)$.

Previous studies have reported a betrayal aversion size ranging from negative - betrayal seeking to neutral (Koppel et al., 2017; Fetchenhauer \& Dunning, 2012) to positive coefficientsbetrayal averse (Bohnet \& Zeckhauser, 2004; Bohnet et al., 2008; Aimone et al., 2015; Cubitt et al., 2017). Yet, most of these studies use a between-subject design and cannot observe individual attitudes of betrayal aversion The work of Aimone et al. (2015) uses a within-subject design and finds an heterogeneity of betrayal attitudes similar to ours (see Table 3.A1 in the Appendix for a review of other papers on betrayal aversion). Moreover, our results are in line with the study by Koppel et al. (2017), both in the negative sign of the betrayal averse coefficient and in the proportions of individual types. The authors explain that the difference in results with respect to the studies by Bohnet \& Zeckhauser (2004) and Bohnet et al. (2008) could be due to the selection of trustees. In Koppel et al. (2017), as well as in our study, trustees are anonymous people who made their decisions at a different point in time than the trustors. Yet, in studies that find a positive coefficient the trustees sit in the same room with the trustors. Koppel et al. (2017) argue that trustors share space with the trustees might activate stronger feelings of betrayal.

In a next step, we explore whether socioeconomic characteristics can predict betrayal aversion attitudes. We examine the relation of betrayal attitudes to farmers' socioeconomic characteristics and victimization using linear regression, where the dependent variable is a dummy that compares betrayal aversion and betrayal-loving attitudes to neutral attitudes (see Table 3.4). ${ }^{12}$ Columns 1 to 3 present the predictions for betrayal aversion attitudes,

\footnotetext{
${ }^{12}$ We run a similar model using the betrayal aversion coefficient as dependent variable. Table 3.A2
} 
and columns 4 to 6 for betrayal loving.

In the table, columns 1 and 4 include only socioeconomic characteristics, and in the other two models, we add different victimization variables. To establish the association of exposure to crime with betrayal attitudes, we use two different measures: victimization reported by others (Victimization-i) and self-reported crime victimization. Since we collected information from the 2017 harvest in the baseline survey, we have a measure of crop theft that only considers farmers who produced before. We add each of these variables (separately) in the estimation. In these estimations, we control for session fixed effects. We also control for inequality aversion. ${ }^{13}$

Previous studies have documented a gender difference towards betrayal attitudes, suggesting that women are more likely to be betrayal averse (e.g., Bohnet et al., 2008; Aimone \& Houser, 2012; Quercia, 2016). Our results do not support gender differences in betrayal aversion. Yet, when considering the reduced sample of old vanilla farmers, we find that women are more likely to be betrayal averse than men. ${ }^{14}$ Overall, we find that older and less educated participants are less likely to be betrayal neutral. Individuals who have confronted more victimization are less likely to be betrayal averse, suggesting that fear of crime rather than actual experiences shape betrayal aversion preferences. Moreover, we do not find a significant relationship between inequality concerns and betrayal aversion.

\footnotetext{
presents the estimates.

${ }^{13}$ We find that 84 percent of the participants can be classified as inequality averse as they voted for Option 1 (equal distribution).

${ }^{14}$ In the estimation where we use the betrayal aversion coefficient as dependent variable we find no gender effect.
} 
Table 3.4: Determinants Betrayal Attitudes

\begin{tabular}{|c|c|c|c|c|c|c|}
\hline & \multicolumn{3}{|c|}{ Betrayal Averse } & \multicolumn{3}{|c|}{ Betrayal Lovers } \\
\hline & $\begin{array}{c}(1) \\
\text { Model } 1 \\
\end{array}$ & $\begin{array}{c}(2) \\
\text { Model } 2 \\
\end{array}$ & $\begin{array}{c}(3) \\
\text { Model } 3 \\
\end{array}$ & $\begin{array}{c}(4) \\
\text { Model } 4 \\
\end{array}$ & $\begin{array}{c}(5) \\
\text { Model } 5 \\
\end{array}$ & $\begin{array}{c}(6) \\
\text { Model } 6 \\
\end{array}$ \\
\hline Female & $\begin{array}{c}0.088 \\
(0.055)\end{array}$ & $\begin{array}{c}0.088 \\
(0.056)\end{array}$ & $\begin{array}{c}0.194^{* * *} \\
(0.072)\end{array}$ & $\begin{array}{c}0.002 \\
(0.057)\end{array}$ & $\begin{array}{c}-0.001 \\
(0.058)\end{array}$ & $\begin{array}{c}0.098 \\
(0.079)\end{array}$ \\
\hline Age in years & $\begin{array}{l}0.004^{*} \\
(0.002)\end{array}$ & $\begin{array}{l}0.003^{*} \\
(0.002)\end{array}$ & $\begin{array}{c}0.004 \\
(0.002)\end{array}$ & $\begin{array}{c}0.005^{* * *} \\
(0.002)\end{array}$ & $\begin{array}{c}0.005^{* * *} \\
(0.002)\end{array}$ & $\begin{array}{c}0.006^{* * *} \\
(0.002)\end{array}$ \\
\hline Married (0-1) & $\begin{array}{l}-0.019 \\
(0.066)\end{array}$ & $\begin{array}{c}-0.018 \\
(0.066)\end{array}$ & $\begin{array}{c}0.051 \\
(0.087)\end{array}$ & $\begin{array}{l}-0.025 \\
(0.067)\end{array}$ & $\begin{array}{l}-0.025 \\
(0.067)\end{array}$ & $\begin{array}{c}0.111 \\
(0.096)\end{array}$ \\
\hline Total of children in $\mathrm{HH}$ & $\begin{array}{l}-0.007 \\
(0.011)\end{array}$ & $\begin{array}{c}-0.007 \\
(0.011)\end{array}$ & $\begin{array}{l}-0.008 \\
(0.014)\end{array}$ & $\begin{array}{c}0.002 \\
(0.011)\end{array}$ & $\begin{array}{c}0.002 \\
(0.011)\end{array}$ & $\begin{array}{c}0.006 \\
(0.014)\end{array}$ \\
\hline No. years of school completed & $\begin{array}{c}-0.023^{* * *} \\
(0.007)\end{array}$ & $\begin{array}{c}-0.023^{* * *} \\
(0.007)\end{array}$ & $\begin{array}{c}-0.029^{* * *} \\
(0.009)\end{array}$ & $\begin{array}{c}-0.026^{* * *} \\
(0.007)\end{array}$ & $\begin{array}{c}-0.026^{* * *} \\
(0.007)\end{array}$ & $\begin{array}{c}-0.036^{* * *} \\
(0.009)\end{array}$ \\
\hline New vanilla farmer $(0-1)$ & $\begin{array}{l}-0.056 \\
(0.048)\end{array}$ & $\begin{array}{l}-0.043 \\
(0.049)\end{array}$ & & $\begin{array}{l}-0.067 \\
(0.049)\end{array}$ & $\begin{array}{l}-0.062 \\
(0.049)\end{array}$ & \\
\hline Inequality aversion & $\begin{array}{c}0.059 \\
(0.061)\end{array}$ & $\begin{array}{c}0.057 \\
(0.060)\end{array}$ & $\begin{array}{c}0.053 \\
(0.076)\end{array}$ & $\begin{array}{c}0.001 \\
(0.059)\end{array}$ & $\begin{array}{l}-0.000 \\
(0.059)\end{array}$ & $\begin{array}{c}0.001 \\
(0.084)\end{array}$ \\
\hline Victimization $-i$ & & $\begin{array}{c}-0.300^{*} \\
(0.182)\end{array}$ & & & $\begin{array}{l}-0.110 \\
(0.185)\end{array}$ & \\
\hline Victim of green vanilla theft in 2017 & & & $\begin{array}{c}0.093 \\
(0.062)\end{array}$ & & & $\begin{array}{c}0.031 \\
(0.061)\end{array}$ \\
\hline Constant & $\begin{array}{c}0.668^{* * *} \\
(0.153)\end{array}$ & $\begin{array}{c}0.659^{* * *} \\
(0.158)\end{array}$ & $\begin{array}{c}0.698^{* * *} \\
(0.184)\end{array}$ & $\begin{array}{c}0.848^{* * *} \\
(0.155)\end{array}$ & $\begin{array}{c}0.838^{* * *} \\
(0.157)\end{array}$ & $\begin{array}{c}0.665^{* * *} \\
(0.214)\end{array}$ \\
\hline Observations & 535 & 535 & 351 & 534 & 534 & 344 \\
\hline Adjusted $R^{2}$ & 0.076 & 0.079 & 0.122 & 0.087 & 0.086 & 0.066 \\
\hline Fixed Effects & Yes & Yes & Yes & Yes & Yes & Yes \\
\hline
\end{tabular}

Notes: Columns (3) and (6) have a reduced sample as only those farmers who are not new can experience green vanilla theft. The victimization variable is standardized. Robust standard errors in parenthesis. * $p<0.10,{ }^{* *} p<0.05,{ }^{* * *} p<0.01$. 


\subsubsection{Betrayal attitudes and decision-making}

Our second hypothesis is that more betrayal averse farmers are less productive compared to less betrayal averse. To test this hypothesis, we use eight different variables that proxy farmers' behavior towards risk and which are captured by trusting behavior: (i) Share of total land with vanilla which takes the value from 0 to 1 and measures the proportion of total land that farmers use for vanilla cultivation; (ii) Average size vanilla plantation which shows how large in hectares (Ha) are on average the vanilla plots of farmers; (iii) Month of green vanilla harvest 2017 takes the values between 3 (March) and 8 (August) and represents in which month of the year 2017 farmers harvested their vanilla; (iv) Harvested vanilla before market opening in 2018 takes the values of 0 or 1 and shows whether the farmer harvested (or not) the vanilla before the official market opening; (v) Farmer prepared vanilla in 2017 takes the values of 0 or 1 and represents whether the farmer prepared or cured the green vanilla in the year 2017 or not; (vi) Farmer prepare vanilla in 2018 takes the values of 0 or 1 and represents whether the farmer prepared or cured the green vanilla in the year 2018 or not; (vii) Share of paid labor compared to total labor which measures the proportion of total labor (female and male) that the farmer hires for vanilla production; and (viii) Guards the vanilla plantations which takes the values of 0 or 1 and represents whether the farmer hires a guardian or not to protect the plantation(s).

We run robust linear regressions where each of the eight variables is used as the dependent variable. As independent variables, we include either the MAP social, the MAP nature, or the betrayal aversion coefficient. We control for other characteristics in each estimation, include session fixed effects and robust standard errors. Figure 3.5 presents the estimated coefficients of the MAPs and the betrayal aversion measure. The coefficients in standard deviations, p-values, and p-values corrected for multiple hypothesis testing can be found in Table 3.A3.

We find that the betrayal aversion measure is not correlated to the different production and commercialization decisions made by farmers. Yet, by decomposing betrayal aversion according to the different risk types (i.e., social and nature), we find that the unwillingness to take social risks is related to a lower share of plantations destined to vanilla cultivation and smaller average plantation sizes. An increase of one standard deviation in the MAP social is associated with a decrease of 0.075 standard deviations in the share of total plantations in vanilla $(\mathrm{p}$-value $<0.05) .{ }^{15}$ This translates into a decrease of 2 percentage points in the share of land with vanilla. The effect of social risk aversion on average vanilla size is similar. A one standard deviation increase in the MAP social is associated to a decrease of 0.051 standard deviations in the average size of vanilla plantations ( $\mathrm{p}$-value $<0.1$ ), or of about 0.06 Ha. However, these effects are not robust when correcting for False Discovery Rate (Anderson, 2008). We find that risk aversion, defined by the MAP nature, cannot explain any production and commercialization decisions farmers make.

\footnotetext{
${ }^{15}$ The MAP measure is based on the switch point from the risky to the safe option. A larger MAP means that farmers move earlier to the safe option, which means that they are not willing to tolerate an extra unit of risk.
} 
We observe that farmers sell an average of 47 kilograms of green vanilla in an average of 1.2 ha. Hence, from rough estimates, a decrease of $0.06 \mathrm{Ha}$ can result in a lower yield of about 2 kilograms. At a price of about 129,000 ariary per kilogram ${ }^{16}(\approx 33.1 €)$, this would mean a reduction in profits of 258,000 ariary $(\approx 65 €)$. Following the data reported by Fairtrade International (2019), the cost of a decent living for an average household (4.2 members) in Madagascar is $5.337 €$ per year, hence, the reduction of $0.06 \mathrm{Ha}$ in the average size of vanilla plantations represent 1,21 percent of this amount. ${ }^{17}$

Result 2. Farmers who are less willing to take social risks tend to have on average fewer and smaller vanilla plantations, which reduces their annual profits. Yet, this result is not robust to multiple hypothesis testing.

Figure 3.5: Relation between betrayal aversion attitudes and outcome variables

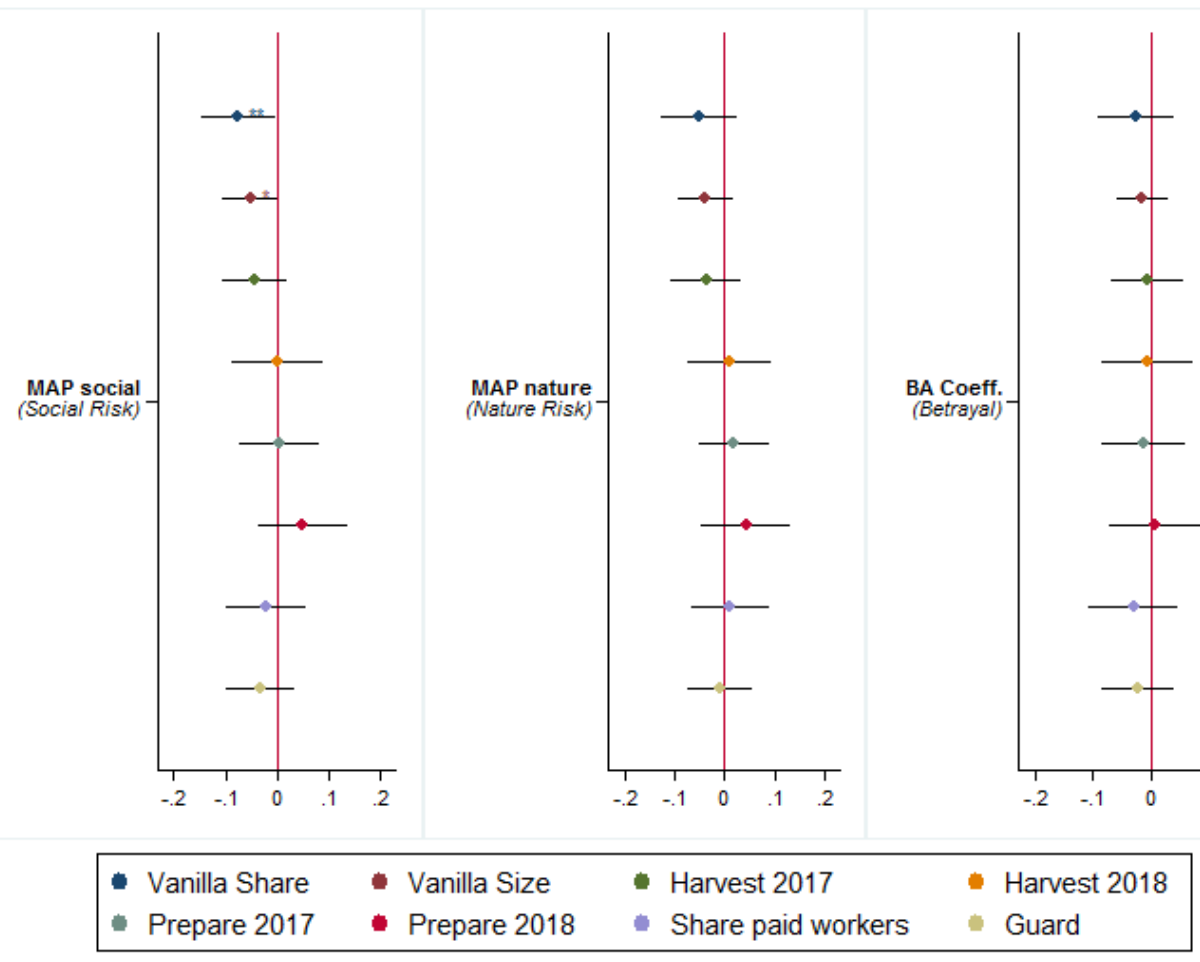

Notes: The figure presents the coefficients from linear regressions and the $95 \%$ confidence intervals. The regression models on the outcome variables Vanilla Share, Vanilla Size, and Guard include the whole sample of $\mathrm{N}=760$. The estimation models of the outcome variables Harvest 2017 and Prepare 2017 have sample of $\mathrm{N}=484$ that corresponds to the reduced sample of old vanilla farmers. The variables Harvest 2018, Prepare 2018 and Share paid labor have different sample sizes because of attrition or because farmers do not have any labor force $\left(\mathrm{N}=464, \mathrm{~N}=467\right.$, and $\mathrm{N}=630$, respectively). ${ }^{*} p<0.10$, ** $p<0.05, * * * p<0.01$.

\footnotetext{
${ }^{16}$ This is the average price of green vanilla sold in 2017

${ }^{17}$ We do not do a similar simulation with the share of land as we do not know how much land a participant has in total. We collected information on land distribution across the different land types by asking each participant to divide 20 beans into different land types categories: vanilla, paddy rice, tavy rice, other crops and no cultivation. From this distribution we calculate the share that corresponds to vanilla.
} 


\subsubsection{Exploratory analysis}

The effect of betrayal attitudes on behavior might be different when we consider previous experiences by individuals. This is particularly important in development contexts, where individuals are vulnerable to different shocks. While there is no evidence on how previous experiences change betrayal attitudes, we expect that experiences of crime make individuals more cautious and hence results in a larger decrease in investments. ${ }^{18}$

Because of its frequency and significant economic consequences, in our context, crop theft is one of the main challenges farmers face (Neimark et al., 2019; Osterhoudt, 2020). Therefore, the intensity of exposure to criminal environments might have an effect on the level of social risk farmers are willing to take.

Supporting this intuition, we find that the MAP in the SocIAL RISK game is positively correlated with the victimization reported by others in the village in 2017 (Pearson correlation is 0.08 , with p-value $<0.05)$. We do not observe a significant correlation between victimization and the MAP in the NATURE RISK game (Pearson correlation is 0.04, with p-value $=0.269)$. This suggests that in higher criminal environments farmers are more likely to avoid taking social risks, which could lead to them making less efficient decisions than farmers who live in environments where exposure to crime is lower. Because of this, we believe that the level of exposure to victimization (i.e., a social risk) matters when predicting the effects of betrayal attitudes on decision-making.

To explore how crime is related to farmers' production decisions, we regress them on the intensity of victimization. We calculate the intensity by dividing the sample based on the mean of the Victimization $-i 2017$ variable $(\mathrm{M}=0.222)$. Hence, farmers living in villages with a victimization above the mean value are in the 'High Victimization' group and farmers living in villages with a victimization below the mean value are in the 'Low Victimization' group.

Figure 3.6 presents the estimates of MAP social, MAP nature, and betrayal aversion for each of the outcome variables. The coefficients in standard deviations and p-values can be found in Table 3.A4. Similar to our main results, we find that farmers living in environments where crop theft is more prominent and are less prone to take social risk, have on average smaller vanilla plantations. We find no evidence for similar effects on the other outcome variables for this sub-sample.

Regarding farmers living in relatively safer environments, we find that the both the MAP social and MAP nature can predict farmers' decisions to prepare the green vanilla. Farmer with higher aversion towards risk (both from a social and nature source) are more likely to prepare the vanilla. Similarly, we find that betrayal aversion can predict the harvest decisions of farmers living in relatively low criminal environments. Farmers with higher

\footnotetext{
${ }^{18}$ We conduct a similar analysis where we divide the sample based on whether the participant is an old or a new vanilla farmer. We find that old vanilla farmers with higher betrayal aversion attitudes have significantly smaller plantations compared to those who are less betrayal averse. An overview of the results can be found in Figure 3.B5.
} 
aversion to betrayal are less likely to harvest before the official market opening. These results suggests that the aversion towards betrayal is not detrimental to farmers' production decision when they are in safer environments. ${ }^{19}$

Figure 3.6: Analysis comparing Victimization levels
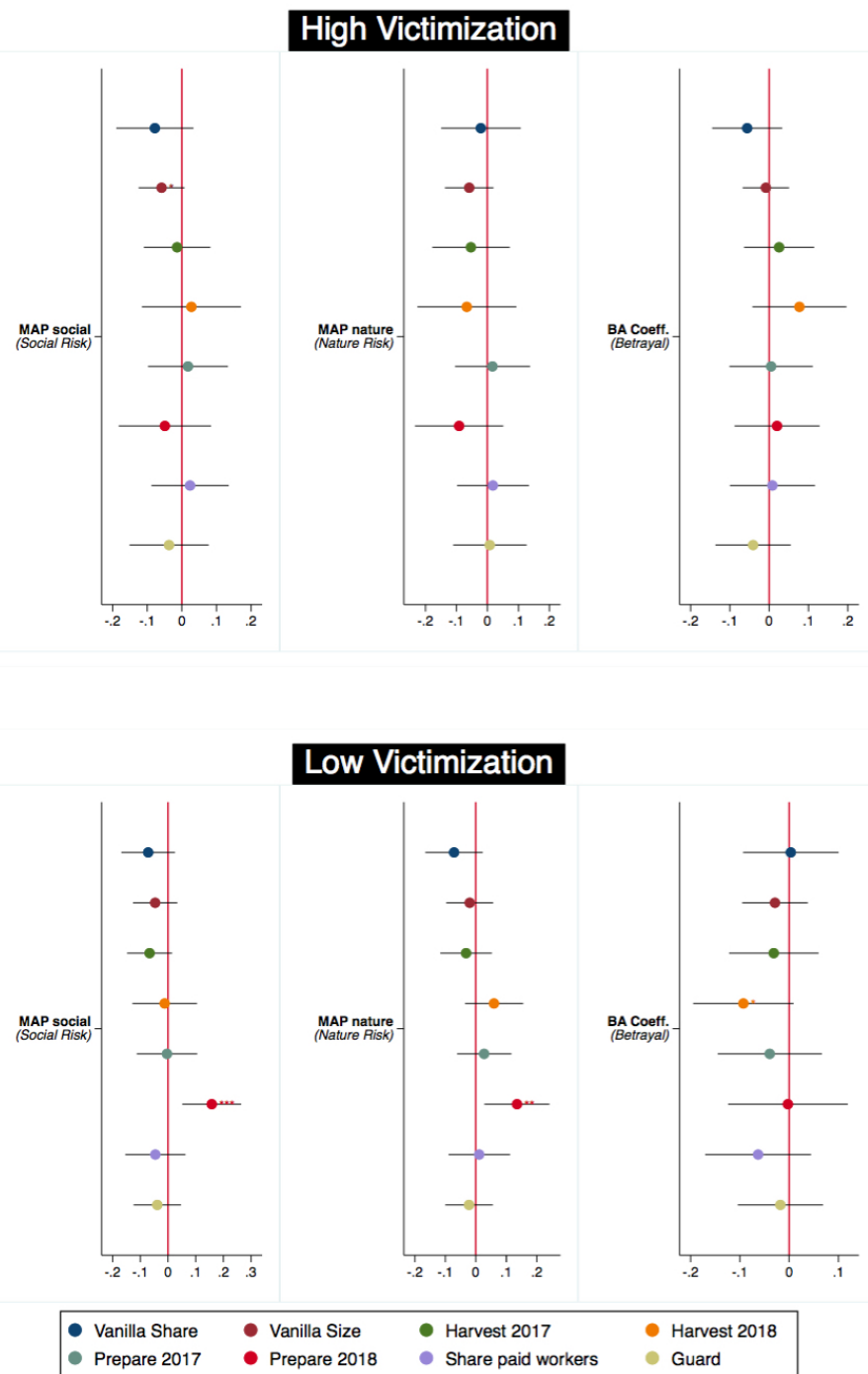

Notes: The figure presents the coefficients from linear regressions and the $95 \%$ confidence intervals. We divided the sample based on the mean of the Victimization- $i 2017$ variable $(\mathrm{M}=0.222)$. The regression models on the outcome variables Vanilla Share, Vanilla Size, and Guard include the whole sample of $\mathrm{N}=760$. The estimation models of the outcome variables Harvest 2017 and Prepare 2017 have sample of $\mathrm{N}=484$ that corresponds to old vanilla farmers. The variables Harvest 2018, Prepare 2018 and Share paid labor have different sample sizes because of attrition or because farmers do not have any labor force $\left(\mathrm{N}=464, \mathrm{~N}=467\right.$, and $\mathrm{N}=630$, respectively). ${ }^{*} p<0.10,{ }^{* *} p<0.05,{ }^{* * *} p<0.01$.

In sum, we find that social risks relate better to some of the production decisions farmers make than the pure risk aversion. Aversion to taking social risk is associate with significantly lower income for farmers, and areas with a high prevalence of crime are particularly susceptible to be affected by aversion to social risk.

\footnotetext{
${ }^{19}$ The results hold when dividing the sample by the median value (Median=0.193).
} 


\subsection{Robustness checks}

Most of the studies measuring betrayal aversion use a between-subject design as they argue that people tended to anchor on the first game presented (e.g Bohnet et al., 2008). In each experimental session, we randomized the order of the games to control for this. In some sessions, the Social RIsk game was played first than the NATURE Risk game, and in others the opposite. From our sample of 760 participants, 51 percent played the SocIAL RISK game first and 49 percent the NATURE RISK game. In the analysis, we include session fixed effects in the analysis to account for the differences.

Yet, by conducting an orthogonality test, we find that while there are no significant differences in the MAP social when the SocIAL RISK game is played first or not, we do find significant differences for the MAP nature. Participants playing the NATURE RISK game first report higher MAP than those who played it after the SocIAL RISK game. This naturally affects the magnitude and sign of the betrayal coefficient, which on average becomes negative. Yet, we do still find that betrayal neutral individuals represent the largest share in our sample with about 40 percent of the total sample (see Table 3.A5). For the second part of our main analysis, we find that the MAP nature cannot predict our production and commercialization variables. Yet, to increase robustness in our results, we conduct an extra analysis by doing a sample split between farmers who played the Social Risk game before or after the NATURE Risk game and analyze whether there are differences in our main analysis predictions. Figure 3.7 presents the point estimates, and Table 3.A6 the coefficients in standard deviations and p-values.

As shown, most of the results do not change when considering the total sample. Yet, the order of the Social Risk and NATURE RISK games matter in terms of significance for the variables where we previously find significant effects (i.e. share of total land dedicated to vanilla and average size of vanilla plantations). However, we still observe that the results have the same direction and magnitude. Overall, the MAP social better relates to the production decisions farmers make. The less willing a farmer is to take social risks, the higher the losses she confronts.

An additional concern of our research is the attrition between the baseline and the two follow-up surveys. In section 3.4, we discuss that about 12 percent of our sample does not participate in both follow-up surveys. We further discuss the different reasons why participants could not take part. As an additional robustness check, we test whether the likelihood to participate can be explained by our measure of betrayal aversion or by socioeconomic variables. As shown in Table 3.A7, we find no evidence that betrayal aversion attitudes or social and economic variables can explain attrition. 
Figure 3.7: Analysis on game played first

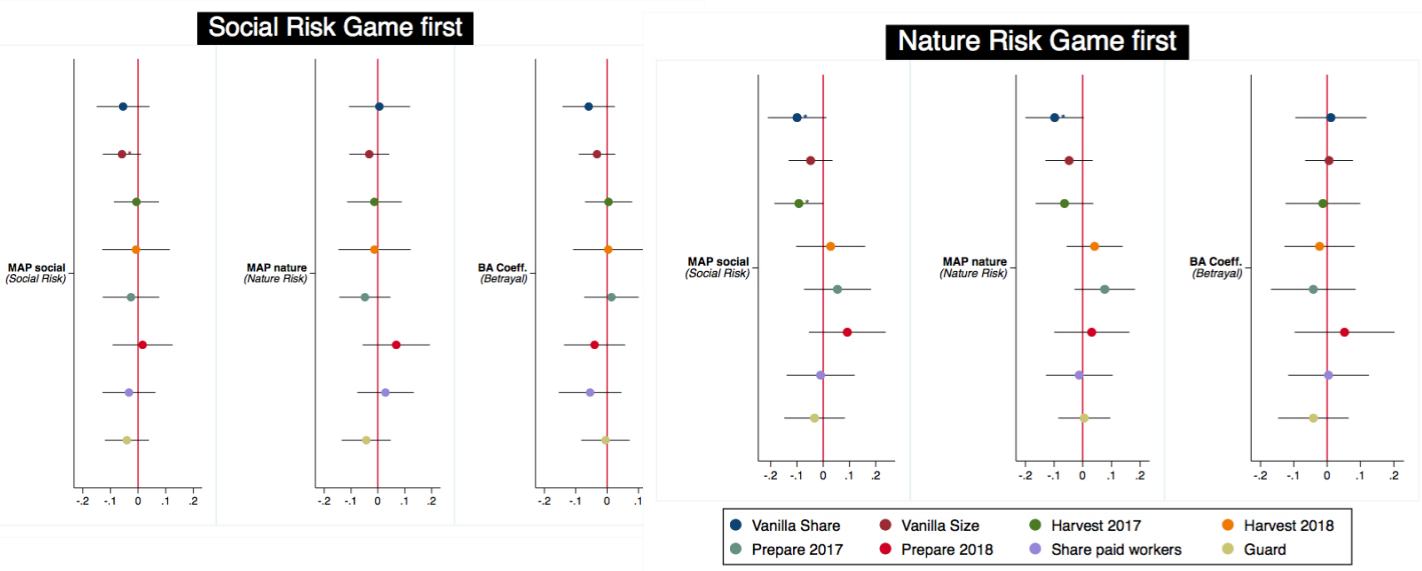

Notes: The figure presents the coefficients from linear regressions and the $95 \%$ confidence intervals. The heterogeneous effect analysis was conducted based on the game that participants played first, either the Social Risk game or the NATURE Risk game. The sample is divided accordingly. The regression models on the outcome variables Vanilla Share, Vanilla Size, and Guard include the whole sample of $\mathrm{N}=760$. The estimation models of the outcome variables Harvest 2017 and Prepare 2017 have sample of $\mathrm{N}=484$ that corresponds to old vanilla farmers. The variables Harvest 2018, Prepare 2018 and Share paid labor have different sample sizes because of attrition or because farmers do not have any labor force $(\mathrm{N}=464, \mathrm{~N}=467$, and $\mathrm{N}=630$, respectively).

${ }^{*} p<0.10,{ }^{* *} p<0.05,{ }^{* * *} p<0.01$.

\subsection{Discussion and Conclusion}

This paper tests whether farmers are averse to betrayal and whether this trait could influence their production and commercialization decisions. We elicit betrayal aversion using the method by Quercia (2016) using a within-subject design. We conducted our study in northeastern Madagascar, at the heart of vanilla production. One of the main challenges farmers face in the study region is crop theft. Anecdotal evidence shows that the perpetrators are from the same village and can be closely related to farmers. Besides the social risks that farmers confront in this area, they are also exposed to extreme weather shocks, cyclones that hit the study region.

Our research is novel in that we are the first to measure betrayal attitudes of a non-WEIRD subject pool that allows us to relate this attitude to production and commercialization decisions. Previous studies have only elicited betrayal aversion but did not study the potential economic consequences of such preferences.

Contrary to previous studies with standard subject pools, we do not find evidence that individuals are, on average betrayal averse. There is heterogeneity in betrayal aversion preferences, and we do find all different betrayal types in our sample: 40 percent are neutral, 30 percent are averse, and 30 percent are betrayal seeking. We use the within-subject design to construct an individual measure of betrayal aversion, instead of having a pooled measure with a between-subject design method. In addition, by using a within-subject 
design, we control for individual differences. However, we acknowledge that most of the studies measuring betrayal aversion use a between-subject design as they argue that people tended to anchor on the first game presented (Bohnet et al., 2008). In our analysis, we control for the order that the games were played by adding session fixed effects. As a robustness check, we perform a sample split between participants who played the SocIAL RISK game or the NATURE RISK game first. By calculating the average MAPs, we observe that while there are no significant differences in the $\overline{M A P}$ social, there are significant differences in the $\overline{M A P}$ nature. Participants who played the NATURE Risk game first have on average a higher MAP than those who played it after the SocIAL RISK game. While this difference in the MAP nature slightly changes the overall betrayal aversion coefficient, the share of betrayal neutral participants remains the largest in the sample, with 40 percent of participants.

When exploring whether socioeconomic characteristics may explain betrayal aversion attitudes, we find that older and less educated participants are less likely to be betrayal neutral. We further include in the analysis self-reported victimization and victimization reported by others, we find that criminality is associated with a lower likelihood to display betrayal aversion attitudes.

Moreover, as pointed out by Bohnet \& Zeckhauser (2004) and Bohnet et al. (2008) there might be as well other factors, for instance loss aversion, that are in principle not related to betrayal aversion but that could explain the behavior taken of participants in the social risk and natural risk games when stating the MAP. Hong \& Bohnet (2007) also discuss the potential effects of aversion to inequality as people dislike being worse-off compared to others. Aimone \& Houser (2012) complements this by adding the dis-utility from the loss of control that uncertainties can create, as well as the cost of doing wrong assessments about the actions of others. In this paper, we measure and control for inequality aversion but not for the other factors because the probabilities of obtaining good or bad outcomes are the same in both the SOCIAL RISK and NATURE RISK games, and they are known by participants at the point of making the decision. In our experiment, participants are exposed to the same level of risk under both games; therefore, this does not apply as they could not have more control in one or the other.

Second, we find that farmers who avoid taking social risks tend to have on average less vanilla plantations as a share of their total land and smaller vanilla plantations than those who are more willing to take social risks. These inefficient production decisions lead farmers to have lower profits as they cannot increase their yield. Various factors, including self-serving biases and strategic motives, could affect the information reported by farmers, especially in providing sensitive information such as their production and commercialization decisions. Yet, our production variables are similar to what other institutions have reported after collecting data in the same region (Hänke et al., 2018; Fairtrade International, 2019). To further explore our results, we conduct a heterogeneity analysis in which we use victimization reported by others in 2017 as the heterogeneous factor. We find similar results 
as in our main analysis when dividing the sample into exposure to high or low victimization. Farmers exposed to high victimization environments and are less willing to take social risks have on average smaller vanilla plantations.

Moreover, since we find that the MAP nature is significantly different when the NATURE RISK game is played first, we do a robustness check by doing a similar analysis as before but dividing the sample according to the order of the games played. We find similar results as in our main analysis in that the MAP social can explain farmers' production decisions that are detrimental to their income. However, we also show that the order of the games matters in estimating the relation between betrayal aversion attitudes and decision-making. Overall, this work shows that while farmers have on average neutral attitudes towards betrayal, certain production decisions can be affected by their avoidance of taking social risks, which endangers their long-term livelihoods. Acquiring new land to cultivate vanilla or expanding the size of the current ones, is not only costly but it is also a long-term investment given the characteristics of vanilla production. Other variables such as harvest time, labor force paid, or guarding would be easier to change from one harvest to the next. A limitation that could arise from the elicitation method we employ is whether the MAP measures are random or not. MAPs are calculated by taking the middle point between the last probability for which the participants chose the risky option and the first one when they chose the safe option. For this reason, one could imagine that farmers make several turning points or that they randomly select one. Yet, in the instructions, we explained with different examples that they should only make one turning point. We do not observe in our sample that participants have different turning points, and none of the observations is excluded for this reason. In addition, the MAPs from the SocIAL Risk and NATURE RISK games are highly correlated (Pearson correlation is 0.57 , with p-value $<0.001$ ), which gives us fewer reasons to believe that the turning points were made at random. We find a similar result when excluding participants whose betrayal aversion coefficient is equal to zero (Pearson correlation is 0.35 , with p-value $<0.001$ ).

We find it relevant to conduct this study in Madagascar because it is one of the most vulnerable countries in the world, and because farmers confront both social and nature risks. In addition, the recent price spike creates new social and economic relationships between the smallholders (Neimark et al., 2019). Yet, our experimental design can be implemented in similar contexts as vanilla is not the only high-value commodity connected to criminality. It is possible to find similar scenarios around the world when looking at the production of diamonds (Billon, 2008), avocado (Grillo, 2020; Frazier, 2018), and other fruits and vegetables (Dyer, 2020). While not much is known about criminality in the rural areas of developing countries, often because of the lack of reliable data, our results could be tested in other countries, such as Kenya or Paraguay, where farmers face similar constraints. 


\subsection{Appendices}

\subsubsection{Appendix A - Tables}

Table 3.A1: Other studies: Betrayal aversion coefficients and individual types

\begin{tabular}{llccc}
\hline Study & Outcome & N & Result & Design \\
\hline \hline Bohnet et al. (2008) & Betrayal Aversion Coeff. & 833 & 0.15 & Between Subjects \\
\hline Aimone et al. (2015) & Betrayal Aversion Coeff. & 56 & 0.04 & Within Subject \\
& Betrayal Averse ind. (\%) & & 44.6 & \\
& Betrayal Loving ind. (\%) & 32.1 & \\
& Betrayal Neutral ind. (\%) & 23.2 & \\
\hline Quercia (2016) & Betrayal Aversion Coeff. & 209 & 0.04 (OP) & Between \\
& & & 0.07 (CL) & \\
\hline \multirow{2}{*}{ Koppel et al. (2017) } & Betrayal Aversion Coeff. & 82 & -0.005 (Treat.) & Within Subject \\
& Betrayal Averse ind. (\%) & & 0.26 & Treatment \\
& Betrayal Neutral ind. (\%) & 0.46 & Treatment \\
& Betrayal Loving ind. (\%) & 0.29 & Treatment \\
& Betrayal Aversion Coeff. & 0.017 (Control) & \\
& Betrayal Averse ind. (\%) & 0.35 & Control \\
& Betrayal Neutral ind. (\%) & 0.43 & Control \\
& Betrayal Loving ind. (\%) & 0.22 & Control \\
\hline
\end{tabular}


Table 3.A2: Determinants Betrayal Aversion

\begin{tabular}{|c|c|c|c|}
\hline & \multicolumn{3}{|c|}{ Betrayal Aversion Coefficient } \\
\hline & $\begin{array}{c}(1) \\
\text { Model } 1\end{array}$ & $\begin{array}{c}(2) \\
\text { Model } 2\end{array}$ & $\begin{array}{c}(3) \\
\text { Model } 3\end{array}$ \\
\hline Female $(0-1)$ & $\begin{array}{c}0.0023 \\
(0.0161)\end{array}$ & $\begin{array}{c}0.0024 \\
(0.0161)\end{array}$ & $\begin{array}{c}0.0041 \\
(0.0203)\end{array}$ \\
\hline Age in years & $\begin{array}{c}-0.0004 \\
(0.0005)\end{array}$ & $\begin{array}{l}-0.0004 \\
(0.0005)\end{array}$ & $\begin{array}{l}-0.0005 \\
(0.0006)\end{array}$ \\
\hline Married (0-1) & $\begin{array}{l}-0.0098 \\
(0.0171)\end{array}$ & $\begin{array}{l}-0.0097 \\
(0.0171)\end{array}$ & $\begin{array}{l}-0.0173 \\
(0.0213)\end{array}$ \\
\hline Total of children in $\mathrm{HH}$ & $\begin{array}{l}-0.0018 \\
(0.0030)\end{array}$ & $\begin{array}{l}-0.0018 \\
(0.0030)\end{array}$ & $\begin{array}{c}-0.0051 \\
(0.0038)\end{array}$ \\
\hline No. years of school completed & $\begin{array}{c}0.0003 \\
(0.0019)\end{array}$ & $\begin{array}{c}0.0003 \\
(0.0019)\end{array}$ & $\begin{array}{l}-0.0001 \\
(0.0024)\end{array}$ \\
\hline New vanilla farmer $(0-1)$ & $\begin{array}{l}-0.0062 \\
(0.0128)\end{array}$ & $\begin{array}{l}-0.0067 \\
(0.0129)\end{array}$ & \\
\hline Inequality aversion & $\begin{array}{c}-0.0157 \\
(0.0170)\end{array}$ & $\begin{array}{l}-0.0157 \\
(0.0170)\end{array}$ & $\begin{array}{c}-0.0326 \\
(0.0230)\end{array}$ \\
\hline Victimization $-i$ & & $\begin{array}{c}0.0084 \\
(0.0529)\end{array}$ & \\
\hline Victim of green vanilla theft in $2017(0-1)$ & & & $\begin{array}{l}-0.0037 \\
(0.0179)\end{array}$ \\
\hline Constant & $\begin{array}{c}0.0080 \\
(0.0529)\end{array}$ & $\begin{array}{c}0.0086 \\
(0.0530)\end{array}$ & $\begin{array}{c}0.0695 \\
(0.0749)\end{array}$ \\
\hline Observations & 760 & 760 & 499 \\
\hline Adjusted $R^{2}$ & 0.024 & 0.023 & 0.045 \\
\hline Controls & Yes & Yes & Yes \\
\hline
\end{tabular}

Notes: Estimations include session fixed effects. Column (3) has a reduced sample as only those farmers who are not new can experience green vanilla theft. The victimization variable is standardized. Robust standard errors in parenthesis. ${ }^{*} p<0.10,{ }^{* *} p<0.05$, $* * * p<0.01$. 
Table 3.A3: Regression Coefficients

\begin{tabular}{|c|c|c|c|c|c|c|c|}
\hline \multirow[b]{2}{*}{ Variable } & \multirow[b]{2}{*}{$\mathrm{N}$} & \multicolumn{2}{|c|}{ MAP Social } & \multicolumn{2}{|c|}{ MAP Nature } & \multicolumn{2}{|c|}{ BA. Coefficient } \\
\hline & & Coeff. & $\begin{array}{c}\text { p-value } \\
\text { [q-value] }\end{array}$ & Coeff. & $\begin{array}{c}\text { p-value } \\
\text { [q-value] }\end{array}$ & Coeff. & $\begin{array}{c}\text { p-value } \\
\text { [q-value] }\end{array}$ \\
\hline Share of total land with vanilla & 760 & -0.075 & $\begin{array}{c}0.042 \\
{[0.362]}\end{array}$ & -0.052 & $\begin{array}{c}0.180 \\
{[1.000]}\end{array}$ & -0.026 & $\begin{array}{c}0.432 \\
{[1.000]}\end{array}$ \\
\hline Average size vanilla plantation & 760 & -0.051 & $\begin{array}{c}0.059 \\
{[0.362]}\end{array}$ & -0.037 & $\begin{array}{c}0.192 \\
{[1.000]}\end{array}$ & -0.016 & $\begin{array}{c}0.481 \\
{[1.000]}\end{array}$ \\
\hline Month of green vanilla harvest 2017 & 484 & -0.042 & $\begin{array}{c}0.182 \\
{[0.468]}\end{array}$ & -0.037 & $\begin{array}{c}0.306 \\
{[1.000]}\end{array}$ & -0.007 & $\begin{array}{c}0.836 \\
{[1.000]}\end{array}$ \\
\hline Harvested vanilla before market opening in 2018 & 464 & 0.002 & $\begin{array}{c}0.956 \\
{[0.849]}\end{array}$ & 0.010 & $\begin{array}{c}0.808 \\
{[1.000]}\end{array}$ & -0.008 & $\begin{array}{c}0.840 \\
{[1.000]}\end{array}$ \\
\hline Farmer prepared vanilla in 2017 & 484 & 0.005 & $\begin{array}{c}0.893 \\
{[0.849]}\end{array}$ & 0.012 & $\begin{array}{c}0.588 \\
{[1.000]}\end{array}$ & -0.014 & $\begin{array}{c}0.705 \\
{[1.000]}\end{array}$ \\
\hline Farmer prepare vanilla in 2018 & 467 & 0.045 & $\begin{array}{c}0.255 \\
{[0.556]}\end{array}$ & 0.039 & $\begin{array}{c}0.334 \\
{[1.000]}\end{array}$ & 0.007 & $\begin{array}{c}0.858 \\
{[1.000]}\end{array}$ \\
\hline Share of paid labor compared to total labor & 630 & -0.019 & $\begin{array}{c}0.623 \\
{[0.862]}\end{array}$ & 0.012 & $\begin{array}{c}0.759 \\
{[1.000]}\end{array}$ & -0.031 & $\begin{array}{c}0.434 \\
{[1.000]}\end{array}$ \\
\hline Guards the vanilla plantations & 760 & -0.032 & $\begin{array}{c}0.347 \\
{[0.681]}\end{array}$ & -0.010 & $\begin{array}{c}0.765 \\
{[1.000]}\end{array}$ & -0.023 & $\begin{array}{c}0.464 \\
{[1.000]}\end{array}$ \\
\hline \multicolumn{2}{|l|}{ Socioeconomic Controls } & Yes & 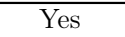 & Yes & Yes & Yes & Yes \\
\hline \multicolumn{2}{|l|}{ Fixed Effects } & Yes & Yes & Yes & Yes & Yes & Yes \\
\hline \multicolumn{8}{|c|}{ 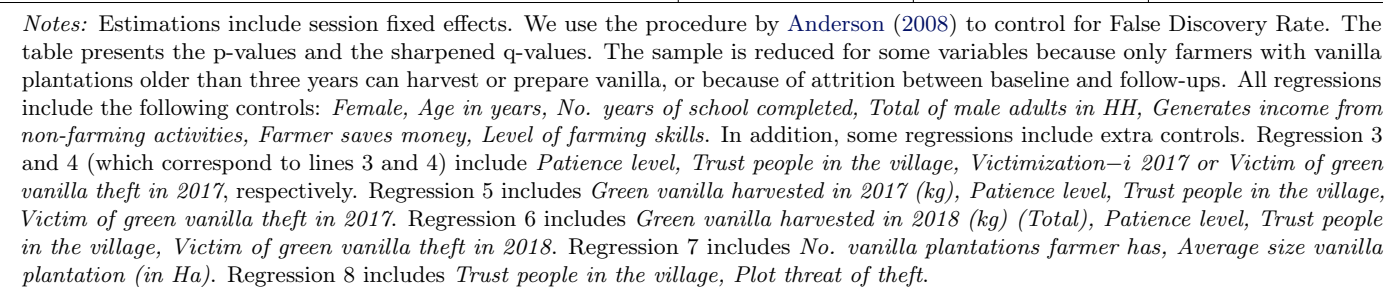 } \\
\hline
\end{tabular}

Table 3.A4: Regression Coefficients High and Low Victimization

\begin{tabular}{|c|c|c|c|c|c|c|c|}
\hline \multirow{2}{*}{ Variable } & \multirow{2}{*}{$\mathrm{N}$} & \multicolumn{2}{|c|}{ MAP Social } & \multicolumn{2}{|c|}{ MAP Nature } & \multicolumn{2}{|c|}{ BA. Coefficient } \\
\hline & & Coeff. & $\mathrm{p}$-value & Coeff. & p-value & Coeff. & $\mathrm{p}$-value \\
\hline \multicolumn{8}{|l|}{ Panel A: High Victimization } \\
\hline Share of total land with vanilla & 303 & -0.081 & 0.170 & -0.022 & 0.746 & -0.060 & 0.218 \\
\hline Average size vanilla plantation & 303 & -0.093 & 0.083 & -0.092 & 0.143 & -0.014 & 0.781 \\
\hline Month of green vanilla harvest 2017 & 205 & -0.015 & 0.778 & -0.055 & 0.401 & 0.030 & 0.575 \\
\hline Harvested vanilla before market opening in 2018 & 192 & 0.027 & 0.703 & -0.063 & 0.412 & 0.080 & 0.205 \\
\hline Farmer prepared vanilla in 2017 & 205 & 0.020 & 0.761 & 0.017 & 0.789 & 0.006 & 0.926 \\
\hline Farmer prepare vanilla in 2018 & 195 & -0.047 & 0.469 & -0.081 & 0.209 & 0.021 & 0.715 \\
\hline Share of paid labor compared to total labor & 248 & 0.027 & 0.676 & 0.019 & 0.762 & 0.010 & 0.880 \\
\hline Guards the vanilla plantations & 303 & -0.035 & 0.525 & 0.007 & 0.898 & -0.040 & 0.402 \\
\hline \multicolumn{8}{|l|}{ Panel B: Low Victimization } \\
\hline Share of total land with vanilla & 457 & -0.070 & 0.147 & -0.071 & 0.138 & 0.003 & 0.944 \\
\hline Average size vanilla plantation & 457 & -0.034 & 0.255 & -0.017 & 0.612 & -0.023 & 0.399 \\
\hline Month of green vanilla harvest 2017 & 279 & -0.062 & 0.109 & -0.032 & 0.461 & -0.029 & 0.500 \\
\hline Harvested vanilla before market opening in 2018 & 272 & -0.012 & 0.839 & 0.065 & 0.216 & -0.094 & 0.074 \\
\hline Farmer prepared vanilla in 2017 & 279 & -0.003 & 0.946 & 0.027 & 0.543 & -0.037 & 0.465 \\
\hline Farmer prepare vanilla in 2018 & 272 & 0.135 & 0.004 & 0.122 & 0.013 & -0.002 & 0.969 \\
\hline Share of paid labor compared to total labor & 382 & -0.042 & 0.409 & 0.011 & 0.825 & -0.057 & 0.250 \\
\hline Guards the vanilla plantations & 457 & -0.041 & 0.375 & -0.023 & 0.580 & -0.018 & 0.687 \\
\hline \multirow{2}{*}{\multicolumn{2}{|c|}{$\begin{array}{l}\text { Socioeconomic Controls } \\
\text { Fixed Effects }\end{array}$}} & Yes & Yes & Yes & Yes & Yes & Yes \\
\hline & & Yes & Yes & Yes & Yes & Yes & Yes \\
\hline \multicolumn{8}{|c|}{$\begin{array}{l}\text { Notes: Estimations include session fixed effects. The sample is split in high and low victimization according to the mean of the } \\
\text { Victimization- } i 2017 \text { variable }(\mathrm{M}=0.222 \text { ). The sample is reduced for some variables because only farmers with vanilla plantations } \\
\text { older than three years can harvest or prepare vanilla, or because of attrition between baseline and follow-ups. All regressions } \\
\text { include the following controls: Female, Age in years, No. years of school completed, Total of male adults in HH, Generates income } \\
\text { from non-farming activities, Farmer saves money, Level of farming skills. In addition, some regressions include extra controls. } \\
\text { Regression } 3 \text { and } 4 \text { (which correspond to lines } 3 \text { and } 4 \text { include Patience level, Trust people in the village. Regression } 5 \text { includes } \\
\text { Green vanilla harvested in } 2017 \text { (kg), Patience level, Trust people in the village. Regression } 6 \text { includes Green vanilla harvested in } \\
2018 \text { (kg) (Total), Patience level, Trust people in the village. Regression } 7 \text { includes No. vanilla plantations farmer has, Average } \\
\text { size vanilla plantation (in Ha). Regression } 8 \text { includes Trust people in the village. }\end{array}$} \\
\hline
\end{tabular}


Table 3.A5: Orthogonality Table by order of SocIAL RISK game

\begin{tabular}{lccc}
\hline \hline & $(1)$ & $(2)$ & $(3)$ \\
& First NATURE RISK game & First Social RISK game & p-value \\
\hline MAP social & 0.465 & 0.455 & 0.418 \\
& $(0.008)$ & $(0.009)$ & 0.003 \\
MAP nature & 0.483 & 0.446 & 0.020 \\
Betrayal Aversion Coeff. & $(0.009)$ & $(0.008)$ & 0.050 \\
Betrayal Averse Individual (0-1) & -0.018 & 0.009 & \multirow{2}{*}{0.076} \\
Betrayal Loving (0-1) & $(0.008)$ & $0.009)$ & \\
& 0.264 & $(0.024)$ & 0.864 \\
Betrayal Neutral (0-1) & $(0.023)$ & 0.267 & $(0.022)$ \\
\end{tabular}

Notes: Column (3) shows the p-values from a joint orthogonality test of treatment arms. Standard errors in parenthesis.

Table 3.A6: Regression Coefficients Order of the Games

\begin{tabular}{|c|c|c|c|c|c|c|c|}
\hline \multirow{2}{*}{ Variable } & \multirow{2}{*}{$\mathrm{N}$} & \multicolumn{2}{|c|}{ MAP Social } & \multicolumn{2}{|c|}{ MAP Nature } & \multicolumn{2}{|c|}{ BA. Coefficient } \\
\hline & & Coeff. & p-value & Coeff. & p-value & Coeff. & \\
\hline \multicolumn{8}{|l|}{ Panel A: Social Risk First } \\
\hline Share of total land with vanilla & 389 & -0.057 & 0.266 & 0.006 & 0.919 & -0.061 & 0.168 \\
\hline Average size vanilla plantation & 389 & -0.084 & 0.099 & -0.043 & 0.401 & -0.046 & 0.278 \\
\hline Month of green vanilla harvest 2017 & 260 & -0.007 & 0.883 & -0.013 & 0.802 & 0.005 & 0.903 \\
\hline Harvested vanilla before market opening in 2018 & 247 & -0.007 & 0.904 & -0.012 & 0.855 & 0.004 & 0.950 \\
\hline Farmer prepared vanilla in 2017 & 260 & -0.027 & 0.620 & -0.048 & 0.322 & 0.015 & 0.753 \\
\hline Farmer prepare vanilla in 2018 & 251 & 0.016 & 0.765 & 0.061 & 0.283 & -0.039 & 0.421 \\
\hline Share of paid labor compared to total labor & 331 & -0.036 & 0.499 & 0.029 & 0.596 & -0.059 & 0.287 \\
\hline Guards the vanilla plantations & 389 & -0.044 & 0.319 & -0.044 & 0.353 & -0.006 & 0.894 \\
\hline \multicolumn{8}{|l|}{ Panel B: Nature Risk First } \\
\hline Share of total land with vanilla & 371 & -0.094 & 0.081 & -0.099 & 0.060 & 0.011 & 0.835 \\
\hline Average size vanilla $\mathrm{p}$ & 371 & -0.037 & 0.260 & -0.039 & 0.258 & 0.004 & 0.874 \\
\hline Month of green vanilla harvest 2017 & 224 & -0.082 & 0.052 & -0.062 & 0.214 & -0.012 & 0.823 \\
\hline Harvested vanilla before market opening in 2018 & 217 & 0.030 & 0.671 & 0.046 & 0.404 & -0.024 & 0.674 \\
\hline Farmer prepared vanilla in 2017 & 224 & 0.051 & 0.401 & 0.079 & 0.154 & -0.040 & 0.520 \\
\hline Farmer prepare vanilla in 2018 & 216 & 0.076 & 0.218 & 0.028 & 0.637 & 0.044 & 0.493 \\
\hline Share of paid labor compared to total labor & 299 & -0.009 & 0.881 & -0.012 & 0.836 & 0.004 & 0.946 \\
\hline Guards the vanilla plantations & 371 & -0.030 & 0.575 & 0.005 & 0.910 & -0.037 & 0.444 \\
\hline \multirow{2}{*}{\multicolumn{2}{|c|}{$\begin{array}{l}\text { Socioeconomic Controls } \\
\text { Fixed Effects }\end{array}$}} & Yes & Yes & Yes & Yes & Yes & Yes \\
\hline & & Yes & Yes & Yes & Yes & Yes & Yes \\
\hline \multicolumn{8}{|c|}{ 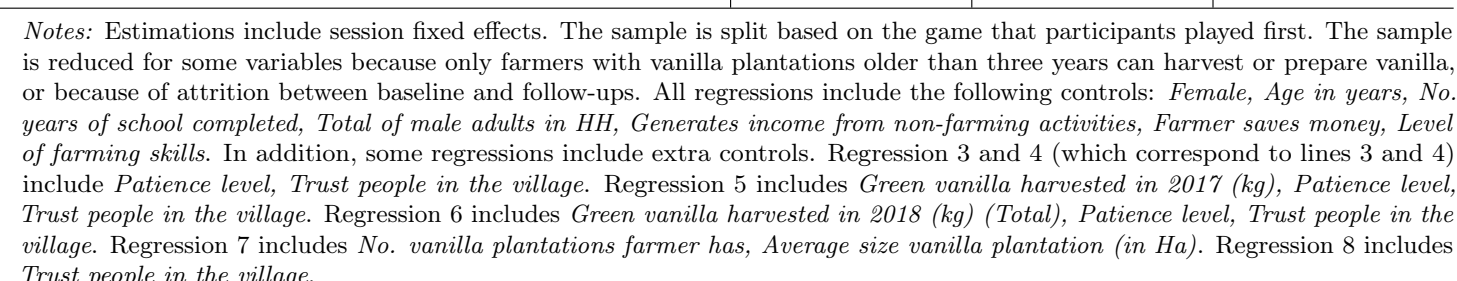 } \\
\hline
\end{tabular}


Table 3.A7: Attrition

\begin{tabular}{lc}
\hline \hline & $(1)$ \\
& Farmer not \\
\hline Betrayal Aversion Coeff. & 0.021 \\
& $(0.075)$ \\
Female & -0.016 \\
& $(0.026)$ \\
Years of experience in farming vanilla 1 or 2 \\
No. years of school completed & -0.001 \\
& $(0.001)$ \\
Generates income from non-farming activities & 0.004 \\
& $(0.004)$ \\
Farmer saves money (0-1) & -0.020 \\
& $(0.026)$ \\
Level of farming skills & 0.016 \\
& $(0.027)$ \\
Constant & 0.003 \\
& $(0.026)$ \\
Observations & 0.132 \\
Fixed Effects & $(0.095)$ \\
\hline \hline
\end{tabular}

Notes: Session fixed effects. Robust standard errors in parenthesis. ${ }^{*} p<0.10,{ }^{* *} p<0.05,{ }^{* * *} p<0.01$.

\subsubsection{Appendix B - Figures}

Figure 3.B1: SAVA region in Madagascar

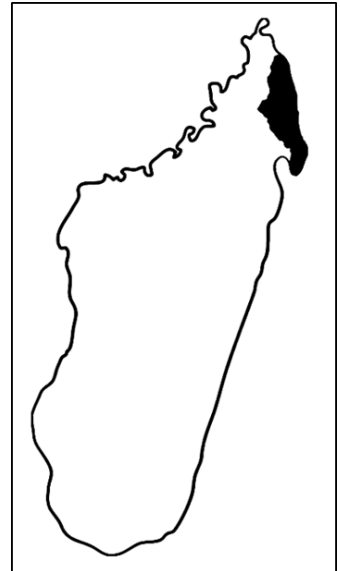


Figure 3.B2: Social Risk Game

\begin{tabular}{|c|c|c|c|c|c|}
\hline Group & $\begin{array}{l}\text { If you give the product to } \\
\text { DELEGATES A you earn: }\end{array}$ & $\begin{array}{l}\text { If you give the product to DELEGATES } \\
\text { confront: }\end{array}$ & Byou & & $\begin{array}{l}\text { ethe } \\
\text { Itct to: }\end{array}$ \\
\hline B0 & $4.000 \mathrm{Ar}$ & 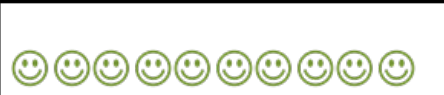 & $\begin{array}{l}1.000 \mathrm{Ar} \\
9.000 \mathrm{Ar}\end{array}$ & A & B \\
\hline B1 & $4.000 \mathrm{Ar}$ & 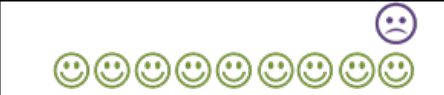 & $\begin{array}{l}1.000 \mathrm{Ar} \\
9.000 \mathrm{Ar}\end{array}$ & A & B \\
\hline B2 & 4.000 Ar & 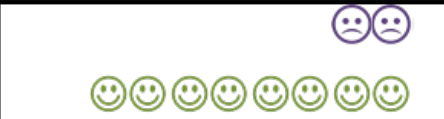 & $\begin{array}{l}1.000 \mathrm{Ar} \\
9.000 \mathrm{Ar}\end{array}$ & A & B \\
\hline B3 & $4.000 \mathrm{Ar}$ & 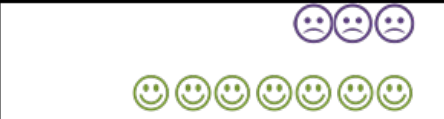 & $\begin{array}{l}1.000 \mathrm{Ar} \\
9.000 \mathrm{Ar}\end{array}$ & A & B \\
\hline B4 & 4.000 Ar & 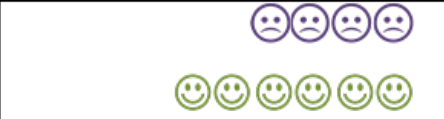 & $\begin{array}{l}1.000 \mathrm{Ar} \\
9.000 \mathrm{Ar}\end{array}$ & A & B \\
\hline B5 & $4.000 \mathrm{Ar}$ & 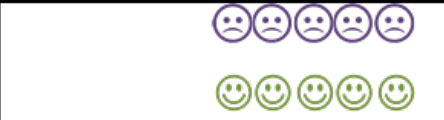 & $\begin{array}{l}1.000 \mathrm{Ar} \\
9.000 \mathrm{Ar}\end{array}$ & A & B \\
\hline B6 & $4.000 \mathrm{Ar}$ & 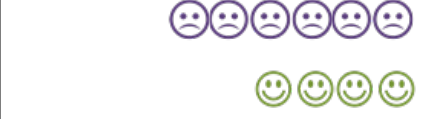 & $\begin{array}{l}1.000 \mathrm{Ar} \\
9.000 \mathrm{Ar}\end{array}$ & A & B \\
\hline B7 & $4.000 \mathrm{Ar}$ & $\begin{array}{r}\odot \odot \odot \odot \odot \odot \odot \\
\odot \odot \odot)\end{array}$ & $\begin{array}{l}1.000 \mathrm{Ar} \\
9.000 \mathrm{Ar}\end{array}$ & A & B \\
\hline B8 & 4.000 Ar & 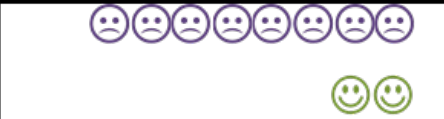 & $\begin{array}{l}1.000 \mathrm{Ar} \\
9.000 \mathrm{Ar}\end{array}$ & A & B \\
\hline B9 & $4.000 \mathrm{Ar}$ & 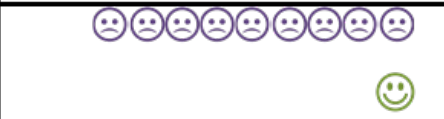 & $\begin{array}{l}1.000 \mathrm{Ar} \\
9.000 \mathrm{Ar}\end{array}$ & A & B \\
\hline B10 & $4.000 \mathrm{Ar}$ & 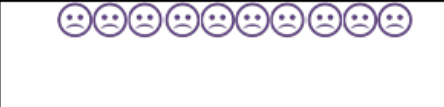 & $\begin{array}{l}1.000 \mathrm{Ar} \\
9.000 \mathrm{Ar}\end{array}$ & A & B \\
\hline
\end{tabular}


Figure 3.B3: Nature Risk Game

\begin{tabular}{|c|c|c|c|c|}
\hline Group & $\begin{array}{l}\text { If you give the product to } \\
\text { DELEGATES A you earn: }\end{array}$ & $\begin{array}{l}\text { If you give the product to DELEGATES B you } \\
\text { confront: }\end{array}$ & & $\begin{array}{l}\text { the } \\
\text { ct to: }\end{array}$ \\
\hline B0 & $4.000 \mathrm{Ar}$ & $\begin{array}{l}1.000 \mathrm{Ar} \\
9.000 \mathrm{Ar}\end{array}$ & A & B \\
\hline B1 & $4.000 \mathrm{Ar}$ & $\begin{array}{l}1.000 \mathrm{Ar} \\
9.000 \mathrm{Ar}\end{array}$ & A & B \\
\hline B2 & $4.000 \mathrm{Ar}$ & $\begin{array}{l}1.000 \mathrm{Ar} \\
9.000 \mathrm{Ar}\end{array}$ & A & B \\
\hline B3 & $4.000 \mathrm{Ar}$ & $\begin{array}{l}1.000 \mathrm{Ar} \\
9.000 \mathrm{Ar}\end{array}$ & A & B \\
\hline B4 & $4.000 \mathrm{Ar}$ & $\begin{array}{l}1.000 \mathrm{Ar} \\
9.000 \mathrm{Ar}\end{array}$ & A & B \\
\hline B5 & $4.000 \mathrm{Ar}$ & $\begin{array}{l}1.000 \mathrm{Ar} \\
9.000 \mathrm{Ar}\end{array}$ & A & B \\
\hline B6 & $4.000 \mathrm{Ar}$ & $\begin{array}{l}1.000 \mathrm{Ar} \\
9.000 \mathrm{Ar}\end{array}$ & A & B \\
\hline B7 & $4.000 \mathrm{Ar}$ & $\begin{array}{l}1.000 \mathrm{Ar} \\
9.000 \mathrm{Ar}\end{array}$ & A & B \\
\hline B8 & $4.000 \mathrm{Ar}$ & $\begin{array}{l}1.000 \mathrm{Ar} \\
9.000 \mathrm{Ar}\end{array}$ & A & B \\
\hline B9 & $4.000 \mathrm{Ar}$ & $\begin{array}{l}1.000 \mathrm{Ar} \\
9.000 \mathrm{Ar}\end{array}$ & A & B \\
\hline B10 & $4.000 \mathrm{Ar}$ & $\begin{aligned} 1.000 \mathrm{Ar} \\
9.000 \mathrm{Ar}\end{aligned}$ & A & B \\
\hline
\end{tabular}

Figure 3.B4: Price development of green vanilla harvest 2017

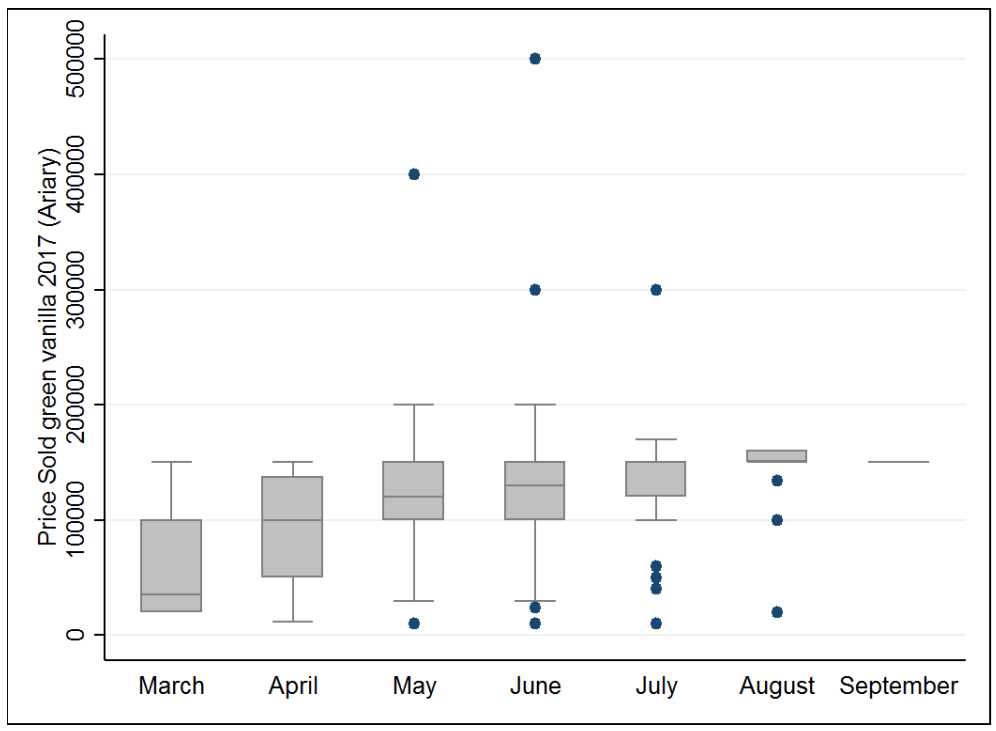


Figure 3.B5: Analysis comparing New and Old Vanilla Farmers

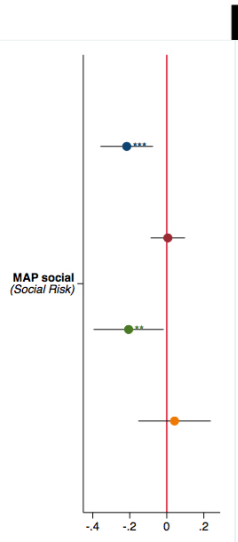

\section{New Vanilla Farmer}

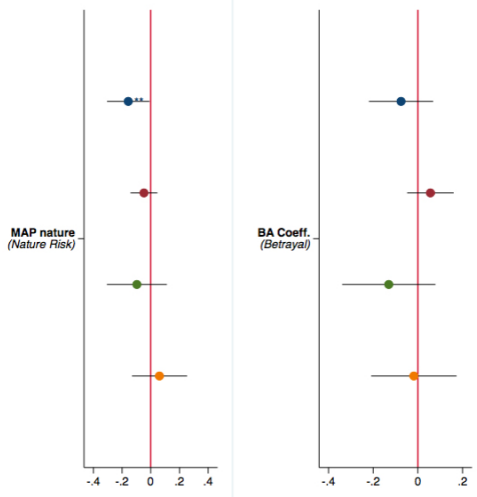

\section{Old Vanilla Farmer}
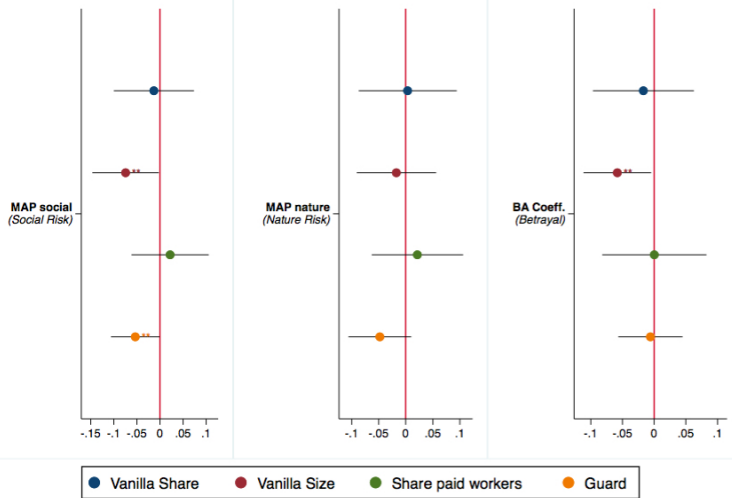

Notes: The figure presents the coefficients from linear regressions and the $95 \%$ confidence intervals. The heterogeneous effect was conducted based on whether the farmer has plantations older than 3 years ('Old Vanilla Farmer') or not ('New Vanilla Farmer'). The sample is divided accordingly. The regression models on the outcome variables Vanilla Share, Vanilla Size, and Guard include the whole sample of $\mathrm{N}=760$. The model with the outcome variable Share paid labor includes a total sample of $\mathrm{N}=630$ as some farmers do not use extra labor. ${ }^{*} p<0.10, * * p<0.05,{ }^{* * *} p<0.01$. 


\subsubsection{Appendix $\mathrm{C}$ - Experimental Instructions and Surveys}

\section{Experimental instructions students}

\section{Dear participant, welcome to our workshop!}

We are part of a research group called Diversity Turn. This is a project from the University of Göttingen. The objective of our project is to study vanilla production and the decisions students make under different incentive schemes in the SAVA region.

\section{What are you doing today?}

Today you will be participating in a workshop in which you will have the opportunity to earn money. Just for your participation you will receive a bonus of 2,000 ariary at the end of the workshop.

In addition, you can increase that amount by earning money in the different activities of the workshop. The amount of money that you earn will depend on your decisions and the decisions taken by people from other communities in the SAVA region. To calculate your earnings, we first need to finish the workshops in the other communities. Therefore, we will pay you in the next week once we have finished the workshops in the region.

This workshop has two parts. The first part will last approximately 2 hours and consist of four different activities. Thereafter, there will be a survey. Once you have finished both parts you will receive the 2,000 ariary as a bonus of your participation.

If at any time you feel uncomfortable, you are free to leave the room whether we have started the workshop or not. However, in that case you will not earn money.

Maybe you might have heard about this workshop before, yet what we will be doing today might be different. In order to do the activities correctly, please read carefully and pay attention when I explain them.

I would like to thank you for taking the time to come to this workshop. The results of each of the activities that we will be doing today will be very helpful for the research project. We appreciate your help very much.

I would also like to clarify that your identity will be kept anonymous along the workshop. This means that except from my colleagues and me, nobody will know your identity. We are only interested in the decisions that you take today and not in your identity. We will 
identify your decisions with the number that is on your table.

From now on, if you have questions, please quietly raise your hand and one of my colleagues will come to you to clarify your questions. Please do not talk to other participants in the workshop. This is very important.

\section{How is this workshop organized?}

Now we will start the first part of the workshop. As I explained before in this part of the workshop you will have the opportunity to earn money. We will do four activities, which we will refer to as Activity Triangle, Activity Circle, Activity Square, and Activity Rhombus. ${ }^{20}$ In each of these activities, except of Activity Square, you have the possibility to earn money. Yet, only one of the activities would be selected for the final payment.

At the end of the session one of the activities will be chosen randomly for payment and your earnings will be calculated according to the results of this activity. This means that each activity can get potentially relevant for your payoff, so please make careful decisions in each activity.

Some of the activities that we will be doing today are very similar that is why we ask you to read carefully each of them and follow the instructions accordingly.

\footnotetext{
${ }^{20}$ We only include the instructions of Activity Triangle and Activity Circle as they are the ones concerning the present experiment.
} 


\section{Activity Triangle}

We are conducting this study in different locations from the SAVA region. In this activity, you will be paired with at least one person from another location were we conduct a similar workshop. What you will be doing today is completely anonymous so the person in the other workshop will not know the decision you take here.

The person from the other location was assigned to the role of seller. The people in this session (you) will take the role of delegates. The sellers are real people and they live, like you, in the SAVA region.

The SELLERS have a product that has a final price of 10,000 ariary in the big market (market of a city). However, the SELLERS cannot sell the product directly and need a DELEGATE who sell the product for them and give them the earnings.

The SELLERS have the option to sell the product to two types of DELEGATES: DELEGATES A or DELEGATES B. Each type of DELEGATE consists of 10 people. Therefore, you would be one of the 20 delegates that exist.

If the SELLER selects DELEGATES A, the seller receives 4,000 ariary and the delegate keeps 6,000 ariary.

If the SELLER selects a DELEGATES B the amount they receive back will depend on whether they confront a DELEGATE B that gives the high amount or a DELEGATE B that gives the low amount. The DELEGATE B that gives the high amount will give most of the earnings to the SELLER, while the DELEGATE B that gives the low amount will take most of the earnings for himself. The DELEGATE B who gives the high amount will keep 1,000 ariary for himself and give 9,000 ariary to the SELLER. The DELEGATE B who gives the low amount will keep 9,000 ariary for himself and give 1,000 ariary to the SELLER.

The SELLER knows the proportion of DELEGATES B that decided to give the high or the low amount. Yet, when they decided who give their product to, they do not know if they would receive the high or the low amount. They only get to know their payment when they are paired with one of the 10 DELEGATES B. Therefore, if the SELLER decides to give his product to DELEGATES B, his payment depends on the decision of who he is paired with.

Your TASK in this activity is therefore to decide which amount you would give to the SELLER if you were allocated in the group of DELEGATES B. 
This information is summarized in the following table:

Table 3.C1: Earnings Table Activity Triangle

\begin{tabular}{|l|c|c|}
\hline If you give the seller: & You receive: & Seller receives: \\
\hline Low amount & 9,000 & 1,000 \\
\hline High amount & 1,000 & 9,000 \\
\hline
\end{tabular}

\section{How your earnings will be calculated?}

After you have made the decision between giving the high or the low amount to the SELLER, we will divide all the participants of this session into two groups. Some will be randomly allocated to the group of DELEGATES A and others will be randomly allocated to the group of DELEGATES B.

If you are allocated in the role of DELEGATES A, your earnings will be 6,000 ariary. If you are selected it in the role of DELEGATES B, your earnings will depend on the amount you decided to give. Therefore you will receive 1,000 or 9,000 ariary depending on the decision you have made.

Note that your decision will affect the payments of at least one SELLER, a real person living in the SAVA region. In any case, you will be paid according to your role in only one interaction with a SELLER.

As explained before, your TASK today is to decide whether to give the high or the low amount to the SELLER. Please mark your answer with an $\mathrm{X}$ at the right site of the paper. Remember that there are no right or wrong answers. Once you have all finished this activity our enumerators will pass by collecting the papers.

Table 3.C2: Decision Sheet Activity Triangle

\begin{tabular}{|l|c|c|l|}
\hline If you give the seller: & You receive: & Seller receives: & My decision is: \\
\hline Low amount & 9,000 & 1,000 & \\
\hline High amount & 1,000 & 9,000 & \\
\hline
\end{tabular}




\section{Activity Circle}

We are conducting this study in different locations from the SAVA region. In this activity, you will be paired with at least one person from another location were we conduct a similar workshop. What you will be doing today is completely anonymous so neither you nor the person in the other workshop will not know the decision you take here.

The person from the other location was assigned to the role of seller. The people in this session (you) will take the role of delegates. The sellers are real people and they live, like you, in the SAVA region.

The SELLERS have a product that has a final price of 10,000 ariary in the big market. However, SELLERS cannot sell the product directly and need a DELEGATE who sell the product for them and give them the earnings.

The SELLERS have the option to sell the product to two types of DELEGATES: DELEGATES A or DELEGATES B. Each type of DELEGATE consists of 10 people. Therefore, you would be one of the 20 delegates that exist.

If the SELLER selects DELEGATES A, the seller receives 4,000 ariary and the buyer keeps 6,000 ariary.

If the SELLER selects DELEGATES B the amount they receive will depend on whether the DELEGATE (you) confront HIGH TRANSPORTATION COSTS or LOW TRANSPORTATION COSTS. If you face HIGH TRANSPORTATION costs, you will give a low amount from the total earnings to the seller as you need to pay for the high costs. But if you face LOW TRANSPORTATION COSTS you will give a high amount from the total earnings to the seller.

To determine if the transport cost was high or low you will participate in a lottery. Each of you will select a ball from a non-transparent bag. From this bag you will take out either a yellow or a blue ball. If the ball is yellow, it means that you face HIGH TRANSPORTATION COSTS and therefore you will receive 9,000 ariary and the seller receives 1,000 ariary. If the ball is blue, it means that you face LOW TRANSPORTATION COSTS and therefore you will receive 1,000 ariary and the seller receives 9,000 ariary.

The SELLER knows the proportion of DELEGATES B that took out the blue or the yellow ball. Yet, when they decided who to sell to, they do not know if they would receive the high or the low amount. They only get to know their payment when they are paired with one of the 10 DELEGATES B. Therefore, if the SELLER decides to give his prod- 
uct to DELEGATES B, his payment depends on the luck of the person who he is paired with.

Your TASK in this activity is to pick one ball of the non-transparent bag. This ball could be blue or yellow and will determine the type of transportation costs that you as DELEGATE will face.

The following table summarizes the information:

Table 3.C3: Earnings Table Activity Circle

\begin{tabular}{|c|c|c|}
\hline Result of the lottery: & You receive: & Seller receives: \\
\hline YELLOW BALL & & 1,000 \\
(HIGH TRANSPORTATION COSTS) & 9,000 & 9,000 \\
\hline BLUE BALL & 1,000 & \\
\hline
\end{tabular}

\section{How your earnings will be calculated?}

After you have participated in the lottery, we will divide all the participants of this session into two groups. Some will be randomly allocated to the group of DELEGATES A and others will be allocated to the group of DELEGATES B.

If you are allocated in the role of DELEGATES A, you will receive 6,000 ariary. If you are selected it in the role of DELEGATES B, what you receive would depend on your luck in the lottery. Therefore you will receive 1,000 or 9,000 ariary depending on the colour of the ball you take out.

Note that your luck will affect the payments of at least one SELLER, a real person living in the SAVA region. In any case, you will be paid according to your role in only one interaction with a SELLER.

As mentioned before, you TASK today is to pick a ball from the bag as our enumerators passed by your place. Please mark immediately the result of the lottery in the "decision sheet Activity Circle" and give the papers to the enumerator.

Results of the lottery (mark an $\mathrm{X}$ in the one that applies)

Table 3.C4: Decision Sheet Activity Circle

\begin{tabular}{|l|l|l|}
\hline Results of the lottery & BLUE BALL & YELLOW BALL \\
\hline
\end{tabular}




\section{Experimental instructions farmers}

\section{Ladies and gentlemen good morning [afternoon] and welcome!}

My name is Gatien and these are my colleagues Evrard, Tatiana, Angeliko, Elsa, Ophelia, Parker, and Salma. We come in behalf of the research group Diversity Turn which is a project from the University of Göttingen in Germany. We are doing a study about vanilla production in the SAVA region.

First of all, I would like to thank you all for taking the time to come to this workshop. The results of the activities that we will be doing today will be very helpful for the research project. We appreciate your help very much.

This workshop is being done in different communities. To make sure that you understand the activities, please pay attention.

\section{What are you doing today?}

This workshop has two parts. The first part will last approximately 2 hours. Thereafter, there will be a survey. In this workshop you will have the opportunity to earn money. The amount of money that you earn today will depend on your decisions and the decisions that other people from the SAVA region take. If at any time you feel uncomfortable, you are free to leave the room whether we have started the workshop or not. However, in that case you will not earn money. Whatever you win today will be paid in cash at the end of the workshop so please pay attention to the instructions.

Maybe you might have heard about this workshop before, yet what we will be doing today might be different.

From now on, if you have questions, please raise your hand and one of us will come to you to clarify your questions. Please do not talk to other participants in the workshop. This is very important. We kindly ask you to turn off your mobile phone.

\section{How is the workshop organized? ${ }^{21}$}

Now we will start the first part of the workshop. As I explained before in this part of the workshop you will have the opportunity to earn some money. We will do five activities, which we will refer to as Activity Green, Activity White, Activity Orange, Activity Grey, and Activity Violet. In each of these activities you have the possibility to earn money. Yet, only one of the activities would be selected for the final payment. You will know which activity will be paid at the end of the workshop. In order to be eligible to receive the payment you need to complete all five activities and also complete the survey.

\footnotetext{
${ }^{21}$ The instructions included omit the last two activities (Activity Grey and Activity Violet) as they are not part of the present study.
} 


\section{Activity Green}

Imagine that you have produced this product (show product ${ }^{22}$ ) and you want to sell it in a big market to earn more money. This product has a final price of 10,000 ariary in the big market. However, you don't have time to go to the big market and therefore you engage a delegate who will sell the product in the big market for you. After selling the product the delegate will give you part of the earnings and keep some money for himself.

\section{How much would you receive from selling?}

It depends on who you give the product to. There are 10 DELEGATES A and 10 DELEGATES B. All DELEGATES A are identical and give you 4,000 ariary and take 6,000 ariary for themselves. DELEGATES B on the other hand are different. The amount you receive depends on how much the delegate wants to give you. Some DELEGATES B give a high amount so you receive 9,000 ariary and they take 1,000 ariary. Other DELEGATES B give a low amount so you receive 1,000 ariary and they take 9,000 ariary for themselves.

Your task is to decide who you want to give your product to, either to DELEGATES A or to DELEGATES B. Once you decide to which type of delegate you want to give your product to, you will be paired with one of the 10 delegates that belong to that specific type. If you decide to give the product to DELEGATES B and the delegate you are match with decides to give you the low amount then you will receive a small part of the earnings. If the delegate decides to give you the high amount it means that you will receive most of the earnings.

The two types of delegates we are referring to are real people. They are participants from another workshop in the SAVA region. In their workshop each participant takes the role of delegate and has to decide whether they would give you the high or the low amount. According to their decisions we formed different groups, each consisting of 10 delegates.

Let's look at an example (show poster Activity Green - Example 1):

Figure 3.C1: Earnings table example - Activity Green

\begin{tabular}{|c|c|c|c|c|}
\hline $\begin{array}{l}\text { If you give the product to } \\
\text { DELEGATES A you earn: }\end{array}$ & \multicolumn{2}{|c|}{$\begin{array}{l}\text { If you give the product to DELEGATES B } \\
\text { you confront: }\end{array}$} & \multicolumn{2}{|c|}{$\begin{array}{l}\text { I give the } \\
\text { product to: }\end{array}$} \\
\hline $4.000 \mathrm{Ar}$ & 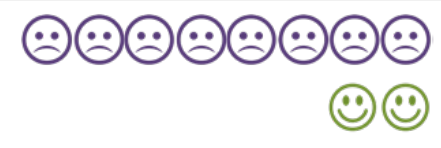 & $\begin{array}{l}1.000 \mathrm{Ar} \\
9.000 \mathrm{Ar}\end{array}$ & $\mathrm{A}$ & B \\
\hline
\end{tabular}

\footnotetext{
${ }^{22}$ Text in italics corresponds to the tasks for the instructor
} 
The earnings table reads as follows:

The first column indicates that if you give the product to DELEGATES A, you receive a secure amount of 4,000 ariary. As the product has a value of 10,000 ariary in the big market, this means that the delegate keeps 6,000 ariary for himself.

The second column indicates that if you give the product to DELEGATES B, the amount you receive back depends on whether you are match with a delegate that gives you a high or a low amount. In this example, you see that there are 8 sad faces next to 1,000 and 2 happy faces next two 9,000 ariary, this means that 8 of the 10 DELEGATES B would give you the low amount while 2 of the DELEGATES B would give you the high amount. Your task is to mark in the last column whether you want to give the product to DELEGATES A or DELEGATES B.

How many delegates giving the high or low amount are in DELGATES B? (show poster Distribution of groups DELEGATES B -- Activity Green)

Figure 3.C2: Distribution of groups DELEGATES B - Activity Green

\begin{tabular}{|c|c|}
\hline Groups & Number of DELEGATES B \\
\hline во & 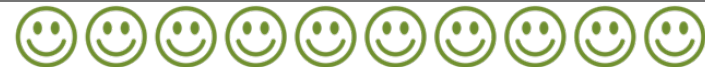 \\
\hline B1 & 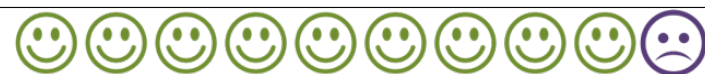 \\
\hline B2 & 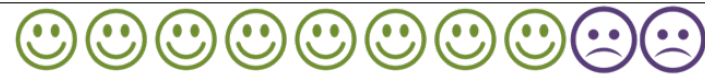 \\
\hline B3 & (ச) \\
\hline B4 & \\
\hline B5 & \\
\hline B6 & \\
\hline B7 & 8 \\
\hline B8 & 6 \\
\hline B9 & 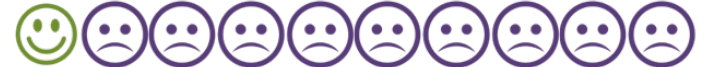 \\
\hline B10 & \\
\hline
\end{tabular}

\section{How will your earnings be calculated?}

If you decide to give your product to DELEGATES B, it could be that all ten delegates give you the high amount, or that all ten give you the low amount or something in between. As I explained, we are doing workshops in other communities from the SAVA region where people take the role of delegates and have to decide whether they would give the high or the low amount. According to their decisions, we formed 11 different groups of DELEGATES 
B. You can see this in the poster.

We call these groups B0, B1, up to B10. In B0 nobody gave the low amount, therefore, all 10 group delegates decided to give the high amount to you. In B1, 1 delegate decided to give the low amount and 9 delegates decided to give the high amount to you. In B9, 9 delegates decided to give you the low amount and 1 delegate decided to give the high amount to you. In B10, all delegates of the group decided to give the low amount and nobody decided to give the high amount to you. As you can see, in groups from B1 to B9, we have a mix of delegates giving the high and the low amount.

As there are different group compositions of DELEGATES B, we will ask you take eleven decisions. You will have to decide if you would give the product to DELEGATES A or to DELEGATES B. (show decision sheet Activity Green) 
Figure 3.C3: Decision sheet - Activity Green

\begin{tabular}{|c|c|c|c|c|c|}
\hline Group & $\begin{array}{l}\text { If you give the product to } \\
\text { DELEGATES A you earn: }\end{array}$ & $\begin{array}{l}\text { If you give the product to DELEGATES } \\
\text { confront: }\end{array}$ & Byou & & $\begin{array}{l}\text { ve the } \\
\text { luct to: }\end{array}$ \\
\hline B0 & $4.000 \mathrm{Ar}$ & (:) (-):-(:) (-):-) & $\begin{array}{l}1.000 \mathrm{Ar} \\
9.000 \mathrm{Ar}\end{array}$ & A & B \\
\hline B1 & $4.000 \mathrm{Ar}$ & 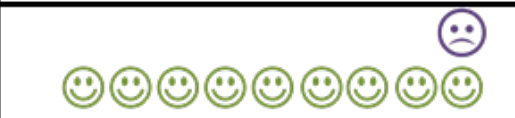 & $\begin{array}{l}1.000 \mathrm{Ar} \\
9.000 \mathrm{Ar}\end{array}$ & A & B \\
\hline B2 & $4.000 \mathrm{Ar}$ & 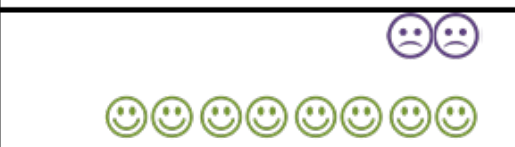 & $\begin{array}{l}1.000 \mathrm{Ar} \\
9.000 \mathrm{Ar}\end{array}$ & A & B \\
\hline B3 & $4.000 \mathrm{Ar}$ & 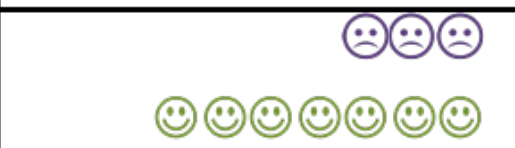 & $\begin{array}{l}1.000 \mathrm{Ar} \\
9.000 \mathrm{Ar}\end{array}$ & A & B \\
\hline B4 & $4.000 \mathrm{Ar}$ & 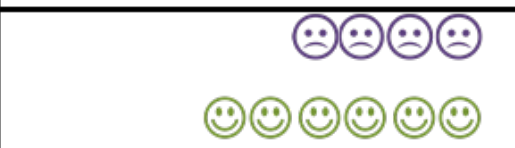 & $\begin{array}{l}1.000 \mathrm{Ar} \\
9.000 \mathrm{Ar}\end{array}$ & A & B \\
\hline B5 & $4.000 \mathrm{Ar}$ & 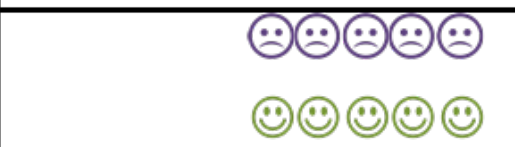 & $\begin{array}{l}1.000 \mathrm{Ar} \\
9.000 \mathrm{Ar}\end{array}$ & A & B \\
\hline B6 & 4.000 Ar & 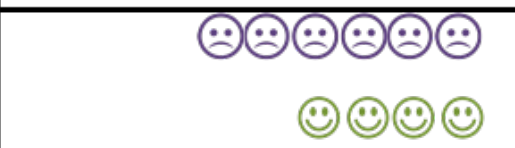 & $\begin{array}{l}1.000 \mathrm{Ar} \\
9.000 \mathrm{Ar}\end{array}$ & A & В \\
\hline B7 & $4.000 \mathrm{Ar}$ & 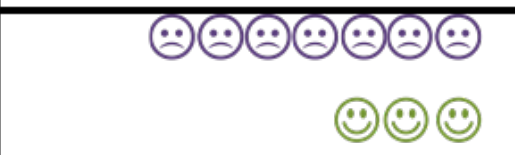 & $\begin{array}{l}1.000 \mathrm{Ar} \\
9.000 \mathrm{Ar}\end{array}$ & A & B \\
\hline B8 & $4.000 \mathrm{Ar}$ & 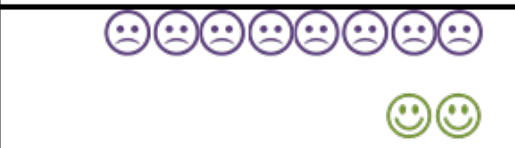 & $\begin{array}{l}1.000 \mathrm{Ar} \\
9.000 \mathrm{Ar}\end{array}$ & A & B \\
\hline B9 & $4.000 \mathrm{Ar}$ & 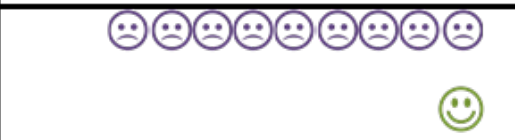 & $\begin{array}{l}1.000 \mathrm{Ar} \\
9.000 \mathrm{Ar}\end{array}$ & A & B \\
\hline B10 & $4.000 \mathrm{Ar}$ & 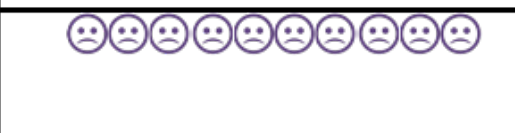 & $\begin{array}{l}1.000 \mathrm{Ar} \\
9.000 \mathrm{Ar}\end{array}$ & A & в \\
\hline
\end{tabular}


At the end, we will select only one of your eleven decisions to calculate the earnings of this activity. Let us assume that we select the decision of the group B8 as in the example. In this group there are 2 DELEGATES B who decide to give the high amount to you and 8 DELEGATES B who decide to give the low amount to you. If you select to give the product to DELEGATES B, we will pair you with 1 of the 10 DELEGATES B in the group B8. The final earnings will depend on your decision and the decision the delegate you are paired with takes.

Before continuing, I will ask you some questions to make sure you understand the activity. We will do this activity together in case somebody has still questions. It is important that we do this because if you don't understand the instructions then you will not be able to participate and earn some money. If after doing this you still want to ask something, please raise your hand and one of the colleagues will come to you.

\section{Control Questions}

I would like to ask number $\mathrm{xx}$ to come to the front.

(Display poster Earnings Table Activity Green B1)

In this first example there is 1 sad face, meaning 1 DELEGATE B gives the low amount, and 9 happy faces, meaning that 9 DELEGATES B give the high amount

Figure 3.C4: Earnings Table Activity Green B1

\begin{tabular}{|c|c|c|c|}
\hline Group & $\begin{array}{l}\text { If you give the product to } \\
\text { DELEGATES A you earn: }\end{array}$ & $\begin{array}{l}\text { If you give the product to DELEGATES B } \\
\text { you confront: }\end{array}$ & I give the product to: \\
\hline B1 & 4.000 $\mathrm{Ar}$ & 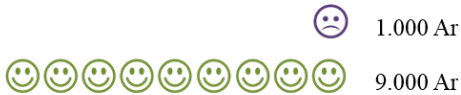 & A \\
\hline
\end{tabular}

(Participant should go to the front and fill the table. Please ask the following questions and let the participant fill the table/tell you the results of the table)

a) If you select to give the product to DELEGATES A, how much will you earn? How much the delegate will earn?

b) How many DELEGATES A give 4,000 ariary?

c) If you select to give the product to DELEGATES B, how much you and the delegate will earn if you are confronted with a delegate that gives the high amount?

d) If you select to give the product to DELEGATES B, how much you and the delegate will earn if you are confronted with a delegate that gives the low amount?

e) Which amount is more likely that you will receive here, the high or the low amount? 
As mentioned before, you task is to take 11 different decisions, one for each of the B groups. Soon, we will give you a table like this one (show decision sheet Activity Green(, where you have to select who you give your product to. You can choose to give it to DELEGATES A or to DELEGATES B for each of the 11 groups. Please be aware that in each group, the number of DELEGATES B deciding to give the high or low amount changes. Remember that there are a total of 10 DELEGATES A and 10 DELEGATES B.

Let's do other example in case somebody has still questions. To do this, I would like to ask number xx to come to the front. Please remember that if you have questions, you can raise your hand and one of the colleagues will come to you.

Let's suppose that all DELEGATES B, in this case the 10 delegates, give the high amount. (Display poster Earnings Table Activity Green B0)

Figure 3.C5: Earnings Table Activity Green B0

\begin{tabular}{|c|c|c|c|c|c|}
\hline Group & $\begin{array}{l}\text { If you give the product to } \\
\text { DELEGATES A you earn: }\end{array}$ & \multicolumn{2}{|c|}{$\begin{array}{l}\text { If you give the product to DELEGATES B } \\
\text { you confront: }\end{array}$} & \multicolumn{2}{|c|}{ I give the product to: } \\
\hline B0 & $4.000 \mathrm{Ar}$ & 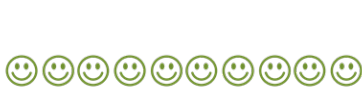 & $\begin{array}{l}1.000 \mathrm{Ar} \\
9.000 \mathrm{Ar}\end{array}$ & A & B \\
\hline
\end{tabular}

(Participant should go to the front and fill the table. Please ask the following questions and let the participant fill the table/tell you the results of the table)

a) If you select to give the product to DELEGATES A, how much will you earn? How much the delegate will earn?

b) How many DELEGATES A give 4,000 ariary?

c) If you select to give the product to DELEGATES B, how much you and the delegate will earn?

d) Which amount is more likely that you will receive here, the high or the low amount?

Let's have one last example. I would like to ask number $\mathrm{xx}$ to come to the front. Let's suppose that 9 DELEGATES B decide to give the low amount and 1 decides to give the high amount.

(Display poster Earnings Table Activity Green B9)

Figure 3.C6: Earnings Table Activity Green B9

\begin{tabular}{|c|c|c|c|}
\hline Group & $\begin{array}{c}\text { If you give the product to } \\
\text { DELEGATES A you earn: }\end{array}$ & $\begin{array}{c}\text { If you give the product to DELEGATES B } \\
\text { you confront: }\end{array}$ & I give the product to: \\
\hline B9 & $4.000 \mathrm{Ar}$ & (-) $1.000 \mathrm{Ar}$ & $\mathrm{A} \quad \mathrm{B}$ \\
\hline
\end{tabular}


(Participant should go to the front and fill the table. Please ask the following questions and let the participant fill the table/tell you the results of the table)

a) If you select to give the product to DELEGATES A, how much will you earn? How much the delegate will earn?

b) How many DELEGATES A give 4,000 ariary?

c) If you select to give the product to DELEGATES B, how much you and the delegate will earn if you are confronted with a delegate that gives the high amount?

d) If you select to give the product to DELEGATES B, how much you and the delegate will earn if you are confronted with a delegate that gives the low amount?

e) Which amount is more likely that you will receive, the high or the low amount?

Now you are going to receive a paper like this one (show decision sheet Activity Green). Please do not unfold it until I tell you that you can start. You are going to decide first for the group B0, followed it by groups B1, B2, B3 ... until B10. I want to emphasize that what you decide in each group is up to you.

(Explain the following text using the poster of decision sheet Activity Green)

I imagine that, if many DELEGATES B decided to give a high amount, like in the first groups, most people would give the product to DELEGATES B, as they could earn 9,000 ariary instead of the 4,000 ariary that the DELEGATES A give. We showed this with our examples before. However, there are other groups where there are very few DELEGATES B giving the high amount (see the few happy faces), and therefore you would prefer to switch and give the product to DELEGATES A. If this is the case, then you would choose to give the product to DELEGATES B in the first groups and then switch to DELEGATES A at some point in the table. For example, we showed that in group B9 it is most likely that you receive the 1,000 ariary than the 9,000 ariary: therefore, choosing to give the product to DELEGATES A it is a better option as you can receive 4,000 ariary instead of 1,000 ariary.

Some people might do the switch here (show one switch), others might switch at this point (show another example), while others would change at this point (show another example). Where would you do the switch? Remember that in every group the number of DELEGATES B giving the high and low amount changes.

(Wait until everybody has a decision sheet Activity Green)

Please open the paper you received. You have to decide between giving the product to DELEGATES A or DELEGATES B for each of the groups. Please mark your answer by 
crossing either the letter $\mathrm{A}$ or the letter $\mathrm{B}$ that are at the right side of the paper. Remember that there are no right or wrong answers. I also want to emphasize that where you decide to switch is up to you. Once you have finished fold your paper again.

(Wait until everybody folds the paper)

Now my colleagues will pass by collecting the papers. If you have not yet fold them, please do it so nobody can see your answer. 


\section{Activity White}

Imagine that you have produced this product (show product) and you want to sell it in a big market to earn more money. This product has a final price of 10,000 ariary in the big market. However, you don't have time to go to the big market and therefore you engage a delegate who will sell the product in the big market for you. After selling the product the delegate will give you part of the earnings according to the luck he had with the transportation costs.

\section{How much would you receive from selling?}

It depends on who you give the product to. There are 10 DELEGATES A and 10 DELEGATES B. All DELEGATES A are identical and give you 4,000 ariary and take 6,000 ariary for themselves. DELEGATES B on the other hand are different. The amount you receive depends on the luck the delegate has with the transportation costs, in particular, whether the delegate faces high or low transportation costs. This is completely outside the control of the delegates as the car they hire might break, the roads might be in bad conditions or there might be unexpected delays. If the transportation costs are low, you will receive 9,000 ariary and the delegate takes 1,000 ariary. If the transportation costs are high, you will receive 1,000 ariary and the delegate takes 9,000 ariary to face the high costs.

Your task is to decide who you want to give your product to, either to DELEGATES A or to DELEGATES B. Once you decide to which type of delegate you want to give the product to, you will be paired with one of the 10 delegates that belong to that specific type. If you decide to give the product to DELEGATES B and the delegate you are match with takes a yellow ball, it means that the delegate confronts high transportation costs and therefore you will receive a small part of the earnings. If the delegate takes a blue ball, it means that the delegate confronts low transportation costs and therefore you will receive most of the earnings.

The two types of delegates we are referring to are real people. They are participants from another workshop in the SAVA region. In their workshop each delegate takes a ball from a non-transparent bag with equal number of yellow and blue balls. This person cannot see which ball he/she is choosing. According to the results of the lottery we formed different groups, each consisting of 10 delegates.

Let's look at an example (show Poster Activity White - Example 1):

Figure 3.C7: Earnings table example - Activity White

\begin{tabular}{|c|c|c|}
\hline $\begin{array}{l}\text { If you give the product to } \\
\text { DELEGATES A you earn: }\end{array}$ & $\begin{array}{l}\text { If you give the product to DELEGATES B you } \\
\text { confront: }\end{array}$ & I give the product to: \\
\hline 4.000 Ar & $\begin{array}{l}1.000 \mathrm{Ar} \\
9.000 \mathrm{Ar}\end{array}$ & A \\
\hline
\end{tabular}


The earnings table reads as follows:

The first column indicates that if you give the product to DELEGATES A, you receive a secure amount of 4,000 ariary. As the product has a value of 10,000 ariary in the big market, this means that the delegate keeps 6,000 ariary for himself.

The second column indicates that if you give the product to DELEGATES B, the amount you receive back depends on whether you are match with a delegate that takes a blue or yellow ball. In this example, you see that there are 8 yellow balls next to 1,000 and 2 blue balls next two 9,000 ariary, this means that 8 of the 10 DELEGATES B took out a yellow ball and therefore confront high transportation costs (you receive the low amount), while 2 of the DELEGATES B took out a blue ball and therefore confront low transportation costs (you receive the high amount).

Your task is to decide who you want to give your product to, either to DELEGATES A or to DELEGATES B.

How many yellow and blue balls the DELEGATES B took out from bag? (show poster Distribution of groups DELEGATES B - Activity White)

Figure 3.C8: Distribution of groups DELEGATES B - Activity White

\begin{tabular}{|c|c|}
\hline Group & \\
\hline B0 & \\
\hline B1 & \\
\hline B2 & \\
\hline B3 & \\
\hline B4 & \\
\hline B5 & \\
\hline B6 & \\
\hline B7 & \\
\hline B8 & \\
\hline
\end{tabular}




\section{How will your earnings be calculated?}

If you decide to give your product to DELEGATES B, it could be that all ten delegates took out a yellow ball and therefore faced high transportation costs, or that all ten took out a blue ball and therefore faced low transportation costs or something in between.

As I explained, we are doing workshops in other communities from the SAVA region where people take the role of delegates and have to take a ball from a non-transparent bag with equal number of yellow and blue balls. This represents the type of transportation costs they face. According to the results of the lottery, we formed 11 different groups of DELEGATES B. You can see this in the poster.

We will call these groups B0, B1, up to B10. In B0 nobody took out a yellow ball from the bag and therefore all 10 delegates faced low transportation costs. This means that all of them give the high amount to you. In B1, 1 delegate took out a yellow ball from the bag and 9 delegates took out a blue ball. In B9, 9 delegates took out a yellow ball and 1 delegate took out a blue ball. In B10, all 10 delegates took out a yellow ball from the bag meaning that they all faced high transportation costs and therefore, nobody gives the high amount to you. As you can see, in groups from B1 to B9, we have a mix of delegates facing high and low transportation costs and therefore giving you the low and high amount.

As there are different group compositions of DELEGATES B, we will ask you take eleven decisions. You will have to decide if you would give the product to DELEGATES A or to DELEGATES B. (show decision sheet Activity White) 
Figure 3.C9: Decision sheet - Activity White

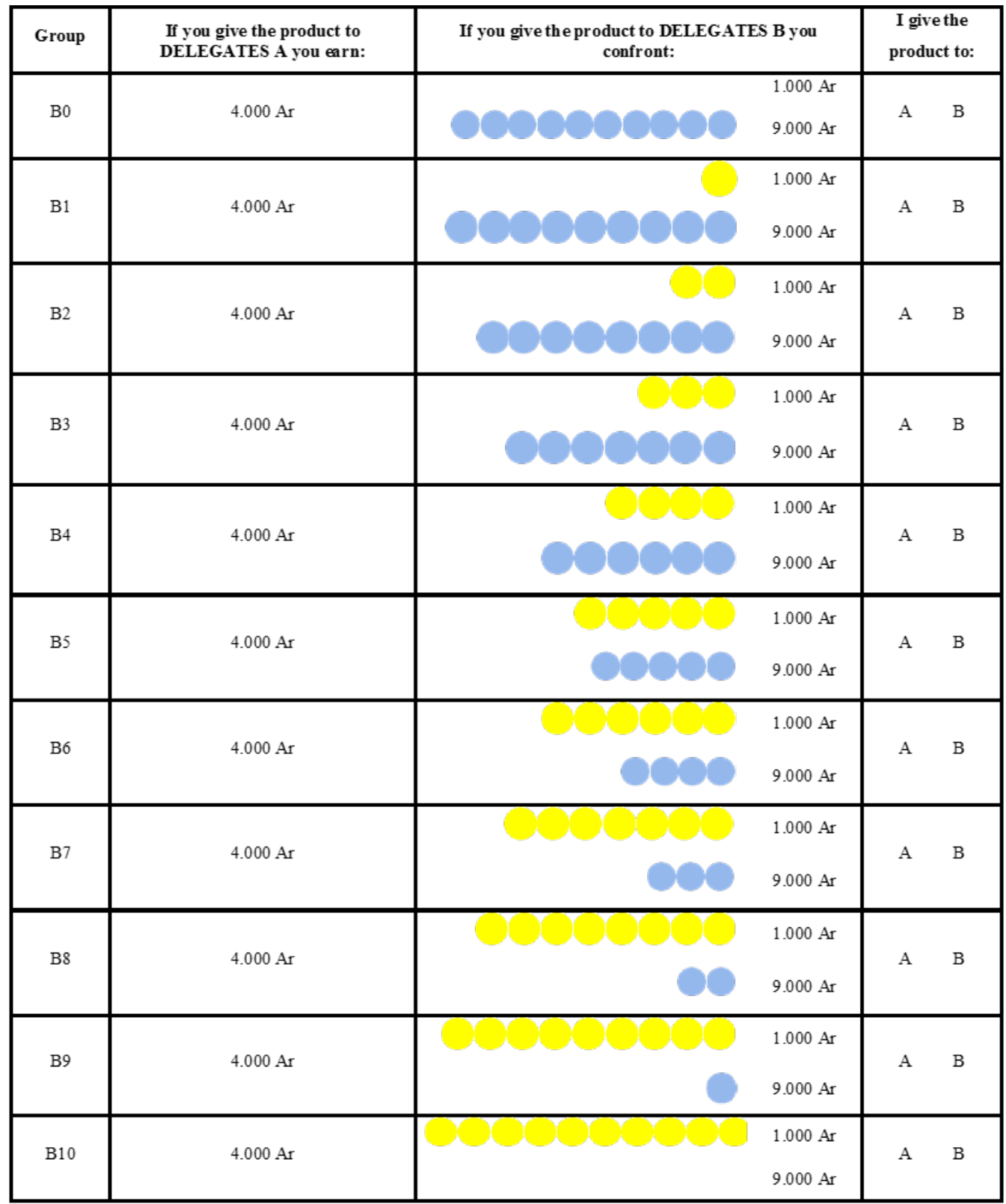

At the end, we will select only one of your 11 decisions to calculate the earnings of this activity. Let us assume that we select the decision of the group B8 for payment as in the example. In this group, there are 2 DELEGATES B who took out a blue ball and 8 DELEGATES B who took out a yellow ball. If you select to give the product to DELEGATES B, we will pair you with 1 of the 10 DELEGATES B in the group B8. The final earnings will depend on your decision and the luck of the delegate you are paired with has.

Before continuing, I will ask you some questions to make sure you understand the activity. We will do this activity together in case somebody has still questions. It is important that we do this because if you don't understand the instructions then you will not be able to 
participate and earn some money. If after doing this you still want to ask something, please raise your hand and one of the colleagues will come to you.

\section{Control Questions}

I would like to ask number $\mathrm{xx}$ to come to the front.

(Display poster Earnings Table Activity White B1)

In this first example there is 1 yellow ball, meaning 1 DELEGATE B faced high transportation costs and 9 blue balls, meaning that 9 DELEGATES B faced low transportation costs.

Figure 3.C10: Earnings Table Activity White B1

\begin{tabular}{|c|c|c|c|}
\hline Group & $\begin{array}{l}\text { If you give the product to } \\
\text { DELEGATES A you earn: }\end{array}$ & $\begin{array}{l}\text { If you give the product to DELEGATES B } \\
\text { you confront: }\end{array}$ & I give the product to: \\
\hline B1 & $4.000 \mathrm{Ar}$ & $1.000 \mathrm{Ar}$ & B \\
\hline
\end{tabular}

(Participant should go to the front and fill the table. Please ask the following questions and let the participant fill the table/tell you the results of the table)

a) If you select to give the product to DELEGATES A, how much will you earn? How much the delegate will earn?

b) How many DELEGATES A give 4,000 ariary?

c) If you select to give the product to DELEGATES B, how much you and the delegate will earn if you are confronted with a delegate that takes out a yellow ball meaning that he or she faces high transportation costs?

d) If you select to give the product to DELEGATES B, how much you and the delegate will earn if you are confronted with a delegate that takes out a blue ball meaning that he or she faces low transportation costs?

e) Which amount is more likely that you will receive here, the high or the low amount?

As mentioned before, you task is to take 11 different decisions, one for each of the $\mathrm{B}$ groups. Soon, we will give you a table like this one (show decision sheet Activity White), where you have to select who you give your product to. You can choose to give it to DELEGATES A or to DELEGATES B for each of the 11 groups. Please be aware that in each group, the number of DELEGATES B confronting high or low transportation costs changes. Remember that there are a total of 10 DELEGATES A and 10 DELEGATES B. 
Let's do other example in case somebody has still questions. To do this, I would like to ask number $\mathrm{xx}$ to come to the front. Please remember that if you have questions, you can raise your hand and one of the colleagues will come to you.

Let's suppose that all DELEGATES B, in this case the 10 delegates took out a blue ball. (Display poster Earnings Table Activity White B0)

Figure 3.C11: Earnings Table Activity White B0

\begin{tabular}{|c|c|c|c|}
\hline Group & $\begin{array}{l}\text { If you give the product to } \\
\text { DELEGATES A you earn: }\end{array}$ & $\begin{array}{l}\text { If you give the product to DELEGATES B } \\
\text { you confront: } \\
\end{array}$ & I give the product to: \\
\hline B0 & $4.000 \mathrm{Ar}$ & $\begin{array}{l}1.000 \mathrm{Ar} \\
9.000 \mathrm{Ar}\end{array}$ & A \\
\hline
\end{tabular}

(Participant should go to the front and fill the table. Please ask the following questions and let the participant fill the table/tell you the results of the table)

a) If you select to give the product to DELEGATES A, how much will you earn? How much the delegate will earn?

b) How many DELEGATES A gave 4,000 ariary?

c) If you select to give the product to DELEGATES B, how much will you and the delegate will earn?

d) Which amount is more likely that you will receive here, the high or the low amount?

Let's have one last example. I would like to ask number $\mathrm{xx}$ to come to the front. Let's suppose that 9 DELEGATES B took out a yellow ball and 1 DELEGATE B took out a blue ball. (Display poster Earnings Table Activity White B9)

Figure 3.C12: Earnings Table Activity White B9

\begin{tabular}{|c|c|c|c|}
\hline Group & $\begin{array}{l}\text { If you give the product to } \\
\text { DELEGATES A you earn: }\end{array}$ & $\begin{array}{l}\text { If you give the product to DELEGATES B } \\
\text { you confront: }\end{array}$ & I give the product to: \\
\hline B9 & $4.000 \mathrm{Ar}$ & $\begin{array}{ll}1.000 \mathrm{Ar} \\
9.000 \mathrm{Ar}\end{array}$ & A \\
\hline
\end{tabular}

(Participant should go to the front and fill the table. Please ask the following questions and let the participant fill the table/tell you the results of the table)

a) If you select to give the product to DELEGATES A, how much will you earn? How much the delegate will earn?

b) How many DELEGATES A give 4,000 ariary? 
c) If you select to give the product to DELEGATES B, how much you and the delegate will earn if you are confronted with a delegate that takes out a yellow ball meaning that he or she faces high transportation costs?

d) If you select to give the product to DELEGATES B, how much you and the delegate will earn if you are confronted with a delegate that takes out a blue ball meaning that he or she faces low transportation costs?

e) Which amount is more likely that you will receive, the high or the low amount?

Now you are going to receive a paper like this one (show decision sheet Activity White). Please do not unfold it until I tell you that you can start. You are going to decide first for the group B0, followed it by groups B1, B2, B3 ... until B10. I want to emphasize that what you decide in each group is up to you.

\section{(Explain the following text using the poster of decision sheet Activity White)}

I imagine that, if many DELEGATES B took out a blue ball, like in the first groups, most people would give the product to DELEGATES B, as they could earn 9,000 ariary instead of the 4,000 ariary that the DELEGATES A give. We showed this in the examples before. However, there are other groups where there are very few blue balls or low transportation costs (see the number of blue balls in the table), and therefore you would prefer to switch from DELEGATES B and give the product to DELEGATES A. If this is the case, then you would choose to give the product to DELEGATES B in the first groups and then switch to DELEGATES A at some point in the table. For example, we showed that in group B9 it is most likely that you receive the 1,000 ariary than the 9,000 ariary; therefore, choosing to give the product to DELEGATES A is a better option as you can receive 4,000 ariary instead of 1,000 ariary.

Some people might do the switch here (show one switch), others might switch at this point (show another example), while others would change at this point (show another example). Where would you do the switch? Remember that in every group the number of DELEGATES B having good and bad luck with the transportation costs changes.

(Wait until everybody has a decision sheet Activity White)

Please open the paper you received. You have to decide between giving the product to DELEGATES A or DELEGATES B for each of the groups. Please mark your answer by crossing either the letter $\mathrm{A}$ or the letter $\mathrm{B}$ that are at the right side of the paper. Remember that there are no right or wrong answers. I also want to emphasize that where you decide to switch is up to you. Once you have finished fold your paper again.

(Wait until everybody folds the paper)

Now my colleagues will pass by collecting the papers. If you have not yet fold them, please do it so nobody can see your answer. 


\section{Activity Orange}

Now we will start activity Orange.

For this activity we will form groups of 3 participants. We will give each of the groups a total amount of 15,000 ariary and you have to distribute it among yourselves. There are two different options on how the distribution of the money can be made and each person has the opportunity to vote for one option. The option that receives the majority of votes, meaning two votes, will be declared the winner and will determine the earnings of each person in the group. The following table shows each of the options:

(show Poster Earnings Table Activity Orange):

Figure 3.C13: Earnings table - Activity Orange

\begin{tabular}{|c|c|c|c|}
\hline & Person A & Person B & Person D \\
\hline OPTION 1 & & & \\
\hline OPTION 2 & 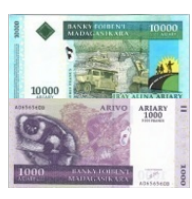 & Nise & $\sqrt{12}$ \\
\hline
\end{tabular}

The earnings table reads as follows:

In OPTION 1, each of the three persons in the group receives 5,000 ariary. In OPTION 2, Person A receives 11,000 ariary, Person B recieves 2,000 ariary and Person D receives 2,000 ariary. Imagine that you are Person A and therefore you have to decide between OPTION 1 or OPTION 2. Which Option would you choose? Your task is to decide between OPTION 1 or OPTION 2.

\section{How will your earnings be calculated?}

In this activity each one of you will be deciding as if you were Person A and as if your earnings were to be implemented. At the end, if this activity is selected for payment, one of the three participants in the group would be randomly selected to have the decision implemented. Payments will be done accordingly to the decision that the selected person took as Person A.

\section{Control Questions}

I would like to ask number $\mathrm{xx}$ to come to the front. We will do this activity together in case somebody has still questions. It is important that we do this because if you don't understand the instructions then you will not be able to participate and earn some money. 
If after doing this you still want to ask something, please raise your hand and one of the colleagues will come to you. (Display poster Earnings Table Activity Orange)

(Participant should go to the front and fill the table. Please ask the following questions and let the participant fill the table/tell you the results of the table)

a) If you vote for OPTION 1 and this option wins, how much Person A will receive? How much person B will receive? How much person D will receive?

b) If you vote for OPTION 2 and this option wins, how much Person A will receive? How much person B will receive? How much person D will receive?

Now you are going to receive a paper like this one (show decision sheet Activity Orange):

Figure 3.C14: Decision Sheet Activity Orange

\begin{tabular}{|l|c|c|c|c|}
\hline Your options & Person A & Person B & Person D & I Vote for... \\
\hline OPTION 1 & & & & \\
\hline & OPTION 1 & \\
\hline OPTION 2 & & & & \\
& OPTION 2 \\
\hline
\end{tabular}

Please do not unfold it until I tell you that you can start. Your task is to vote either for OPTION 1 or for OPTION 2 if you were in the role of Person A. I want to emphasize that what you decide is up to you.

\section{(Wait until everybody has a decision sheet Activity Orange)}

Please open the paper you received. Please mark your answer by crossing either at OPTION 1 or OPTION 2. Remember that there are no right or wrong answers. Once you have finished fold your paper again.

(Wait until everybody folds the paper)

Now my colleagues will pass by collecting the papers. Please fold them so that nobody can see your answer. 


\section{End}

Now, one of you will take out one card of this non-transparent bag. According to the name written in the card we will pay the earnings of that activity. For example if the name "Activity Green" comes up, we will pay the total earnings of this activity, if the name "Activity White" comes up, then we will pay that activity. Same with Activities Orange, Grey and Violet.

If the result of the bag is Activity Green or Activity White, then we will use an extra card to decide which group will be used to calculate the earnings. Remember that in Activities Green and White we had 11 different groups where you made decisions; however, only one of them will be paid. Therefore, the same person that comes to the front will randomly select the group that we will be using to calculate your earnings and the delegate's earnings for the activity that is chosen. In this sense, additional to taking a paper from the bag with either "Activity Green", "Activity White", "Activity Orange", "Activity Grey" or "Activity Violet", this person has to take out a paper from another non-transparent bag. In this other bag there are 11 small and equal papers. Each paper has a number from 0 to 10 written on it. This will guarantee that only one group will be picked for the payment calculation of Activities Green or White in case they are selected.

In addition to the amount you earn from the Activity selected, each of you will receive 2,000 ariary as a bonus for your assistance today. In the name of Diversity Turn and the University of Göttingen, I want to thank you very much for your time and collaboration today.

While we prepare the payments, we would like to ask you some question. Please do not leave the room, my colleagues will come to you as soon as possible. If some of you need to shortly go you can do it, but please come back soon to fill the questionnaire and receive your earnings of today. 


\section{Experiment Questionnaire (Baseline)}

Participant No.

Date of Interview: $-/-/-$ Village:
Questionnaire No.:

Female

Male

ID of Interviewer:

District: Sambava Andapa Antalaha

Hello! We are part of a research project from the University of Göttingen in Germany. This project investigates the vanilla production in the SAVA region. Today we want to ask for your cooperation by answering some questions about you and the work you do. The answers you will provide here are completely anonymous and will only be used for academic purposes. This means that neither your name, nor any other names, will be ever mentioned. Nobody will be able to identify that you gave this information. Taking part in this survey is your choice. You can decide to participate or not. If you do participate you still can tell us to stop at any time for any reason. This is not a test, thus there are no right or wrong answers. The answers should only correspond to your reality or your opinion. In name of the University we thank you very much for your time and collaboration.

In order to do a good job in our research we would like to ask for your permission to visit you two more times and ask a few questions about your vanilla production. Would you like to participate and help us with our data collection? Yes No

\section{SECTION 1- FEEDBACK ABOUT THE ACTIVITIES:}

Before starting with the questions regarding your work, we would like to first know how you felt during the activities that we did today.

1. Did you understand the instructions of the activities? Yes No [IF YES please continue to question 2 / IF NO please continue to question 1.1 $]^{23}$ 1.1 In which one(s) you had difficulty?

2. Did you have difficulties in answering one or more of the activities? Yes No [IF YES please continue to question 2.1 / IF NO please continue to question 3]

2.1 In which one(s) you had difficulty?

3. What was the most important factor you took into account when deciding to give your product either to DELEGATES A or to DELEGATES B in the Activity Green?

\section{I always want to maximize my earnings}

\footnotetext{
${ }^{23}$ Text in italics corresponds to the tasks for the enumerators
} 
I don't like taking risks

4. What was the most important factor you took into account when deciding to give your product either to DELEGATES A or to DELEGATES B in the Activity White?

I always want to maximize my earnings

$\square$ I don't like taking risks

\section{SECTION 2 - PRODUCTION ACTIVITIES:}

In the next section I am going to ask you some questions related to the farming activities that you and your family do.

5. Think about all the agricultural plantations that you have or have worked on. How many are they?

\begin{tabular}{|c|c|c|c|}
\hline Plant. & $\begin{array}{c}5.1 \text { What is the size } \\
\text { in hectares of this plant.? }\end{array}$ & $\begin{array}{c}5.2 \text { What do you have in this } \\
\text { plant.? }{ }^{\text {a }}\end{array}$ & $\begin{array}{c}5.3 \text { How you obtained this } \\
\text { plant.? }^{\text {b }}\end{array}$ \\
\hline 1 & & & \\
\hline 2 & & & \\
\hline 3 & & & \\
\hline 4 & & & \\
\hline 5 & & & \\
\hline 6 & & & \\
\hline 7 & & & \\
\hline 8 & & & \\
\hline 9 & & & \\
\hline 10 & & & \\
\hline
\end{tabular}

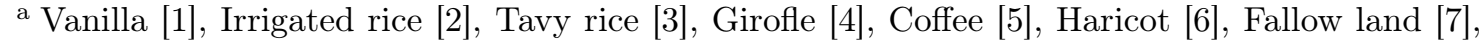
Forest fragment [8], Nothing [9], Other [10]

${ }^{\text {b }}$ You Inherited from your family [1], You obtained it through marriage [2], You Bought it [3], You rent it from someone [4], You share it with someone [5], You cut the forest [6], Other [7]

6. To answer this question you are going to receive 20 beans. Please distribute them under each of the following pictures to show us how much of your total land you have for each of the types:

\begin{tabular}{|c|c|c|c|c|}
\hline No cultivation & Vanilla & Irrigated rice & Tavy rice & Others \\
\hline & & & \\
\hline & & & & \\
\hline & & & & \\
\hline
\end{tabular}


7. How many bags of rice did your house produce this year (2018)?

8. How many of those bags of rice did you sell or plan to sell (2018)?

9. How many of those bags did you save for your own consumption (2018)?

\section{SECTION 3-VANILLA PRODUCTION:}

Now, I am going to ask you questions related to your vanilla production. Please answer the following questions taking only into account the activities and experiences that you have had as vanilla farmer

10. At which time in the year green vanilla should be harvested to get the best price? January February March April May June July (...)

11. At which time in the year green vanilla should be sold to get the best price? January February March April May June July (...)

12. In which year you started cultivating vanilla?

13. Usually, how many adults work in the field with you (including family and hired labor) for [ACTIVITY]?

\begin{tabular}{|c|l|l|l|l|}
\hline ACTIVITY & Men (family) & Men (hired labor) & Women (family) & Women (hired labor) \\
\hline Pollination & & & & \\
\hline Weeding & & & & \\
\hline Guarding & & & & \\
\hline Harvesting & & & & \\
\hline Curing & & & & \\
\hline Triage & & & & \\
\hline Drying & & & & \\
\hline Selling & & & & \\
\hline
\end{tabular}

14. In question 5 , you mentioned that you have $[\mathrm{X}]$ vanilla plantations. In the following questions, I will refer to those vanilla plantations that you have. 


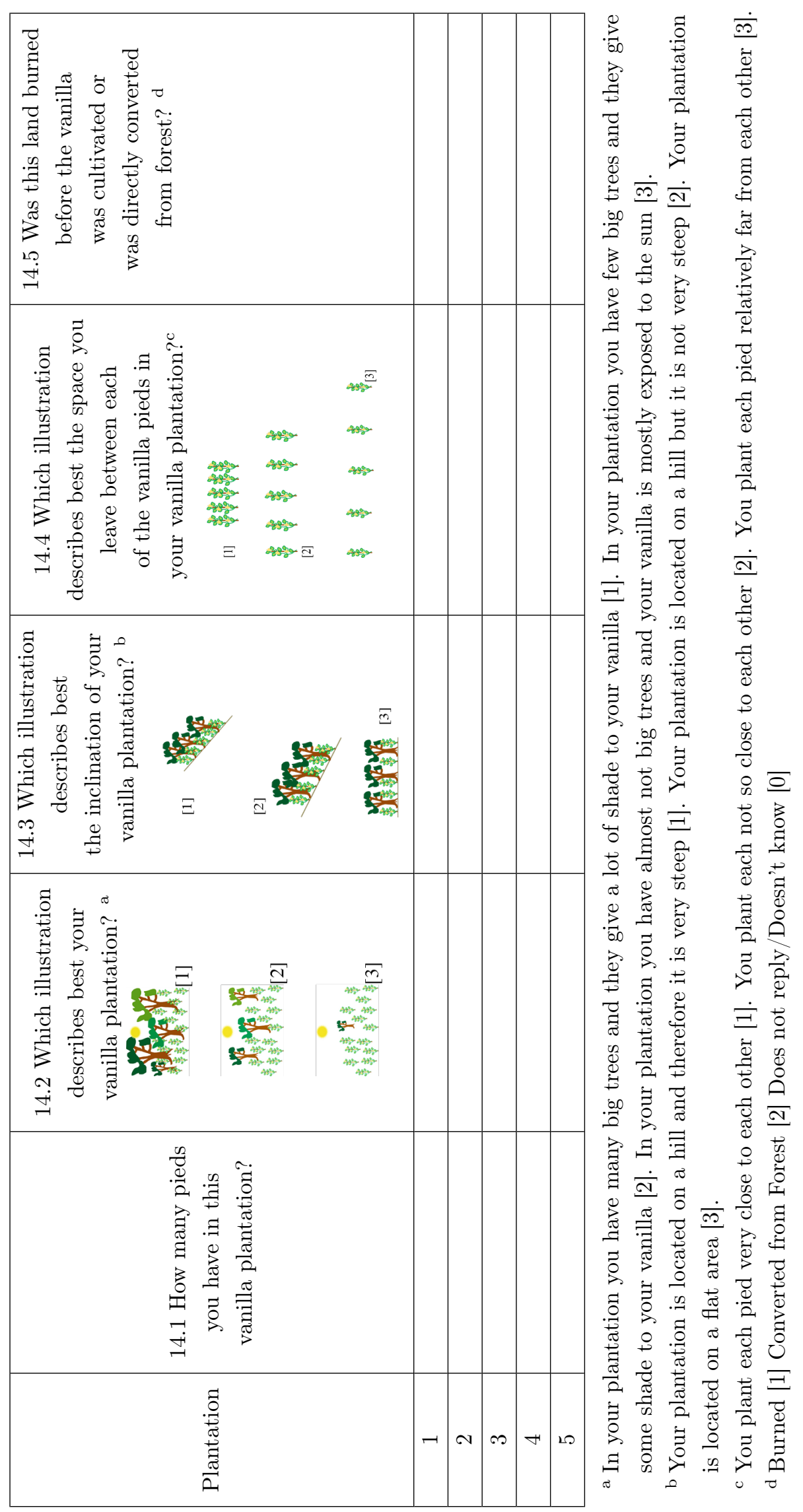




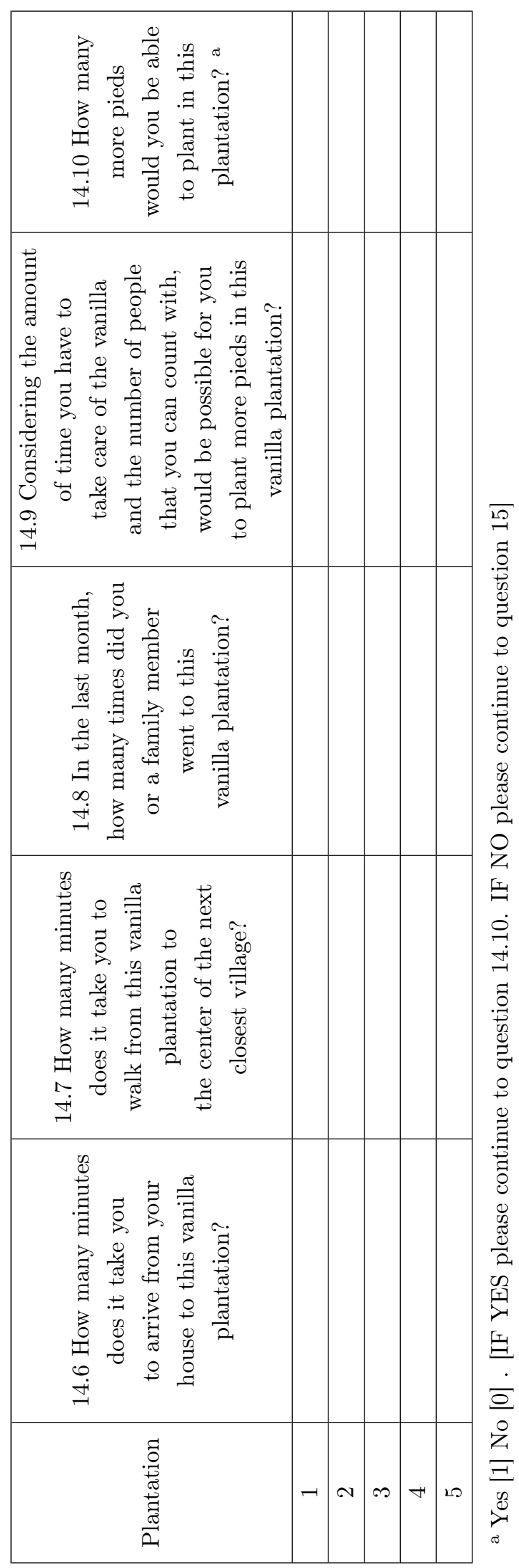


15. Are you a new vanilla farmer? (A new vanilla farmer cultivated for the first time in his/her life vanilla in the years 2016, 2017 or 2018)

Yes No

[IF YES please continue to question 23 / IF NO please continue to question 16]

16. When did you harvest your vanilla last year in 2017? (Do not mention options to farmers. According to their answers select the one that applies best)

January February March April May June (...)

16.1 Was the vanilla mature at this time? Yes No

16.2 How many kilograms of green vanilla did you harvest last year (2017)? _ Kgs.

17. Did you prepare your green vanilla last year (2017)? Yes No [IF YES please continue to question 18 / IF NO please continue to question 20]

18. Did you sell black vanilla in the second half of last year (july - december 2017)? Yes No

18.1 How many kilos did you sell? Kgs.

18.2 For which price did you sell them? (ariary/ Franc Malagache) per Kg.

19. Have you sold black vanilla this year (2018)? Yes No [IF YES please continue to question 19.1 / IF NO please continue to question 19.3]

19.1 How many kilos did you sell? Kgs.

19.2 For which price did you sell them? (ariary/ Franc Malagache) per $\mathrm{Kg}$

19.3 At which price you expect to sell black vanilla this year? (ariary/ Franc Malagache) per Kg.

19.4 Have you given all or part of your black vanilla to another person or association to sell it for you in a big market or to a company to get a better price than the one offered in the market of your village? Yes No [IF YES please continue to question 20 / IF NO please continue to question 19.5]

19.5 Would you give all or part of your black vanilla to another person or association to sell it for you in a big market or to a company to get a better price than the one offered in the market of your village? Yes No

20. Did you sell green vanilla last year (2017)? Yes No [IF YES please continue to question 21 / IF NO please continue to question 22] 
21. When did you start selling green vanilla last year (2017)? (Do not mention options to farmers. According to their answers select the one that applies best)

January February March April May June July August (...)

21.1 When the market for green vanilla opened in 2017? (Do not mention options to farmers. According to their answers select the one that applies best( January February March April May June July August (...)

21.2 How many kilos of green vanilla did you sell last year (2017)? Kgs.

21.3 For which price did you sell them? (ariary/ Franc Malagache) per Kg.

21.4 Where or to whom did you sell most of them?

At the market

To a middle man (commisionnaire/collecteur)

To a big company

To an association

I can't tell/ I don't know

21.5 Have you given all or part of your green vanilla to another person to sell it for you in a big market or to a company to get a better price than the one offered in the market of your village? Yes No

[IF YES please continue to question 22 / IF NO please continue to question 21.6]

21.6 Would you give all or part of your green vanilla to another person to sell it for you in a big market or to a big buyer to get a better price than the one offered in the market of your village? Yes No

22. Are you planning to prepare your vanilla this year (2018)? Yes No [IF NO please continue to question 22.1 / IF YES please continue to question 22.2]

22.1 Do you know how to prepare vanilla? Yes No

22.2 For how many years have you been preparing the green vanilla? years.

22.3 Do you have enough space to store your green vanilla safely before preparing it? Yes No 
SECTION 4 - BELIEFS, ATTITUDES AND EXPERIENCES:

Thank you so much for your answers regarding your agricultural activities. Now we will ask more general questions about you, your experiences and your beliefs.

23. Suppose you were given the choice between receiving some money today or some money in one year. We will present to you three different situations. For each of these situations we would like to know which option you would choose. These situations are hypothetical.

23.1 Would you rather receive 100,000 ariary today or 150,000 ariary in 1 year?

$\square$ Today

In one year

23.2 Would you rather receive 100,000 ariary today or 125,000 ariary in 1 year?

Today

In one year

23.3 Would you rather receive 100,000 ariary today or 105,000 ariary in 1 year?

Today

In one year

24. Are you generally a person who likes to take risks or avoids taking risks?

I like to take risks

I avoid taking risks

25. According to your personal experience and beliefs, on a scale from 1 to 5 , where 1 is strongly disagree and 5 is strongly agree, how much you agree or disagree with the following sentences:

25.1 Generally speaking I trust most of the people in my village:

1- strongly disagree

2- disagree

3- neither agree nor disagree

4- agree

$\square$ 5- strongly agree

25.2 Generally speaking during harvest time is difficult to trust other people in my village:

1- strongly disagree

2- disagree

$\square$ 3- neither agree nor disagree

4- agree

5- strongly agree 
26. This year, you expect the price per $\mathrm{kg}$ of green vanilla to be: (ariary/ Franc Malagache per Kg).

27. This year, you expect your sells from green vanilla to be: (ariary/ Franc Malagache).

28. In the next five years, you expect the price per $\mathrm{kg}$ of green vanilla to be: (ariary/ Franc Malagache per Kg).

29. In the next five years, you expect your sells from green vanilla to be: (ariary/ Franc Malagache).

30. If there was a problem that affected your entire village, for example a disease or a cyclone, how do you think the people of your village would work with the situation?

Each person or house would work alone

Few neighbors would help each other to deal with the situation

The entire village will work together

31. Compared to other farmers you have ...

Better farming skills

Same farming skills

Worse farming skills

32. According to your personal experience and beliefs, on a scale from 1 to 5 , where 1 is strongly disagree and 5 is strongly agree, how much you agree or disagree with the following sentences:

32.1 I think my plot is constantly threat from theft

1- strongly disagree

2- disagree

3- neither agree nor disagree

4- agree

5- strongly agree

32.2 I think somebody will steal my green vanilla if my plantation has no supervision

1- strongly disagree

2- disagree

3- neither agree nor disagree

4- agree

5- strongly agree

32.3 I think somebody will steal my green vanilla even if my plantation has supervision

1- strongly disagree

2- disagree

3- neither agree nor disagree

4- agree

5- strongly agree 
32.4 I think that somebody will steal my green vanilla even if I keep it at home

1- strongly disagree

2- disagree

$\square$ 3- neither agree nor disagree

$\square$ 4- agree

5- strongly agree

32.5 I think that somebody will steal my black vanilla if I keep it at home

1- strongly disagree

$\square$ 2- disagree

$\square$ 3- neither agree nor disagree

$\square$ 4- agree

$\square$ 5- strongly agree

33. What do you use to guard your plot? (Do not mention options to farmers. According to their answers select the ones that apply best or add a new one in "Other". You can mark several options)

I guard alone

I guard with members of my family

Member(s) of my family guardian my plot

I pay a guardian

I have fences

$\square$ I have traps

$\square$ I have watchdog(s)

$\square$ I carry a gun

$\square$ I don't guardian my plot

$\square$ Other:

[IF PAYS A GUARDIAN please continue to question 33.1 / IF DOES NOT PAY A GUARDIAN please continue to question 33.2]

33.1 How much you pay a guardian per day? ariary/Franc Malagache

33.2 Would you be willing to pay a guardian? Yes No

[IF YES please continue to question 33.2.1 / IF NO please continue to question 34]

33.2.1. How much would you pay this person per day? ariary/Franc Malagache

34. In the last month, how many nights did you stay in your plot to make sure that nobody steals your vanilla?

Every night

Most of the nights

Half of the nights

Less than half of the nights

None of the nights 
35. Did somebody steal green vanilla or lianas from you last year (2017)? Yes No [IF YES please continue to question 35.1 / IF NO please continue to question 36] 35.1 How many times?

35.2 How many kilograms were stolen each time?

\begin{tabular}{|c|c|c|c|}
\hline 35.2 .1 Times & $\begin{array}{c}35.2 .2 \text { Number of } \\
\text { Kgs. }\end{array}$ & $\begin{array}{c}35.2 .3 \text { Did you catch } \\
\text { the person(s) who stole } \\
\text { your vanilla? (Yes/No) }\end{array}$ & $\begin{array}{c}35.2 .4 \text { Did you report } \\
\text { the person(s) to } \\
\text { the police? (Yes/No) }\end{array}$ \\
\hline 1 & & & \\
\hline 2 & & & \\
\hline 3 & & & \\
\hline 4 & & & \\
\hline 5 & & & \\
\hline $\begin{array}{c}\text { More than } 5 \\
\text { approximate of the total) }\end{array}$ & & & \\
\hline
\end{tabular}

36. Did somebody steal black vanilla from you last year (2017)? (Only if farmers prepare the green vanilla) Yes No [IF YES please continue to question 36.1 / IF NO please continue to question 37] 36.1 How many times?

36.2 How many kilograms were stolen each time?

\begin{tabular}{|c|c|c|c|}
\hline 36.2 .1 Times & $\begin{array}{c}36.2 .2 \text { Number of } \\
\text { Kgs. }\end{array}$ & $\begin{array}{c}36.2 .3 \text { Did you catch } \\
\text { the person(s) who stole } \\
\text { your vanilla? (Yes/No) }\end{array}$ & $\begin{array}{c}36.2 .4 \text { Did you report } \\
\text { the person(s) to } \\
\text { the police? (Yes/No) }\end{array}$ \\
\hline 1 & & & \\
\hline 2 & & & \\
\hline 3 & & & \\
\hline 4 & & & \\
\hline 5 & & & \\
\hline $\begin{array}{c}\text { (If more than } 5 \text {, ask for an } \\
\text { approximate of the total) }\end{array}$ & & & \\
\hline
\end{tabular}

37. Has somebody stolen green vanilla or lianas from you this year (2018)?

Yes No

[IF YES please continue to question 37.1 / IF NO please continue to question 38]

37.1 How many times?

37.2 How many kilograms were stolen each time? 


\begin{tabular}{|c|c|c|c|}
\hline 37.2 .1 Times & $\begin{array}{c}37.2 .2 \text { Number of } \\
\text { Kgs. }\end{array}$ & $\begin{array}{c}37.2 .3 \text { Did you catch } \\
\text { the person(s) who stole } \\
\text { your vanilla? (Yes/No) }\end{array}$ & $\begin{array}{c}37.2 .4 \text { Did you report } \\
\text { the person(s) to } \\
\text { the police? (Yes/No) }\end{array}$ \\
\hline 1 & & & \\
\hline 2 & & & \\
\hline 3 & & & \\
\hline 4 & & & \\
\hline 5 & & & \\
\hline $\begin{array}{c}\text { More than 5 } \\
\text { approximate of the total) }\end{array}$ & & & \\
\hline
\end{tabular}

38. Has somebody stolen black vanilla from you this year (2018)? Yes No [IF YES please continue to question 38.1 / IF NO please continue to question 39] 38.1 How many times?

38.2 How many kilograms were stolen each time?

\begin{tabular}{|c|c|c|c|}
\hline 38.2 .1 Times & $\begin{array}{c}38.2 .2 \text { Number of } \\
\text { Kgs. }\end{array}$ & $\begin{array}{c}38.2 .3 \text { Did you catch } \\
\text { the person(s) who stole } \\
\text { your vanilla? (Yes/No) }\end{array}$ & $\begin{array}{c}38.2 .4 \text { Did you report } \\
\text { the person(s) to } \\
\text { the police? (Yes/No) }\end{array}$ \\
\hline 1 & & & \\
\hline 2 & & & \\
\hline 3 & & & \\
\hline 4 & & & \\
\hline 5 & & & \\
\hline $\begin{array}{c}\text { (If more than 5, ask for an } \\
\text { approximate of the total) }\end{array}$ & & & \\
\hline
\end{tabular}

\section{SECTION 5 - SOCIOECONOMICS}

We are in the last section of our survey. Some of the questions will be related to your income and some will be related to characteristics of your house.

39. Do you or your spouse receive income from activities different from farming?

Yes No

[IF YES please continue to question 39.1 / IF NO please continue to question 40]

39.1 Now you are going to receive 20 beans. Please distribute them under each of the following images to show us how much income you receive from each of the different sources:

\begin{tabular}{|l|l|}
\hline Farming activities & Off-farming activities \\
\hline & \\
\hline
\end{tabular}


40. I am going to read you a statement regarding food consumption. For these statement, please tell me whether the situation was happening often (more than 10 times) or sometimes (3-10 times) or rarely (1-2 times) or never in the last 30 days in your house. 40.1 In the last month was there ever no food to eat of any kind in your house because of lack of money to buy food

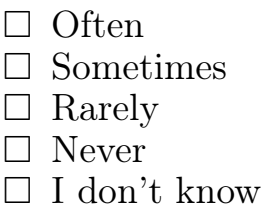

41. Do you have an account with OTIV or with other financial institution? Yes No

42. Do you save money? Yes No

43. In which year were you born?

44. Which is your last year of education you approved?

45. What is your marital status?

Never Married
Married
Divorced
Widow

46. Who lives with you?

\begin{tabular}{|c|c|c|}
\hline & Male (Number.) & Female (Number.) \\
\hline Adults & & \\
\hline Children & & \\
\hline
\end{tabular}

47. What is your name?

\section{Thank you for your time!}




\section{Experiment Questionnaire (Follow-up 1)}

GEORG-AUGUST-UNIVERSITÄT GÖTTINGEN

Participant No.

Questionnaire No.:

Female

Diversity Turn

Date of Interview: $-/-/-$

ID of Interviewer:

Male

Village:

District: Sambava Andapa Antalaha

Hello! We are part of a research project from the University of Göttingen in Germany. This project investigates the vanilla production in the SAVA region. Last time at the workshop you gave us permission to visit you again in order to ask some questions regarding your vanilla production. The questionnaire today will be short and should not take much of your time. The answers you will provide here are completely anonymous and will only be used for academic purposes. This means that neither your name, nor any other names, will be mentioned at any time. Nobody will be able to identify that you gave this information.

Taking part in this survey is your choice. You can decide to participate or not. If you do participate you still can tell us to stop at any time for any reason. As a thank you for your collaboration you will receive 3,000 ariary at the end of the survey. Please remember that this is not a test thus there are no right or wrong answers. The answers should only correspond to your reality or your opinion. In name of the University we thank you very much for your time and collaboration.

1. Approximately how many hours do you work in a typical day in your plantation? (Maximum value 24) hours.

2. In the last 30 days, how many days did you or any family member visited your vanilla plots? days

(Answers of 2.1 and 2.2 must be equal to the answer in question 2)

2.1. How many of those visits were to work on the plot? times

2.2. How many of those visits were only to check that the vanilla was fine? times

3. In the last 30 days, have you harvested your vanilla? Yes No [IF YES please continue to question 3.1 / IF NO please continue to question 3.3] 3.1. Why? (Do not mention options to farmers. According to their answers select the one that applies best or add a new one in "Other")

Vanilla is mature

Theft already started

I need money at this time

Other: 
3.2. How many kilograms of green vanilla have you harvested in the last 30 days? Kgs.

3.3. Why? (Do not mention options to farmers. According to their answers select the one that applies best or add a new one in "Other")

I finished harvesting already

Vanilla is not yet mature

Market is not opened yet

I am a new vanilla farmer

Other:

4. In the last 30 days, have you sold green vanilla? Yes No

[IF YES please continue to question 4.1 until 4.4, then to question 5 / IF NO please continue to question 4.5]

4.1. Why? (Do not mention options to farmers. According to their answers select the one that applies best or add a new one in "Other")

Market is already open

Theft already started

The prices are high at the moment

I need money at this time

Other:

4.2. How many kilos of green vanilla have you sold in the last 30 days? Kgs.

4.3. For which price did you sell them? (ariary/ Franc Malagche) per $\mathrm{Kg}$.

4.4. Where or to whom did you sell most of them?

At the market

To a middle man (commisionnaire/collecteur)

To a big company

To an association

I can't tell/ I don't know

4.5. Why? (Do not mention options to farmers. According to their answers select the one that applies best or add a new one in "Other")

I am waiting until the market opens

I already sold all my vanilla

I am waiting for higher prices

I am a new vanilla farmer

Other: 
5. In the last 30 days, how many nights did you stay in your plot to make sure that nobody steals your vanilla/lianas?

Every night

Most of the nights

Half of the nights

$\square$ Less than half of the nights

None of the nights

6. In the last 30 days, has somebody stolen green vanilla from you? Yes No [IF YES please continue to question 6.1 / IF NO please continue to question 7]

6.1. How many times?

6.2. How many kilograms were stolen each time?

\begin{tabular}{|c|c|c|c|}
\hline 6.2 .1 Times & $\begin{array}{c}6.2 .2 \text { Number of } \\
\text { Kgs. }\end{array}$ & $\begin{array}{c}6.2 .3 \text { Did you catch } \\
\text { the person(s) who stole } \\
\text { your vanilla? (Yes/No) }\end{array}$ & $\begin{array}{c}6.2 .4 \text { Did you report } \\
\text { the person(s) to } \\
\text { the police? (Yes/No) }\end{array}$ \\
\hline 1 & & & \\
\hline 2 & & & \\
\hline 3 & & & \\
\hline 4 & & & \\
\hline 5 & & & \\
\hline $\begin{array}{c}\text { More than } 5 \\
\text { If more than 5, ask for an } \\
\text { apprimate of the total) }\end{array}$ & & & \\
\hline
\end{tabular}

7. In the last 30 days, have you planted more pieds in your vanilla plot(s)? Yes No [IF YES please continue to question 7.1 / IF NO please continue to question 8]

7.1. How many new pieds have you planted? pieds.

7.2. Why?

Replace old pies

$\square$ Increase the vanilla plantation

8. How long have you lived in this village (in years)? years.

9. Have you ever lived in another area/village? Yes No

10. Are you a member of a vanilla association? Yes No [IF YES please continue to question 10.1 /IF NO please continue to question 11] 10.1. For how long have you been a member (in years)? years.

11. Are you voluntarily associated to community organizations such as community meetings, security groups, etc.? Yes No 
[IF YES please continue to question 11.1 / IF NO please continue to question 12]

11.1. In how many?

12. In the last month was there ever no food to eat of any kind in your house because of lack of money to buy food?
Often
Sometimes
Rarely
Never
I don’t Know

13. Which one is your ethnic group?
Betsimsaraka
Antemoro
Tsimihety
Other:

14. What is the religion which you most identify with?
Catholic
Adventist
Muslim
Protestant
$\square$ Other:

15. What is your name?

\section{Thank you for your time!}




\section{Experiment Questionnaire (Follow-up 2)}

Participant No.

Date of Interview: $-/-/-$

Village:
Questionnaire No.:

ID of Interviewer:

District: Sambava Andapa Antalaha
Diversity Turn in Land Use Science Female

Male

Hello! We are part of a research project from the University of Goettingen in Germany. This project investigates the vanilla production in the SAVA region. Last time at the workshop you gave us permission to visit you again in order to ask some questions regarding your vanilla production. The questionnaire today will be short and should not take much of your time. The answers you will provide here are completely anonymous and will only be used for academic purposes. This means that neither your name, nor any other names, will be mentioned at any time. Nobody will be able to identify that you gave this information. Taking part in this survey is your choice. You can decide to participate or not. If you do participate you still can tell us to stop at any time for any reason. As a thank you for your collaboration you will receive 3,000 ariary at the end of the survey. Please remember that this is not a test thus there are no right or wrong answers. The answers should only correspond to your reality or your opinion. In name of the University we thank you very much for your time and collaboration.

1. Approximately how many hours do you work in a typical day in your plantation? (Maximum value 24) hours.

2. In the last 15 days, how many days did you or any family member visited your vanilla plots? days

(Answers of 2.1 and 2.2 must be equal to the answer in question 2)

2.1. How many of those visits were to work on the plot? times

2.2. How many of those visits were only to check that the vanilla was fine? times

3. In the last 15 days, have you harvested your vanilla? Yes No IIF YES please continue to question 3.1 until 3.2 and then go to question 4 / IF NO please continue to question 3.3] 
3.1. Why? (Do not mention options to farmers. According to their answers select the one that applies best or add a new one in "Other")

Vanilla is mature

Theft already started

I need money at this time

Market already opened

Other:

3.2. How many kilograms of green vanilla have you harvested in the last 15 days? Kgs.

3.3. Why? (Do not mention options to farmers. According to their answers select the one that applies best or add a new one in "Other")

I finished harvesting already

Vanilla is not yet mature

Market is not opened yet

I am a new vanilla farmer

Other:

4. In the last 15 days, have you sold green vanilla? Yes No

[IF YES please continue to question 4.1 / IF NO please continue to question 4.5]

4.1. Why? (Do not mention options to farmers. According to their answers select the one that applies best or add a new one in "Other")

Market is already open

Theft already started

The prices are high at the moment

I need money at this time

Other:

4.2. How many kilos of green vanilla have you sold in the last 15 days? Kgs.

4.3. For which price did you sell them? (ariary/ Franc Malagche) per Kg.

4.4. Where or to whom did you sell most of them?

At the market

To a middle man (commisionnaire/collecteur)

To a big company

To an association

I can't tell/ I don't know

4.5. Why? (Do not mention options to farmers. According to their answers select the one that applies best or add a new one in "Other")

I am waiting until the market opens

I already sold all my vanilla

I am waiting for higher prices

I am a new vanilla farmer

Other: 
5. In the last 15 days, how many nights did you stay in your plot to make sure that nobody steals your vanilla/lianas?

Every night

Most of the nights

$\square$ Half of the nights

$\square$ Less than half of the nights

$\square$ None of the nights

6. In the last 15 days, has somebody stolen green vanilla from you? Yes No [IF YES please continue to question 6.1 / IF NO please continue to question 7]

6.1. How many times?

6.2. How many kilograms were stolen each time?

\begin{tabular}{|c|c|c|c|}
\hline 6.2 .1 Times & $\begin{array}{c}6.2 .2 \text { Number of } \\
\text { Kgs. }\end{array}$ & $\begin{array}{c}6.2 .3 \text { Did you catch } \\
\text { the person(s) who stole } \\
\text { your vanilla? (Yes/No) }\end{array}$ & $\begin{array}{c}6.2 .4 \text { Did you report } \\
\text { the person(s) to } \\
\text { the police? (Yes/No) }\end{array}$ \\
\hline 1 & & & \\
\hline 2 & & & \\
\hline 3 & & & \\
\hline 4 & & & \\
\hline 5 & & & \\
\hline $\begin{array}{c}\text { More than } 5 \\
\text { (If more than 5, ask for an } \\
\text { approximate of the total) }\end{array}$ & & & \\
\hline
\end{tabular}

7. In the last 15 days, have you planted more pieds in your vanilla plot(s)? Yes No [IF YES please continue to question 7.1 / IF NO please continue to question 8]

7.1. How many new pieds have you planted? pieds.

7.2. Why?

Replace old pies

Increase the vanilla plantation

8. Have you prepared or are you preparing the green vanilla from this last harvest?

Yes $\quad$ No

[IF YES continue to question 10 / IF NO please continue to question 9 and then question 16] 
9. Why don't you prepare green vanilla? (Do not mention options to farmers. According to their answers select the one that applies best or add a new one in "Other")

I don't have enough space to store it

My yield is not big enough

I don't have enough people/other people to help me

I don't have the materials to do it

I don't know how to do it

I prefer to sell green

It's very dangerous because of crime

I don't trust people around me

Other:

10. Have you sold black vanilla from this last harvest? Yes No [IF YES please continue to question 11 / IF NO please continue to question 14]

11. How many kilos did you sell?

12. For which price did you sell them? (ariary/ Franc Malagache) per Kg.

13. Where or to whom did you sell most of the black vanilla?

At the market

To a middle man (commisionnaire/collecteur)

To a big company

To an association

I can't tell/ I don't know

14. At which price you expect to sell the black vanilla from this last harvest?

(ariary/ Franc Malagache) per Kg.

15. Has somebody stolen black vanilla from you from this last harvest? Yes No [IF YES please continue to question 15.1 / IF NO please continue to question 16]

15.1. How many times?

15.2. How many kilograms were stolen each time?

\begin{tabular}{|c|c|c|c|}
\hline 15.2 .1 Times & $\begin{array}{c}15.2 .2 \text { Number of } \\
\text { Kgs. }\end{array}$ & $\begin{array}{c}15.2 .3 \text { Did you catch } \\
\text { the person(s) who stole } \\
\text { your vanilla? (Yes/No) }\end{array}$ & $\begin{array}{c}15.2 .4 \text { Did you report } \\
\text { the person(s) to } \\
\text { the police? (Yes/No) }\end{array}$ \\
\hline 1 & & & \\
\hline 2 & & & \\
\hline 3 & & & \\
\hline 4 & & & \\
\hline 5 & & & \\
\hline $\begin{array}{c}\text { More than } 5 \\
\text { approximate of the total) }\end{array}$ & & & \\
\hline
\end{tabular}


16. In the last 15 days was there ever no food to eat of any kind in your house because of lack of money to buy food?
Often
Sometimes
$\square$ Rarely
$\square$ I don't Know

$\square$ Never

17. What is your name?

Thank you for your time! 


\section{Chapter 4}

\section{"It pays to be green": The role of persuasive communication to foster conservation}

This chapter is joint work with Marcela Ibañez (University of Göttingen) and Gerhard Riener (Heinrich Heine University Düsseldorf). We appreciate the helpful comments and suggestions received from Alexia Gaudeul and the participants at the ESA Global Conference 2020. All remaining errors are ours. Magdalene Trapp, Marius Willmann, Erika Carcache, and Vivan Coelho provided great research assistance. We would want to thank all enumerators and coordinators that worked with us during the data collection and the people that participated in our study. Special thanks to the team of Duke Lemur Center-SAVA for their great compromise in the implementation of the restoration activities in the region. We thank the NGOs and private companies that took part in our exploratory visit and provided us with important insights to motivate this study. To the local people who supported us unconditionally during the data collection (village chiefs, drivers, cooks, hotel owners, and employees, etc.) we are immensely thankful. Project funding was provided by the 'Niedersächsisches Vorab' of Volkswagen Foundation, grant number: 11-76251-99-35/13 (ZN3119). We are very grateful to the Diversity Turn research group for their constant feedback and support in the field. Project registered at the AEA RCT Registry (AEARCTR-0004505). 


\subsection{Introduction}

Fables and myths are a universal feature of human culture. We, humans, are "inveterate storytellers" (Flanagan, 1993, p. 198). Evidence strongly suggests that all societies use stories to convey important lessons about nature and transmit moral and ethical values (e.g Vitz, 1990; De Groot \& Zwaal, 2007; Fernández-Llamazares \& Cabeza, 2018; Michalopoulos \& Meng Xue, 2021). By representing animals and natural forces that interact with each other, fables aim at explaining the dilemmas that nature faces and generate an educational effect. However, are these forms of narratives effective at changing behavior? Alternatively, could simple commands as "Save paper, save the planet" or "Don't let garbage replace wildlife", ${ }^{1}$ be more effective?

In this paper, we test the effectiveness of narratives and imperatives to promote prosocial behavior. While a narrative provides a warm message to request and justifies moral actions implicitly, imperatives transmit a request or command on how to behave. The theoretical model in Bénabou et al. (2019) suggests that imperatives issued by a trusted principal are more effective at changing behavior than narratives. First, they provide rules-ofthumb that are quick, instinctive, and easy to follow in unfamiliar contexts. Second, they provide precise guidance on behavior and are less subject to interpretation uncertainty than narratives. Third, they provide a commitment device that helps overcome temptations and expand morally acceptable behavior to other contexts. Despite those notional predictions, the empirical evidence on the comparative effectiveness of narratives and imperatives is nonexistent.

The context of our study is Madagascar, one of the richest nations in biodiversity and natural resources, but yet seriously threatened by deforestation. The role of persuasion is important in this context, as environmental institutions struggle to motivate individuals towards more sustainable practices (Styger et al., 2007). With the objective to support forest restoration initiatives led by a non-governmental organization (NGO), we launched in 2018 a crowdfunding campaign in the SAVA region, located in the northeast of the country. We visited 15 rural communities and requested a non-monetary donation to the forest restoration project among 670 individuals. Participants were offered material and could decide whether to devote part of their time to produce hand-made bookmarks that would be used as gifts to donors in Germany. We opted for a non-monetary contribution to the environment because, according to the 2017 World Giving Index Report by Charities Aid Foundation (CAF), individuals in developing countries are more likely to contribute by volunteering than with monetary donations (Charities Aid Foundation, 2017). This is supported by experimental studies showing that individuals are more willing to donate time than money (Brown et al., 2019). Moreover, voluntary activities are commonly used worldwide by organizations such as Greenpeace, World Wide Fund for Nature (WWF), and other charities.

\footnotetext{
${ }^{1}$ Both campaign ads are from The World Wide Fund for Nature (WWF) and were launched in 2017.
} 
The experimental conditions vary the messages used to persuade participants about the importance of environmental protection. We use a $2 \times 2$ factorial between-subject design where messages emphasize either the consequences of environmental degradation for humans (e.g. lack of food, no water to cultivate) or for nature (e.g. less rain, animal extinction). We refer to these two conditions as EGOISTIC and Biospheric messages. Furthermore, we used either a story (NARRATIVE) or commands (IMPERATIVE) to issue the recommendation to support environmental conservation. We analyze the impact of four different audio messages on non-monetary donations to the project versus a CONTROL treatment. Understanding the effectiveness of these campaigns on rural populations living in low-income countries is important as they are more vulnerable to shocks and are directly dependent on the availability of natural resources. Moreover, environmental conservation is intertwined with social and economic development. Yet, individuals worldwide need to make an effort to slow climate change and restore degraded ecosystems.

Our results show a substantial degree of voluntarism with 81 percent of participants in the CONTROL group willing to produce hand-made crafts for the crowdfunding campaign. The results support the implications of the model by Bénabou et al. (2019). We show that the ImPERATIVE message that uses EGOISTIC frame effectively persuades participants to contribute to the campaign. Donations increased by 9.0 percentage points at the extensive margin and by 7.0 percentage points at the intensive margin relative to the CONTROL group. Our results are robust to the inclusion of socioeconomic controls and village fixed effects.

We find no significant differences when comparing participants' behavior in the NARRATIVE treatment groups with respect to the CONTROL. Yet, while in our experiment, we measure the short-term effects of the intervention, we cannot rule out positive effects of NARRATIVE in the long term due to the internalization of the values in the story.

Contrary to our expectations, we find that the congruence in the participants' environmental values and messages frame does not increase pro-environmental behavior. When splitting the sample according to participants' environmental values (Altruistic, BIospheRIC, or EGOISTIC), we find that the EGOISTIC frame has a larger effect on behavior for all value types. This finding suggests that for individuals in low-income countries, the need to make a living takes primes over other moral motives.

Moreover, we find that when the NGO has the opportunity to collect more money per unit of work donated, participants reduce on average the number of bookmarks they are willing to produce, suggesting that individual giving is not motivated by warm-glow. This finding is relevant as it suggests that external donors can easily crowd out environmental efforts.

Last, we include two heterogeneous analyses. First, we explore which message persuades individuals with high and low schooling levels towards pro-environmental behaviors. Second, we analyze which message is more persuasive to individuals who report a higher degree of intergenerational altruism towards future generations. Our results show that the NARRATIVE Non-EGOISTIC message is more effective for individuals with low schooling levels, compared 
to Control and the other treatments. In contrast, messages with an EGOISTIC frame are effective for individuals with high levels. Moreover, we find that messages with an EGOISTIC frame crowd out the donations for individuals with a high concern for future generations. These results suggest that policy interventions aimed at increasing pro-environmental behavior should avoid using one-size communication campaigns, as they do not fit all.

Our contribution to the literature is threefold. First, our research adds to the previous work on persuasive communication and particularly on the role that framing plays in encouraging prosocial or moral behaviors (Brañas-Garza, 2007; Dal Bó \& Dal Bó, 2014; Hillenbrand \& Verrina, 2018; Bénabou et al., 2019). Previous work suggests that warm messages are more persuasive than cold messages as they are more engaging and reduce the distance between the sender and receiver (Dubois et al., 2016). Besides, narrative persuasion has been studied and proved successful in domains such as health, education, and prosocial behavior (Vitz, 1990; Dahlstrom, 2014; Hillenbrand \& Verrina, 2018). In the domain of environmental conservation, previous work has shown that sending persuasive messages - compared to no messages - is an effective tool for behavioral change, suggesting that environmental campaigns may be a good complement for policy (e.g Katz et al., 2016) Yet, there is large evidence showing that the type of information and sender matters in persuading individuals to behave pro-environmentally. For example, studies have shown that providing social information induces behavioral changes for resource conservation (e.g Allcott, 2011; Allcott \& Rogers, 2014; Ferraro \& Price, 2013; Jaime Torres \& Carlsson, 2018), or in increasing voluntary contributions for the environment. (e.g Alpizar et al., 2008). Moreover, Ho et al. (2020) show that the identity of the sender matters for driving behavioral changes in plastic consumption. Our research is novel in that the dyad of narratives and imperatives has not been tested, neither alone nor in conjunction with value-framed messages as we do in this study.

Second, our work contributes to research that focuses on the role of congruence between the message and the receiver's beliefs (Mullainathan \& Shleifer, 2005a,b). We empirically test whether messages that correspond to participants' environmental values are more effective at affecting behavior. Hence, our work also relates to the recent conservation literature that explores how value-frames can promote pro-environmental behavior (Evans et al., 2013; Reddy et al., 2020). The closest to our study is Reddy et al. (2020) who experimentally assesses the effectiveness of different message frames that make either the economic or environmental benefits of conservation salient or include both on farmers' willingness to enroll in an agricultural program. The authors find no significant effect of the messages compared to a control condition where there is no frame and where only information is provided. While previous studies tested the relation between value frames and behavior with subjects from WEIRD (Western, educated, and industrialized, rich, and democratic) countries, we extend the research to consider participants in a low-income country. Motivations and concerns for environmental conservation might differ for people living in low-income countries who are more vulnerable to environmental degradation (IPBES, 2018). As a large share of the population lives in the rural areas (World Bank, 
2019), and thus depend on the availability of natural resources, frames appealing to natural conservation or to egoistic motives could trigger pro-environmental behavior. This paper provides new evidence on the relative effectiveness of those frames. Our work contributes to this literature by providing empirical evidence on the role of framing and showing that the mode of communication (i.e., narratives or imperatives) matters.

Last, our work adds to the literature on charitable giving. Compared to studies that focus on monetary donations, there is little empirical evidence on non-monetary contributions. For example, no previous studies use a matching mechanism with non-monetary contributions to our knowledge. Until now, matching grant experiments have shown that matches help increase the number of donations (Karlan \& List, 2007; Meier, 2007). Yet, even when contributions should increase as the cost for giving decreases (Andreoni \& Miller, 2002), there is mixed evidence regarding the average contributions when the match size increases. A previous study by Meier (2007) found an increase while Karlan \& List (2007) did not find a change.

Our results raise concerns for a potential communication mismatch between conservationists and individuals. While the former expect individuals to care for the environment because of non-egoistic concerns and frame their communication campaigns in such a way, individuals are likely to be rather guided by a logic of self-interest based on a calculation of gains and losses (Schultz, 2001; De Dominicis et al., 2017). From a policy perspective, our results provide NGOs, charities, and public institutions present in low-income countries new elements that could be incorporated in their communication campaigns to nudge individuals towards pro-environmental behaviors that can be beneficial for social and economic development.

The paper proceeds as follows. Section 4.2 presents the conceptual framework. Section 4.3 describes the context, and Section 4.4 the experimental design. Section 4.5 presents the data and the estimation results. Section 4.6 discusses the results and concludes.

\subsection{Conceptual framework and hypothesis}

Bénabou et al. (2019) highlight the importance of exploring different communication forms to persuade subjects towards actions that are beneficial for society. They propose two forms a sender can use to persuade a receiver towards the desired action: a narrative or an imperative.

On the one hand, a narrative provides moral arguments to highlight the existence of a norm or reason to support prosocial behavior (Bénabou et al., 2019). Narratives can be characterized as warm messages (Dubois et al., 2016). Therefore, comprehension, interest, and engagement from the audience might be higher than with the transmission of a competent or cold message (Dahlstrom, 2014; Dubois et al., 2016). They typically focus on characters (human or not) and describe their subjective experience and the particular consequences they face after taking a certain course of action (Vitz, 1990). As individuals 
identify with the characters, fables might help educate citizens. Yet, narratives leave a broad leeway for interpretation on the side of the receiver (Bruner, 1991), who might face uncertainty on the expected behavior implicit in the narrative.

On the other hand, imperatives are general precepts that transmit a request, a suggestion, or a command on how to behave (Bénabou et al., 2019). They are found in the Ten Commandments, the National Constitution, etc. Imperatives usually transmit a command without providing further arguments or justification and can (or not) include the consequences of a particular behavior. In contrast to narratives, imperatives can be seen as competent or cold messages (Dahlstrom, 2014; Dubois et al., 2016). They can also reduce the problem of interpretation gaps as they are clear on the action that is expected from the sender. This implies that what is communicated is what should be understood. However, for imperatives to be effective, they should be transmitted by a perceived (moral) authority, meaning a sender whose interests are perceived to be more in line with those of the receiver.

Since no previous empirical studies are testing the effectiveness of these communication modes, it is unclear which one can predominate. The channels through which persuasive communication works have been rarely discussed in the literature. Bénabou et al. (2019) propose that imperatives are more effective at changing behavior, particularly so when a credible institution issues them. On the one hand, as imperatives encompass simple messages, there is a low cognitive cost in understanding the recommendation it entails. Hence, individuals can adopt the precepts as simple rules-of-thumb. In addition, imperatives can help to promote prosocial behavior in diverse contexts, working as a commitment device to overcome temptations.

An alternative mechanism by which persuasive communication can operate is through guilt aversion. Previous academic work has shown that individuals avoid disappointing others as they anticipate a feeling of guilt from falling short of the expectations that others put on them (e.g Charness \& Dufwenberg, 2006). In a sender-receiver interaction, the degree of guilt generated will increase the feeling of attachment towards the sender and the clarity of her expectations. As the narrative is a warmer message, we hypothesize that it will be easier for receivers to develop a closer relationship towards a narrative-sender to an imperative-sender. Therefore, guilt aversion might be more relevant to explain prosocial behavior. Yet, with narrative messages, a receiver cannot be entirely sure if she interprets the message correctly. Hence, she faces uncertainty on whether she is not disappointing the sender with her actions. This is different from imperative messages where the behavior expected is more explicit. Hence, the relative effect between narratives and imperatives on changing behavior becomes an empirical question.

Besides the mode of communication, the congruence between the sender and receiver beliefs could determine the effectiveness of the message. Different studies have shown that individuals have different levels of moral reasoning or moral justification for behavior. For example, in psychology, the motivations behind pro-environmental behaviors can be driven by a mix between self-interest (EGOISTIC), altruistic and prosocial motives or concerns 
(Biospheric) (Schultz, 2001; W. Schultz \& Zelezny, 2003; Steg, Perlaviciute, et al., 2014; Steg, Bolderdijk, et al., 2014; De Dominicis et al., 2017). When the EGOISTIC values dominate an individual's behavior, behavior is more sensitive to information about positive or negative incentives. In this case, people will be more likely to engage in pro-environmental behavior if they think they can gain something from it or believe they can avoid high costs by doing so (Lindenberg \& Steg, 2007). When the Biospheric values dominate an individual's behavior, they are motivated to protect the environment irrespective of whether there are personal gains to make (De Dominicis et al., 2017).

We aim to test whether it is enough to send one message that "fits all" or better personalize communications to fit the individual's moral reasoning. If there is low congruence, individuals can be unlikely to listen to the message or pay attention to it (Dewatripont \& Tirole, 2005). Besides, individuals might be more likely to remember information that is closer to their beliefs (Mullainathan \& Shleifer, 2005b). We, therefore, expect that congruent messages are more effective at promoting pro-environmental behavior.

\subsection{Context}

Madagascar is among the richest nations in biodiversity and natural resources, yet one of the poorest nations in the world in terms of GDP, with around 74 percent of its population living under USD 1.90 per day (Stocker et al., 2019). As one of the world's biodiversity hotspots (Myers et al., 2000), it is an important target for conservation initiatives. Even though there have been many conservation efforts in place (Waeber et al., 2016), Madagascar still scores very low in the "Environmental Performance Index" by ranking 174 out of 180 countries, ${ }^{2}$ and in the "Human Development Index" ranking 162 out of 182 countries."

We conduct our experiment in northeastern Madagascar, in the Sambava-Antalaha-VohemarAndapa (SAVA) region which produces ca. 40 percent of the world's natural vanilla (FAO, 2020). It hosts a large tract of tropical forest which is of great importance for biodiversity (Martin et al., 2020). Most of the population living in the region is involved in agriculture activities and is vulnerable to environmental shocks, especially to cyclones that frequently hit the area. Next to vanilla, rice (both irrigated paddies and hill rice) is an important cash and subsistence crop (Hänke et al., 2018).

A traditional practice by the population is slash-and-burn agriculture or 'tavy' , which is considered the main cause of deforestation and loss of biodiversity (Styger et al., 2007; Waeber et al., 2016; Martin et al., 2020). 'Tavy' is a self-provisioning practice rooted in the culture, which serves as a buffer against seasonal income volatility (Laney \& Turner, 2015). However, the expansion of this practice to the natural reserve borders creates great

\footnotetext{
${ }^{2}$ For more information see https://epi.yale.edu/epi-results/2020/component/epi

${ }^{3}$ For more information see http://hdr.undp.org/en/countries/profiles/MDG

${ }^{4}$ In this practice, primary or secondary forests are cut and burned to cultivate rice one season, followed by another short productive period. After this cycle, the land is left alone to fallow. (For more information see Styger et al. (2007)).
} 
pressure on the region's biodiversity.

Besides the predominance of practices like slash-and-burn agriculture, other human-made activities create high pressure on the environment. Even though northeastern Madagascar is a relatively wealthy region in the country (Osborne et al., 2016), the infrastructure in the rural areas is poor. For example, few villages have a water supply, and sanitation services are rare. Further, wood is the primary material for house construction, and there is extensive charcoal production. Hence, forests provide land and services to the population to support their well-being, but the lack of regulation has increased the pressure on ecosystems and biodiversity (Llopis et al., 2020).

Our study region is one of the few that still hosts tropical forests in the country, which are in danger of disappearance - risking ecosystem services and biodiversity - if no action is taken in the upcoming years. However, the interaction between the population and environmental institutions or NGOs has not been efficient in achieving compromises for environmental protection and conservation. People believe that those organizations do not understand their traditional practices or are not concerned about their economic well-being (Styger et al., 2007). This is similar to what we encountered during our exploratory phase in 2018 after conducting eight focus group discussions in four different villages located in the region. The first finding from the exploratory phase is that there are communication difficulties between the population and the environmental organizations, in which the latter struggles to persuade the former. The second finding is that there might be a communication mismatch between the two parties. According to what the organizations reported to us, people are more willing to engage in pro-environmental behaviors when economic losses that directly affect the population are at stake. This resembles a more self-interest or egoistic thinking, which goes in the opposite direction to how conservation actors communicate with the population as they usually highlight non-egoistic motivations.

Moreover, some studies argue that conservation actors in Madagascar have failed to integrate the knowledge, traditions, norms, or taboos, and the ancient connections that the population has regarding the environment (e.g Jones et al., 2008; Fritz-Vietta et al., 2017; FernándezLlamazares \& Cabeza, 2018). In Madagascar, there is a set of community laws ("dina") that govern the population and the relations within and between villages (Andriamalala \& Gardner, 2010). These laws contemplate sanctions and are recognized by the Malagasy government. With the increase of community resource management programs - to conserve forests, marine reserves, etc.- environmental organizations have used "dina" to increase compliance (Jones et al., 2008; Andriamalala \& Gardner, 2010).

In many cases, environmental organizations, using their expertise and 'western' knowledge, have designed rules that are communicated as commands to the population and that are expected to be followed (e.g Fritz-vietta et al., 2011). One of the most common problems with this type of "dina" is that when they are not adequately socialized with the community or do not fit the community's aspirations, they can backfire by reducing compliance. This can endanger the community's social cohesion and the relationship between the community 
and the environmental organization (e.g Jones et al., 2008; Andriamalala \& Gardner, 2010; Fritz-vietta et al., 2011). The use of "dina" for environmental conservation has as well overshadowed the "fady" - a system of taboos that aim to guide behavior - that already exist in the communities. Many of the "fady" protect and regulate the use of natural resources and are orally transmitted through generations in the form of stories (Jones et al., 2008; Fritz-vietta et al., 2011). Various academics working in Madagascar (e.g Jones et al., 2008; Fritz-Vietta et al., 2017; Fernández-Llamazares \& Cabeza, 2018) have proposed the use of stories to improve the relationship between the population and the conservation institutions and direct the behavior of the population towards pro-environmental practices that can be naturally internalized. Stories that people know, can relate to, and which have been orally transmitted for generations.

Northeastern Madagascar serves as an example where the lack of persuasive communication might be present and where communication interventions could result effectively. Crafting persuasive messages that match the population's moral reasoning and that reduce the distance towards environmental organizations might be a cost-effective practice that could be implemented in the future here or elsewhere where such a mismatch is present.

\subsection{Experimental Design and Procedures}

\subsubsection{Experimental Design}

Our experiment was conducted with female and male participants living in the Sambava region in Madagascar. The experiment follows a between-within-subject design and consists of three stages (see Figure 4.1). The first stage collects the baseline characteristics of the population. The measures elicited in this stage are used as control measures to explain behavior in the last stage of the game. The complete survey can be found in Appendix E. The second stage exposes participants to one out of five different persuasion audio messages. The messages vary the form of communication and the frame on the consequences of environmental degradation. In the third stage, participants have the opportunity to support a crowdfunding campaign by producing handcrafted bookmarks.

Figure 4.1: Experimental sequence

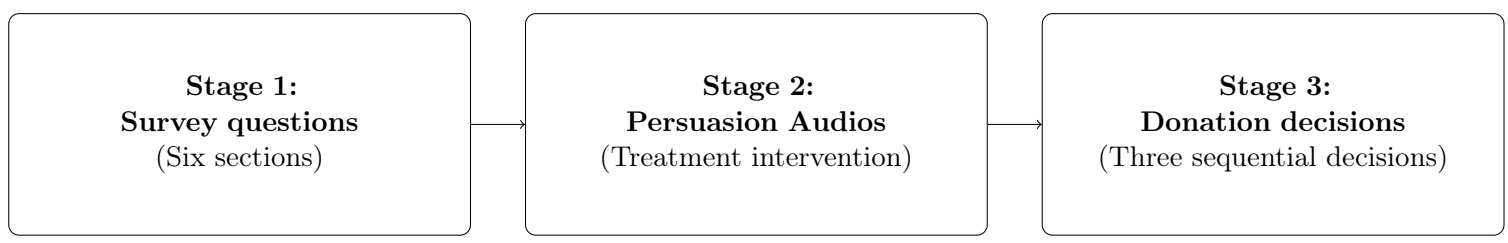

\section{Stage 1: Survey questions}

At this stage, we elicit household and individual characteristics of the sample using an individual survey with six sections. 
Section 1: Household and individual characteristics The first section includes questions on the number of children, household size, migration, main economic activities, religion, savings, age, education, and marital status.

Section 2: Environmental concerns This section aims at eliciting individuals' environmental values. We ask participants about their general concern for environmental problems such as deforestation, air pollution, water pollution, and soil degradation and the reasons for their concerns. First, participants have to rate their concerns on a scale of 1 (I am not concerned at all) to 5 (I am very concerned). After that, participants are asked about their reasons for concern for environmental problems in general. In this second step, participants have to rank six different categories indicating which one they are most concerned about (rank of 1) to the least they are concerned about (rank of 6). The categories are the following: i) plants, ii) animals, iii) myself, iv) my future, v) people of the village, and vi) future generations. To avoid order effects, we display six cards - one per category - on the table or floor so that each participant can order them according to their preference.

Based on the ranking of the categories, we can classify the participants as BIOSPHERIC, Altruistic or Egoistic. If a participant ranked 'plants' or 'animals' first, she is characterized Biospheric. If she ranked 'people of the village' or 'future generations' first, she is characterized as Altruistic. Last, if a participant ranked 'myself' or 'my future' first, it is characterized as EGOIstic. ${ }^{5}$

Section 3: Social Capital This section includes questions on social capital perceptions. We ask participants about their satisfaction with the level of cooperation in their village, if the people of their village can be trusted, and if people usually help each other.

Section 4: Intra- and intergenerational altruism This section measures participants' altruism towards the past, present, and future generations. Previous research has shown the tension between present and future generations regarding environmental conservation (e.g Jacquet et al., 2013). On the one hand, the present generations have to decide whether to bear the costs or not. On the other hand, future generations could either profit or suffer the consequences of today's decisions. In this context, where traditional religion is still predominant, the role of ancestors is an important factor for conservation. In many countries around the world, like Madagascar, the existence of taboos has prevented the extinction of many animal species (e.g Jones et al., 2008). By measuring participants' intra- and inter-generational altruism, we can shed light on which message types are more persuasive for individuals when considering their altruism preferences towards their or others' generations.

\footnotetext{
${ }^{5}$ In the cases where participants ranked items from the same category (EGoistic, Altruistic, or Biospheric) as first and last, we used the category ranked as second for the classification. This procedure follows a similar logic as the one used by Schultz (2001).
} 
Participants are asked to distribute an endowment from $25,000 \mathrm{FMG}^{6}(\approx 1.25 €)$ into three categories: 'Ancestors', 'Society/people from the village', and 'Children' to explore their intra- and inter-generational altruism preferences. We inform participants that the money allocated in each category will be spent on different goods: flowers for the ancestors in the cemetery ('Ancestors' category), rice for people in the hospital ('Society/people from the village' category), and school material for school children ('Children' category). Once the experimental survey is finished in each village, the amounts donated in each category are aggregated. Two or three days after the visit, the donations for each group are made effective. ${ }^{7}$ The selection of goods was based on the information provided by chiefs and school directors about the needs of the different groups. To test whether participants related each of the goods to a particular generation, we asked in the second pilot which generation they think will profit from each of them. From a total of 24 participants, 83 percent answered all questions according to our expectations. Hence, we have reason to believe that most of the participants can associate each of the goods to the different generation groups.

Section 5: Time and risk preferences Time preferences are elicited following a similar quantitative measurement described in Falk et al. (2018). The measure consists of five sequential and interdependent hypothetical binary choices between receiving an immediate versus a delayed financial reward. Different from the authors' measure, we adapted the procedure to reduce the time frame individuals have to think about for the future from twelve to seven months. In particular, participants are asked whether they would rather receive ' $x$ ' in one month or ' $y$ ' in seven months. Risk preferences are measured using the same qualitative question as in Falk et al. (2018). Participants have to rate on a scale from 0 (Completely unwilling to do it) to 10 (Very willing to do it), how willing or unwilling they would be to take part in a lottery in which they could lose money.

Section 6: Perceptions and experiences with natural disasters This section asks participants whether they have ever experienced a cyclone or a tropical storm and, if so, how many times in the last ten years. We also collect information on the type of damage the latest cyclone, "Enawo", caused to them and how much they worry that a cyclone hits their village in the near future.

\section{Stage 2: Persuasion Audios}

When participants finish answering the questions in Stage 1, they are randomly allocated to one of the four persuasion treatment groups or the CONTROL group. In each group, participants listened to a one minute audio spot which was pre-recorded by the same

\footnotetext{
${ }^{6}$ We use the 'Franc Malagache' (FMG) as currency instead of ariary (the national currency), because participants felt more comfortable and showed higher understanding when deciding in FMG than in ariary. Participants made decisions in FMG but were paid in ariary. The ratio between FMG and ariary is 5:1. The exchange rate at the time of the experiments was around 4,000 ariary equivalent to $1 €$.

${ }^{7}$ The donation certificates can be facilitated by request.
} 
person in the local language Malagasy. The audio spots aimed at creating awareness of the consequences of human activity on the environment. Information is transmitted orally as in different areas of the world - primarily due to low levels of schooling - oral tradition is still the main form of communication used. This situation applies to the rural areas of Madagascar (Waeber et al., 2017). The information provided in the treatment audios is similar among the four treatment groups, but as described in Table 4.1 vary in two dimensions: i) the mode of communication (NARRATIVE or Imperative), and ii) the frame of environmental degradation consequences (EGoistic or Biospheric). The frames used in the treatments are presented in Appendix B.

Table 4.1: Treatment groups

\begin{tabular}{c|c|c} 
& Story & Command \\
\hline Biospheric & NARrative Non-Egoistic & Imperative Non-Egoistic \\
\hline Egoistic & NARrative EgOistic & Imperative EGOISTIC \\
\hline
\end{tabular}

The NARRATIVE messages tell the story of a gathering in which different characters (trees, animals, water, and air) complain about the problems they are facing due to human activities. They conclude by explaining how the future would be if no human action to protect the environment is taken. The experimental conditions used either an EGOISTIC or a Biospheric frame. The Egoistic frame explains that if no human action is taken to protect the environment, there will be negative consequences on the living conditions of the individual, such as: "There will be no water to grow rice [...] there will be less food to eat". In addition, this message ended with the following sentence: "When you do not take care of the environment, it is likely that one day you will not be able to profit from it and you will suffer the consequences". Participants who listen to this audio are in the NARrative EGOIstic treatment group. In the Biospheric frame, the consequences of no human action to protect the environment would affect nature or others rather than directly oneself: " the rain will not come anymore [...] All the animals [...] will be gone [...]". This message ended with the following sentence: "When you do not take care of the environment, it is likely that one day it will disappear and the world will suffer the consequences". Participants who listen to this audio are in the NARRATive Non-Egoistic treatment group. The NARRATIVE messages were not created by us but were slightly adapted from a story we heard in one of the villages we visited during the exploratory phase.

Different from the NARRATIVE, the IMPERATIVE describes different environmental problems and provides clear information on which actions should be taken and the consequences if such actions are not taken. The consequences were framed similarly to the narratives but presented as statements: "Do not cut the trees from the forests or there will be no rain and thus less water to produce rice [...]" in the EGOISTIC frame, and "Do not cut the trees from the forests or there will be no rain [...]" in the BIOSPHERIC frame. The IMPERATIVE messages ended with the same sentences as the NARRATIVE for each of the 
two frames Egoistic and Biospheric. Participants who listen to the former frame are in the ImPERATIVE EGOISTIC treatment group, and participants who listen to the latter are in the Imperative Non-Egoistic group. As with the NARRAtive, the Imperative messages were not created by us but were adapted from pamphlets and posters given to some people in the region by different vanilla certification companies.

Participants in the ConTrol group listen to an audio about the invention of the telephone. This message is not related to the environment. It has a neutral frame and mode, which means that it is not narrated as a story, nor are recommendations included. Just information about the telephone is provided. The ConTrol message was taken from Wikipedia in English language and was translated to Malagasy and then back to English to check for consistency.

Since the treatment messages were adapted from the local language Malagasy, they underwent two times a double translation. First, from Malagasy to English to have an exact wording of the messages. After some changes, they were translated back to Malagasy. The second round was from Malagasy to English to ensure all adaptations were included. Finally, all messages were translated back to Malagasy. The transcription of the five audios is provided in Appendix B. To verify that all audios were clear in intonation, language and volume, on the first day of work of our group of enumerators they had to listen to the pre-recorded messages and give detailed comments or suggestions, if necessary. This helped us to make sure that all messages have a similar intonation.

\section{Stage 3: Donation decisions}

After participants listen to the audio, we inform them that they have the opportunity to support a fundraising campaign for an NGO working in the SAVA region. They can do so by volunteering to produce hand-made bookmarks. We provide background information about the NGO such as that it comes from the United States and has been working seven years in the region doing different projects to protect the environment.

To avoid confounds in terms of willingness to volunteer, all participants are requested to produce the same number of bookmarks and then decide how to distribute their efforts between paid or unpaid work. In total, they could produce 12 bookmarks that were either green or blue. For each blue bookmark, participants received 5,000 FMG $(\approx 0.25 €)$, whereas no payment was offered for green bookmarks. In addition, green bookmarks have an associated positive environmental externality as we use them to incentivize donations for a reforestation project.

We explain to the participants that the bookmarks will be brought back to Germany but would have different uses according to the color. Whereas green bookmarks are to be used to raise funds to plant trees in the SAVA region by providing donors with those bookmarks as gifts, the blue bookmarks are to be distributed to random people who have not made a monetary contribution to the campaign. Hence, the green bookmark has positive effects on 
the environment, whereas the blue one does not. We decided on the green and blue colors for the bookmarks as they are context neutral and are easy to associate with the cause.

To study the effect of different messages and matching ratios on participants' giving behavior, we vary the relative value of each green bookmark across three different scenarios that are presented to each participant in the following order: In scenario-1 for each green bookmark participants decide to make, the NGO can collect 5,000 FMG $(\approx 0.25 €)$. In scenario-2 the price the NGO could receive is raised to $7,500 \mathrm{FMG}(\approx 0.35 €)$, and in scenario-3 the price is raised to $10,000 \mathrm{FMG}(\approx 0.50 €)$.

The scenarios are presented in the same order for all participants because, in the pilot, we observed that people had difficulty in realizing the price changes when the scenarios were randomized. To have more insights on what might motivate the contributions from one scenario to another, we ask participants, after making the decisions in scenarios 1 and 2 , for their reasons to change with respect to their previous contributions. After participants decide in each of the three scenarios, using the strategy method, a randomization device selects one of the scenarios to be implemented. According to the selected scenario, participants have to make the respective number of green and/or blue bookmarks and receive the earnings accordingly. In neither scenario, a donation threshold is mentioned, but participants can not decide for more than 12 bookmarks in each scenario.

\subsubsection{Experimental Procedures}

The experiment was conducted between August and September 2019. Departing from a large database owned by the project Diversity Turn, ${ }^{8}$ that includes information on the villages in the SAVA region that are located up to $10 \mathrm{~km}$ away from the main road, we randomly chose sixteen villages that are farther away from the main natural reserves to conduct the survey-based experiments. ${ }^{9}$ Some of the villages in this area have dispersed tropical forest fragments that are important for conservation but are not in the core area of environmental programs offered by the NGOs present in the region. Using the information from the database, we conducted a stratified random sampling based on village size. ${ }^{10}$ From this sample of villages, we selected our participants by inviting a percentage of the total population $(\approx 1.5$ percent $)$ to take part in our experiment. The percentage was selected according to the power calculations and our logistical capacity. Due to bad weather conditions and inundation, one village could not be reached, which leaves us with a total sample of fifteen villages.

Households participating in the experiment were selected randomly using a die. Half of the enumerators started from the village center and the other half from the borders. After rolling the die, each enumerator went into one of the cardinal directions and, according to

\footnotetext{
${ }^{8}$ More information can be found at https://www. uni-goettingen.de/en/529181.html.

${ }^{9}$ We only considered villages located in the Sambava and Antalaha districts as the presence of environmental NGOs in these two areas is less compared to the Andapa and Vohemar districts.

${ }^{10} \mathrm{We}$ classified the villages into five types according to their population size.
} 
the number shown on the die, counted the number of houses and visited the corresponding one (see Figure 4.A1). Once the enumerator reached a corner, they tossed a coin to decide whether to continue right (head) or left (tail). As we conducted the surveys on the days where people usually stay at their homes to rest, and as we previously announced our visit, most of the time, we could randomly select whether the female or male head of the household would participate in the survey. The selection was made by tossing a coin. Individuals were told that their participation in the survey was voluntary. If the subject in the household selected did not agree to participate, the enumerator went back to the previous point and rolled the die again. Those who accepted to participate were told that if they wanted to stop at any point, they were free to do so, but they would not receive the participation fee of 2,000 ariary $(\approx 0.5 €)$.

The survey questions were asked orally by an instructor in Malagasy. The answers were typed in a tablet using the Kobotoolbox. ${ }^{11}$ The survey was translated from English to Malagasy and then back to English to guarantee comparability. In some of the questions, visual material was used to ensure that participants correctly understood the questions and tasks.

Participants were allocated to each treatment with the help of a randomization device that was programmed in the tablets. ${ }^{12}$ In total, 685 individuals participated in our experimental survey. We excluded fifteen observations as the survey response time was less than 10 minutes. ${ }^{13}$ The total sample size we consider for the analysis is 670 observations. Table 4.A1 shows the number of observations according to the village types.

We selected 12 bookmarks as a total because if a participant decided to make all of them blue, then the incentives are comparable to the daily wage in the region for working in a vanilla plantation $(\approx 4 €)$. Besides, we prefer a discrete decision over a binary choice of contributing versus not contributing to observe participants' trade-offs in each scenario.

A bookmark is considered as complete if (a) there are three beads at the top of a blue or green string; (b) the participant signs the card with their name; and (c) the card is attached to the string with tape. We designed the bookmarks in a way that is easy for the participants to make and look appealing to the people in Germany as they will receive the green bookmark in exchange for a contribution. All necessary materials to make the bookmarks are provided (12 green and blue strings, 12 cards, 36 beads, tape, and scissors); hence participants do not need to use any personal material. ${ }^{14}$ The pilot study showed that the production of a bookmark takes on average 2 minutes, which is the same independent of the color. Before participants start making the bookmarks, each enumerator shows how

\footnotetext{
${ }^{11}$ Kobotoolbox is a free and open software to collect data online and offline with the use of portable devices. For more information, see https://www.kobotoolbox.org

${ }^{12}$ Our treatment randomization device had difficulties during the first week of data collection. Hence, some villages had to be revisited to balance the number of observations per treatment. We use the same strategy of choosing households as described above. Therefore, some village types have, on average more observations than initially planned.

${ }^{13}$ From the pilot, we inferred that the sections related to this paper lasted between 20 to 30 minutes

${ }^{14}$ During the data collection all farmers completed the 12 bookmarks following these specifications.
} 
they should be made. If there are no questions, the enumerator moves to the next household and comes back later to pick up the 12 complete bookmarks and deliver the corresponding payment. If the 12 bookmarks are not made, the participant does not receive the earnings from the activity. This condition is known beforehand by participants. An example of a green and blue bookmark can be found in Figure 4.C1.

Participants made on average eight blue bookmarks and thus earned on average 8,800 ariary $(\approx 2.2 €)$, plus a participation fee of 2,000 ariary $(\approx 0.5 €)$. The experimental earnings correspond to the decisions participants made in Stage 3. The payment was made privately at the end of the survey and once we have collected the bookmarks from stage 3. Each participant received the corresponding earnings in a white envelope.

\subsection{Results}

\subsubsection{Summary statistics}

We start our empirical discussion describing the socio-demographic characteristics of participants by treatment, as well as their social capital perceptions in Panel A of Table 4.2. Half of our participants are female and 76 percent work as farmers. Participants reported an average of 9.4 years of education. They are on average 41 years old, live in a household with 3 other persons, and have 3 children. Most of our subjects come from families whose main activity is or was agriculture. In addition, 45 percent of participants reported having saved money in the year previous to the experiment and 67 percent to be part of a savings group. Savings are mostly used to finance significant investments like motorbikes or as a risk coping strategy against bad harvests. Moreover, 88 percent of participants consider themselves religious, the majority as Christians. 36 percent of the participants reported having experienced food insecurity in the months previous to the experimental sessions. Variables related to community experience show that social cohesion in the villages is not strong. The perception about the level of cooperation within the village has a mean value of 2.92 out of 5 , constituting the perceived maximum cooperation, the mode is two. This impression is confirmed when considering that 47 percent of the subjects reported that 'most people cannot be trusted'.

In Panel B of Table 4.2 we report the variables related to the environment. The majority of participants experienced a cyclone and reported to be economically affected by the cyclone "Enawo" which hit the region in 2017. Thus, it is not surprising that participants reported an average of 9.2 out of 10 on how much they worry about cyclones. In addition, participants reported an average of 4.2 out of 5 regarding their concern for the environment.

After running a joint orthogonality test, we found that participants' years of education, level of satisfaction with village cooperation, and cyclone experience are not balanced across our treatment and control groups. We add these variables as controls in the subsequent analysis. 
Table 4.2: Orthogonality Table

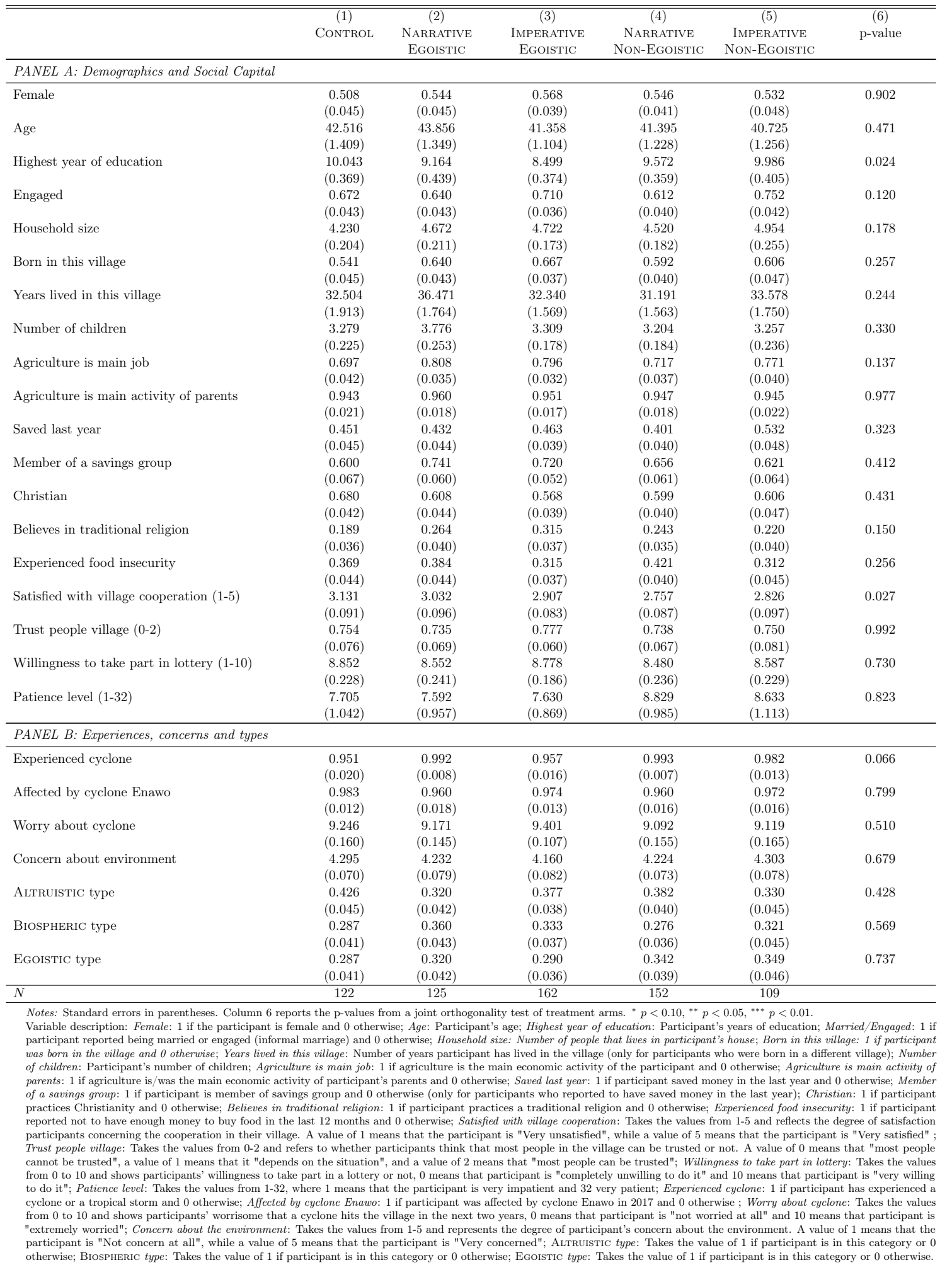




\subsubsection{Effort provision: Extensive and intensive margins}

We now turn to the main results of our experiment. Figure 4.2 shows the average number of green bookmarks the participants made in the treatment and the control groups. We find that individuals in the IMPERATIVE EGOISTIC group contribute on average more compared to participants in the Control group (two-sided $t$-test, p-value $<0.01$ ), in the NARRATIVE Egoistic group (two-sided $t$-test p-value $<0.01$ ), and in the Imperative Non-Egoistic group (two-sided $t$-test $\mathrm{p}$-value $<0.05$ ). This provides the first evidence that IMPERATIVE messages that make EGOISTIC values salient are more effective than other message types.

Figure 4.2: Average number of green bookmarks by treatment All scenarios, $N=670$

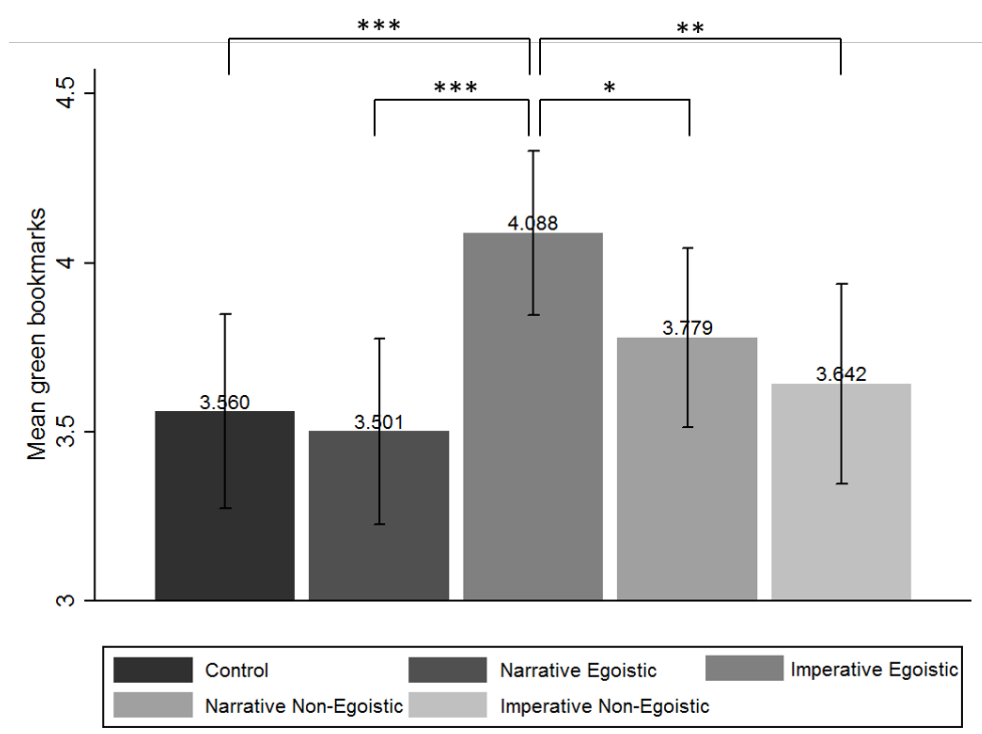

Notes: The graph displays confidence intervals of $95 \%$.

${ }^{*} p<0.10$, ** $p<0.05$, *** $p<0.01$.

To further explore the treatment effects on contributions to control for the effects of subject heterogeneity and check robustness, we estimate the following model:

$$
p g_{i s}=\alpha+\delta T_{i}+\beta p_{i s}+X_{i}^{\prime} \gamma+\mu_{v}+\epsilon_{i s}
$$

where $i$ represents each individual and $s$ indicates the scenario. $p g_{i s}=\mathbf{1}$ (contribution $>0$ ) is an indicator variable that takes the value of 1 if they produced a strictly positive amount of green bookmarks. $T_{i}$ denotes the vector of treatment dummies for NARRATIVE EGOISTIC, Imperative Egoistic, Narrative Non-Egoistic, and Imperative Non-Egoistic. $p_{i}$ is the vector of price dummies for each scenario. $X_{i}^{\prime}$ is a vector of individual characteristics. $\mu_{v}$ are village fixed effects and $\epsilon_{i} s$ is an i.i.d. random error.

$$
g_{i s}=\alpha+\delta T_{i}+\beta p_{i s}+X_{i}^{\prime} \gamma+\mu_{v}+\epsilon_{i s}
$$


where $i$ represents each individual and $s$ indicates the scenario. $g_{i s}$ represents the intensive margin of donation in each scenario: Number of green bookmarks that takes values between 0 and 12. The other variables follow the description mentioned in Equation 4.1.

Table 4.3 provides evidence of treatment effects on the extensive margin of giving (Columns 1 and 2), namely, whether an individual made a positive amount of green bookmarks. We use ordinary least squares (OLS) to estimate the treatment effects. Columns (3) and (4) report the average effects on the number of work units contributed by participants (no conditional on a positive donation effort) using a Tobit model, taking into account potential censoring.

Regarding the extensive margin of donation, we found that in the CONTROL group, 81 percent of participants contributed to the fundraising by making green bookmarks. Our results show that the ImPERATIVE EGOISTIC message is the most effective in persuading individuals to contribute. Participants listening to this message are 9.0 percentage points more likely to donate in comparison to participants in the ConTROL group ( $\mathrm{p}$-value $<0.05$ ) (see Column 3). In addition, we found that participants in this treatment made on average the highest number of green bookmarks, increasing their contribution by 0.9 more bookmarks (p-value $<0.05$ ) compared to the Control group (see Column 6). This translates into an increase of 7.0 percentage points. These results hold adding socioeconomic controls and village level fixed effects. Also, they hold when correcting for multiple hypothesis testing (see Table 4.D2).

In comparison to analogous messages (NARRAtive Egoistic and Imperative NonEGOISTIC), participants exposed to the ImPERATIVE EgOISTIC message are significantly more likely to contribute and contribute on average more (t-test p-value $<0.06$ ). We find no significant differences when comparing participants' behavior in the NARRATIVE treatment groups with respect to the CONTROL group.

We also observe interesting correlations with our covariates (see Table 4.D1). Similar to the findings reported by Landry et al. (2006), the enumerator's gender affects the extensive margin. We observe that participants exposed to female enumerators are, on average 13 percentage points more likely to donate their effort. Yet, female enumerators did not have a treatment effect on the number of green bookmarks participants made. We find that individuals with higher schooling are more likely to contribute and make on average more green bookmarks. Moreover, we find that participants who have experienced food insecurity contribute a higher number of green bookmarks, probably because they are already experiencing the effects of environmental degradation. Last, we find that more patient participants contribute on average more.

Result 1. The ImPERATIVE EGOISTIC message increase the likelihood to make a donation (external margin) and in increasing their average donation (intensive margin). 
Table 4.3: Treatment effects on effort (Full sample, OLS and Tobit models)

\begin{tabular}{|c|c|c|c|c|c|c|}
\hline & $\begin{array}{c}\text { (1) } \\
\text { Positive effort }\end{array}$ & $\begin{array}{c}\text { (2) } \\
\text { Positive effort }\end{array}$ & $\begin{array}{c}(3) \\
\text { Positive effort }\end{array}$ & $\begin{array}{c}(4) \\
\text { No. Green }\end{array}$ & No. Green & No. Green \\
\hline NARrative Egoistic & $\begin{array}{l}-0.001 \\
(0.045)\end{array}$ & $\begin{array}{c}0.008 \\
(0.045)\end{array}$ & $\begin{array}{c}0.006 \\
(0.043)\end{array}$ & $\begin{array}{c}-0.052 \\
(0.393)\end{array}$ & $\begin{array}{c}0.056 \\
(0.386)\end{array}$ & $\begin{array}{c}0.096 \\
(0.381)\end{array}$ \\
\hline IMPERATIVE EGOISTIC & $\begin{array}{l}0.095^{* *} \\
(0.039)\end{array}$ & $\begin{array}{c}0.085^{* *} \\
(0.039)\end{array}$ & $\begin{array}{l}0.089^{* *} \\
(0.039)\end{array}$ & $\begin{array}{l}0.799^{* *} \\
(0.369)\end{array}$ & $\begin{array}{l}0.698^{*} \\
(0.363)\end{array}$ & $\begin{array}{c}0.859^{* *} \\
(0.361)\end{array}$ \\
\hline Narrative Non-Egoistic & $\begin{array}{c}0.019 \\
(0.043)\end{array}$ & $\begin{array}{c}0.022 \\
(0.043)\end{array}$ & $\begin{array}{c}0.022 \\
(0.043)\end{array}$ & $\begin{array}{c}0.309 \\
(0.375)\end{array}$ & $\begin{array}{c}0.289 \\
(0.370)\end{array}$ & $\begin{array}{c}0.228 \\
(0.366)\end{array}$ \\
\hline IMPERATIVE Non-EgoistiC & $\begin{array}{l}-0.014 \\
(0.047)\end{array}$ & $\begin{array}{l}-0.003 \\
(0.046)\end{array}$ & $\begin{array}{l}-0.016 \\
(0.044)\end{array}$ & $\begin{array}{c}0.077 \\
(0.407)\end{array}$ & $\begin{array}{c}0.174 \\
(0.399)\end{array}$ & $\begin{array}{c}0.109 \\
(0.394)\end{array}$ \\
\hline Constant & $\begin{array}{c}0.806^{* * *} \\
(0.033)\end{array}$ & $\begin{array}{c}0.918^{* * *} \\
(0.047)\end{array}$ & $\begin{array}{c}0.883^{* * *} \\
(0.138)\end{array}$ & $\begin{array}{c}3.134^{* * *} \\
(0.280)\end{array}$ & $\begin{array}{c}4.444^{* * *} \\
(0.520)\end{array}$ & $\begin{array}{c}3.546^{* * *} \\
(1.241)\end{array}$ \\
\hline Observations & 670 & 670 & 670 & 670 & 670 & 670 \\
\hline Fixed effects & No & Yes & Yes & No & Yes & Yes \\
\hline Controls & No & No & Yes & No & No & Yes \\
\hline p-value $\mathrm{T} 1$ vs $\mathrm{T} 2$ & 0.0116 & 0.0487 & 0.0254 & 0.0203 & 0.0776 & 0.0338 \\
\hline p-value T3 vs T4 & 0.4660 & 0.5625 & 0.3845 & 0.5503 & 0.7628 & 0.7493 \\
\hline p-value T1 vs T3 & 0.6502 & 0.7506 & 0.7008 & 0.3335 & 0.5274 & 0.7150 \\
\hline p-value T2 vs T4 & 0.0070 & 0.0269 & 0.0075 & 0.0586 & 0.1640 & 0.0440 \\
\hline
\end{tabular}

Next, we pool the treatment and control groups and analyze participants' behavior across scenarios. The difference between the scenarios is the return per bookmark for the NGO. The amount participants can receive for each blue bookmark remains constant. 76 percent of the participants contributed to the fundraising by producing a strictly positive amount of green bookmarks in all of the three scenarios. In scenario 1, 17 percent of the sample did not contribute at all, while in scenarios 2 and 3 it was 16 percent and 18 percent, respectively. There are no significant differences between scenarios 2 and 3 compared to 1 at the extensive margin of donation (see Table 4.D1). Yet, there is a significant difference at the intensive margin. We find that a higher return decreases the number of green bookmarks. As shown in Figure 4.3 the decrease is significantly different from Scenario 1 to 2 ( $\mathrm{p}$-value $<0.01$ ), but it is not significantly different when comparing Scenario 3 and 2 ( $\mathrm{p}$-value $=0.5$ ). This crowding out of contributions suggests that the participants' main motivation for giving is not warm-glow, as otherwise we would not have observed a significant change in the contributions, and suggests that they act as impure altruists. 
Figure 4.3: Average contributions by Scenario

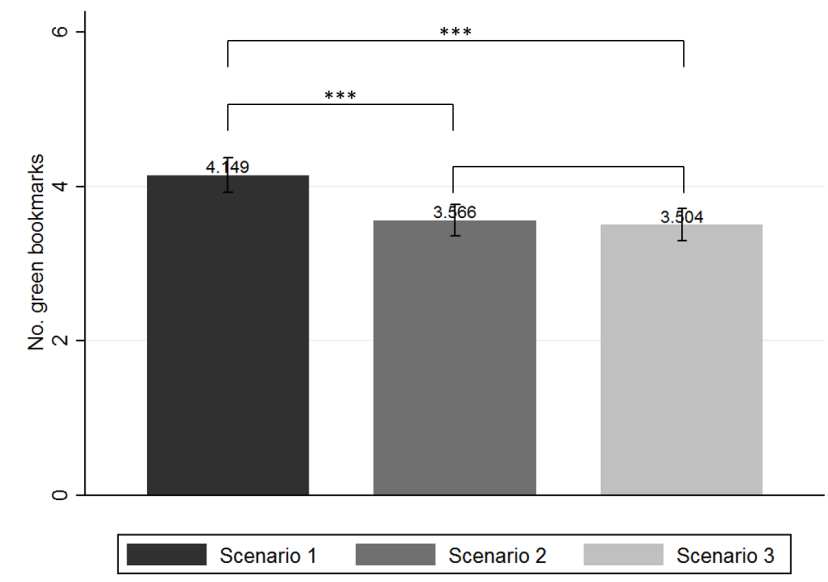

Notes: The graph displays confidence intervals of $95 \%$. ${ }^{*} p<0.10,{ }^{* *} p<0.05,{ }^{* * *} p<0.01$.

\subsubsection{Environmental concerns and giving}

Based on the environmental concerns stated in the questionnaire, we classify subjects into three types. On average, we find that: 37 percent are Altruistic, 31 percent Biospheric, and 32 percent EGOISTIC. In the conceptual framework, we highlight the importance of congruence between the sender and receiver. Hence, individuals with egoistic or altruistic environmental concerns should react more to EGOISTIC messages than to NON-EGOISTIC, as they worry about the negative effects that land degradation can have on themselves or people from their village. This is what we make salient in the EGOISTIC message. Table 4.4 shows that the treatment effects at the extensive and intensive margins previously shown in Table 4.3 are mainly driven by individuals characterized as EGOistic or Altruistic. However, we find no such treatment effects for individuals characterized as BIOSPHERIC. Table 4.4 further shows that individuals with EGOISTIC or Altruistic environmental concerns are significantly more likely to contribute and give on average more when listening to the IMPERATIVE EGOISTIC in comparison to other treatments.

To explore which form of communication (NARRATIVE or IMPERATIVE) and frame (EGOISTIC or Non-Egoistic) is more persuasive, we pool our treatment messages. Table 4.4 reports the results according to the characterization of individuals. Columns 3 and 4 show no significant treatment effects at the extensive and intensive margins for individuals characterized as Egoistic or Altruistic. Yet, we find that Imperative messages drive a higher amount of contributions than the NARrative messages. Columns 5 and 6 show that individuals with EgOISTIC or Altruistic environmental concerns do not react more towards EGOISTIC than to Non-EGOISTIC messages, or respect to the CONTROL message. For individuals characterized as BIOsPHERIC, we find evidence for weak treatment effects for treatment NARRATIVE EGOISTIC at the extensive margin, but no effects at the intensive margin. We do not find differences when comparing the extensive and intensive margins 
in NARrative messages versus Imperative messages. Yet, when pooling our treatments and comparing the two frames (EGOISTIC versus Non-EGOISTIC messages), we find that BIOSPHERIC individuals are more likely to contribute and give on average more when listening to messages that highlight EGOISTIC motives to conserve (see columns 11 and 12). In sum, our results suggest that imperative messages that make salient egoistic motivations to conserve the environment are successful in persuading individuals to donate for proenvironmental causes. 


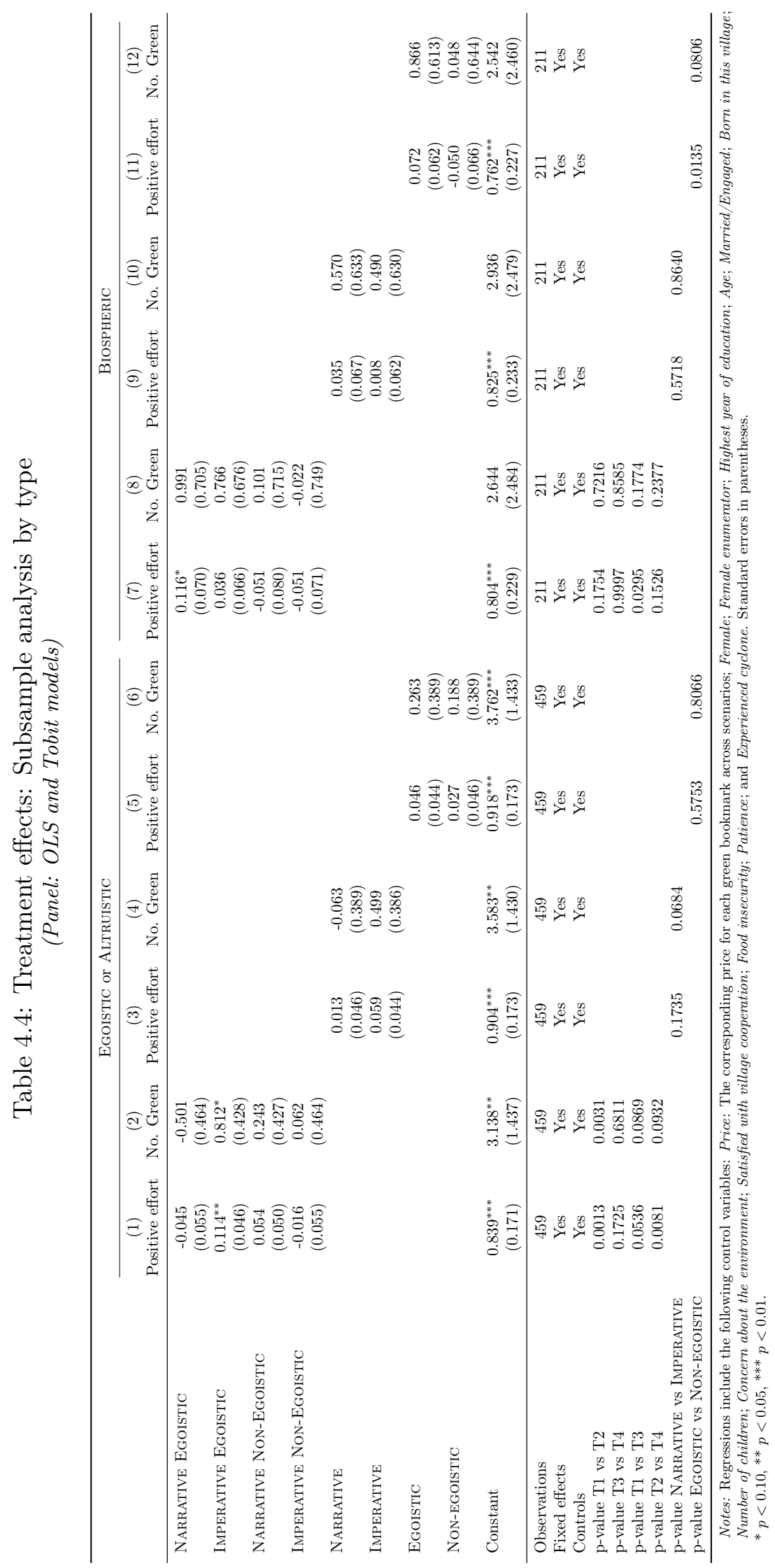




\subsubsection{Additional analysis}

In the following two subsections, we extend our research and explore the heterogeneous effects of persuasion for two different groups. First, we explore whether individuals with different levels of schooling react to different treatment messages, respect to the CONTROL group and each other. We find it relevant to include this analysis because, from our main regression analysis, we find that education level and contributions to environmental causes are highly correlated. Second, we explore whether individuals who have are more altruistic towards future generations are more likely to react to persuasive messages, and if so, to which ones. We include this analysis because environmental problems are more likely to affect future generations heavily. Hence, it is important to explore which messages are more persuasive to people with higher concerns for this population.

\section{Treatments and level of education}

We divide our sample by the median of years of education completed (median $=11$ ). Table 4.7 presents the results of a linear regression for the extensive margin (columns 1 and 3 ) and a tobit censored regression for the intensive margin (columns 2 and 4).

We find that individuals with years of education equal or above the median are significantly more likely to contribute after listening to an ImPERATIVE EGOISTIC or a NARRATIVE EGOISTIC message in comparison to the CONTROL message. When comparing the IMPERATIVE EGOISTIC message with the other treatments, we did not observe significant differences at the extensive margin. NARRATIVE EGOISTIC messages are more effective in driving contribution than NARRATIVE Non-Egoistic messages. The latter is the least effective when compared to other messages. At the intensive margin, we also find that the IMPERATIVE EGOISTIC message has an effect in comparison to CONTROL, but we find no significant differences with respect to the other treatments.

Regarding the giving behavior of individuals with years of education below the median, we find that the Narrative Non-Egoistic message increases the likelihood to contribute with respect to CONTROL. This message is also significantly more effective at the extensive and intensive margins compared to its analogous NARrative EGOISTIC and ImPERATIVE Non-Egoistic (see Columns 3 and 4). Interestingly, the Imperative Non-Egoistic message is the least effective compared to other messages, especially at the extensive margin. In sum, we find that NARRATive Non-Egoistic messages are the most effective in persuading individuals with low education levels to contribute, while IMPERATIVE NoNEGOISTIC messages, which is how most of the communication is framed, are the least effective. On the contrary, our results suggest that messages highlighting egoistic motives are more effective with more educated individuals. Hence, communication campaigns can be targeted according to the education level of the population to increase persuasion. 
Table 4.5: Treatments and education level

(Panel: OLS and Tobit models)

\begin{tabular}{lccccc}
\hline & \multicolumn{2}{c}{ Education equal and above median } & & \multicolumn{2}{c}{ Education below median } \\
\cline { 2 - 3 } \cline { 5 - 6 } & $(1)$ & $(2)$ & & $(3)$ & $(4)$ \\
& Positive effort & No. Green & & Positive effort & No. Green \\
\hline NARRATIVE EGOISTIC & $0.091^{*}$ & 0.476 & & -0.101 & -0.185 \\
& $(0.053)$ & $(0.470)$ & & $(0.071)$ & $(0.630)$ \\
IMPERATIVE EGOISTIC & $0.146^{* * *}$ & $1.071^{* *}$ & & 0.026 & 0.679 \\
& $(0.049)$ & $(0.457)$ & & $(0.061)$ & $(0.574)$ \\
NARRATIVE NON-EGOISTIC & -0.011 & 0.040 & & $0.094^{*}$ & 0.919 \\
& $(0.059)$ & $(0.448)$ & & $(0.057)$ & $(0.617)$ \\
ImPERATIVE NoN-EGOISTIC & 0.074 & 0.463 & & $-0.147^{*}$ & -0.169 \\
& $(0.055)$ & $(0.477)$ & & $(0.079)$ & $(0.670)$ \\
Constant & $0.973^{* * *}$ & $3.360^{* *}$ & & $0.955^{* * *}$ & $5.705^{* * *}$ \\
& $(0.156)$ & $(1.520)$ & & $(0.219)$ & $(1.926)$ \\
\hline Observations & 397 & 397 & & 273 & 273 \\
Fixed effects & Yes & Yes & & Yes & Yes \\
Controls & Yes & Yes & & Yes & Yes \\
p-value T1 vs T2 & 0.1766 & 0.1845 & & 0.0730 & 0.1398 \\
p-value T3 vs T4 & 0.0986 & 0.3386 & & 0.0011 & 0.0957 \\
p-value T1 vs T3 & 0.0485 & 0.3231 & & 0.0030 & 0.0706 \\
p-value T2 vs T4 & 0.1037 & 0.1792 & & 0.0226 & 0.1780 \\
\hline
\end{tabular}

Notes: Regressions include the following control variables: Price: The corresponding price for each green bookmark across scenarios; Female; Female enumerator; Age; Married/Engaged; Born in this village; Number of children; Concern about the environment; Satisfied with village cooperation; Food insecurity; Patience; and Experienced cyclone. Standard errors in parentheses. ${ }^{*} p<0.10,{ }^{* *} p<0.05,{ }^{* * *} p<0.01$.

\section{Intergenerational concerns and giving behavior}

We asked participants to distribute an endowment across three categories, representing a different generation: past, present, and future. Table 4.6 shows that individuals distribute a larger share of the endowment to present and future generations in comparison to past generations (paired t-test p-value $<0.01$ ). In the following, we explore heterogeneous treatment effects across individuals' inter-generational altruism preferences. In particular, we categorize individuals to have a 'concern about future generations' if the fraction donated to future generations is larger than 50 percent. From our classification, 16 percent of our total sample falls into this category.

Table 4.6: Donations to each generation

\begin{tabular}{lccccc}
\hline & Mean & SD & Min & Max & N \\
\hline Fraction Past generations & 0.175 & 0.172 & 0.000 & 1.000 & 670.000 \\
Fraction Present generations & 0.408 & 0.182 & 0.000 & 1.000 & 670.000 \\
Fraction Future generations & 0.416 & 0.176 & 0.000 & 1.000 & 670.000 \\
\hline
\end{tabular}

Notes: Fraction is the share donated from an endowment of 25,000 FMG $(\approx$ $1.25 €)$

With a regression analysis, we explore which of our treatment messages has a greater impact on giving behavior at the extensive and intensive margins for individuals with a preference or higher concern for future generations. Table 4.7 shows that with respect to the CONTROL 
message, individuals who have a preference for the past and present generations are more likely to contribute and increase their contributions when listening to the IMPERATIVE EGOISTIC message.

Participants in the CONTROL group who are altruistic towards future generations give on average more in comparison to participants who show are more altruistic towards past and present generations. Yet, we do not observe a treatment effect for individuals who are altruistic towards future generations at the extensive margin, but a negative treatment effect at the intensive margin. Our results show that individuals who are more altruistic towards future generations crowd out the donation amount when exposed to a message with an EGOISTIC frame.

Table 4.7: Treatments and intergenerational altruism (Panel: OLS and Tobit models)

\begin{tabular}{|c|c|c|}
\hline & $\begin{array}{c}\text { (1) } \\
\text { Positive effort }\end{array}$ & $\begin{array}{c}(2) \\
\text { No. Green }\end{array}$ \\
\hline NARrative Egoistic & $\begin{array}{c}0.012 \\
(0.048)\end{array}$ & $\begin{array}{c}0.405 \\
(0.409)\end{array}$ \\
\hline IMPERATIVE EGOISTIC & $\begin{array}{l}0.104^{* *} \\
(0.042)\end{array}$ & $\begin{array}{c}1.166^{* * *} \\
(0.392)\end{array}$ \\
\hline Narrative Non-Egoistic & $\begin{array}{c}0.024 \\
(0.050)\end{array}$ & $\begin{array}{l}0.446 \\
(0.405)\end{array}$ \\
\hline IMPERATIVE Non-Egoistic & $\begin{array}{l}-0.018 \\
(0.051)\end{array}$ & $\begin{array}{c}0.284 \\
(0.430)\end{array}$ \\
\hline Concern about future $=1$ & $\begin{array}{c}0.042 \\
(0.077)\end{array}$ & $\begin{array}{l}1.695^{* *} \\
(0.746)\end{array}$ \\
\hline NARRAtive Egoistic $\times$ Concern about future $=1$ & $\begin{array}{l}-0.039 \\
(0.115)\end{array}$ & $\begin{array}{c}-1.987^{*} \\
(1.135)\end{array}$ \\
\hline IMPERATIVE EGOISTIC $\times$ Concern about future $=1$ & $\begin{array}{l}-0.093 \\
(0.102)\end{array}$ & $\begin{array}{c}-1.973^{* *} \\
(0.982)\end{array}$ \\
\hline NARrative Non-EgOISTIC $\times$ Concern about future $=1$ & $\begin{array}{l}-0.019 \\
(0.099)\end{array}$ & $\begin{array}{l}-1.375 \\
(0.946)\end{array}$ \\
\hline IMPERATIVE Non-Egoistic $\times$ Concern about future $=1$ & $\begin{array}{c}0.017 \\
(0.106)\end{array}$ & $\begin{array}{l}-1.029 \\
(1.084)\end{array}$ \\
\hline Constant & $\begin{array}{c}0.883^{* * *} \\
(0.139)\end{array}$ & $\begin{array}{c}3.365^{* * *} \\
(1.242)\end{array}$ \\
\hline Observations & 670 & 670 \\
\hline Fixed effects & Yes & Yes \\
\hline Controls & Yes & Yes \\
\hline
\end{tabular}

Notes: Regressions include the following control variables: Price: The corresponding price for each green bookmark across scenarios; Female; Female enumerator; Highest year of education; Age; Married/Engaged; Born in this village; Number of children; Concern about the environment; Satisfied with village cooperation; Food insecurity; Patience; and Experienced cyclone. Standard errors in parentheses. ${ }^{*} p<0.10,{ }^{* *} p<0.05,{ }^{* * *} p<0.01$. 


\subsection{Conclusions and Discussion}

Environmental conservation is a problem that concerns everyone in the world. Hence, it is important to understand what is the most effective mechanism to persuade individuals to support conservation activities. The role of persuasive communication on the environment is particularly important in developing countries, as the vulnerable population is most likely to suffer the consequences of environmental degradation. Departing from this gap, this paper experimentally tests the effectiveness of narratives and imperatives to promote donations to an environmental cause. By varying the mode - NARRATIVE or ImPERATIVE - and the frame of communication-EGOISTIC or NON-EGOISTIC-, we crafted four different messages and tested their effectiveness relative to a CONTROL condition, in which participants listened to a neutral message that is not related to the environment. The context of our analysis is northeastern Madagascar, one of the areas with high biodiversity value but seriously threatened by deforestation.

Our results show that ImPeRATIVE EGOISTIC messages are most effective in driving contributions both in the extensive and intensive margins. Yet, this result should be validated in a different context. Furthermore, while our study considers the short-term effects of the intervention, there could be differential effects in the long run. For instance, stories might need to be part of the local folklore to be more accepted.

We also find that when the donation can increase the positive externality (public good is cheaper), participants contribute significantly less. Further work could examine whether motivations to support the environment are driven by warm-glow motives or depend on impure altruistic preferences.

In addition, we find that the congruence between the sender and receiver is not an important channel for persuasion among our population group. Irrespective of the environmental values expressed by individuals in a survey (Altruistic, Egoistic or Biospheric), we find that participants in the sample contribute more when the EGOISTIC frame is used compared to the NON-EGOISTIC frame. This result suggests that populations living close to subsistence cannot afford to care about high order values such as environmental protection.

Moreover, our results indicate that policymakers should carefully pretest their campaigns with the local population, as a one-size intervention might not fit all. In particular, we find that messages that were framed using egoistic values crowd out the donations from participants who expressed a higher degree of intergenerational altruism towards future generations. Last, our exploratory results show that the level of education matters for persuasion. Individuals with high schooling react more after listening to messages that highlight egoistic motives, while low educated individuals prefer the NARRATIVE NON-EGOISTIC message. Our results suggest that the ImPERATIVE Non-EGOISTIC communication currently transmitted by conservation parties might not be the most effective, especially regarding audiences with low levels of schooling. 


\subsection{Appendices}

\subsubsection{Appendix A - Selection}

Figure 4.A1: Household selection

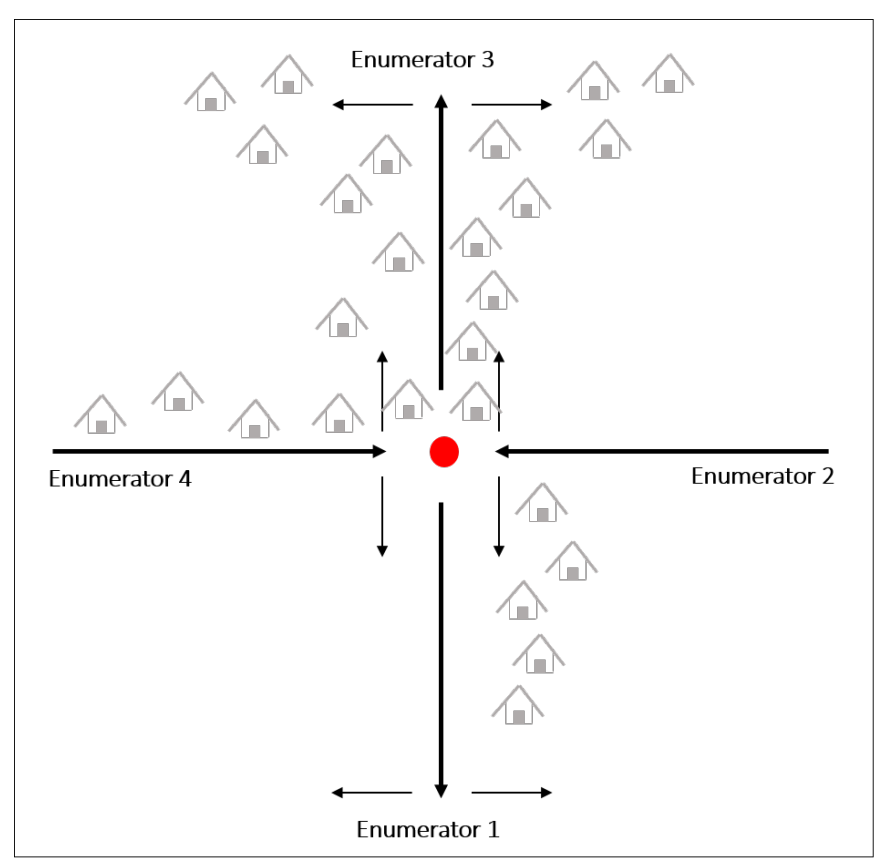

Table 4.A1: Village types and sample size

\begin{tabular}{lccccc}
\hline & Type 1 & Type 2 & Type 3 & Type 4 & Type 5 \\
\hline No. habitants & $0-1000$ & $1001-2000$ & $2001-3000$ & $3001-4000$ & $>4000$ \\
No. villages & 3 & 2 & 3 & 4 & 3 \\
No. observations planned & 12 & 24 & 32 & 48 & 88 \\
Average no. observations collected & 16 & 22 & 42 & 45 & 92 \\
Total no. observations & 47 & 44 & 126 & 176 & 277 \\
\hline
\end{tabular}




\subsubsection{Appendix B - Audios}

\section{NARRATIVe Egoistic}

Once upon a time there were trees, animals, water and air that gathered. The trees said: "Men don't stop cutting us". The animals said: "And because of the fire in the mountains our homes are getting smaller". The water said, "We keep getting dirty". And then, one animal said: "What is going to happen if people don't do something about it?" "There will be no water to grow rice", said one of the trees. Then the wind said: "I will star spinning around more often and the storms will destroy the houses and flood the plantations". The water added, "There will be no springs to collect water and there will be less food to eat". When you do not take care of the environment, it is likely that one day you will not be able to profit from it and you will suffer the consequences.

\section{IMPERATIVE EGOISTIC}

In recent years, people have increased the number of trees cut, and also the land and forests they burned. This has destroyed the habitats of animals and polluted the air and water. If people do not do something, there will be consequences:

Do not cut the trees from the forests or there will be no rain and thus less water to produce rice.

Do not cut the trees from the forests or there will be less protection for the houses against the strong wind and the plantations will be more vulnerable to floods.

Do not pollute the rivers or there will be no clean water and less food to eat.

When you do not take care of the environment, it is likely that one day you will not be able to profit from it and you will suffer the consequences.

\section{Narrative Non-Egoistic}

Once upon a time there were trees, animals, water and air that gathered. The trees said: "Men don't stop cutting us". The animals said: "And because of the fire in the mountains our homes are getting smaller". The water said, "We keep getting dirty". And then, one animal said: "What is going to happen if people don't do something about it?" "If I disappear my friend the rain will not come anymore" said one of the trees. Then the wind said, "I will start spinning around more often and the storms will destroy the houses of the animals". And then the water said, "All the animals that live with me will be gone and without rain then I will dry". When you do not take care of the environment, it is likely that one day it will disappear and the world will suffer the consequences. 


\section{IMPERATIVE NoN-EgOISTIC}

In recent years, people have increased the number of trees cut, and also the land and forests they burned. This has destroyed the habitats of animals and polluted the air and water. If people do not do something, there will be consequences:

Do not cut the trees from the forests or there will be no rain.

Do not cut the trees from the forests or there will be less protection for the animal habitats against the strong wind.

Do not pollute the rivers or there will be no clean water and the fishes will disappear.

When you do not take care of the environment, it is likely that one day it will disappear and the world will suffer the consequences.

\section{Control}

"The telephone is a telecommunication device that was invented by American citizen A.Graham Bell in 1876. The telephone transports the human voice through zit change or the cable in the transmitter. In order to use the phone, there is a need for infrastructure called 'telephone networks' that can be cable or antenna. This infrastructure will be leased by subscription to the telecommunications company. In order to make the call feature available to anyone who has a phone on the entire network, these phones have been assigned a telephone number." (Text taken from Wikipedia)

\subsubsection{Appendix C - Example green and blue bookmarks}

Figure 4.C1: Bookmarks

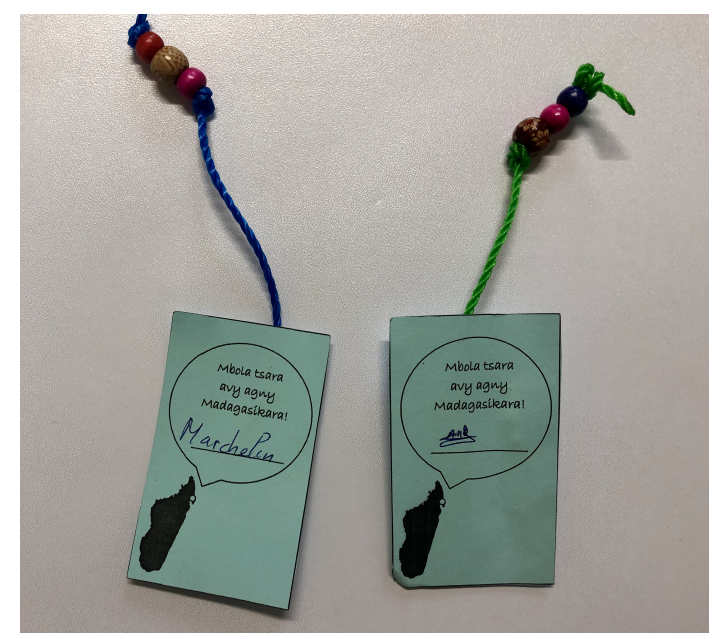

\subsubsection{Appendix D - Regression analysis}


Table 4.D1: Treatment effects on effort

(Full sample, OLS and Tobit models)

\begin{tabular}{|c|c|c|c|c|}
\hline & $\begin{array}{c}\text { (1) } \\
\text { Positive effort }\end{array}$ & $\begin{array}{c}\text { (2) } \\
\text { Positive effort }\end{array}$ & No. $\stackrel{(3)}{\text { Green }}$ & No. Green \\
\hline Narrative Egoistic & $\begin{array}{l}0.008 \\
(0.045)\end{array}$ & $\begin{array}{c}0.006 \\
(0.043)\end{array}$ & $\begin{array}{c}0.056 \\
(0.386)\end{array}$ & $\begin{array}{l}0.096 \\
(0.381)\end{array}$ \\
\hline IMPERATIVE EGOISTIC & $\begin{array}{l}0.085^{* *} \\
(0.039)\end{array}$ & $\begin{array}{l}0.089^{* *} \\
(0.039)\end{array}$ & $\begin{array}{l}0.698^{*} \\
(0.363)\end{array}$ & $\begin{array}{l}0.859^{* *} \\
(0.361)\end{array}$ \\
\hline Narrative Non-Egoistic & $\begin{array}{c}0.022 \\
(0.043)\end{array}$ & $\begin{array}{c}0.022 \\
(0.043)\end{array}$ & $\begin{array}{l}0.289 \\
(0.370)\end{array}$ & $\begin{array}{c}0.228 \\
(0.366)\end{array}$ \\
\hline IMPERATIVE NON-EgOISTIC & $\begin{array}{l}-0.003 \\
(0.046)\end{array}$ & $\begin{array}{l}-0.016 \\
(0.044)\end{array}$ & $\begin{array}{c}0.174 \\
(0.399)\end{array}$ & $\begin{array}{c}0.109 \\
(0.394)\end{array}$ \\
\hline Price Green Bookmarks $=7500$ & $\begin{array}{c}0.004 \\
(0.011)\end{array}$ & $\begin{array}{c}0.004 \\
(0.011)\end{array}$ & $\begin{array}{c}-0.644^{* * *} \\
(0.114)\end{array}$ & $\begin{array}{c}-0.644^{* * *} \\
(0.113)\end{array}$ \\
\hline Price Green Bookmarks $=10000$ & $\begin{array}{l}-0.015 \\
(0.013)\end{array}$ & $\begin{array}{l}-0.015 \\
(0.013)\end{array}$ & $\begin{array}{c}-0.732^{* * *} \\
(0.114)\end{array}$ & $\begin{array}{c}-0.731^{* * *} \\
(0.114)\end{array}$ \\
\hline Female & & $\begin{array}{l}-0.039 \\
(0.026)\end{array}$ & & $\begin{array}{l}-0.340 \\
(0.243)\end{array}$ \\
\hline Female enumetator & & $\begin{array}{c}0.135^{* * *} \\
(0.027)\end{array}$ & & $\begin{array}{l}-0.075 \\
(0.257)\end{array}$ \\
\hline Highest year of education & & $\begin{array}{l}0.007^{* *} \\
(0.003)\end{array}$ & & $\begin{array}{c}0.088^{* * *} \\
(0.027)\end{array}$ \\
\hline Age & & $\begin{array}{l}-0.002^{*} \\
(0.001)\end{array}$ & & $\begin{array}{l}-0.003 \\
(0.010)\end{array}$ \\
\hline Married/Engaged & & $\begin{array}{l}-0.005 \\
(0.036)\end{array}$ & & $\begin{array}{c}0.005 \\
(0.294)\end{array}$ \\
\hline Born in this village & & $\begin{array}{l}-0.006 \\
(0.028)\end{array}$ & & $\begin{array}{l}-0.191 \\
(0.248)\end{array}$ \\
\hline Number of children & & $\begin{array}{l}0.011^{*} \\
(0.006)\end{array}$ & & $\begin{array}{l}-0.000 \\
(0.057)\end{array}$ \\
\hline Concern about environment & & $\begin{array}{l}-0.007 \\
(0.016)\end{array}$ & & $\begin{array}{c}0.024 \\
(0.140)\end{array}$ \\
\hline Satisfied with village cooperation & & $\begin{array}{l}-0.019 \\
(0.014)\end{array}$ & & $\begin{array}{l}-0.161 \\
(0.118)\end{array}$ \\
\hline Experienced food insecurity & & $\begin{array}{l}-0.010 \\
(0.029)\end{array}$ & & $\begin{array}{l}0.484^{*} \\
(0.260)\end{array}$ \\
\hline Patience level & & $\begin{array}{c}0.001 \\
(0.001)\end{array}$ & & $\begin{array}{l}0.027^{* *} \\
(0.011)\end{array}$ \\
\hline Experienced cyclone & & $\begin{array}{l}0.050 \\
(0.077)\end{array}$ & & $\begin{array}{l}0.680 \\
(0.764)\end{array}$ \\
\hline Constant & $\begin{array}{c}0.918^{* * *} \\
(0.047) \\
\end{array}$ & $\begin{array}{c}0.883^{* * *} \\
(0.138) \\
\end{array}$ & $\begin{array}{c}4.444^{* * *} \\
(0.520) \\
\end{array}$ & $\begin{array}{c}3.546^{* * *} \\
(1.241) \\
\end{array}$ \\
\hline Observations & 670 & 670 & 670 & 670 \\
\hline Fixed effects & Yes & Yes & Yes & Yes \\
\hline Controls & No & Yes & No & Yes \\
\hline $\mathrm{p}$-value $\mathrm{T} 1$ vs $\mathrm{T} 2$ & 0.0487 & 0.0254 & 0.0776 & 0.0338 \\
\hline p-value $\mathrm{T} 3$ vs $\mathrm{T} 4$ & 0.5625 & 0.3845 & 0.7628 & 0.7493 \\
\hline $\mathrm{p}$-value $\mathrm{T} 1$ vs $\mathrm{T} 3$ & 0.7506 & 0.7008 & 0.5274 & 0.7150 \\
\hline p-value $\mathrm{T} 2$ vs $\mathrm{T} 4$ & 0.0269 & 0.0075 & 0.1640 & 0.0440 \\
\hline
\end{tabular}

Table 4.D2: Multiple Hypothesis Testing

\begin{tabular}{|c|c|c|c|}
\hline Outcome variable & Treatment & p-value not adjusted & p-value adjusted $(\mathrm{B}-\mathrm{H})$ \\
\hline Positive effort & NARRATIVE EgOIStIC vs. CONTROL & 0.898 & 0.898 \\
\hline Positive effort & ImPERATIVE EgOISTIC vs. CONTROL & 0.021 & 0.084 \\
\hline Positive effort & NARRATIVE Non-EGOIStiC vs. CONTROL & 0.616 & 0.898 \\
\hline Positive effort & IMPERATIVE NON-EGOISTIC vs. CONTROL & 0.721 & 0.898 \\
\hline No. green bookmarks & NARRATIVE EGOISTIC vs. CONTROL & 0.801 & 0.898 \\
\hline No. green bookmarks & IMPERATIVE EGOISTIC vs. CONTROL & 0.017 & 0.084 \\
\hline No. green bookmarks & NARRATIVE NON-EGOISTIC vs. CONTROL & 0.533 & 0.898 \\
\hline No. green bookmarks & NARRATIVE NON-EGOISTIC vs. CONTROL & 0.783 & 0.898 \\
\hline
\end{tabular}

Notes: For the multiple hypothesis testing we use the Benjamini-Hochberg method as it has been shown to be less conservative than the Bonferroni correction. 


\subsubsection{Appendix $\mathrm{E}$ - Instructions}

\section{Invitation to participate}

Good morning/afternoon! We are part of a research project from the University of Göttingen in Germany. With our project, we want to learn more about the social and economic characteristics of the people living in the SAVA region. Today, we would like to ask for your participation in a survey that will help us to succeed with our project. The survey will take in total 1 hour and the answers you provide will be anonymous. For your participation, you will receive a bonus of 2,000 ariary. However, during the questionnaire you might be able to increase this amount.

Would you like to take part in the survey? Yes No

If the participant says 'Yes', proceed with the questionnaire. ${ }^{15}$

If the participant says ' $N o$ ', thank for their time and continue with the random selection of households

\section{Survey questions ${ }^{16}$}

Thank you very much for your participation. Your answers will be very helpful for our research. We appreciate your time and help very much.

The questions that we will ask you are not a test, and therefore there are no right or wrong answers, we just want to know more about how people live here. If you decide to participate, but at some point during the meeting you feel uncomfortable, you can tell us to stop and we will leave, however you will not receive the bonus payment.

Before we start, I would like to clarify that the answers you will provide here are completely anonymous and will only be used for academic purposes. Please remember that this is not a test and therefore there are no right or wrong answers. The answers you provide here should only correspond to your reality or your opinion. We kindly ask you to answer as accurate as possible.

\footnotetext{
${ }^{15}$ Text in italics corresponds to the tasks for the enumerators

${ }^{16}$ Section names was not visible for participants
} 


\section{PART 1: Household and individual characteristics}

1. District: Sambava Antalaha

2. Village Name:

3. How many people live with you?

4. Were you born in this village? Yes No

If answer in question 4 is 'Yes', go to question 5 and then 8. If answer in question is 'No', go to question 6 and then 7

5. How long has your family (ancestors) lived in this village?

6. How long have you lived in this village?

7. Why did you move from your previous place?

(Select the answer that best fits the participant's answer)

Because of marriage

Because I had to take care of a family member

Because I did not have land in the previous place

Because I did not have a job in the previous place

$\square$ Because of a natural disaster

$\square$ Other:

8. How many children do you have?

(If answer in question 8 is different from 0, go to question 9. If answer in question is 0 , go to question 11)

9. In the previous question, you mentioned that you have children. How many of them currently work on activities related to agriculture?

10. In the previous question, you mentioned that you have children. If you would have the chance to decide the future of each of them, how many would you like to see working in activities related to agriculture?

11. Was/is agriculture the main activity of your parents? Yes No

12. In the last 12 months, did it happen that there was not enough money to buy food? Yes No 
13. How often did this happen in the last 12 months?

$\square$ Very often (at least once a month)

$\square$ Often (8-12 times)

$\square$ Sometimes (4-8 times)

$\square$ Almost never (1-4 times)

$\square$ Never

14. Did you visit the cemetery this year? Yes No

15. In which month was your last visit?

January February March May June July August September

16. Which religion you practice?

$\square$ Traditional

$\square$ Christianity

$\square$ Islam

$\square$ None

17. How often do you go to practice your religion?

Every day

$\square$ 2-3 times a week

Once a week

$\square$ Every other week

Almost never

18. What is your main Economic Activity defined as the activity in which you spent the most time during the year?

Agriculture

No activities related to agriculture

I do not have a job / I stay at home

19. How many hours do you spend on a normal day doing that activity? hours.

20. If you would have the chance to work for a day on somebody else's vanilla plantation, how much would you ask this person to pay you? (ariary/Franc Malagache)

21. Have you saved money in the last year? Yes No If answer in question 21 is 'Yes', go to question 22. If answer in question is 'No', go to question 24 
22. In the last year, have you been a member of a savings group? Yes No

23. Why is the main reason for you to save money? (Do not read the options, select the answer that best fits the participant's answer)

To cover the expenses of festivities for the ancestors

To cover the funeral expenses for relatives

To cover wedding expenses for children

To cover the education of children

As precaution against bad harvests

To finance a big investment (motorbike or car or a house)

To cover my expenses in case I get sick

Other:

24. In which year were you born?

25. Gender: Male Female

26. What is your Marital status?

Married Engaged Single Separated/Divorced Widowed

27. What is the highest year you have completed in school?

\section{PART 2: Environmental concerns}

People around the world are generally concerned about environmental problems such as deforestation, air pollution, water pollution, and soil degradation, among others.

28. In general how concerned are you about the consequences that those environmental problems can bring? Please rate your answer using the following categories from 1 (I am not concerned at all) to 5 (I am very concerned):

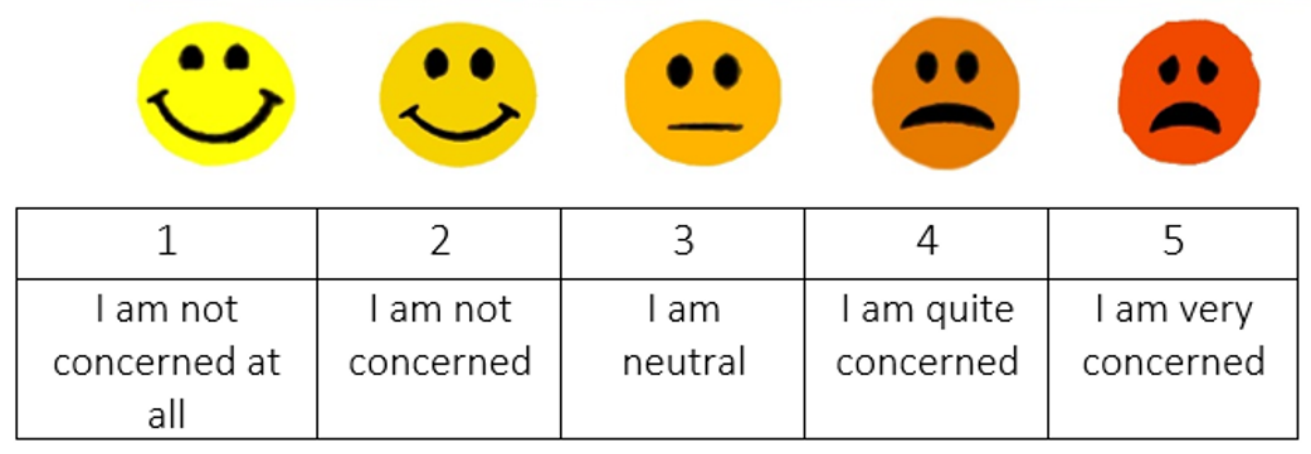


29. People differ on the reasons why they are concerned about environmental problems. I would like to ask you about the reasons why you are concerned.

Please rank the following categories in order of the concern it generates for you. 1 means that this category is the one you are most concerned about and 6 means that is the category you are least concerned about.

29.1 Concern about the consequences that environmental problems have on plants:

29.2 Concern about the consequences that environmental problems have on animals:

29.3 Concern about the consequences that environmental problems have on myself:

29.4 Concern about the consequences that environmental problems have on my future:

29.5 Concern about the consequences that environmental problems have on the people of the village:

29.6 Concern about the consequences that environmental problems have on the future generations:

\section{PART 3: Social Capital}

30. How often do people in your village help each other out these days?

Always helping each other

Helping most of the time each other

Helping sometimes each other

Rarely helping each other

Never helping each other

I do not know

31. How satisfied do you feel with the level of cooperation that exists in this village?

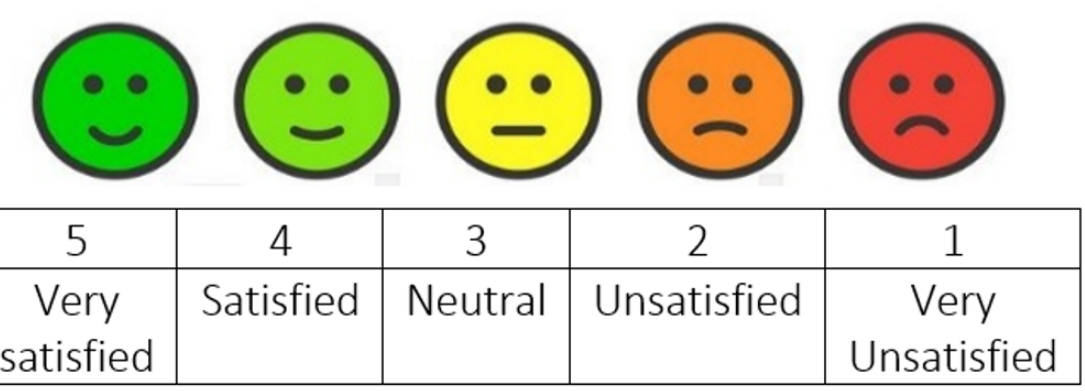


32. Do you think most people try to take advantage of you if they got a chance, or that they would not do it?

Would take advantage of you

Would not take advantage of you

It depends on the situation

$\square$ I do not know

33. Would you say that most of the time people try to be helpful, or that they do not try to be helpful?

Try to be helpful

Do not try to be helpful

It depends on the situation

I do not know

34. Generally speaking, would you say that most people can be trusted or not?

Most people can be trusted

Most people cannot be trusted

$\square$ It depends on the situation

$\square$ I do not know

35. How often do you leave your door unlocked?

Very often

Often

Sometimes

$\square$ Rarely

$\square$ Never

36. If you lend money to a friend, how likely is that he or she will pay you back?

Very unlikely

Unlikely

$50-50$

$\square$ Likely

Very likely

I do not know 


\section{PART 4: Intergenerational altruism}

37. For the next question, you have 25.000 FMG and your task is to decide how to divide this money into the following three categories:

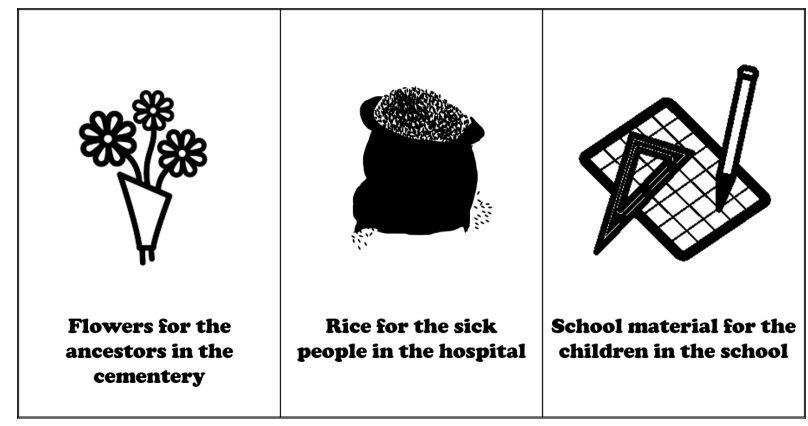

How would you like to divide the 25.000 FMG? Our project coordinators will implement your decisions tomorrow. Please make a decision now. We will record your answers afterwards. Remember that this is not a test. You can divide the money as you wish.

37.1 Flowers for the ancestors in the cemetery: FMG

37.2 Rice for the sick people in the hospital: FMG

37.3 School material for the children in the school: FMG

\section{Control questions (for pilots only)}

37.4 Who profits from placing flowers in the cemetery?
Ancestors
Society/people from the village
Children
I do not now

37.5 Who profits from giving rice to the hospital?

Ancestors Society/people from the village Children I do not now

37.6 Who profits from giving school material to the schools?

Ancestors Society/people from the village Children I do not now

\section{PART 5: Time and risk preferences}

38. Suppose you were given the choice between receiving a payment in 1 month or a payment in 7 months. We will now present to you five situations. The payment in 1 month is the same in each of these situations. However, the payment in 7 months is different in every situation.

Each situation is hypothetical which means that you will not receive that money. 
However, we would like to know what payment you would choose in each situation. There are no right or wrong answers. Please assume that products do not get more expensive along time.

38.1 Would you rather receive 200.000 FMG in 1 month or 244.000 FMG in 7 months?

In 1 month

$\square$ In 7 months

38.2 [if the answer in 1 is "In 1 month"]

Would you rather receive 200.000 FMG in 1 month or 263.000 FMG in 7 months?

$\square$ In 1 month

$\square$ In 7 months

38.3 [if the answer in 1 is "In 7 months"]

Would you rather receive 200.000 FMG in 1 month or 223.000 FMG in 7 months?

In 1 month

$\square$ In 7 months

38.4 [if the answer in 2 is "In 1 month"]

Would you rather receive 200.000 FMG in 1 month or 272.000 FMG in 7 months?

$\square$ In 1 month

$\square$ In 7 months

38.5 [if the answer in 2 is "In 7 months"]

Would you rather receive 200.000 FMG in 1 month or 254.000 FMG in 7 months?

In 1 month

$\square$ In 7 months

38.6 [if the answer in 3 is "In 1 month"]

Would you rather receive 200.000 FMG in 1 month or 233.000 FMG in 7 months?

In 1 month

$\square$ In 7 months

38.7 [if the answer in 3 is "In 7 months"]

Would you rather receive 200.000 FMG in 1 month or 211.000 FMG in 7 months?

In 1 month

In 7 months 
38.8 [if the answer in 4 is "In 1 month"]

Would you rather receive 200.000 FMG in 1 month or 277.000 FMG in 7 months?

$\square$ In 1 month

$\square$ In 7 months

38.9 [if the answer in 4 is "In 7 months"]

Would you rather receive 200.000 FMG in 1 month or 266.000 FMG in 7 months?

$\square$ In 1 month

$\square$ In 7 months

38.10 [if the answer in 5 is "In 1 month"]

Would you rather receive 200.000 FMG in 1 month or 258.000 FMG in 7 months?

In 1 month

In 7 months

38.11 [if the answer in 5 is "In 7 months"]

Would you rather receive 200.000 FMG in 1 month or 249.000 FMG in 7 months?

In 1 month

$\square$ In 7 months

38.12 [if the answer in 6 is "In 1 month"]

Would you rather receive 200.000 FMG in 1 month or 238.000 FMG in 7 months?

In 1 month

In 7 months

38.13 [if the answer in 6 is "In 7 months"]

Would you rather receive 200.000 FMG in 1 month or 228.000 FMG in 7 months?

$\square$ In 1 month

$\square$ In 7 months

38.14 [if the answer in 7 is "In 1 month"]

Would you rather receive 200.000 FMG in 1 month or 218.000 FMG in 7 months?

In 1 month

In 7 months 
38.15 [if the answer in 7 is "In 7 months"]

Would you rather receive 200.000 FMG in 1 month or 206.000 FMG in 7 months?

In 1 month

$\square$ In 7 months

38.16 [if the answer in 8 is "In 1 month"]

Would you rather receive 200.000 FMG in 1 month or 279.000 FMG in 7 months?

$\square$ In 1 month

$\square$ In 7 months

38.17 [if the answer in 8 is "In 7 months"]

Would you rather receive 200.000 FMG in 1 month or 274.000 FMG in 7 months?

In 1 month

In 7 months

38.18 [if the answer in 9 is "In 1 month"]

Would you rather receive 200.000 FMG in 1 month or 270.000 FMG in 7 months?

In 1 month

$\square$ In 7 months

38.19 [if the answer in 9 is "In 7 months"]

Would you rather receive 200.000 FMG in 1 month or 265.000 FMG in 7 months?

In 1 month

$\square$ In 7 months

38.20 [if the answer in 10 is "In 1 month"]

Would you rather receive 200.000 FMG in 1 month or 261.000 FMG in 7 months?

In 1 month

$\square$ In 7 months

38.21 [if the answer in 10 is "In 7 months"]

Would you rather receive 200.000 FMG in 1 month or 256.000 FMG in 7 months?

In 1 month

In 7 months 
38.22 [if the answer in 11 is "In 1 month"]

Would you rather receive 200.000 FMG in 1 month or 251.000 FMG in 7 months?

$\square$ In 1 month

$\square$ In 7 months

38.23 [if the answer in 11 is "In 7 months"]

Would you rather receive 200.000 FMG in 1 month or 247.000 FMG in 7 months?

$\square$ In 1 month

$\square$ In 7 months

38.24 [if the answer in 12 is "In 1 month"]

Would you rather receive 200.000 FMG in 1 month or 241.000 FMG in 7 months?

In 1 month

In 7 months

38.25 [if the answer in 12 is "In 7 months"]

Would you rather receive 200.000 FMG in 1 month or 236.000 FMG in 7 months?

In 1 month

$\square$ In 7 months

38.26 [if the answer in 13 is "In 1 month"]

Would you rather receive 200.000 FMG in 1 month or 231.000 FMG in 7 months?

In 1 month

$\square$ In 7 months

38.27 [if the answer in 13 is "In 7 months"]

Would you rather receive 200.000 FMG in 1 month or 226.000 FMG in 7 months?

$\square$ In 1 month

$\square$ In 7 months

38.28 [if the answer in 14 is "In 1 month"]

Would you rather receive 200.000 FMG in 1 month or 220.000 FMG in 7 months?

In 1 month

In 7 months 
38.29 [if the answer in 14 is "In 7 months"]

Would you rather receive 200.000 FMG in 1 month or 215.000 FMG in 7 months?

In 1 month

In 7 months

38.30 [if the answer in 15 is "In 1 month"]

Would you rather receive 200.000 FMG in 1 month or 209.000 FMG in 7 months?

In 1 month

$\square$ In 7 months

38.31 [if the answer in 15 is "In 7 months"]

Would you rather receive 200.000 FMG in 1 month or 203.000 FMG in 7 months?

In 1 month

In 7 months

39. For this question, please use the following scale ranging from 0 to 10 , where 0 means "completely unwilling to do it" and 10 means "very willing to do it". You can also use any numbers between 0 and 10 to indicate where you fall on the scale, like $0,1,2,3$, $4, \ldots, 8,9,10$.

If you would have the chance to take part in a lottery where you can lose money, how willing or unwilling would you be to take part in the lottery?

\begin{tabular}{|c|c|c|c|c|c|c|c|c|c|c|}
\hline $\begin{array}{c}\text { Completely } \\
\text { unwilling } \\
\text { to do it }\end{array}$ & 1 & 2 & 3 & 4 & 5 & 6 & 7 & 8 & 9 & $\begin{array}{c}\text { Very much } \\
\text { willing } \\
\text { to do it }\end{array}$ \\
\hline
\end{tabular}

PART 6: Perceptions and experiences on natural disasters

40. Cyclones and tropical storms affect people living along the coast in different ways, causing substantial damage in some areas and less in others. Have you ever experienced a cyclone or tropical storm since you started living here? Yes No

If answer in question 40 is "Yes", go to question 41 . If answer in question is "No", go to question 44]

41. How many times in the last 10 years? 
42. Were you affected by Cyclone ENAWO? Yes No IIf answer in question 42 is "Yes", go to question 43. If answer in question is "No", go to question 44]

43. What damages did you experience from this cyclone? (several options is possible, mark all that participant mentions)

Damages on vanilla plantation

Damages on vanilla harvest/production

Damages on rice plantation

Damages on rice harvest/production

Damages on other plantations

Damages on other plantations harvest/production

Damages on my house

Somebody from my family was injured

Other:

44. For this question, please use the following scale ranging from 0 to 10 , where 0 means "not worried at all" and 10 means "extremely worried". You can also use any numbers between 0 and 10 to indicate where you fall on the scale, like $0,1,2,3,4,5,6,7,8,9,10$.

How worried are you that a cyclone will come to your village in the next two years?

\begin{tabular}{|c|c|c|c|c|c|c|c|c|c|c|}
\hline $\begin{array}{c}0 \\
\text { Not worried } \\
\text { at all }\end{array}$ & 1 & 2 & 3 & 4 & 5 & 6 & 7 & 8 & 9 & $\begin{array}{c}10 \\
\text { Extremely } \\
\text { worried }\end{array}$ \\
\hline
\end{tabular}

\section{PART 7: Narratives and Imperatives}

45. Please listen carefully to the following message: (messages will be selected randomly)

\section{Narrative \& self-enhancement values:}

Once upon a time there were trees, animals, water and air that gathered. The trees said: "Men don't stop cutting us". The animals said: "And because of the fire in the mountains our homes are getting smaller". The water said, "We keep getting dirty". And then, one animal said: "What is going to happen if people don't do something about it?" "There will be no water to grow rice", said one of the trees. Then the wind said: "I will star spinning around more often and the storms will destroy the houses and flood the plantations". The water added, "There will be no springs to collect water and there will be less food to eat". 
When you do not take care of the environment, it is likely that one day you will not be able to profit from it and you will suffer the consequences.

\section{Imperative \& self-enhancement values:}

In recent years, people have increased the number of trees cut, and also the land and forests they burned. This has destroyed the habitats of animals and polluted the air and water. If people do not do something, there will be consequences:

- Do not cut the trees from the forests or there will be no rain and thus less water to produce rice.

- Do not cut the trees from the forests or there will be less protection for the houses against the strong wind and the plantations will be more vulnerable to floods.

- Do not pollute the rivers or there will be no clean water and less food to eat.

When you do not take care of the environment, it is likely that one day you will not be able to profit from it and you will suffer the consequences.

\section{Narrative \& self-transcendence values:}

Once upon a time there were trees, animals, water and air that gathered. The trees said: "Men don't stop cutting us". The animals said: "And because of the fire in the mountains our homes are getting smaller". The water said, "We keep getting dirty". And then, one animal said: "What is going to happen if people don't do something about it?" "If I disappear my friend the rain will not come anymore" said one of the trees. Then the wind said, "I will start spinning around more often and the storms will destroy the houses of the animals". And then the water said, "All the animals that live with me will be gone and without rain then I will dry".

When you do not take care of the environment, it is likely that one day it will disappear and the world will suffer the consequences.

\section{Imperative \& self-transcendence values:}

In recent years, people have increased the number of trees cut, and also the land and forests they burned. This has destroyed the habitats of animals and polluted the air and water. If people do not do something, there will be consequences:

- Do not cut the trees from the forests or there will be no rain.

- Do not cut the trees from the forests or there will be less protection for the animal habitats against the strong wind.

- Do not pollute the rivers or there will be no clean water and the fishes will disappear. 
When you do not take care of the environment, it is likely that one day it will disappear and the world will suffer the consequences.

\section{Control message}

The telephone is a telecommunication device that was invented by American citizen A. Graham Bell in 1876. The telephone transports the human voice through zit change or the cable in the transmitter. In order to use the phone, there is a need for infrastructure called "telephone networks" that can be cable or antenna. This infrastructure will be leased by subscription to the telecommunications company. In order to make the call feature available to anyone who has a phone on the entire network, these phones have been assigned a telephone number. (Text taken from Wikipedia)

45.1 Did you listen to the audio? Yes No

[If the answer is "No", please play the audio again. If the answer is "Yes", please continue with the questionnaire]

46. Thank you for listening. Now, we would like to start an activity. We have designed these two bookmarks (show boomarks). Until now, we have the shapes ready but we still need to insert the bead in the string and tie it. Also, we need that somebody signs it. To do all this we need your help.

Apart from their color, the only difference among the blue and the green bookmarks is the destination they will have at the end. For each green bookmark that you finish we will bring it to Germany and give it to each person that donates to the NGO Duke Lemur Center that will plant trees in the SAVA region with the money collected. This NGO comes from the United States and has been working 7 years in this region doing different projects to conserve the environment.

On the other hand, for each blue bookmark that you finish you will have the opportunity to earn some money. Each blue bookmark that you finish we will bring it to Germany as well, but they will not be used to collect donations for planting trees but will just be given to any person.

We will give you a total of 12 bookmarks that you will have to prepare. However, you can decide how many green and blue bookmarks you would like to make.

Right now, we will offer you three different scenarios. In each scenario, you have to answer how many green and blue bookmarks you would be willing to make. At the 
end, the tablet will select one of the scenarios randomly and you will have to make the number of green and blue bookmarks that you said you would make in that scenario.

In the first scenario, you can receive 5.000 FMG for each blue bookmark that you finish. On the other hand, for each green bookmark you finish, we will collect 5.000 FMG in donations for planting trees in the SAVA region. You can decide how many blue and green bookmarks you would like to finish. In this first scenario, you can also choose a combination of green and blue bookmark, meaning that you can get some payment but also give some of the bookmarks to collect donations.

46.1 How many green and blue bookmarks would you like to make?

Please allocate the number of the green and blue bookmarks in the image below.

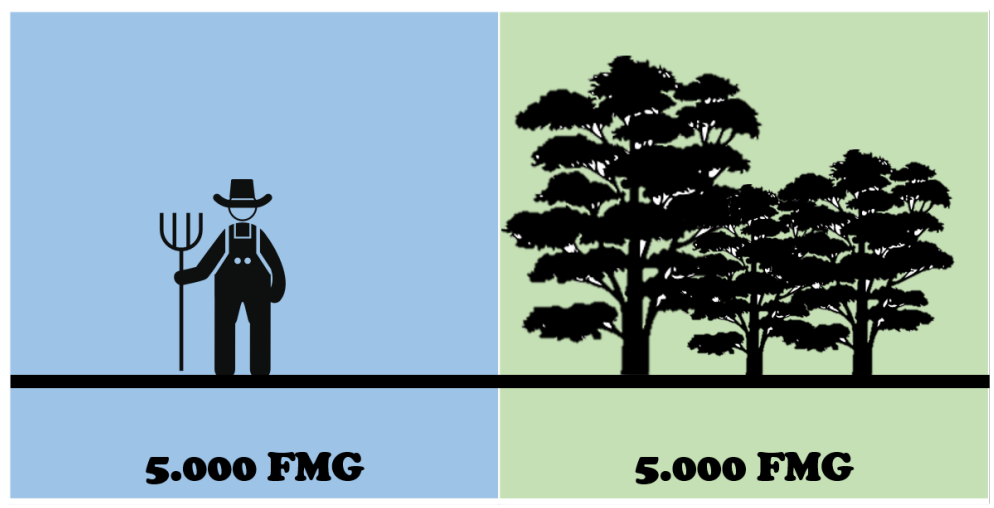

In the second scenario, you can receive 5.000 FMG for each blue bookmark that you finish. On the other hand, for each green bookmark you finish, we will collect 7.500 FMG in donations for planting trees in the SAVA region. You can decide how many blue and green bookmarks you would like to finish. In this second scenario, you can also choose a combination of green and blue bookmark, meaning that you can get some payment but also give some of the bookmarks to collect donations.

46.2 How many green and blue bookmarks would you like to make?

Please allocate the number of the green anf blue bookmarks in the image below.

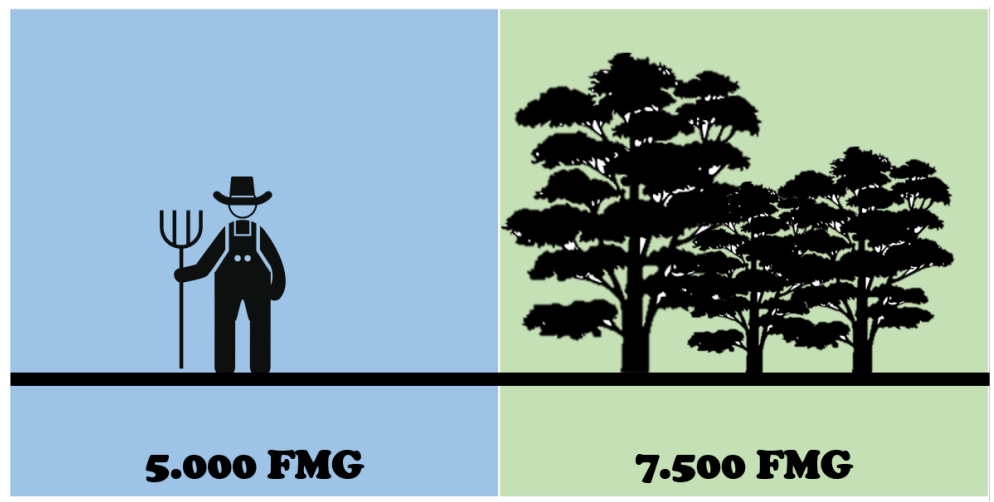


In the third scenario, you can receive 5.000 FMG for each blue bookmark that you finish. On the other hand, for each green bookmark you finish, we will collect 10.000 FMG in donations for planting trees in the SAVA region. You can decide how many blue and green bookmarks you would like to finish. In this second scenario, you can also choose a combination of green and blue bookmark, meaning that you can get some payment but also give some of the bookmarks to collect donations.

46.3 How many green and blue bookmarks would you like to make?

Please allocate the number of the green anf blue bookmarks in the image below.

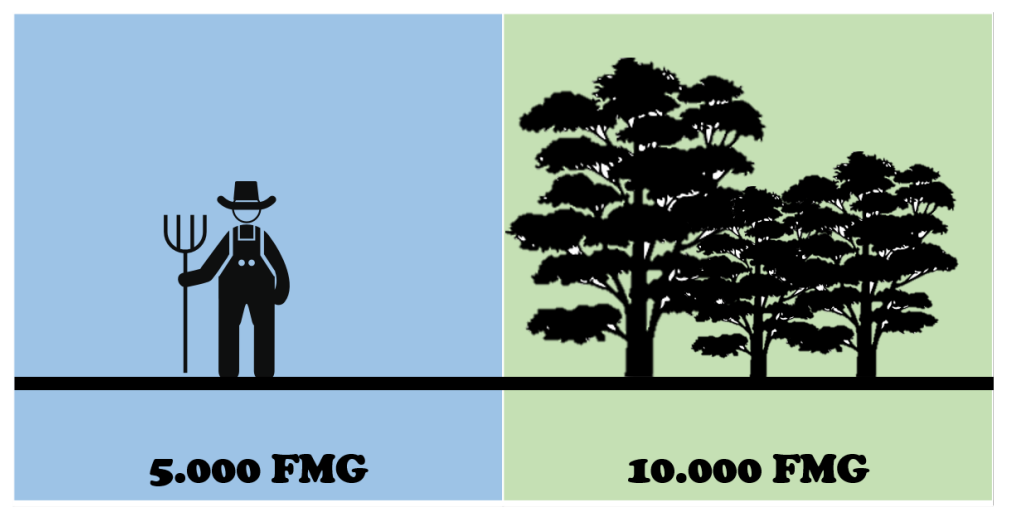

46.4 Why did you change your decision from scenario 1 to scenario 2 ?

Because I need more money than the NGO

Because if the NGO earns more, I want to earn more

Because I care about the future

Because I want to invest more in the environment

There is no change

I do not know

Other:

46.5 Why did you change your decision from scenario 2 to scenario 3 ?

Because I need more money than the NGO

Because if the NGO earns more, I want to earn more

Because I care about the future

Because I want to invest more in the environment

There is no change

I do not know

$\square$ Other: 
Now we will decide the scenario randomly so you decide how many blue and green bookmarks you will have to make as well as your possible earnings.

The scenario that chosen was number

You said that for this scenario you will make blue bookmarks and green bookmarks. We will give you now the material and we will pick the bookmarks up later. Once we have received the bookmarks we will give you the payment of this activity. We will do together one example and then you can proceed with the others.

PARTS 7 AND 8 are not included as they are not part of this study

Thank you for your cooperation! For your participation you will receive 2,000 ariary. From the bookmarks you will receive ariary. Between the two last game, the keychain game/rice game was selected for payment. When we come back to pick up the bookmarks we will give you the earnings from all these activities. Have a good day! 


\section{Chapter 5}

\section{Can role models influence female's decision to participate in the labor market? Evidence from a field experiment}

This chapter is joint work with Christina Martini (University of Göttingen). We are grateful for the comments and suggestions received from the participants at the 18th EUDN PhD Workshop and the GlobalFood Brownbag Seminar. We especially thank Marcela Ibañez, Friederike Lenel and Holger Rau for their feedback and helpful comments on our paper. All remaining errors are ours. Ana Maria Montañez, Magdalene Trapp and Marius Willmann provided great research assistance. Special thanks to the Diversity Turn team for their constant feedback and support in the field. This research was financed by the "Niedersächsisches Vorab" of Volkswagen Foundation (grant number: 11-76251-99-35/13 - ZN3119) and by the German Research Foundation (DFG) through the GlobalFood Program (RTG1666). We would like to thank all enumerators who participated in the data collection in Madagascar, and all the students that attended our experimental sessions. We would also like to thank the school directors that from the beginning showed great support for the project. 


\subsection{Introduction}

Worldwide women are underrepresented in labor markets compared to men. According to data modeled by the International Labour Organization (ILO) ${ }^{1}, 45$ percent of women are employed in the labor market compared to 70 percent of men (World Bank, 2020). ${ }^{2}$ In addition, only 19 percent of corporate top managers in the world are female (International Labour Organization, 2018; World Bank, 2020). Women in developing countries face additional challenges. They often work in precarious and informal employment compared to men (Nordman et al., 2010). The shortage of women participation in the labor market and the lack of women in leading positions - especially from those with higher education and ability -, generates an economic loss as there is a valuable share of the labor force which is not being efficiently used (Cuberes \& Teignier, 2016; Ostry et al., 2018; Hsieh et al., 2019). Increasing female participation in the labor market can contribute to economic growth and long-term poverty reduction (Duflo, 2012) and lead to increases in female's bargaining power, helping to reverse gender inequalities in the long run. Moreover, studies female participation in the labor market improves the household's economic situation, reduces the son preference, and increases children's welfare (Duflo, 2003; Qian, 2008; Kolev \& Sirven, 2010; Duflo, 2012; Jayachandran, 2015; Ibanez et al., 2017).

Prominent reasons put forward in explaining the gender imbalances in labor market outcomes in developing countries are: fewer opportunities due to lower human capital (Arbache et al., 2010; Jensen, 2012), trade deficits and weak economic conditions (Arbache et al., 2010; AlAzzawi, 2014), lack of decision power within the household (Field et al., 2019; Cheema et al., 2019), concerns about women's safety and "purity" (Jayachandran, 2015), and social norms (Bursztyn et al., 2017; Jayachandran, 2020). Whereas these explanations refer to external constraints, this paper provides a different perspective and focuses on the role of aspirations as an internal constraint of females' participation in labor markets. It is argued that an individual's aspirations are determined by the lives and achievements of other people in the individual's cognitive window (Ray, 2006). However, people often lack successful examples, which prevent them from building aspirations and thus invest in a better future (Appadurai, 2004; Ray, 2006).

Since only a few women are in paid employment, and even fewer hold leadership positions, women in developing countries might lack successful examples from which they can learn from and form aspirations for a different future, In Madagascar, our study region, female adolescents lack role models that continue with their education and work in paid employment. Women in Madagascar are most often unpaid family workers. Moreover, early marriage and childbearing during adolescence are very common (Epstein et al., 2010). In 2018, 41 percent of women aged 20-24 years were married or in union before the age of 18 and 35.6 percent gave birth before that age (UNICEF, 2018, 2020). Under these conditions, females can find

\footnotetext{
${ }^{1}$ Employment to population ratio of individuals above the age of 15 in low-income countries obtained from World Development Indicators corresponds to 2020 estimates.

${ }^{2}$ In high income countries 51 percent of women and 65 percent of men are employed, while in low income countries 55 percent of women and 73 percent of men reported to be employed in 2020 (World Bank, 2020).
} 
themselves in a behavioral poverty trap, in which low aspirations produce low economic investments (Ray, 2006; Dalton et al., 2014; Genicot \& Ray, 2017).

A possible route out of the behavioral trap is to provide successful examples of what similar individuals have achieved (Ray, 2006). In this paper we experimentally test whether exposure to role model videos, in which individuals narrate how they set and achieved a personal goal, can motivate female high-school students to apply to a job in a developing country context. Our study aims to answer the following research questions: Do female role models increase the propensity of females to apply and choose a high responsibility position? Does the gender of the role model matter in females' decision to apply?

Observing how a similar person succeeds can raise individuals' aspirations by changing their perceptions of their opportunities and thereby inducing future-oriented behavior (Beaman et al., 2012; Bernard et al., 2014). Further, role models can also affect the determinants of aspirations, i.e. locus of control and self-efficacy beliefs. Observing how investments are connected to desired results can also increase individuals' (internal) locus of control beliefs, i.e. the beliefs of how actions and outcomes are connected (Rotter, 1966). Lastly, role models can lead individuals to revise their beliefs in the ability to achieve the same outcome - so-called self-efficacy beliefs (Stout et al., 2011). Based on the above evidence, we suggest that role models, who come from the same background, can lead female students to raise their aspirations, revise their beliefs about themselves, and also on women's performance in leading positions in general.

To shed light on our research questions, we conducted a field experiment with students in their last year of secondary studies in four public schools in Madagascar in 2018. Our study region is a relevant context to study since Madagascar is one of the poorest nations in the world (World Bank, 2019), where paid jobs are scarce (Nordman et al., 2010), and where labor market participation of women, especially young women, is a real challenge (Herrera et al., 2019). We focus our interest on the student population finishing their last year of high school because these young men and women are at the stage to decide what to do next. Moreover, women likely start lagging due to marriage or pregnancy at this stage. In the experiment, we randomly assigned 336 female and male students to watch either a FEMALE Role Model, a Male Role Model, or a Placebo video. The treatment videos depict a female or male character who set a goal (becoming a teacher at a University) and show how they achieved it despite the different challenges they encountered. These characters provide an example of successful individuals and come from a similar background as the students participating in the experiment. The PLACEBO video includes the same two characters but discusses the differences in lifestyles between rural and urban areas. We measured students' aspirations, self-efficacy, and locus of control beliefs after video exposure. In addition, we conducted a lab-in-the-field experiment to measure participants' performance in a real-effort task and their preference to enter into competition. At the end of the session, we informed the students about the possibility to apply to one of two jobs in the research project of one of the principal investigators: assistant or coordinator. The main difference between the two real jobs is that the coordinator's position involves more responsibilities and has 
a higher remuneration. A week after the experiment, we gave the students their earnings from the lab-in-the-field experiment and collected their job applications.

Our results show that the Female Role Model video, compared to the Placebo, encourages female participants and male participants to apply to one of the positions. Female students in the Female Role Model video are 24.8 percentage points more likely to apply to any of the advertised positions compared to females in the PlaceBo group. We do not find similar evidence when comparing the Male Role Model and the Placebo group. When analyzing the type of position they applied to, we find a gender gap in the decision to apply to the more competitive position (coordinator position) present in the Placebo and the Female Role Model video. Yet, this gender gap almost disappears in the Male Role Model group. For the coordinator position, we find that female students in the MALe Role Model group are 16 percentage points more likely to apply compared to females in the PlaceBo group. Our results provide evidence that not only successful people from an in-group can be role models. However, the gender of the role model matters in that they can serve different purposes.

Our role models are effective in increasing performance in the real-effort task, aspirations, and self-efficacy beliefs of female students. We find no evidence for changes in competitive behavior of female students after being exposed to the treatment videos. In addition, we test for a potential mechanism driving applications to any of the positions. We find that aspirations and the current level of achievements can partially explain the decision to apply. The latter is positively correlated with the decision to apply to one of the positions.

To our knowledge, our study is the first that investigates the effect of role model videos on the willingness to apply for a job. Previous studies have shown that female role models are effective in closing the gender gap and encourage women to select into competitive environments (Stout et al., 2011; Breda et al., 2020; Meier et al., 2020; Schier, 2020; Ginther et al., 2020; Porter \& Serra, 2020). The study closest to ours is by Meier et al. (2020), which assesses whether role models in videos affect competitive preferences in an online experiment. Compared to their study, we focus on the decision to apply to a job in a development context. Also, there is empirical evidence that role models shown in media or videos effectively alter the opportunities people perceive, the goals they set for themselves, and the investments they make (Chong \& Ferrara, 2009; Jensen \& Oster, 2009; La Ferrara et al., 2012; Beaman et al., 2012; Bernard et al., 2014; Riley, 2018). For example, Lubega et al. (2018) conducted a randomized controlled trial (RCT) in which they screened role model videos to women with HIV in Uganda and found that treated females were more likely to start a business, have higher income and savings, and better health. Yet, the above studies have not investigated the effect of exposure to role model videos on female's decision to apply to engage in paid employment. In addition, we are the first to investigate whether aspirations are the mechanism through which role models are effective in promoting behavioral changes. We further explore whether mechanisms such as competition, self-efficacy, and locus of control beliefs also play a role. 
We contribute to two other important strands of literature. First, as we show a positive effect of role models on job applications, our paper is related to the literature that explores different strategies to encourage women to participate in the labor market. For example, Jensen (2012) finds that reducing asymmetries of information on labor market opportunities is effective in increasing labor market participation and career aspirations of young women in India. Further, Ibanez \& Riener (2018) show how affirmative action in a field experiment attracts women to apply to jobs in Colombia. In similar lines, McKelway (2020) conducts an RCT in India, where she offered women a psycho-social program, followed by a job promotion video from the hiring company that was screened to participants and family members. The intervention increased women's generalized self-efficacy (GSE) and labor market participation.

Second, by showing that information on role models mitigates the gap in the willingness to select into competition by applying to the coordinator position, we extend the experimental knowledge on incentives that close the gender difference in the willingness to compete (Wozniak et al., 2014; Meier et al., 2020). The study of Meier et al. (2020) also provides evidence that the gender gap in selection into competition decreases when females receive information from role models. However, the kind of information and the type of role models are different from our study. Our intervention shows successful individuals from a similar background to those of the participants, who talk about their aspirations and how they achieved them. Meier et al. (2020) chose public figures who highlight the important role of competition in their careers.

The remainder of this paper is structured as follows. Section 5.2 presents the field setting and Section 5.3 explains the experimental design and procedures. Section 5.4 presents the hypotheses and Section 5.5 describes the empirical strategy. Section 5.6 describes the data and explains the main results. Section 5.7 shows an exploratory analysis about the potential mechanisms driving the main results. Section 5.8 discusses the results and concludes.

\subsection{Field Setting}

To study the effects of a role model intervention on the decision to apply to a job, we chose Madagascar as our study region. Madagascar is one of the poorest nations in the world, with around 77.6 percent of its population living under USD 1.90 per day (2011 PPP) (World Bank, 2019). As a large share of the population is involved in agriculture, most of Madagascar's labor force is working in unpaid jobs or in the informal sector (Nordman et al., 2010). Paid jobs are scarce, making the formal labor market very competitive and difficult to access (Stifel \& Rakotomanana, 2007). In 2018, 83.3 percent of females were estimated to be in the labor force compared to 89 percent of the males (ILO, 2020). However, the largest share of the female workforce is involved in agricultural activities or is employed in the informal sector and thus receives lower wages compared to men (Nordman et al., 2010). Similar to other countries in the world, women are not only underrepresented in the formal 
labor market, but also in private and public leadership positions compared to men (Kolev \& Sirven, 2010). For instance, according to the data reported by World Economic Forum (2019), 28 percent of top managers in Madagascar are women, and 16 percent of seats in parliament are held by women.

There is also a gender gap in the formal labor market for young cohorts (Stifel \& Rakotomanana, 2007) and, although less prominent, in tertiary education enrollment rates (UNESCO Institute of Statistics, 2020). While there is no evidence of cognitive ability differences between female and male students (Herrera Almanza et al., 2017), one reason that explains these gaps is the prevalence of child marriage and early pregnancies (UNFPA, 2015; Glick et al., 2015; Herrera et al., 2019). Postponing marriage and childbearing to pursue higher education or a professional career usually goes against family norms, which expect young women to marry and continue with the hereditary line (Skjortnes \& Zachariassen, 2010). In addition, given that a minority of the Malagasy population has access to wage jobs and pursued secondary or tertiary education, there is a lack of financial and social support to encourage young girls to pursue higher education (Skjortnes \& Zachariassen, 2010).

Besides the difficult economic conditions present in Madagascar, social norms result in low participation of women in national politics and leadership and community governance. Also, in limited access of women to productive resources (e.g. land, credits) and other economic opportunities to increase their income (Kellum et al., 2020). Consequently, most female students who are currently in secondary school lack successful examples of women who continued with their education, accessed the formal labor market, and achieved top and competitive jobs. Because of these reasons, we suggest that Madagascar is an example of a country where women are likely to experience a behavioral poverty trap where low aspirations produce low investments. An intervention that provides examples of similar successful individuals could help women imagine a different future, form higher aspirations, and make them more willing to enter a competitive formal labor market.

\subsection{Experimental Design}

We conducted our study with female and male students from public high schools. We decided to include males in our experiment for different reasons: First, it is not easy to exclude half of the students given our field setting, and it could have been perceived as discriminating and not natural, which could have raised concerns about potential demand effects. Second, it was difficult to separate the group as we invited the students by going from classroom to classroom. Last, and most important, is that observing how role models affect male students' behavior is also relevant. There is a debate about the effect of affirmative action policies on men (e.g Balafoutas et al., 2016; Ibanez \& Riener, 2018); hence, we can contribute to this discussion by studying the behavior of male students after exposure to a female role model. 
Our experiment comprised three stages (see Figure 5.1). In the first stage, we screened one of the treatment videos (Female Role Model, Male Role Model) or a Placebo video, followed by a short survey about participants' perceptions regarding the main character(s) of the videos. In the second stage, we measured student's aspirations using a similar approach as in Bernard et al. (2014) and Bernard \& Taffesse (2014). Moreover, we measured inter-and intrapersonal competition preferences by following the experimental design of Niederle \& Vesterlund (2007) and Carpenter et al. (2018). We also collected attitudinal and socioeconomic information. Stage 3 assessed the willingness of students to enter the labor market. We first advertised two different job offers, and students could express their interest in the positions (Stage 3A). One week after, we met the students again to distribute the experimental earnings and collect the job applications (Stage 3B). The experimental instructions can be found in Appendix B. In the following sections, we explain each of the stages in detail.

Figure 5.1: Experimental Sequence

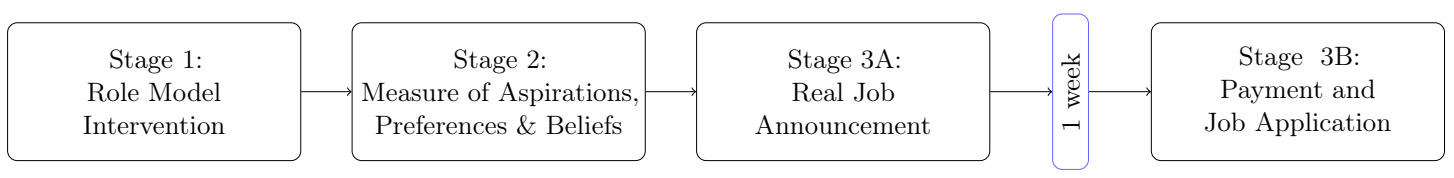

\section{Stage 1: Role model intervention}

In the first stage, we introduced our treatments by showing students one of three 10 minute videos in their local language. Students could either watch: a Female Role Model, a Male Role Model, or a Placebo. In the first two videos, the role models introduce themselves and narrate how they succeeded in achieving an important goal they set for themselves (becoming a teacher at a University) despite their hardships (lack of financial resources, lack of confidence, and lack of successful examples). They describe the steps they went through to achieve their goal and how they felt once they achieved it. In addition, the video narrates how some people from their network admire them for imagining and achieving a different future.

To increase the connection with the students' background, each role model shows the place they were raised (rural areas) and the school they attended. In the end, a family member, a friend, and a colleague of each of the role models express how they perceive them and the image they have in the community they live in. The role model videos end with each of the characters achieving their goal, and the videos close with the following sentence from the narrator: "The story of Marie-Rolande (Fulgence) shows that if one aims at doing something and works towards it, it is possible to achieve it. She (He) imagined a different life than most of her (his) friends and family have, and even though the journey was long and with many obstacles, she (he) was able to make that imagination a reality." The main factor changing between the two videos is gender. ${ }^{3}$ We chose both role models coming

\footnotetext{
${ }^{3}$ Even though our role models come from different villages, their backgrounds are still comparable as the villages and the places we showed in the videos (i.e: school and houses) are very similar to each other. The family member, friend and colleague that we show in the videos for each role model are also different,
} 
from a poor background, similar to our participants, as there is evidence that the role model's background matters to increase the identification with the character. None of the treatment videos provide information to the students on how to behave in the subsequent experimental stages. The role models do not refer to competition or the decision to enter the labor market. This allows us to exclude potential demand effects.

In the PlACEBO video, both characters separately appear, present themselves (similar to the other two videos) and talk about the differences between life in rural and urban areas. We consider this topic neutral as we refer to differences in lifestyles, clothing, climate, ethnicity, traditional ceremonies, and schools that exist. We chose this topic because it is easy to understand and students know it. In this video, we do not provide new information to students or a different perspective of their life. Furthermore, we did not present the characters as role models nor mentioned their achievements. The video compares two different lifestyles and thus should not have an effect on our outcome variables. The PlaceBo video closes with the following sentence from the narrator: "Living in the city has advantages and disadvantages, same as in the rural area. However, this diversity makes the SAVA region a beautiful place to live."

Following the screening, students had to report their perceptions of the character(s) in the video. In particular, we asked them if they like the character, the degree to which they identify with him or her, and their perceptions of the role models' success and risk-taking. In the survey we also asked participants whether they knew the character.

\section{Stage 2: Measure of aspirations, preferences and beliefs}

\section{A. Aspirations:}

Our measurement of aspirations is taken from Bernard et al. (2014) and Bernard \& Taffesse (2014). Each of our participants had to answer a set of questions on four specific dimensions: education, income, social status, and assets. In each of the dimensions, students had to report the level they currently possess, the level they would like to achieve (aspirations), and the level they think they will be able to reach (expectations). Furthermore, we include questions on the maximum, and the minimum levels students think an average person from the place they come from can achieve in each dimension. This is important as it helps them find answers and make sure they do not report mere wishes (Bernard \& Taffesse, 2014). After the students have completed the survey, they had to distribute 20 points according to the importance they attach to each dimension. Based on these indicators, we constructed the aspiration index according to the one in Bernard et al. (2014):

$$
A=\sum_{d} w^{d}\left(\frac{a_{i}^{d}-\mu^{d}}{\sigma^{d}}\right)
$$

but to keep the videos comparable, only the mother, one female friend, and one male colleague give their testimony in the videos. 
where $\sigma^{d}$ is the standard deviation of the Placebo group, $\mu^{d}$ the mean of the Placebo group for each aspiration question from dimension $d$ and $w^{d}$ is the average weight students in the Placebo group attached to each dimension.

To control for differences in students' achievements, we constructed a current index using the above procedure. Instead of aspirations, we use the level of each dimension that the participants have already achieved.

\section{B. Inter- and intrapersonal competitive preferences, performance and beliefs:}

To measure interpersonal competitive preferences, we used a laboratory experiment following the design by Niederle \& Vesterlund (2007) with slight variations. In addition to the four tasks included in their study, we introduce a fifth task to measure intrapersonal competition preferences. We included this task following a similar structure as in Carpenter et al. (2018). In the laboratory, participants were seated in rows of four people and were informed that they were forming a group with the people sitting in the same row. To avoid negative externalities from gender imbalances in each group, we sat two female and two male students in each row when possible. During the experiment we did not make the gender of the group participants salient. Since they could see the other group members, gender characteristics were observed. As students were allocated in each classroom randomly, we expect to reduce noise created by previous beliefs about the group's ability. Yet, we acknowledge that knowing other people in the group could have potential effects on the behavior. To control for this, we asked students how many people of the group they are friends with in the post-experimental survey.

Before starting with the real-effort task, participants received an explanation from the instructor who, by using a poster, showed an example of how the task should be performed, the time for performing the task, and what would be taken as a correct and incorrect answer. The instructor did not continue with the explanation until the task was clear for all students. Instead of using a math task as in Niederle \& Vesterlund (2007), our real-effort task consisted of counting and reporting the number of 1's that are in an 8x8 matrix (see example Figure 5.2). The task is solved correctly when the participant reports the correct number of 1's. This task is similar to the one used by Abeler et al. (2011). We chose this task as it is very simple. As mentioned by the authors, it does not require any prior knowledge, which is appropriate given our context. ${ }^{4}$ Participants were told that they would be asked to complete five tasks but that one of them would be relevant for payment if this stage would randomly be chosen for payment at the end of the experiment.

This stage consisted of five tasks in which the compensation varies. In Task-1 each participant received an individual payment for each correct answer in the real-effort task

\footnotetext{
${ }^{4}$ We are not the first ones in using a different effort task than the one described by Niederle \& Vesterlund (2007) to measure competition. For example, Andersen et al. (2013) conduct an experiment in India where participants had to throw tennis balls into a bucket.
} 
(piece-rate payment). In Task-2, participants entered into a 'winner takes it all' tournament, where they competed against the other group members. In Task-3, participants had the opportunity to choose the compensation scheme they would like to have if this task is randomly selected for payment. They could decide between a piece-rate compensation or enter into the 'winner takes it all' tournament against the people in their group. If the participant chose to enter into tournament, she competed with her performance in Task-3 versus the performance of the other group members in Task-2. In Task-4, participants did not have to solve matrices. Instead of performing the real-effort task, participants in Task- 4 were asked to choose which compensation scheme they would like to apply for their past performance in Task-1: piece-rate vs. 'winner takes it all' tournament pay. Since we do not condition participants' earnings on future performance, Task-4 allows making a comparison with the decision taken in Task-3 on whether to compete or not. In particular, we can observe whether factors such as risk aversion play a role in participants' preferences for interpersonal competition. In Task-5, we observed whether participants rather opt for piece-rate or in a 'winner takes it all' tournament with themselves. If they decided to compete, they had to outperform the number of matrices that they solved correctly in Task-2. We use Task-2 as a comparison because students were framed in a competitive environment and thus more likely to exert a higher effort. If participants decided not to compete, they performed this Task- 5 and were paid with the piece-rate compensation scheme.

In each of the tasks where participants had to solve matrices, they had three minutes to solve up to ten matrices. The difficulty of the matrices remained constant for all tasks. In contrast to Niederle \& Vesterlund (2007), we did not provide participants with information on their absolute performance after each task to avoid possible differences in feedback aversion across gender. Instead, we use an incentivized question to ask subjects for their belief on their absolute performance after every task. In addition, at the end of Task- 5 , participants were asked to provide their beliefs regarding their relative rank within their group for Tasks-1 and 2, the average performance of all participants in the session, and the number of people from the group that decided to compete in Task-3. For each correct answer, participants received an additional 1,000 ariary $(0.25 €)$. 
Figure 5.2: Example Task

\section{Matrix 1}

\begin{tabular}{|cccccccccc}
\hline 1 & 1 & 0 & 0 & 1 & 0 & 0 & 1 \\
0 & 0 & 1 & 0 & 0 & 1 & 0 & 1 \\
0 & 1 & 0 & 1 & 1 & 1 & 1 & 0 \\
0 & 0 & 1 & 1 & 0 & 0 & 0 & 0 \\
1 & 1 & 1 & 0 & 1 & 0 & 0 & 0 \\
1 & 1 & 1 & 0 & 1 & 0 & 0 & 0 \\
0 & 0 & 1 & 0 & 0 & 0 & 0 & 0 \\
0 & 1 & 1 & 1 & 1 & 0 & 1 & 1 \\
\hline
\end{tabular}

How many 1's are in this picture?

\section{Locus of control and self-efficacy beliefs:}

In the post-experimental questionnaire, participants were asked about their socioeconomic situation, if they have any role models, time and risk preferences, and their parents' education. Lastly, we included a set of questions to measure our additional outcome variables: locus of control, academic self-efficacy, and generalized self-efficacy. We explain below the measurement of these outcome variables. A complete version of the post-experimental questionnaire can be found in Appendix B.

- Locus of control: A subset of six statement pairs was selected from the twenty-nine pairs that comprise the 'Internal versus External Scale' from Rotter (1966) to measure this variable. The selection was made by considering students' context to enhance comprehension and reduce noise in the answers. In this part of the questionnaire, each student is provided with pairs of two statements, A and B. The task of the students is to mark the pair to which statement they agree the most on a 1-4 scale (from "I agree much more with A" to "I agree much more with B"). A and B-statements present situations where people reflect an external or internal control of the corresponding outcomes. The final score is calculated according to the total number of internal control choices the student answered. This means that the higher the score, the higher the locus of control beliefs.

- Academic self-efficacy: Students had to rate their degree of confidence in learning different subjects, for instance, in mathematics, biology, or a foreign language, by writing down a number from 1 to 10, where 1 means "Cannot do at all" and 10 means "Highly certain can do". This question comprised seven different subjects. To obtain the measure, we sum up the answers in each subject. The measurement of this 
variable is similar to the one described by Bandura (2006), with the difference that we do not take a scale from 1 to 100 but from 1 to 10 to increase comprehension.

- Generalized self-efficacy (GSE): It is calculated by taking the sum of 10 statements where students had to decide whether the statement says something that is "Not true of myself", which takes the value of (1), or whether it is "True of myself" which takes the value of (5). Higher values reflect larger GSE. Examples of the statements are the following: "I can always manage to solve difficult problems if I try hard enough"; "I can solve most problems if I invest the necessary effort'; "If I am in trouble, I can usually think of a solution". This measure is the Jerusalem \& Schwarzer (1995) scale with two slight modifications. First, we rephrased the scale in the first person, meaning that instead of having the option of "Not true at all", the participant read "Not true of myself". Second, instead of having a 1-4 scale, we used a 1-5, to add a category in the middle representing "Half true of myself".

\section{Stage 3A: Real job announcement ${ }^{5}$}

After the students finished the questionnaire, the experimenter casually entered the room to tell them about a job opportunity. Students could apply for a job as an assistant or as coordinator in a research project in Madagascar of one of the principal investigators. We gave them the opportunity to apply to only one job to mimic a situation where they have to decide whether to confront a high (coordinator) or a low (assistant) competitive environment. ${ }^{6}$ The experimenter told the students that the research project works with vanilla farmers in the SAVA region and that she is looking for assistants and a coordinator to help her with the organization of the workshops with vanilla farmers. Independent of the treatment group, all students who took part in the experiment received the exact same information. After the job was announced, each participant received a paper sheet with more information about the positions. The information provided includes that the assistants' job consists of helping with the organization of the workshops and filling questionnaires with different farmers, while the job of the coordinator is to visit the villages and plan workshops in advance with the village chief. The main difference between the two job offers was that the coordinator position had more responsibilities and hence a higher salary (13 percent higher) compared to the assistant position. We also required that candidates for each position should be motivated to work in rural areas, be good team members, and have good communication skills.

\footnotetext{
${ }^{5}$ We introduced two further treatments in this stage: Public and private sub-treatments to test whether social norms or social stigma may discourage female students to apply for the jobs. In each session, one group of students had to express their interest in the job privately and in the other publicly. This was known by the students before they made the decisions. Unlike the private treatment, in the public treatment, the room participants knew to which positions other participants have applied. Due to power issues, the paper does not focus on these treatments, and to report the results, we pooled the decisions taken in the two sub-treatments.

${ }^{6}$ The job was to take place from November to December 2018 for the experimental sessions conducted in July, or during July to August 2019 for the experimental sessions conducted in November. The dates were chosen according to the school calendar.
} 
In this stage, students had to decide whether they are interested in applying for one of the positions or if they are not interested at all. After students have made their decisions and gave the corresponding decision sheet to the experimenter, they were told that to be considered a potential candidate for any position, they must bring a recent photograph in one week. We added this requirement to make the application process somewhat demanding for the students. ${ }^{7}$ Once students received the information, they were told to leave one by one, and at the door, each of them received a participation fee of 2,000 ariary from the experimenter. This bonus payment was independent of their experimental earnings, given one week after each session.

\section{Stage 3B: Payment and job application}

A week after the experiment, we met the students again at each school to distribute their earnings from the experiment and hand the application forms to interested students. This type of form, which provides the same information as a curriculum vitae (CV), is a standard format that companies in Madagascar and other developing countries receive and accept for their hiring process. Hence, we also adopted this standard procedure for our hiring process. One of our main outcome variables is the number of complete applications received. To be considered as a complete application, each student should have filled the form with their personal information and included a recent photograph. We consider students who have applied as those who handed in a complete application form. Participants were informed about the photo requirement during stage $3 \mathrm{~A}$ of the experiment, and each of them received one private call during the week in between the experimental session and the earnings distribution to remind them about this condition. ${ }^{8}$ The application is valid for the position students expressed interest in stage $3 \mathrm{~A} .{ }^{9}$

\subsubsection{Experimental Procedures}

We conducted our study in the four biggest public high schools of the Sambava-AntalahaVohemar-Andapa (SAVA) region in northeastern Madagascar between July and November 2018 (See Figure 5.3). We selected only public schools because students in those schools

\footnotetext{
${ }^{7}$ In a standard application process, individuals incur different costs; for example, they may have to print their curriculum and send it to the potential employer or bring it directly to him or her. They also face opportunity costs in preparing an application as they invest time in it. Since we provide a standard form, we reduce such costs, and therefore with the photo, we mimic the costs of applying. We do not observe significant differences in the self-reported economic status between those who applied and those who did not (two-sided $t$-test $\mathrm{p}$-value $=0.453$ ); therefore, we do not believe that this requirement prevented students from applying due to economic concerns. Further, the photo price is not high as a package of 4 photos cost 2,000 ariary (approx. 0.5€). From anecdotal evidence, we know that students usually have some photos at home or need them often because they are required for the matriculation process every year and other administrative processes.

${ }^{8}$ Reminders are a common and cost-effective tool that has been used in different domains such as health (increase show-up rates for appointments, childhood vaccinations, etc.) and finance (encourage individuals to save). When students expressed their interest in the job and filled the form, they had to include a phone number where they could be reached. The procedure was the same for all treatment groups. All students that expressed interest in applying for a job were reached.

${ }^{9}$ We chose this procedure since it reduces potential spillover effects in the decision to apply to a position.
} 
are more likely to face income constraints and thus experience an aspiration failure. ${ }^{10}$ To conduct our experimental sessions, we invited students who were in their last year of secondary education. We consider this group particularly relevant to study as students are at the point of life to decide what to do after graduation.

To select the participants, we visited the public high schools several days before the experiments were taking place and invited students to take part in a workshop. We registered interested students during the lunch break and gave further information about the venue. With the students' information, we could allocate each of them to one of the treatment groups, ensuring that we have the same number of females and males in each treatment (stratified random sampling). However, due to a school strike that started right before we scheduled our data collection, we could not effectively use this previous allocation in two schools. ${ }^{11}$ Thus, there are groups of four where we do not have the same number of male and female participants. To control for this, we included the variable Gender imbalance group in our analysis, which takes the value of one if the group of four is not balanced and zero otherwise.

In total, 336 students took part in our three treatment between-subject experiment. During each experimental session, communication between students was not allowed. The sessions lasted on average two and a half hours, including the post-experimental survey and the job announcement. Before starting with the post-experimental questionnaire, one participant per session - randomly chosen - came to the front to select the activity that will be relevant for payment. After the activity was selected, students started to fill the questionnaire. At this point, participants did not know their experimental earnings, and this information was provided only when students came to collect their earnings (a week after the experimental session).

On average students earned 7,700 ariary $(\approx 2 €)$ plus a bonus payment for participation of 2,000 ariary $(0.51 €)$. The potential earnings are similar to the average wage for a working day on a farm $(\approx 3 €)$. Participants could earn money in stage 2 and in two activities that are not included in the present study, yet only one was randomly selected for payment. In cases where stage 2 was randomly selected for payment, the earnings of only one of the five tasks - chosen randomly- were paid out.

\footnotetext{
${ }^{10}$ While in private schools fees reach on average 240,000 ariary (approx. 61.5€) for a complete school year, in public schools the fees are on average 50,000 ariary (approx. 12.8€).

${ }^{11}$ In these schools very few participants and more males than females came to the meeting point. We, therefore, used the following procedure: We divided the students by gender and told them to make a line. One by one, we sent each student to one of the three rooms (one room for each treatment and control group), being careful to keep a similar share of female and male participants.
} 
Figure 5.3: Study Region

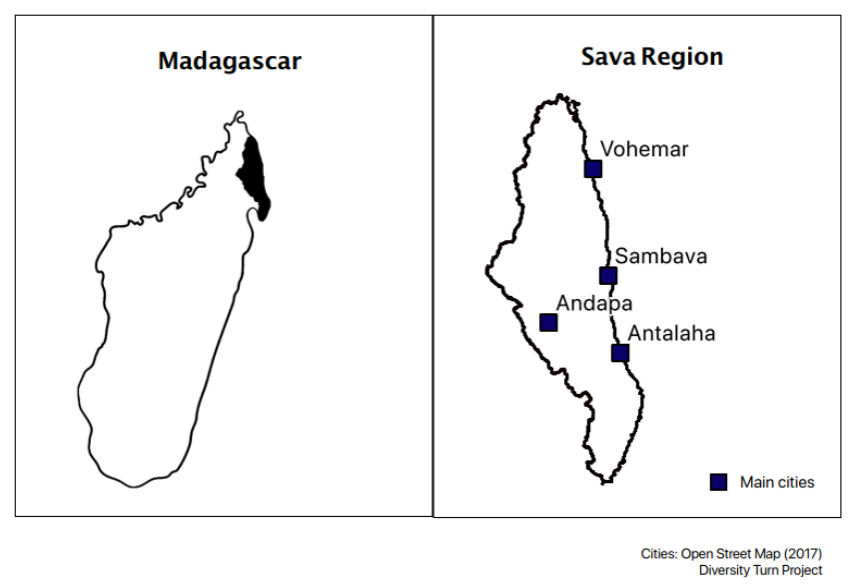

\subsection{Hypotheses}

The link between exposure to the role model videos and the decision to enter the labor market can be through several channels. Although there is no previous literature testing this relation, we argue that a rise in aspirations is the main channel. Aspirations are defined as distant goals that motivate individuals to provide investments in order to attain them (Bernard et al., 2012; Lybbert \& Wydick, 2018). When individuals lack examples to look up to and/or their capacity to aspire is constrained by their economic conditions, individuals may experience an aspiration failure (Ray, 2006), in which low aspirations produce low investments. Females in low-income countries are likely to face an aspiration failure. On the one hand, their economic condition constrains them. On the other hand, they lack successful examples from their social networks that can serve as reference points to help them imagine a different future. Hence, role models can increase females' aspirations.

The experiences of successful individuals can help women to imagine a different future and expand the opportunities they perceive for themselves. Further, observing a woman or a man succeeding by setting high goals and following them, females might feel inspired by the outcomes they have achieved and also set high goals for themselves. Aspirations have been found to correlate with educational and employment attainment of female adolescents (Roy et al., 2018) and with outcomes of peers with higher status (Janzen et al., 2017). Several experimental studies have shown that role models can increase aspirations (Beaman et al., 2012; Jensen, 2012; Bernard et al., 2014; Riley, 2018). Having higher aspirations can lead females to apply to one of the advertised positions and even apply to more competitive jobs, as they can imagine a different future for themselves.

Based on the above empirical evidence, we argue that being exposed to the Female Role Model or the Male Role Model video increases applications of female participants. Thus, our first hypothesis is: 
Hypothesis 1. Female participants will be more likely to apply to the job positions in the Female Role Model video and Male Role Model video treatment compared to females in the PLACEBO group.

In addition, we believe that showing a successful female character will encourage female students to apply for the more competitive job - the coordinator position. Our second hypothesis is:

Hypothesis 2. Female students will be more willing to apply to the coordinator position when exposed to the Female Role Model video compared to the Placebo group.

While we believe that an increase in aspirations is the main channel that links the exposure to the role model videos and the decision to enter the labor market, we discuss three other potential mechanisms that have been discussed in the related literature below: competitive preferences, self-efficacy and locus of control beliefs. ${ }^{12}$ Yet, we do not provide any hypotheses as there are no previous studies in which such mechanisms are compared and tested. We conduct an exploratory analysis in section 5.7 to study which mechanisms could explain females' decision to complete an application.

First, role models can have an effect on labor market outcomes through competitive preferences. The gender difference in competition has been largely studied through laboratory and field experiments (Gneezy et al., 2003; Niederle \& Vesterlund, 2007; Carpenter et al., 2018). The common finding is that women are less willing to enter into competition in comparison to men (Niederle \& Vesterlund, 2011). By observing a successful and similar example, women can become more ambitious and thus compete more (Schier, 2020). Exposing female students to a successful female of a similar background, who set a goal and achieved it, can make them more competitive and thus willing to apply.

Second, the mechanism could also run through changes in self-efficacy beliefs, which refer to an individual's belief in her capacity to achieve an outcome (Bandura, 1977, 1997). Self-efficacy is a key predictor of female education and employment aspirations (Roy et al., 2018) and, as aspirations, can also be increased through social comparison with role models and peers. Individuals who observe how similar people succeed can come to trust their own abilities more (Bandura, 1977, 2004). Individuals, who believe more in their abilities due to the role model intervention, might be more willing to complete an application.

Lastly, role models can also lead to a change in locus of control beliefs. Locus of control refers to the beliefs an individual has regarding the control she has over her life outcomes. Having an internal locus of control belief has been associated with several labor market outcomes (Cobb-Clark, 2015). We suggest that seeing similar individuals succeed can also lead to a change in locus of control beliefs. The information provided in the videos could lead students to revise their beliefs on how behavior and outcomes are connected and thus

\footnotetext{
${ }^{12}$ We do not test for other potential mechanisms such as mitigation of stereotype threats and discrimination.
} 
on what is possible to achieve, making them more willing to exert effort and complete an application.

\subsection{Empirical Strategy}

To study the effects of our role model intervention on the decision to apply to one of the advertised position, we estimate the following model:

$$
L_{i}=\alpha+\delta T_{i}+\lambda F_{i}+\beta\left(T_{i} \cdot F_{i}\right)+X_{i}^{\prime} \gamma+\mu_{s}+\epsilon_{i}
$$

where $L_{i}$ represents one of our two main outcome variables: (1) Complete Application that takes the values: $0=$ Not applied, $1=$ Applied to one of the advertised positions, (2) Coordinator Position that takes the values: $0=$ Applied to Assistant Position, $1=$ Applied to Coordinator Position. $T_{i}$ denotes the treatment variable that takes the values: $0=$ Placebo video, $1=$ Female Role Model video and $2=$ Male Role Model video. $F_{i}$ is an indicator variable equal to one when the participant is female and zero if male. $X_{i}^{\prime}$ is a vector of individual characteristics, such as number of brothers, whether their family cultivates vanilla, the frequency individuals meet outsiders, the frequency they used their smartphone and their mother's highest degree. $\mu_{s}$ are school fixed effects and $\epsilon_{i}$ is the random error. We estimate an ordinary least squares model (OLS) to facilitate the interpretation of the interactions and calculate robust standard errors.

In addition to the OLS estimation, we run a multinomial logistic model where the dependent variable Complete Application can take one of three values: $0=$ Not Applied, $1=$ Applied for Assistant Position, 2 = Applied for Coordinator Position. The treatment variables, the interaction term, as well as the vector of socioeconomic characteristics are included in this model.

\subsection{Results}

In this section we outline the results from our field experiment. Section 5.6.1 includes descriptive statistics and randomization checks. In section 5.6.2 we present the results of the role model intervention on job applications and in section 5.6.3 we show participants' rating of the role models.

\subsubsection{Descriptive Statistics and Randomization Checks}

From a total sample of 336 students, 43 percent are female and have on average 19 years old. Before starting the last year of high school, students can decide whether to opt for a science or a language focus. This means that the classes they attend are different. In our sample, 54 percent of participants are in the science focus. On average, students reported to 
have two brothers and rated their economic status with an average of 2.6 out of 5 , where 5 indicates being wealthy. About half of the students were raised in one of the main cities of the region and most of them reported not to have a job at the moment of the experiment.

Table 5.A1 in Appendix A presents the means and p-values of balance tests for individual variables in the two treatments and control groups. There are no significant differences in the proportion of females, the age of the participants, their chosen focus in secondary school, the economic status, their job situation, whether their family is involved in the vanilla business, whether they were raised in the city or in the rural area, and the highest degree achieved by the mother. We find significant differences in the frequency of smartphone usage, the frequency of meeting people who are not from their school or their family, as well as whether there were any friends in their group of four. To account for these differences, we will control for these variables in the analysis.

\subsubsection{Treatment Effects on Applications}

Overall, the job positions announced were attractive for students. In total we received complete applications from more than half of the participants (186 out of 336 students). Figure 5.4 displays the percentage of complete applications by gender in each treatment (left side), as well as the share of applications for the assistant and the coordinator position by gender in each treatment group (right side). ${ }^{13}$

In the PlaCEBO group, 48 percent of students completed an application. This share increases in the Female Role Model group where 63 percent of the students applied. A two-sample Fisher's exact test reveals that the difference is significant at the five percent level $(\mathrm{p}$-value $=0.023)$. In the MALE Role Model group 55 percent of the students applied, which is not significantly different from the PLACEBO group (A two-sample Fisher's exact test $\mathrm{p}$-value $=0.287)$. As already suggested by the left side of Figure 5.4, we find no gender differences in each of the treatments for the outcome Complete Application (Two-sided Fisher's exact test, all test p-values $\geq 0.917$ ).

Next, we look at the share of applications for each type of position advertised (right side of Figure 5.4). In the PlaceBo group 62 percent of female students who applied chose the assistant position. This share increases to 71 percent in the Female Role Model group, but the difference with respect to to the PLACEBO group is not statistically significant (two-sample t-test $\mathrm{p}$-value $=0.504$ ). Similar results can be found for the male students. In the PlaCEBo group 32 percent of the male students applied to the assistant position, while in the Female Role Model treatment 49 percent of the males applied (two-sample t-test p-value $=0.161)$.

For the coordinator position we find that, conditioning on applying, 38 percent of females applied to this job in the PlaceBo. Our treatment groups change this share, especially the Male Role Model group in which the share increases to 50 percent. However,

\footnotetext{
${ }^{13}$ Shares conditional on participants who applied in each treatment.
} 
the differences are not statistically significant (all two-sample t-tests p-values $\geq 0.278$ ). Applications to the coordinator position among males are almost equally high in each of the treatment groups: while 68 percent of the males applied in the PlaceBo, 51 percent applied in the Female Role Model group, and 45 percent in the Male Role Model group (all Fisher's exact tests p-values $\geq 0.845$ ). Although we do not find that female students are significantly more likely to apply to the coordinator position in the MALE Role Model group compared to the Placebo group, we find that the gender difference present in the proportion of applicants for the coordinator position in the PLACEBO and the Female Role Model groups (two-sided Fisher's exact test p-values $=0.050 \& 0.087$ ), is not present in the MALE Role Model group (two-sided Fisher's exact test p-value = $0.800)$.

The above results show that, compared to the Placebo group, the Female Role Model video increases the application rate among students, while the MALE Role Model video bridges the gender differences in the decision to apply for the high responsibility position.

Figure 5.4: Complete Applications by Gender and Type of Position in each Treatment

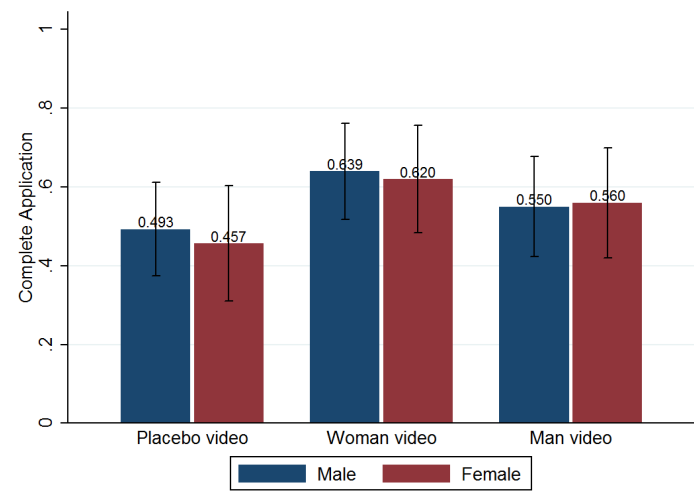

Notes: The graph displays confidence intervals of $95 \%$

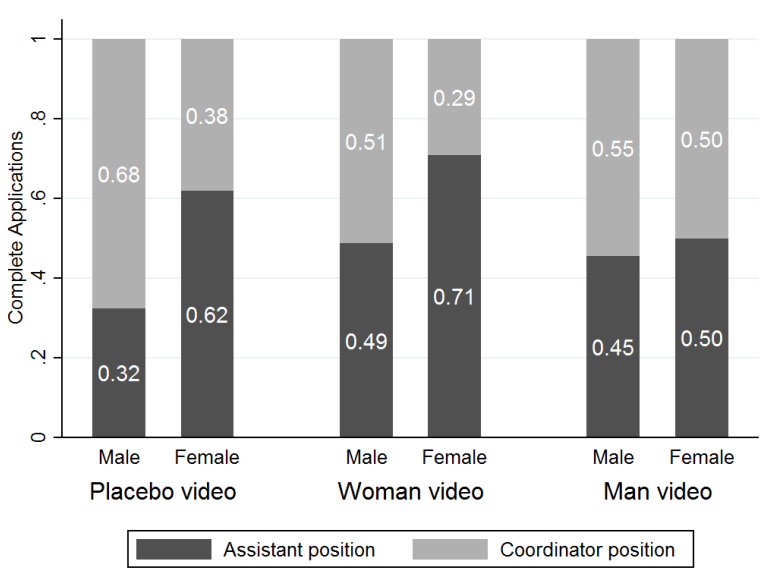

In the following, we use regression analysis to control for the effects of subject heterogeneity. In Table 5.1 column 1 we regress Completed Application on the treatments and include school fixed effects. The model in column 2 includes further controls. The above results remain: The Female Role Model video treatment has a positive effect on participants' decision to apply to one of the jobs, while the Male Role Model video has no effect. Also, as can be seen from column 3, we find no gender difference in the propensity to apply to the positions. We find a significant difference in the probability of females to apply in the Female Role Model video group compared to females in the Placebo group, while there is no significant difference in the likelihood of females to apply in the MALE Role Model video group compared to the Placebo group (see comparisons in Table 5.1). Thus, our results provide evidence in favor of Hypothesis 1 for the Female Role Model treatment and lack evidence for the MALE Role Model treatment. 
Columns 4 to 6 in Table 5.1 include the results on the outcome Coordinator Position. Controlling for further covariates in column 5 , we find that there is no average treatment effect of the Female Role Model or Male Role Model video on the choice of position. However, conditional on applying, we find that female participants are less likely to apply to the coordinator position than males in the PlaceBo condition. We include an interaction term in column 6 to assess whether the treatment had differential effects on female and male students. We find that the gender difference, which is found in the PlacEBo group, is prevalent in the Female Role Model but not in the Male Role Model treatment group. Our results suggest that this is driven by an increase in females applying to the competitive position compared to females in the PLACEBO (although the difference is weakly significant $\mathrm{p}$-value $=0.136$ ). Our results do not provide evidence in favor of Hypothesis 2 as the Male Role Model, instead of the Female Role Model, encourages female students to apply to the coordinator position.

In sum, we find that the Female Role Model is successful in encouraging female and male students to apply for one of the advertised positions. In addition, we find that the Male Role Model almost closes the gender gap in applications for the coordinator position present in the Placebo group and the Female Role Model treatment. These results indicate that only a MALE Role Model encourages applications among females to more competitive jobs. These results hold if we instead estimate a probit model and after controlling for multiple hypothesis testing (See Tables 5.A2 and 5.A5 in the Appendix).

Table 5.1: Treatment Effects on Applications

\begin{tabular}{|c|c|c|c|c|c|c|}
\hline & \multicolumn{3}{|c|}{ Complete Application } & \multicolumn{3}{|c|}{ Coordinator Position } \\
\hline & (1) & (2) & (3) & (4) & $(5)$ & $(6)$ \\
\hline Woman video & $\begin{array}{l}0.155^{* *} \\
(0.065)\end{array}$ & $\begin{array}{c}0.205^{* * *} \\
(0.068)\end{array}$ & $\begin{array}{l}0.173^{* *} \\
(0.085)\end{array}$ & $\begin{array}{l}-0.149^{*} \\
(0.089)\end{array}$ & $\begin{array}{l}-0.102 \\
(0.102)\end{array}$ & $\begin{array}{l}-0.108 \\
(0.126)\end{array}$ \\
\hline Man video & $\begin{array}{c}0.077 \\
(0.064)\end{array}$ & $\begin{array}{c}0.096 \\
(0.070)\end{array}$ & $\begin{array}{l}0.086 \\
(0.086)\end{array}$ & $\begin{array}{l}-0.021 \\
(0.095)\end{array}$ & $\begin{array}{c}0.047 \\
(0.107)\end{array}$ & $\begin{array}{l}-0.087 \\
(0.130)\end{array}$ \\
\hline Female & & $\begin{array}{c}0.068 \\
(0.059)\end{array}$ & $\begin{array}{l}0.036 \\
(0.100)\end{array}$ & & $\begin{array}{c}-0.240^{* * *} \\
(0.082)\end{array}$ & $\begin{array}{c}-0.363^{* * *} \\
(0.139)\end{array}$ \\
\hline Woman video $\times$ Female & & & $\begin{array}{c}0.075 \\
(0.132)\end{array}$ & & & $\begin{array}{c}0.043 \\
(0.182)\end{array}$ \\
\hline Man video $\times$ Female & & & $\begin{array}{c}0.025 \\
(0.134)\end{array}$ & & & $\begin{array}{l}0.327^{*} \\
(0.198)\end{array}$ \\
\hline Constant & $\begin{array}{c}0.630^{* * *} \\
(0.057)\end{array}$ & $\begin{array}{l}-0.380 \\
(0.437)\end{array}$ & $\begin{array}{l}-0.392 \\
(0.438)\end{array}$ & $\begin{array}{c}0.490^{* * *} \\
(0.079)\end{array}$ & $\begin{array}{l}1.223^{* *} \\
(0.595)\end{array}$ & $\begin{array}{l}1.160^{* *} \\
(0.578)\end{array}$ \\
\hline Woman Video vs. Placebo (only females) & & & $\begin{array}{l}0.248^{* *} \\
(0.106)\end{array}$ & & & $\begin{array}{l}-0.065 \\
(0.147)\end{array}$ \\
\hline Man Video vs. Placebo (only females) & & & $\begin{array}{c}0.111 \\
(0.109)\end{array}$ & & & $\begin{array}{c}0.240 \\
(0.160)\end{array}$ \\
\hline Observations & 336 & 336 & 336 & 186 & 186 & 186 \\
\hline School Fixed Effects & Yes & Yes & Yes & Yes & Yes & Yes \\
\hline Controls & No & Yes & Yes & No & Yes & Yes \\
\hline
\end{tabular}


To further explore our results, and without conditioning the treatment effects on completing an application, we run a multinomial logit where the dependent variable can take one of three values: $0=$ Not Applied, $1=$ Applied for Assistant Position, $2=$ Applied for Coordinator Position. Table 5.A3 in Appendix A shows the results of the logistic regression, where column 1 indicates the average treatment effects and column 2 includes an interaction term between treatment and gender. Without interpreting the effect sizes, as above, we find that female and male students exposed to the Female Role Model video are more likely to apply to the assistant position, both with respect to the PLACEBO group and to our base outcome of not applying. In addition, we find an average treatment effect on the likelihood to apply for the coordinator position. We explore heterogeneous treatment effects in column 2 and find that female students are more likely to apply to the assistant position in the Placebo and the Female Role Model video group compared to male students. For the coordinator position we also find that females are less likely to apply than males in the Placebo and the Female Role Model video group. We study the treatment effects for each gender in detail below.

Figure 5.5 shows the predictive marginal effects of the multinomial logit model for each of the advertised positions by gender. Compared to females in the Placebo, female students exposed to the Female Role Model video are 21 percentage points more likely to apply to the assistant position ( $\mathrm{p}$-value $=0.0353$ ). In addition, we find that female students are 27 percentage points more likely to apply to the assistant position compared to male students in the Female Role Model treatment video ( $\mathrm{p}$-value $=0.0019$ ). Regarding the coordinator position, we show that there is still a gender gap in the PLACEBO and Female Role Model groups. Females are 16 percentage points less likely to apply to the coordinator position in the Female Role Model video compared to men (p-value $=0.0514)$ and 13 percentage points less likely in the PLACEBO group ( $\mathrm{p}$-value $=0.0911$ ) Thus, compared to the OLS estimation above (see Table 5.1 column 6), the gap is smaller. In line with the OLS estimation above, we find that there is no gender difference in the Male Role Model treatment ( $\mathrm{p}$-value $=0.8027$ ). The reason to explain this is that compared to female students in the Placebo group, females watching the MALE Role MODEL video are 16 percentage points more likely to apply to the coordinator position $(\mathrm{p}$-value $=0.0743)$. 
Figure 5.5: Predictive Margins Multinomial Logit: Complete Applications for each Position
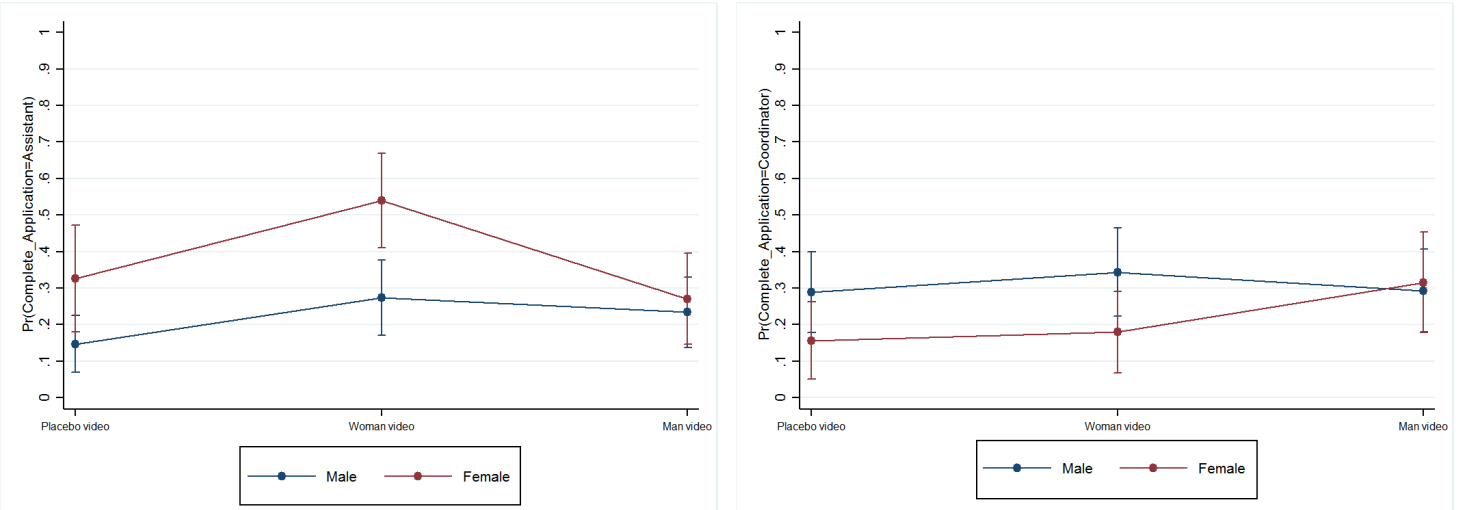

Notes: The graphs display confidence intervals of $95 \%$

\subsubsection{Role Model Assessment}

After the video screening, we asked the students about their perceptions on the video and the main character(s). ${ }^{14}$ Table 5.2 shows the means and the two-sided $t$-tests p-values from the answers reported by female and male participants to five questions. Each question could be answered with the following scale: strongly disagree (1), disagree (2), neither agree nor disagree (3), agree (4), strongly agree (5).

Both female and male participants agree quite strongly that the main characters in the Female Role Model video and the Male Role Model video are not afraid of taking risks. The ratings are significantly different compared to the ratings of participants who watched the Placebo video. Further, we find that females and males identify with the role models. However, male students report to equally identify with the FEMALE RoLE Model and the Male Role Model, while female students identify much more with the Female Role Model. Participants also agree quite strongly with the question of whether they like the characters. Females and males significantly like the Female Role Model character more compared to the Placebo. Interestingly, females in the Female Role Model treatment report to be quite certain to be as successful as the main character $(4.3$ out of 5), whereas in the Male Role Model treatment females report lower scores (3.96 out of $5 ; \mathrm{p}$-value $=0.099$ ).

The selection of role models regarding their similarity to female participants has been successful, as females identify with the main character of the Female Role Model video and with the Male Role Model video. However, we find that the character's success is not rated significantly different across females in the treatment groups. A potential explanation is that both role model characters were also the main characters of the PLACEBO video and their profession was mentioned. This implies that the treatment effect could

\footnotetext{
${ }^{14}$ One limitation of our study design is that we have the main characters of the Female Role Model and the Male Role Model video in the Placebo video. The ratings of the Placebo video thus refer to both characters.
} 
be underestimated. Yet, female students in the two treatment video groups agree more strongly to whether they have been motivated by the video compared to female students in the PlaceBo group. Therefore, the characters may serve as role models in showing how they achieved a goal.

Table 5.2: Rating of the Role Model

\begin{tabular}{|c|c|c|c|c|c|c|}
\hline & $\begin{array}{c}\text { (1) } \\
\text { Placebo video }\end{array}$ & $\begin{array}{c}(2) \\
\text { Woman video }\end{array}$ & $\begin{array}{c}(3) \\
\text { Man video }\end{array}$ & $\begin{array}{c}\text { (4) } \\
\text { (1) vs. (2), } \\
\text { p-value }\end{array}$ & $\begin{array}{c}(5) \\
\text { (1) vs. (3), } \\
\text { p-value }\end{array}$ & $\begin{array}{c}(6) \\
\text { (2) vs. (3) } \\
\text { p-value }\end{array}$ \\
\hline \multicolumn{7}{|l|}{ Panel A - Female participants } \\
\hline Character is not afraid of risks & $\begin{array}{c}3.935 \\
(0.160)\end{array}$ & $\begin{array}{l}4.740 \\
(0.069)\end{array}$ & $\begin{array}{l}4.740 \\
(0.063)\end{array}$ & 0.000 & 0.000 & 1.000 \\
\hline Character is successful & $\begin{array}{l}4.457 \\
(0.102)\end{array}$ & $\begin{array}{l}4.640 \\
(0.102)\end{array}$ & $\begin{array}{l}4.620 \\
(0.094)\end{array}$ & 0.207 & 0.241 & 0.886 \\
\hline Participant likes character & $\begin{array}{l}4.326 \\
(0.099)\end{array}$ & $\begin{array}{l}4.700 \\
(0.065)\end{array}$ & $\begin{array}{l}4.520 \\
(0.087)\end{array}$ & 0.002 & 0.142 & 0.101 \\
\hline Identifies with character & $\begin{array}{c}3.565 \\
(0.186)\end{array}$ & $\begin{array}{l}4.700 \\
(0.077)\end{array}$ & $\begin{array}{l}4.280 \\
(0.125)\end{array}$ & 0.000 & 0.002 & 0.005 \\
\hline Can be as successful as character & $\begin{array}{l}4.283 \\
(0.111)\end{array}$ & $\begin{array}{l}4.260 \\
(0.124)\end{array}$ & $\begin{array}{c}3.960 \\
(0.131)\end{array}$ & 0.893 & 0.065 & 0.099 \\
\hline $\begin{array}{l}\text { Participant is motivated by the video } \\
N\end{array}$ & $\begin{array}{c}4.043 \\
(0.139) \\
46\end{array}$ & $\begin{array}{c}4.760 \\
(0.061) \\
50\end{array}$ & $\begin{array}{c}4.500 \\
(0.087) \\
50\end{array}$ & 0.000 & 0.006 & 0.016 \\
\hline \multicolumn{7}{|l|}{ Panel B - Male participants } \\
\hline Character is not afraid of risks & $\begin{array}{c}4.101 \\
(0.124)\end{array}$ & $\begin{array}{c}4.787 \\
(0.053)\end{array}$ & $\begin{array}{c}4.700 \\
(0.060)\end{array}$ & 0.000 & 0.000 & 0.277 \\
\hline Character is successful & $\begin{array}{l}4.377 \\
(0.095)\end{array}$ & $\begin{array}{c}4.574 \\
(0.092)\end{array}$ & $\begin{array}{l}4.467 \\
(0.087)\end{array}$ & 0.141 & 0.492 & 0.400 \\
\hline Participant likes character & $\begin{array}{c}4.333 \\
(0.076)\end{array}$ & $\begin{array}{c}4.754 \\
(0.056)\end{array}$ & $\begin{array}{c}4.467 \\
(0.084)\end{array}$ & 0.000 & 0.241 & 0.005 \\
\hline Identifies with character & $\begin{array}{c}3.913 \\
(0.113)\end{array}$ & $\begin{array}{c}4.426 \\
(0.098)\end{array}$ & $\begin{array}{c}4.433 \\
(0.093)\end{array}$ & 0.001 & 0.001 & 0.958 \\
\hline Can be as successful as character & $\begin{array}{l}4.188 \\
(0.091)\end{array}$ & $\begin{array}{c}4.377 \\
(0.094)\end{array}$ & $\begin{array}{l}4.100 \\
(0.113)\end{array}$ & 0.152 & 0.539 & 0.062 \\
\hline Participant is motivated by the video & $\begin{array}{c}4.261 \\
(0.082)\end{array}$ & $\begin{array}{c}4.672 \\
(0.065)\end{array}$ & $\begin{array}{l}4.517 \\
(0.077)\end{array}$ & 0.000 & 0.026 & 0.125 \\
\hline$N$ & 69 & 61 & 60 & & & \\
\hline
\end{tabular}

\subsection{Exploratory Analysis}

In this section we perform an exploratory analysis to assess whether the treatment effects can be explained by changes in the measures obtained from the lab experiment. As a first step we report descriptive statistics on the variables that we obtained in the lab-in-the-field experiment for the PlaceBo group. We then analyze whether our role model intervention affects behavior in the lab, before we control for the lab measures in our main outcome regression.

\subsubsection{Descriptive Statistics of Mechanism Variables}

Table 5.3 shows the descriptive statistics for our mechanism variables in the PlaceBo group. On average, students solve 4.42 matrices in Task-1 and 5.69 matrices in Task-2. About a third of the students (31 percent) chose tournament pay in Task- 3 and 24 percent chose intra-competition in Task-5. Concerning our aspiration measures, we find that our sample includes observations with very high levels of income and asset aspirations, as can 
be seen from the maximum levels reported and the difference in the mean and median. The median aspired income is 2,000,000 ariary (about $464 €$ ), and the median aspired level of assets is 150,000,000 ariary (about 34,780€). Since the minimum wage per month in Madagascar is about 34 Euro ("Caisse Nationale de Prévoyance Sociale Madagascar", 2015), students' aspire relatively high. Moreover, students' education and social status aspirations are high. On average, they aspire to achieve 19.43 years of schooling and a social status of 9.16. We test for differences in aspirations across gender reported in Table 5.A4 in the Appendix, but find that there are no significant differences. Further, students in the PlACEBO group on average report a general self-efficacy score of 36.47 (out of 55) and an academic self-efficacy score of 41.08, which is quite low given that the highest score is 70 . Lastly, students in the PLACEBO group on average report to have 3.92 locus of control beliefs (out of 6 ). ${ }^{15}$

Table 5.3: Mechanism Variables in the Placebo Group

\begin{tabular}{lcccccc}
\hline & Mean & Median & SD & Min & Max & N \\
\hline Performance task 1 & 4.42 & 5.00 & 1.65 & 0.00 & 8.00 & 115.00 \\
Performance task 2 & 5.69 & 6.00 & 1.68 & 0.00 & 9.00 & 115.00 \\
Compete in task 3 & 0.31 & 0.00 & 0.47 & 0.00 & 1.00 & 115.00 \\
Compete in task 5 & 0.24 & 0.00 & 0.43 & 0.00 & 1.00 & 115.00 \\
Income goal (in 1000 ariary) & $966,752.57$ & $2,000.00$ & $9,353,898.46$ & 10.00 & $100,000,000.00$ & 115.00 \\
Asset goal (in 1000 ariary) & $3,292,051.96$ & $150,000.00$ & $15,604,268.64$ & 25.00 & $100,000,000.00$ & 115.00 \\
Education goal & 19.43 & 22.00 & 2.80 & 12.50 & 22.00 & 115.00 \\
Social status goal & 9.16 & 8.00 & 11.00 & 1.00 & 100.00 & 115.00 \\
Locus of control & 3.92 & 4.00 & 0.99 & 0.00 & 6.00 & 115.00 \\
General self-efficacy & 36.47 & 37.00 & 6.38 & 21.00 & 48.00 & 115.00 \\
Academic self-efficacy & 41.08 & 40.97 & 9.29 & 11.00 & 61.00 & 115.00 \\
\hline
\end{tabular}

\subsubsection{Treatment Effects on Mechanism Variables}

In Table 5.4 we present the results of estimating ordinary least squares (OLS) regressions on performance and competitive preferences. ${ }^{16}$ First, we assess whether the treatments have an effect on performance in the real-effort task as it might influence the decision to compete. In Columns 1 and 2 we regress the number of correctly solved matrices in Task- 1 and Task- 2 on the treatment variable, gender, an interaction of treatment and gender, school fixed effects and further controls specified in the table notes. We find that female students perform better in Task-1 and Task-2 compared to males in all but one case (performance in Task-1 in the Male Role Model video treatment). Female students on average solve 4.8 matrices out of 10 in the PlaceBo group, 5.7 matrices in the Female Role Model group and 6.5 in the Male Role Model group. Overall, we find that the

\footnotetext{
${ }^{15}$ We do not find evidence for significant gender differences in the placebo video in general self-efficacy (t-test, $\mathrm{p}$-value $=0.183$, academic self efficacy ( $\mathrm{t}$-test, $\mathrm{p}$-value $=0.1075)$, or in locus of control beliefs ( $\mathrm{t}$-test, $\mathrm{p}$-value $=0.302)$.

${ }^{16}$ Overall, students are able to assess their absolute performance very accurately. The belief of their performance and their actual performance correlate strongly (between 65 and 75 percent). This confirms our assumption that feedback on performance is not needed, as performance could easily be evaluated in this task. However, students are less able to judge their relative performance. Students' belief in their relative rank in Task- 2 and Task- 3 correlates moderately (35 and 40 percent) with their actual rank in the competition against others.
} 
Female Role Model and the Male Role Model video have a positive effect on female and male students' Task-1 and Task-2 performance. If we look at the performance increases in the two treatment groups compared to the PlaceBo, we find that especially the Male Role Model drove effort provision, not only among male, but also among female students. Females in the Male Role Model group solve 1.6 (1.7) matrices more in Task-1 (Task-2) compared to females in the Placebo group, whereas males in the Male Role Model group solve 1.9 (2.0) more matrices correctly in Task-1 (Task-2) compared to males in the PlACEBO condition.

In a next step we assess the effects of the role model videos on students' decision to enter into competition with other students in their group of four people. We find that only 17 percent of the female students in the PlaceBo group chose tournament pay, 24 percent in the Female Role Model video and 28 percent in the Male Role Model video treatment. We employ OLS regressions to control for differences in performance in the previous tasks and other covariates that could potentially effect the decision to compete. The estimations are shown in Table 5.4 in column 3. The dependent variable takes on the value of 1 if the student chose tournament compensation or 0 if she decided for piece rate. Our results show that female students in the PLACEBO condition are 26 percentage points less likely to enter into competition compared to male students. However, we find no gender difference in the choice to compete in the two treatment groups. This can be explained by a decrease in the propensity of male students to enter into competition in the two treatment groups compared to the PlaceBo condition. Only 25 percent of the male students decide for tournament compensation in the Female Role Model video group and 28 percent in the MAle Role Model group compared to 41 percent in the Placebo condition. Compared to Meier et al. (2020), we used a placebo video that we also produced in Madagascar and that showed the same characters and surroundings as the treatment videos. In retrospective we assumed that this placebo video was neutral, but our results suggest that it could have encouraged competitive behavior due to the mentioning of decreasing land availability in the rural areas and that many young people search for income in the cities.

Next, we analyze whether the role model intervention has an effect on the propensity of students to enter into intra-competition with their past performance in Task-2. The results can also be found in Table 5.4 in column 4. Compared to inter-competition we find that there is no gender differences in the PLACEBO group. We find that the treatment videos do not have an effect on the propensity to enter into intra-competition among female and male students. We observe that 22 percent of the females in the PlaceBo group competed against their past performance, 36 percent in the Female Role Model and 38 percent in the Male Role Model treatment. For the male sample we find that 26 percent chose intra-competition in the Placebo group, 25 percent in the Female Role Model and 52 percent in the Male Role Model treatment. 
Table 5.4: Treatment Effects on Performance and Competitive Preferences

\begin{tabular}{|c|c|c|c|c|}
\hline & $\begin{array}{c}\text { (1) } \\
\text { Perf. } 1\end{array}$ & $\begin{array}{c}(2) \\
\text { Perf. } 2\end{array}$ & $\begin{array}{c}(3) \\
\text { Compete } 3\end{array}$ & $\begin{array}{c}\text { (4) } \\
\text { Compete } 5\end{array}$ \\
\hline Woman video & $\begin{array}{c}0.827^{* * *} \\
(0.306)\end{array}$ & $\begin{array}{c}0.980^{* * *} \\
(0.282)\end{array}$ & $\begin{array}{c}-0.223^{* * *} \\
(0.074)\end{array}$ & $\begin{array}{c}-0.039 \\
(0.081)\end{array}$ \\
\hline Man video & $\begin{array}{c}1.881^{* * *} \\
(0.301)\end{array}$ & $\begin{array}{c}2.014^{* * *} \\
(0.271)\end{array}$ & $\begin{array}{c}-0.234^{* * *} \\
(0.089)\end{array}$ & $\begin{array}{c}0.171 \\
(0.104)\end{array}$ \\
\hline Female & $\begin{array}{l}0.546^{*} \\
(0.305)\end{array}$ & $\begin{array}{l}0.471^{*} \\
(0.272)\end{array}$ & $\begin{array}{c}-0.260^{* * *} \\
(0.074)\end{array}$ & $\begin{array}{l}-0.044 \\
(0.078)\end{array}$ \\
\hline Woman video $\times$ Female & $\begin{array}{l}-0.060 \\
(0.407)\end{array}$ & $\begin{array}{c}0.177 \\
(0.345)\end{array}$ & $\begin{array}{l}0.215^{* *} \\
(0.102)\end{array}$ & $\begin{array}{c}0.154 \\
(0.112)\end{array}$ \\
\hline Man video $\times$ Female & $\begin{array}{l}-0.317 \\
(0.431)\end{array}$ & $\begin{array}{l}-0.320 \\
(0.365)\end{array}$ & $\begin{array}{l}0.220^{* *} \\
(0.107)\end{array}$ & $\begin{array}{l}-0.094 \\
(0.123)\end{array}$ \\
\hline Constant & $\begin{array}{c}5.135^{* * *} \\
(1.445)\end{array}$ & $\begin{array}{c}7.519^{* * *} \\
(1.136)\end{array}$ & $\begin{array}{l}0.990^{* *} \\
(0.395)\end{array}$ & $\begin{array}{c}0.249 \\
(0.387)\end{array}$ \\
\hline Woman Video vs. Placebo (only females) & $\begin{array}{c}0.767^{* * *} \\
(0.296)\end{array}$ & $\begin{array}{c}1.158^{* * *} \\
(0.259)\end{array}$ & $\begin{array}{l}-0.007 \\
(0.080)\end{array}$ & $\begin{array}{c}0.115 \\
(0.095)\end{array}$ \\
\hline Man Video vs. Placebo (only females) & $\begin{array}{c}1.563^{* * *} \\
(0.319)\end{array}$ & $\begin{array}{c}1.694^{* * *} \\
(0.278)\end{array}$ & $\begin{array}{l}-0.014 \\
(0.081)\end{array}$ & $\begin{array}{c}0.077 \\
(0.105)\end{array}$ \\
\hline Observations & 336 & 336 & 336 & 336 \\
\hline$R^{2}$ & 0.325 & 0.524 & 0.280 & 0.191 \\
\hline School Fixed Effects & Yes & Yes & Yes & Yes \\
\hline Controls & Yes & Yes & Yes & Yes \\
\hline \multicolumn{5}{|c|}{$\begin{array}{l}\text { Notes: Robust standard errors in parentheses. }{ }^{*} p<0.10,{ }^{*} p<0.05, * * * p<0.01 \text {. The two rows } \\
\text { located in the middle part of the table indicate the treatment effect sizes and were obtained by using the } \\
\text { contrast command in Stata. Control variables: Age in years, Science focus, Number of brothers, Vanilla } \\
\text { family, Friends group, Frequency meeting outsiders, Frequency smartphone usage, Gender imbalance group: } \\
1 \text { if there is an uneven number of female and males in the group of four, } 0 \text { if there is a balance. Column } 2 \\
\text { further includes Performance difference 2-1: the difference in performance between Task- } 1 \text { and Task- } 2 \text {. } \\
\text { Column } 3 \text { additionally controls for Performance task2: number of correct matrices solved in Task-2; Belief } \\
\text { rank 2: Participant's belief in his rank in Task-2 (1=highest, } 4=\text { lowest) in the group. In column } 4 \text { instead } \\
\text { of including Belief rank } 2 \text { as control, we include Belief performance Task-2. }\end{array}$} \\
\hline
\end{tabular}

The results of the OLS regressions on the aspiration index, locus of control, and self-efficacy beliefs are reported in Table 5.5. In column 1 we regress the aspiration index on the treatment variables, gender, an interaction of treatment and gender, school fixed effects, the current index and further individual level controls. ${ }^{17}$ We find that the female students in the Female Role Model video treatment report an aspiration index that 20 percent of a standard deviation higher compared to females in the Placebo group. The Male Role Model also has a positive effect on females' aspiration index. Treated female students have a 23 percent of a standard deviation higher index compared to females in the PlaceBo group. We find no treatment effects for male students.

In column 2 we regress the outcome variable Locus of control on the same controls (except for the current index). We find no treatment effect for each of the role model treatments. Moreover, while our Female Role Model treatment did not increase General self-efficacy beliefs of female students compared to females in the Placebo (see column 3), we find that females in the Male Role Model video report a significantly higher score in this type of beliefs respect to females in the Placebo group. Last, we find that the Female Role Model video has a positive effect on females' Academic self-efficacy beliefs (see column 4). Treated female students report a 3.85 higher score compared to females in the PlaceBo.

\footnotetext{
${ }^{17}$ For the analysis on aspirations we drop observations that have extreme high aspiration index values by trimming the sample to the 95 percentile, which results in 17 observations less compared to the whole sample. We find that there are no treatment effects without dropping the outliers.
} 
The above analysis revealed that the treatment videos have an effect on some of our mechanism variables. We find a treatment effect for female students on task performance, aspirations, general self-efficacy, and academic self-efficacy beliefs. In the following section we include these variables into our main outcome regression to assess whether any of these variables can explain the treatment effects on our main outcome variable Completed application.

Table 5.5: Treatment Effects on Aspirations and Beliefs

\begin{tabular}{lcccc}
\hline \hline & $(1)$ & $(2)$ & $(3)$ & $(4)$ \\
& Asp. index & Locus of C. & General SE & Academic SE \\
\hline Woman video & 0.016 & -0.067 & 0.270 & 2.528 \\
& $(0.081)$ & $(0.192)$ & $(1.120)$ & $(1.722)$ \\
Man video & 0.073 & -0.039 & 1.197 & 0.868 \\
& $(0.073)$ & $(0.187)$ & $(1.004)$ & $(1.836)$ \\
Female & -0.086 & -0.218 & -1.602 & -2.654 \\
& $(0.074)$ & $(0.181)$ & $(1.295)$ & $(1.797)$ \\
Woman video $\times$ Female & $0.186^{*}$ & 0.354 & 1.493 & 1.319 \\
& $(0.110)$ & $(0.264)$ & $(1.747)$ & $(2.603)$ \\
Man video $\times$ Female & 0.155 & 0.145 & 1.823 & 1.402 \\
& $(0.121)$ & $(0.243)$ & $(1.635)$ & $(2.844)$ \\
Constant & 0.113 & $5.247^{* * *}$ & $33.043^{* * *}$ & $32.869^{* * *}$ \\
& $(0.392)$ & $(0.942)$ & $(5.028)$ & $(9.107)$ \\
\hline Woman Video vs. Placebo (only females) & $0.202^{* *}$ & 0.287 & 1.763 & $3.847^{*}$ \\
& $(0.083)$ & $(0.212)$ & $(1.368)$ & $(2.167)$ \\
Man Video vs. Placebo (only females) & $0.228^{* *}$ & 0.106 & $3.020^{* *}$ & 2.271 \\
& $(0.099)$ & $(0.178)$ & $(1.286)$ & $(2.317)$ \\
\hline Observations & 319 & 336 & 336 & 336 \\
$R^{2}$ & 0.194 & 0.048 & 0.087 & 0.092 \\
School Fixed Effects & Yes & Yes & Yes & Yes \\
Controls & Yes & Yes & Yes & Yes \\
\hline \hline
\end{tabular}

\subsubsection{Can the Mechanism Variables Explain Behavior in the Field Exper- iment?}

In Table 5.6 we present the results of the OLS estimation for our outcome Complete Application controlling for performance in Task-1 and Task-2 (see column 2), the aspiration and current index (see column 3), and general and academic self-efficacy beliefs (see column 4). Controlling for the mechanism variables, we find that the significance level of the Female Role Model treatment effect reduces to the 10 percent level when we control for the aspiration and current index. Further, we find that the current index is significantly and positively related to the outcome variable (yet very small in magnitude). These results hold when adding all mechanism variables (see column 5). 
Table 5.6: Relation of Mechanism Variables to Complete Application

\begin{tabular}{|c|c|c|c|c|c|}
\hline & $\begin{array}{c}(1) \\
\text { Complete application }\end{array}$ & $\begin{array}{c}(2) \\
\text { Complete application }\end{array}$ & $\begin{array}{c}(3) \\
\text { Complete application }\end{array}$ & $\begin{array}{c}(4) \\
\text { Complete application }\end{array}$ & $\begin{array}{c}\text { (5) } \\
\text { Complete application }\end{array}$ \\
\hline Woman video & $\begin{array}{l}0.173^{* *} \\
(0.085)\end{array}$ & $\begin{array}{l}0.190^{* *} \\
(0.086)\end{array}$ & $\begin{array}{c}0.149^{*} \\
(0.086)\end{array}$ & $\begin{array}{l}0.176^{* *} \\
(0.085)\end{array}$ & $\begin{array}{c}0.162^{*} \\
(0.088)\end{array}$ \\
\hline Man video & $\begin{array}{c}0.086 \\
(0.086)\end{array}$ & $\begin{array}{l}0.119 \\
(0.092)\end{array}$ & $\begin{array}{c}0.072 \\
(0.091)\end{array}$ & $\begin{array}{c}0.086 \\
(0.087)\end{array}$ & $\begin{array}{c}0.093 \\
(0.096)\end{array}$ \\
\hline Female & $\begin{array}{l}0.036 \\
(0.100)\end{array}$ & $\begin{array}{c}0.044 \\
(0.100)\end{array}$ & $\begin{array}{c}0.032 \\
(0.100)\end{array}$ & $\begin{array}{c}0.033 \\
(0.100)\end{array}$ & $\begin{array}{l}0.031 \\
(0.101)\end{array}$ \\
\hline Woman video $\times$ Female & $\begin{array}{c}0.075 \\
(0.132)\end{array}$ & $\begin{array}{l}0.078 \\
(0.133)\end{array}$ & $\begin{array}{c}0.096 \\
(0.133)\end{array}$ & $\begin{array}{c}0.076 \\
(0.133)\end{array}$ & $\begin{array}{c}0.102 \\
(0.135)\end{array}$ \\
\hline Man video $\times$ Female & $\begin{array}{c}0.025 \\
(0.134)\end{array}$ & $\begin{array}{l}0.020 \\
(0.134)\end{array}$ & $\begin{array}{c}0.030 \\
(0.139)\end{array}$ & $\begin{array}{c}0.027 \\
(0.135)\end{array}$ & $\begin{array}{c}0.032 \\
(0.140)\end{array}$ \\
\hline Perf. 1 & & $\begin{array}{l}-0.005 \\
(0.020)\end{array}$ & & & $\begin{array}{l}-0.002 \\
(0.022)\end{array}$ \\
\hline Perf. 2 & & $\begin{array}{l}-0.012 \\
(0.020)\end{array}$ & & & $\begin{array}{l}-0.008 \\
(0.021)\end{array}$ \\
\hline Asp. index & & & $\begin{array}{c}0.082 \\
(0.064)\end{array}$ & & $\begin{array}{c}0.088 \\
(0.065)\end{array}$ \\
\hline Current index & & & $\begin{array}{l}0.006^{* *} \\
(0.003)\end{array}$ & & $\begin{array}{l}0.006^{*} \\
(0.003)\end{array}$ \\
\hline General SE & & & & $\begin{array}{c}0.000 \\
(0.005)\end{array}$ & $\begin{array}{l}-0.001 \\
(0.005)\end{array}$ \\
\hline Academic SE & & & & $\begin{array}{l}-0.001 \\
(0.003)\end{array}$ & $\begin{array}{l}-0.001 \\
(0.003)\end{array}$ \\
\hline Constant & $\begin{array}{c}-0.392 \\
(0.438)\end{array}$ & $\begin{array}{l}-0.241 \\
(0.476)\end{array}$ & $\begin{array}{l}-0.406 \\
(0.440)\end{array}$ & $\begin{array}{l}-0.358 \\
(0.471)\end{array}$ & $\begin{array}{l}-0.242 \\
(0.518)\end{array}$ \\
\hline Observations & 336 & 336 & 319 & 336 & 319 \\
\hline School Fixed Effects & Yes & Yes & Yes & Yes & Yes \\
\hline Controls & Yes & Yes & Yes & Yes & Yes \\
\hline
\end{tabular}

\subsection{Discussion and Conclusion}

In this paper, we analyze the effect of a role model intervention on female's decision to participate in the labor market. We implemented a field and lab-in-the-field experiment with secondary school students in Madagascar. We either screened a Female Role Model, a Male Role Model, or a Placebo video to the students. The female and the male video tell the story of two individuals who succeeded in becoming a teacher at a University, while the placebo video is about life in rural and urban Madagascar. After video exposure, we measured inter and intra- competitive preferences using a lab-in-the-field experiment and obtained students' aspirations and beliefs through survey questions. At the end of the session, we offered students the opportunity to apply for two jobs in the research project of one of the principal investigators. They could either apply to be an assistant or a coordinator. The coordinator position involves tasks with more responsibility and has a 13 percent higher compensation. The students were aware of this at the moment of making the decision.

Our research finds that providing information of a role model through a video has a positive effect on students' willingness to apply for the jobs we advertised. In particular, the FemaLE Role Model video significantly increases female (and male students) applications to one of the two positions offered compared to the PlaceBo video. While we find no average treatment effect in the likelihood to apply to the coordinator position compared to not applying, we observe that the MALE Role Model video increases the chances that female students apply to the coordinator position compared to the PlaceBo condition. The 
proportion of females applying to the coordinator position increases by 16 percentage points in the Male Role Model video compared to the Placebo group. Consequently, the gender gap in applications to the coordinator position present in the PLACEBO group and even in the Female Role Model group shrinks.

One novelty of our study lies in relating the decisions from the lab experiment with the decisions students took in the field experiment. This allowed us to explore potential mechanisms through which role models encourage behavioral changes. We find that role models encourage female and male students to exert more effort and thus increase their performance in the real-effort task. We also find treatment effects on aspirations, general self-efficacy, and academic self-efficacy beliefs. Female students in the Female Role Model and the Male Role Model video report higher aspirations and beliefs compared to females in the Placebo group. Yet, we do not find similar results when comparing male students in the treatment groups versus male students in the placebo. We use these measures to explore a possible mechanism and find that the decision to apply to any of the two job positions can partly be explained by participants' aspirations and current level of achievements.

Our results also show that exposing individuals to role models who share a similar background with the target population and talk about how they achieved their goals effectively encourage students to apply. We can rule out that our observed treatment effects are driven by demand effects since our videos do not refer to the labor market or gave information about the announced positions. Further, the experimenter advertised the positions at the end of the session in a casual way and provided the same information to all groups without raising hopes about future outcomes. Yet, important to consider is the effect of unsuccessful applications on aspirations and beliefs (McKelway, 2020). Unfortunately, we were not able to hire any of the applicants due to low communication skills. ${ }^{18}$ If aspirations are not realized, this can lead to frustration and a decrease in investments (Genicot \& Ray, 2017). A possible remedy could be to increase exposure to successful experiences of others (role models) or decrease the barriers to attaining a job.

The literature studying the effects of role models on social behavior suggests that same-sex interactions are successful (Stout et al., 2011; Beaman et al., 2012; Meier et al., 2020). Our female character was successful in encouraging female students to apply to the assistant position, which is less competitive. Surprisingly, we find that the Male Role Model video encourages more females to apply to the more competitive job (coordinator position). This

\footnotetext{
${ }^{18}$ After receiving the job applications, we went through the screening process. We checked each application taking into account the following points: 1) Check names in the database to make sure applicants participated in the sessions; 2) Check for the position applied; 3) Check the English and French level reported. At least one has to be rated as "good". After the screening, we selected 33 candidates for the personal interviews. Since we collected all the candidates' personal information, it was possible to reach all of them after the sessions. The interviews took place in November 2018 and July 2019 in each of the different cities the experiments took place. Unfortunately, none of the candidates we interviewed was eligible for the assistant or coordinator positions as they were very shy towards the researcher and translator, and hence it was difficult to communicate with them. Thus, even though they had the formal requirements, they lacked the confidence that probably develops through previous work experiences.
} 
might imply that it is important to consider the traits that the different genders represent. In general, males are perceived to be more competitive than females (Blau \& Kahn, 2017). Hence, one way to explain that females are more likely to apply to the more competitive position after being exposed to the MALE Role Model, is that videos with a male character could nudge females towards more competitive behavior since males could appear more competitive compared to females. However, we find no effect on competitive behavior in the lab-in-the-field experiment. One could also argue that females' decision to apply for a competitive job after seeing a MALE Role Model, could be driven by a 'defiance' response of females to stop replicating stereotypes embedded in social norms (Schier, 2020). Interestingly the MALE RoLE MODEL did not encourage competitive behavior among male participants. A potential reason why males did not react to the Male Role Model compared to the Placebo could lie in the content of the Placebo video. Future research could use different PlaceBo videos or different characters to test this conjecture.

Our paper does not address other potential mechanisms that could play a role in determining females' willingness to participate in the labor market, such as discrimination, stereotype threats, or pre-existing social norms, which could have been affected by the video. We did not collect information on students' ability at school (i.e: the grade point average GPA). Thus, we cannot tell which one of the females applied more to one of the positions in terms of their ability which is also important to consider when exposed to competitive environments. Lastly, we acknowledge that, due to the school strikes, our sample is smaller than what we registered, and we encourage future research to replicate this study using larger samples.

The results obtained in Madagascar can be similar to other contexts in which female students experience a behavioral poverty trap. It would be interesting for future research to test whether similar results can be drawn from other contexts. Our study shows that video interventions about successful individuals provide a low-cost alternative in contexts where there is a lack of role models that are similar and geographically close. Other examples of policy measures that could be implemented are to increase the share of female role models through affirmative action such as quotas (Beaman et al., 2012; Niederle et al., 2013; Ibanez \& Riener, 2018). These measures should go hand in hand with lifting external constraints such as discrimination and tertiary enrollment barriers. 


\subsection{Appendices}

\subsubsection{Appendix A - Tables}

\section{Randomization checks}

Table 5.A1: Summary Statistics

\begin{tabular}{|c|c|c|c|c|}
\hline & $\begin{array}{c}(1) \\
\text { Placebo }\end{array}$ & $\begin{array}{c}(2) \\
\text { Woman Video }\end{array}$ & $\begin{array}{c}(3) \\
\text { Man Video }\end{array}$ & $\begin{array}{c}(4) \\
\text { p-value }\end{array}$ \\
\hline Female & $\begin{array}{c}0.400 \\
(0.046)\end{array}$ & $\begin{array}{c}0.450 \\
(0.047)\end{array}$ & $\begin{array}{c}0.455 \\
(0.048)\end{array}$ & 0.655 \\
\hline Age in years & $\begin{array}{c}19.192 \\
(0.180)\end{array}$ & $\begin{array}{l}18.968 \\
(0.160)\end{array}$ & $\begin{array}{l}18.884 \\
(0.175)\end{array}$ & 0.420 \\
\hline Science focus & $\begin{array}{c}0.557 \\
(0.047)\end{array}$ & $\begin{array}{c}0.577 \\
(0.047)\end{array}$ & $\begin{array}{c}0.509 \\
(0.048)\end{array}$ & 0.587 \\
\hline Number of brothers & $\begin{array}{c}2.339 \\
(0.134)\end{array}$ & $\begin{array}{c}2.180 \\
(0.149)\end{array}$ & $\begin{array}{l}1.973 \\
(0.119)\end{array}$ & 0.156 \\
\hline Economic status & $\begin{array}{c}2.652 \\
(0.070)\end{array}$ & $\begin{array}{l}2.748 \\
(0.082)\end{array}$ & $\begin{array}{c}2.609 \\
(0.078)\end{array}$ & 0.429 \\
\hline Job at present & $\begin{array}{c}0.061 \\
(0.022)\end{array}$ & $\begin{array}{c}0.117 \\
(0.031)\end{array}$ & $\begin{array}{c}0.109 \\
(0.030)\end{array}$ & 0.297 \\
\hline Vanilla family & $\begin{array}{c}0.713 \\
(0.042)\end{array}$ & $\begin{array}{c}0.658 \\
(0.045)\end{array}$ & $\begin{array}{c}0.700 \\
(0.044)\end{array}$ & 0.646 \\
\hline Friends group & $\begin{array}{c}0.835 \\
(0.088)\end{array}$ & $\begin{array}{l}1.090 \\
(0.102)\end{array}$ & $\begin{array}{l}1.418 \\
(0.088)\end{array}$ & 0.000 \\
\hline Frequency meeting outsiders & $\begin{array}{l}4.200 \\
(0.097)\end{array}$ & $\begin{array}{c}4.667 \\
(0.083)\end{array}$ & $\begin{array}{l}4.600 \\
(0.071)\end{array}$ & 0.000 \\
\hline Frequency smartphone usage & $\begin{array}{l}2.670 \\
(0.164)\end{array}$ & $\begin{array}{l}4.135 \\
(0.137)\end{array}$ & $\begin{array}{l}3.855 \\
(0.156)\end{array}$ & 0.000 \\
\hline Raised in city & $\begin{array}{c}0.513 \\
(0.047)\end{array}$ & $\begin{array}{c}0.545 \\
(0.048)\end{array}$ & $\begin{array}{c}0.545 \\
(0.048)\end{array}$ & 0.854 \\
\hline Highest degree mother & $\begin{array}{l}1.545 \\
(0.074)\end{array}$ & $\begin{array}{l}1.640 \\
(0.052)\end{array}$ & $\begin{array}{l}1.736 \\
(0.070)\end{array}$ & 0.126 \\
\hline
\end{tabular}

Notes: Column 4 reports the p-value from joint orthogonality test of treatment arms. Mean values are shown. Standard errors in parentheses. Variable description: Female: 1 if the student is female and 0 otherwise; Age in years: Age of participant calculated from the year participants were born; Science focus: 1 if the student chose the science focus and 0 if he/she instead chose the language focus; Number of brothers: Number of brothers (not siblings) participants reported; Economic status: Takes the values from 1 (poor) to 5 (wealthy) according to the economic situation reported by the student; Job at present: 1 if the participant has a job at the moment of the experiment, 0 otherwise; Vanilla family: 1 if the participant comes from a family that is in the vanilla business, 0 otherwise; Friends group: Number of friends the participant reported to be in his/her group of four, takes the values from 0 to 3; Frequency meeting outsiders: takes values from 1 to 5 , where 1 indicates that students never meet outsiders and 5 indicates they meet every day with outsiders; Frequency smartphone usage: takes values from 1 to 5 , where 1 indicates students never have used an smartphone and 5 indicates they use it every day; Raised in city: 1 if the participant was raised in an urban area, 0 otherwise; Highest degree mother: $0=$ no education, $1=$ primary education, $2=$ secondary education, $3=$ university degree. 


\section{Robustness}

Table 5.A2: Treatment Effects on Applications: Probit Model

\begin{tabular}{|c|c|c|c|c|c|c|}
\hline & \multicolumn{3}{|c|}{ Complete Application } & \multicolumn{3}{|c|}{ Coordinator Position } \\
\hline & $(1)$ & $(2)$ & $(3)$ & $(4)$ & $(5)$ & $(6)$ \\
\hline Woman video & $\begin{array}{l}0.155^{* *} \\
(0.063)\end{array}$ & $\begin{array}{c}0.213^{* * *} \\
(0.065)\end{array}$ & $\begin{array}{l}0.183^{* *} \\
(0.084)\end{array}$ & $\begin{array}{l}-0.149^{*} \\
(0.088)\end{array}$ & $\begin{array}{l}-0.107 \\
(0.096)\end{array}$ & $\begin{array}{l}-0.105 \\
(0.116)\end{array}$ \\
\hline Man video & $\begin{array}{c}0.077 \\
(0.063)\end{array}$ & $\begin{array}{c}0.096 \\
(0.067)\end{array}$ & $\begin{array}{c}0.090 \\
(0.083)\end{array}$ & $\begin{array}{l}-0.021 \\
(0.093)\end{array}$ & $\begin{array}{c}0.041 \\
(0.095)\end{array}$ & $\begin{array}{c}-0.092 \\
(0.117)\end{array}$ \\
\hline Female & & $\begin{array}{c}0.064 \\
(0.055)\end{array}$ & $\begin{array}{c}0.065 \\
(0.055)\end{array}$ & & $\begin{array}{c}-0.242^{* * *} \\
(0.076)\end{array}$ & $\begin{array}{r}-0.240^{* * * *} \\
(0.074)\end{array}$ \\
\hline Woman video $\times$ Female & & & $\begin{array}{c}0.059 \\
(0.121)\end{array}$ & & & $\begin{array}{c}0.033 \\
(0.161)\end{array}$ \\
\hline Man video $\times$ Female & & & $\begin{array}{c}0.015 \\
(0.126)\end{array}$ & & & $\begin{array}{l}0.321^{*} \\
(0.177)\end{array}$ \\
\hline Observations & 336 & 336 & 336 & 186 & 186 & 186 \\
\hline Fixed effects & Yes & Yes & Yes & Yes & Yes & Yes \\
\hline Controls & No & Yes & Yes & No & Yes & Yes \\
\hline
\end{tabular}

Notes: Robust standard errors in parentheses. Coefficient present marginal effects evaluated at a man. ${ }^{*} p<0.10,{ }^{* *} p<0.05,{ }^{* * *} p<0.01$. Control variables: Age in years: Age of participant calculated from the year participants were born; Science focus: 1 if the student chose the science focus and 0 if he/she instead chose the language focus; Number of brothers: Number of brothers (not siblings) participants reported; Economic status: Takes the values from 1 (poor) to 5 (wealthy) according to the economic situation reported by the student; Job at present: 1 if the participant has a job at the moment of the experiment, 0 otherwise; Vanilla family: 1 if the participant comes from a family that is in the vanilla business, 0 otherwise; Friends group: Number of friends the participant reported to be in his/her group of four, takes the values from 0 to 3 ; Frequency meeting outsiders: takes values from 1 to 5 , where 1 indicates that students never meet outsiders and 5 indicates they meet every day with outsiders; Frequency smartphone usage: takes values from 1 to 5 , where 1 indicates students never have used an smartphone and 5 indicates they use it every day; Gender imbalance group: 1 if there is an uneven number of female and males in the group of four, 0 if there is a balance; Highest degree mother: $0=$ no education, $1=$ primary education, $2=$ secondary education, $3=$ university degree. 
Table 5.A3: Multinomial Logit Complete Applications

\begin{tabular}{|c|c|c|}
\hline & $\begin{array}{l}\text { Complete Application } \\
\text { (1) }\end{array}$ & $\begin{array}{c}\text { Complete Application } \\
\text { (2) }\end{array}$ \\
\hline \multicolumn{3}{|l|}{ Assistant Position } \\
\hline Woman video & $\begin{array}{c}1.313^{* * *} \\
(0.413)\end{array}$ & $\begin{array}{l}1.222^{* *} \\
(0.538)\end{array}$ \\
\hline Man video & $\begin{array}{c}0.411 \\
(0.428)\end{array}$ & $\begin{array}{c}0.761 \\
(0.524)\end{array}$ \\
\hline Female & $\begin{array}{l}0.862^{* *} \\
(0.337)\end{array}$ & $\begin{array}{l}1.037^{*} \\
(0.573)\end{array}$ \\
\hline Woman video $\times$ Female & & $\begin{array}{c}0.188 \\
(0.760)\end{array}$ \\
\hline Man video $\times$ Female & & $\begin{array}{l}-0.694 \\
(0.784)\end{array}$ \\
\hline Constant & $\begin{array}{c}-6.521^{* * *} \\
(2.486) \\
\end{array}$ & $\begin{array}{c}-6.488^{* * *} \\
(2.514) \\
\end{array}$ \\
\hline \multicolumn{3}{|l|}{ Coordinator Position } \\
\hline Woman video & $\begin{array}{l}0.765^{* *} \\
(0.386)\end{array}$ & $\begin{array}{c}0.682 \\
(0.461)\end{array}$ \\
\hline Man video & $\begin{array}{c}0.501 \\
(0.372)\end{array}$ & $\begin{array}{c}0.253 \\
(0.447)\end{array}$ \\
\hline Female & $\begin{array}{l}-0.140 \\
(0.328)\end{array}$ & $\begin{array}{l}-0.478 \\
(0.564)\end{array}$ \\
\hline Woman video $\times$ Female & & $\begin{array}{c}0.231 \\
(0.762)\end{array}$ \\
\hline Man video $\times$ Female & & $\begin{array}{c}0.726 \\
(0.738)\end{array}$ \\
\hline Constant & $\begin{array}{l}-3.948 \\
(2.455) \\
\end{array}$ & $\begin{array}{l}-4.083^{*} \\
(2.409) \\
\end{array}$ \\
\hline Observations & 336 & 336 \\
\hline School Fixed Effects & Yes & Yes \\
\hline Controls & Yes & Yes \\
\hline
\end{tabular}




\section{Aspirations}

Table 5.A4: Aspirations in the Placebo Group by gender

\begin{tabular}{lccc}
\hline \hline & $(1)$ & $(2)$ & $(3)$ \\
& Male & Female & p-value \\
\hline Education & 19.196 & 19.135 & 0.911 \\
& $(0.349)$ & $(0.408)$ & \\
Income & 23685.652 & 11196.563 & 0.457 \\
& $(13566.069)$ & $(4675.124)$ & \\
Status & 9.304 & 9.063 & 0.907 \\
& $(1.055)$ & $(1.966)$ & \\
Assets & 687011.123 & 431542.188 & 0.353 \\
& $(177387.262)$ & $(207055.172)$ & \\
\hline$N$ & 69 & 48 & \\
\hline
\end{tabular}

Notes: Column 3 reports the p-value from joint orthogonality test of treatment arms. Standard errors in parentheses. Comparisons of income and asset goals are based on a $95 \%$ reduced sample.

\section{Multiple Hypothesis Testing}

Table 5.A5: Multiple Hypothesis Testing

\begin{tabular}{|c|c|c|c|c|c|}
\hline Outcome variable & Treatment & Subgroup & Difference & p-value not adjusted & p-value adjusted (B-H) \\
\hline Complete Application & Female Video vs. Control & Female & 0.248 & 0.020 & 0.070 \\
\hline Complete Application & Male Video vs. Control & Female & 0.111 & 0.308 & 0.451 \\
\hline Complete Application & Female Video vs. Control & Male & 0.173 & 0.041 & 0.096 \\
\hline Complete Application & Male Video vs. Control & Male & 0.086 & 0.322 & 0.451 \\
\hline Coordinator Position & Female Video vs. Control & Female & -0.065 & 0.659 & 0.769 \\
\hline Coordinator Position & Female Video & Female vs. Male & -0.320 & 0.010 & 0.070 \\
\hline Coordinator Position & Male Video & Female vs. Male & -0.036 & 0.799 & 0.799 \\
\hline
\end{tabular}

Notes: For the multiple hypothesis testing we use the Benjamini-Hochberg method as it has been shown to be less conservative, especially with low power samples, than the Bonferroni correction. 


\subsubsection{Appendix B - Experimental Instructions and Survey}

\section{General Instructions}

\section{Dear participant, welcome to our workshop!}

We are part of a research group called Diversity Turn. This is a project from the University of Göttingen. The objective of our project is to study vanilla production and the decisions students make under different incentive schemes in the SAVA region.

\section{What are you doing today?}

Today you will be participating in a workshop in which you will have the opportunity to earn money. Just for your participation you will receive a bonus of 2,000 ariary at the end of the workshop. In addition, you can increase that amount by earning money in the different activities of the workshop. The amount of money that you earn will depend on your decisions and the decisions taken by people from other communities in the SAVA region. To calculate your earnings, we first need to finish the workshops in the other communities. Therefore, we will pay you in the next week once we have finished the workshops in the region.

This workshop has two parts. The first part will last approximately 1 hour and consist of four different activities. Thereafter, there will be a survey. Once you have finished both parts you will receive the 2,000 ariary as a bonus of your participation and you will receive the additional earnings next week.

If at any time you feel uncomfortable, you are free to leave the room whether we have started the workshop or not. However, in that case you will not earn money.

Maybe you might have heard about this workshop before, yet what we will be doing today might be different. In order to do the activities correctly, please read carefully and pay attention when I explain them.

I would like to thank you for taking the time to come to this workshop. The results of each of the activities that we will be doing today will be very helpful for the research project. We appreciate your help very much.

I would also like to clarify that your identity will be kept anonymous along the workshop. This means that except from my colleagues and me, nobody will know your identity. We are only interested in the decisions that you take today and not in your identity. We will identify your decisions with the number that is on your table. 
From now on, if you have questions, please quietly raise your hand and one of my colleagues will come to you to clarify your questions. Please do not talk to other participants in the workshop. This is very important.

\section{How is this workshop organized ${ }^{19}$}

Now we will start the first part of the workshop. As I explained before in this part of the workshop you will have the opportunity to earn money. We will do four activities, which we will refer to as Activity Triangle, Activity Circle, Activity Square, and Activity Rhombus. In each of these activities, except of Activity Square, you have the possibility to earn money. Yet, only one of the activities would be selected for the final payment.

At the end of the session one of the activities will be chosen randomly for payment and your earnings will be calculated according to the results of this activity. This means that each activity can get potentially relevant for your payoff, so please make careful decisions in each activity. Some of the activities that we will be doing today are very similar that is why we ask you to read carefully each of them and follow the instructions accordingly.

\footnotetext{
${ }^{19}$ The instructions included omit the first two activities (Activity Triangle, Activity Circle) as they are part of another study. The activities were the same for all treatment and control groups.
} 


\section{Lab-in-the-field Instructions}

Instructor: Now we will prepare our next activity. In the meantime we will show you a video. Please remain in your seat and be quiet. Please pay attention, after the video has finished you we will be asked some questions about the video and yourself.

[Individuals were randomly allocated into 3 different rooms, in each room they either watched a video of a female, male role model or a placebo video about the life in rural vs. urban areas]

Please answer the following questions. Circle the answer that best applies to what you think or feel:

1. Do you know the person in the video? $\square$ Yes $\square$ No

If your answer is "YES" please continue with question 2

If your answer is "NO" please continue with question 3

2. On a scale from 1 to 5 , where 1 is not close at all and 5 is very close, how you rate the relationship you have with the main character[s] shown in the video?

\begin{tabular}{|c|c|c|c|c|}
\hline $\begin{array}{c}1 \\
\text { Not close at all }\end{array}$ & 2 & 3 & 4 & 5 \\
\hline
\end{tabular}

3. On a scale from 1 to 5 where 1 means "I strongly disagree" and 5 means "I strongly agree", how much do you agree or disagree with the following statements? Please circle your answer.

3.1. "I feel motivated by the video I have just seen"

\begin{tabular}{|c|c|c|c|c|}
\hline 1 & 2 & 3 & 4 & 5 \\
Strongly disagree & Disagree & Neither agree nor disagree & Agree & Strongly agree \\
\hline
\end{tabular}

3.2. "I like the main character(s) of the video"

\begin{tabular}{|c|c|c|c|c|}
\hline 1 & 2 & 3 & 4 & 5 \\
Strongly disagree & Disagree & Neither agree nor disagree & Agree & Strongly agree \\
\hline
\end{tabular}

3.3. "I can identify with the main character(s) of the video"

\begin{tabular}{|c|c|c|c|c|}
\hline 1 & 2 & 3 & 4 & 5 \\
Strongly disagree & Disagree & Neither agree nor disagree & Agree & Strongly agree \\
\hline
\end{tabular}


3.4. "The main character(s) of the video is successful in his/her life"

\begin{tabular}{|c|c|c|c|c|}
\hline 1 & 2 & 3 & 4 & 5 \\
Strongly disagree & Disagree & Neither agree nor disagree & Agree & Strongly agree \\
\hline
\end{tabular}

3.5. "The main character(s) of the video is a person who is not afraid of taking risks"

\begin{tabular}{|c|c|c|c|c|}
\hline 1 & 2 & 3 & 4 & 5 \\
Strongly disagree & Disagree & Neither agree nor disagree & Agree & Strongly agree \\
\hline
\end{tabular}

3.6. "I think I can be as successful as the main character(s) of the video within the next ten years"

\begin{tabular}{|c|c|c|c|c|}
\hline 1 & 2 & 3 & 4 & 5 \\
Strongly disagree & Disagree & Neither agree nor disagree & Agree & Strongly agree \\
\hline
\end{tabular}

\section{Activity Square}

Instructor: Now, we will start with a new activity. We will ask you some questions on the categories: education, income, social status and assets. For every category we will provide you with a scale to help you answer the questions. You can also report higher levels than those that we suggest in the scales. Please be careful in answering the questions. Consider that when we ask you for what you would like to achieve, we aim to understand your desires, your goals; and with the question on what do you expect to achieve we would like to know the level that you think you will probably achieve.

The answers you will provide here are completely anonymous and will only be used for academic purposes. This means that neither your name, nor any other names, will be mentioned at any time. Nobody will be able to identify that you gave this information. This is not a test; therefore there are no right or wrong answers. You should answer the questions according to your opinion and current situation.

If you still do not understand the difference between what would you like to achieve and what do you expect to achieve please mark the "I still don't understand the difference" box below. If you have understood the difference please mark the "I understand the difference" box below.

I still do not understand the differences

I understand the difference 


\section{Categories Questions}

\section{Category 1. Education:}

To answer the following questions, please consider the scale below. You are free to report higher levels than those suggested. If you have questions please raise your hand.

Figure 5.B1: Education scale

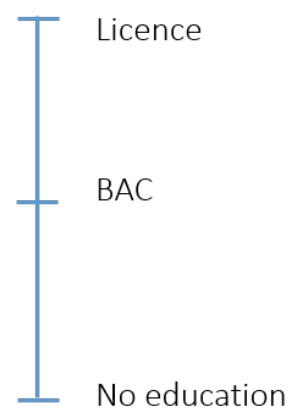

(a) What is the maximum level of education an average person in the city or village that you come from can have?

(b) What is the minimum level of education that an average person in the city or village that you come from can have?

(c) What is the education level that you have achieved until now?

(d) What is the level of education you would like to achieve in your life? (goal/desire)

(e) What is the level of education you expect to achieve in your life? (what you will probably achieve)

Category 2. Income:

To answer the following questions, please consider the scale below. You are free to report higher levels than those suggested. If you have questions please raise your hand.

Figure 5.B2: Income scale

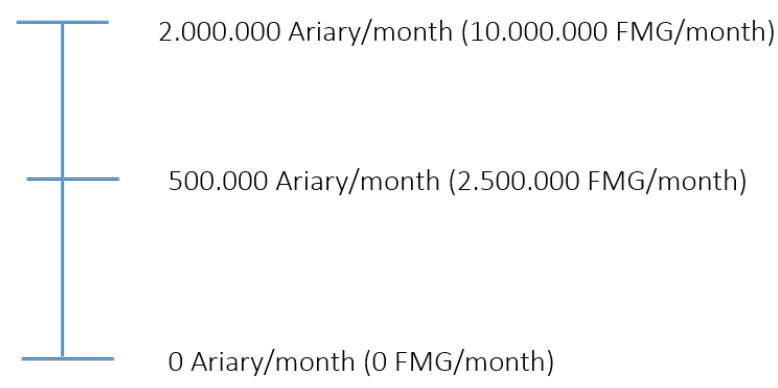


(a) What is the maximum level of average income per month that an average person in the city or village that you come from can have? (ariary/month)

(b) What is the minimum level of average income per month that an average person in the city or village that you come from can have? (ariary/month)

(c) What is your average income per month at the present? (ariary/month)

(d) What is the level of average income per month you would like to achieve in your life? (goal/desire) (ariary/month)

(e) What is the level of average income per month you expect to achieve in your life? (what you will probably achieve) (ariary/month)

\section{Category 3. Social Status:}

To answer the following questions, please consider the ladder below. High social status means that your friends ask you regularly for your advice. No social status means that none of your friends asks you for your advice. You are free to report higher levels than those suggested. If you have questions please raise your hand.

Figure 5.B3: Social Status ladder

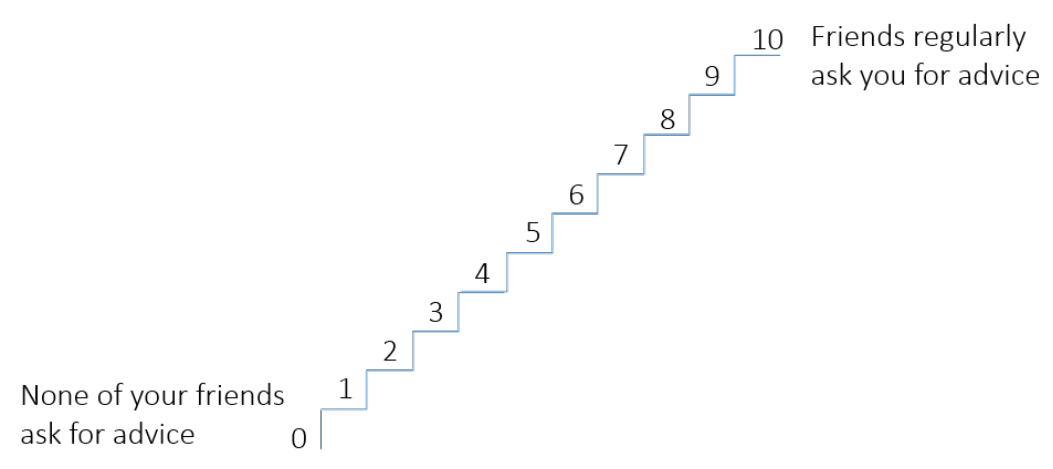

(a) What is the maximum level of social status that an average person in the city or village that you come from can have?

(b) What is the minimum level of social status that an average person in the city or village that you come from can have?

(c) What is the level of your social status at present?

(d) What is the level of social status you would like to achieve in your life? (goal/desire)

(e) What is the level of social status you expect to achieve in your life? (what you will probably achieve) 
Category 4. Assets:

To answer the following questions, please consider the scale below. You are free to report higher levels than those suggested. If you have questions please raise your hand.

Figure 5.B4: Asset scale

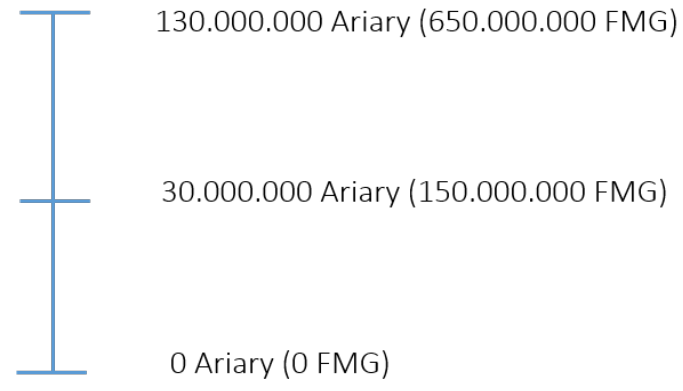

(a) What is the maximum level of assets (house and furniture, no other assets) an average person in the city or village that you come from can have? (ariary)

(b) What is the minimum level of assets (house and furniture, no other assets) that an average person in the city or village that you come from can have? (ariary)

(c) What is the level of assets (house and furniture, no other assets) you have at present? (ariary)

(d) What is the level of assets (house and furniture, no other assets) you would like to achieve in your life? (goal/desire) (ariary)

(e) What is the level of assets (house and furniture, no other assets) you expect to achieve in your life? (what you will probably achieve) (ariary)

Now we would like you to tell us which of these four categories are the most important for you and to weight them accordingly. A small weight attributed to a category means that you do not attach any importance to it. A large weight in a category means that you attach a high importance to it.

You have 20 points that you can distribute among the categories according to the importance you attach to them.

\begin{tabular}{|l|c|}
\hline Category & Number of points (importance) \\
\hline Education & \\
\hline Income & \\
\hline Social Status & \\
\hline Assets & \\
\hline Total & $\mathbf{2 0}$ \\
\hline
\end{tabular}




\section{Activity Rhombus}

Instructor: Now we will start activity Rhombus. This activity has a total of 5 Tasks.

\section{What TASK will you be doing today?}

The TASK consists in circling and counting the 1's in matrices for 3 minutes. After you have finished counting the 1's in each matrix, you will have to write down the number of 1 's that you found. You can see this in the example.

Each one of you will receive the same pile of matrices. We will provide you with enough number of matrices so you will have the chance to solve as many as you can in the 3 minutes time, one after the other. To perform the TASK you have to start with Matrix 1 and continue with Matrix 2, 3, etc. Please follow the given order. You will be paid according to your performance in correctly counting the 1's in the matrices. However, only one of your performances of the five tasks will determine your earnings of this activity and it will be randomly chosen at the end of the workshop. If you still do not understand the task please raise your hand.

\section{TASK 1}

Instructor: Now, we will start TASK 1. If TASK 1 is randomly selected for payment at the end of the workshop, you will be paid 500 ariary for each matrix that you solve correctly, meaning circling and finding the correct number of 1's in the matrix, during the 3 minutes time limit.

As you can see there are many matrices, and you have the chance to solve as many as you can, one after the other. Please start with Matrix 1 and continue with Matrix 2, 3, etc. Please follow the given order.

Once everybody has received the papers we will blow a whistle so you know that you can turn around the papers with the matrices and start the TASK. We will blow a whistle again for you to know that the time is up. Once the whistle sounds after the three minutes please put your pen aside. Please remain quiet and in your seat. Our enumerators will be collecting the papers. Do not discuss your performance with anyone else.

\section{- MATRICES —}

Instructor: Please stop counting and writing. Our enumerators will collect the TASK 1 now. Before continuing with TASK 2, please answer the question that our enumerators are distributing at the moment. 


\section{TASK 1-a}

Now please answer the following question. If your guess is correct you will be paid 1,000 ariary.

How many matrices do think you have solved correctly during the 3 minutes time in this TASK 1 ?

\section{TASK 2}

Instructor: Now, we will start TASK 2. In this TASK you will be competing against the 3 persons who are sitting in the same row as you. This means that you will be in a group of 4 people. The person who solves more matrices correctly, meaning circling and finding the correct amount of 1's in the matrix, during the 3 minutes time will win the tournament. If TASK 2 is randomly selected for payment at the end of the workshop, the person who wins the tournament will be paid 2,000 ariary per correct solved matrix. The persons who lose the tournament will receive nothing. If there is a tie for the first place, the winner will be selected randomly.

You will not know how many matrices your competitors have solved correctly. Therefore, you will not know whether you have won the tournament or not.

As you can see there are many matrices and you have the chance to solve as many as you can, one after the other. Please start with Matrix 1 and continue with Matrix 2, 3, etc. Please follow the given order.

Once everybody has received the papers we will blow a whistle so you know that you can turn around the papers with the matrices and start the TASK. We will blow a whistle again for you to know that the time is up. Once the whistle sounds after the three minutes please put your pen aside. Please remain quiet and in your seat. Our enumerators will be collecting the papers. Do not discuss your performance with anyone else.

\section{— MATRICES —}

Instructor: Please stop counting and writing. Our enumerators will collect the TASK 2 now. Before continuing with TASK 3, please answer the question that our enumerators are distributing at the moment.

\section{TASK 2-a}

Now please answer the following questions. If your guess is correct you will be paid 1,000 ariary. 
How many matrices do think you have solved correctly during the 3 minutes time in this TASK 2 ?

\section{TASK 3}

Instructor: Now, will start TASK 3. In this TASK you will have the opportunity to choose the payment that you would like to have in case TASK 3 is randomly selected for payment at the end of the workshop. You can either decide to have an individual pay rate of 500 ariary for each matrix that you solve correctly, or to enter into tournament against the persons in your group, the 3 persons sitting in the same row as you.

If you choose to enter into tournament and compete against the persons in your group, your performance in this TASK 3 will be compared with the number of matrices that each of the members of your group had solved correctly in TASK 2.

We will not provide you with the information of the scores that you have to beat. Before you make a decision, we will explain how each of the payment choices work:

Individual Pay: You will be paid 500 ariary for each matrix that you solve correctly in TASK 3, meaning circling and finding the correct number of 1's in the matrix, during the 3 minutes time limit.

Tournament against the TASK 2 performances of the persons in your group: You will be competing against the performance the persons in your group had in TASK 2.

If in this TASK 3 you solve more matrices correctly than the persons in your group had in TASK 2, you will win the tournament and you will be paid 2,000 ariary for each matrix that you solve correctly in this TASK. If you solve fewer matrices correctly than the persons in your group had in TASK 2, you will receive nothing.

You will not know how many matrices your competitors have solved correctly in TASK 2. Therefore, you will not know whether you have won the tournament or not. If there is a tie for the first place, the winner will be selected randomly.

Before performing the TASK you first have to decide which of the two payment choices you would prefer to have for this TASK. Please mark an X only in one of the options. Your decision will not influence the payoff of the other participants as you will compete against their past performance. Now, our enumerators will start distributing the decision sheet for the TASK 3. 


\section{Decision sheet TASK 3}

Now you will have the opportunity to choose the payment that you would like to have for this TASK 3. You can either decide to have an individual pay rate of 500 ariary for each matrix that you solve correctly, or to enter into tournament against the persons in your group, the 3 persons sitting in the same row as you.

If you choose to enter into tournament and compete against the persons in your group, your performance in this TASK 3 will be compared with the number of matrices that each of the members of your group had solved correctly in TASK 2. We will not provide you with the information of the scores that you have to beat.

The payment choices are the following:

Individual Pay: You will be paid 500 ariary for each matrix that you solve correctly in TASK 3, meaning circling and finding the correct number of 1's in the matrix, during the 3 minutes time limit.

Tournament against the TASK 2 performances of the persons in your group: You will be competing against the performance the persons in your group had in TASK 2.

If in this TASK 3 you solve correctly more matrices than the persons in your group had in TASK 2, you will win the tournament and you will be paid 2,000 ariary for each matrix that you solve correctly in this TASK 3. If you solve fewer matrices correctly than the persons in your group had in TASK 2, you will receive nothing.

You will not know how many matrices your competitors have solved correctly in TASK 2. Therefore, you will not know whether you have won the tournament or not. If there is a tie for the first place, the winner will be selected randomly.

Which payment do you prefer for TASK 3? Please mark an X only in one of the options below. Your decision will not influence the payoff of the other participants as you will compete against their past performance.

\begin{tabular}{|c|l|c|}
\hline Option & \multicolumn{1}{|c|}{ Payment } & $\begin{array}{c}\text { Your decision } \\
\text { (mark an X in one option) }\end{array}$ \\
\hline Individual Pay & $\begin{array}{l}500 \text { ariary for each correctly } \\
\text { solved matrix }\end{array}$ & \\
\hline $\begin{array}{c}\text { Tournament against the } \\
\text { performance of the people in }\end{array}$ & $\begin{array}{l}\text { If you win: } 2,000 \text { ariary for each } \\
\text { correctly solved matrix } \\
\text { your group in TASK 2 }\end{array}$ & \\
\hline
\end{tabular}


Instructor: Now, our enumerators will start distributing the papers for TASK 3. In this TASK you chose already which payment option you would like to have for your performance in this TASK in case it is randomly selected for payment at the end of the workshop. As you can see there are many matrices [show pile of papers] and you have the chance to solve as many as you can, one after the other. Please start with Matrix 1 and continue with Matrix 2, 3, etc. Please follow the given order. Once everybody has received the papers we will blow a whistle so you know that you can turn around the papers with the matrices and start the TASK. We will blow a whistle again for you to know that the time is up. Once the whistle sounds after the three minutes please put your pen aside. Please remain quiet and in your seat. Our enumerators will be collecting the papers. Do not discuss your performance with anyone else.

\section{- MATRICES —}

Instructor: Please stop counting and writing. Our enumerators will collect the TASK 3 now. Before continuing with TASK 4, please answer the question that our enumerators are distributing at the moment.

\section{TASK 3-a}

Now please answer the following question. If your guess is correct you will be paid 1,000 ariary.

How many matrices do think you have solved correctly during the 3 minutes time in this TASK 3 ?

\section{TASK 4}

Instructor: Now we will start TASK 4. In this TASK 4 you do not have to solve matrices. You only have to decide which payment you would like to receive for your performance in TASK 1. You can either decide to have an individual pay rate of 500 ariary for each matrix that you solve correctly or to enter into tournament against the persons in your group, the 3 persons sitting in the same row as you.

If you choose to enter into tournament and compete against the persons in your group, your performance in this round will be compared with the number of matrices that each of the members of your group had solved correctly in TASK 1.

We will not provide you with the information of the scores that you have to beat. We will just remind you about the number of matrices that you believed you solved correctly in TASK 1. 
Before you make a decision, we will explain how each of the payment choices work:

Individual Pay: You will be paid 500 ariary for each matrix that you solve correctly in TASK 1.

Tournament against the TASK 1 performances of the persons in your group: You will be competing against the performance the persons in your group had in TASK 1 .

If in TASK 1 you solved more matrices correctly than the persons in your group had in TASK 1, you will win the tournament and you will be paid 2,000 ariary for each matrix that you solved correctly in TASK 1 . If you solved fewer matrices correctly than the persons in your group had in TASK 1, you will receive nothing.

You will not know how many matrices your competitors have solved correctly in TASK 1. Therefore, you will not know whether you have won the tournament or not.

If there is a tie for the first place, the winner will be selected randomly.

Now our enumerators will give back the paper where you stated your beliefs for TASK 1 in order to help you to make the decision for this TASK. 


\section{Decision sheet TASK 4}

In the paper you have just received, you will find your belief of the correct matrices that you have solved in TASK 1. Please have a look at it before answering the question below.

In this TASK 4 you will have the opportunity to choose the payment that you would like to have for TASK 1. You can either decide to have an individual pay rate of 500 ariary per correctly solved matrix or to enter into tournament against the persons in your group, the 3 persons sitting in the same row as you.

If you choose to enter into tournament and compete against the persons in your group, your performance in TASK 1 will be compared with the number of matrices that each of the members of your group had solved correctly in TASK 1.

We will not provide you with the information of the scores that you have to beat. The payment choices are the following:

Individual Pay: You will be paid 500 ariary for each matrix that you solved correctly in TASK 1 during the 3 minutes time limit.

Tournament against the TASK 1 performances of the persons in group: You will be competing against the performance the persons in your group had in TASK 1.

If in TASK 1 you solved more matrices correctly than the persons in your group had in TASK 1, you will win the tournament and you will be paid 2,000 ariary for each matrix that you solved correctly in TASK 1 .

You will not know how many matrices your competitors have solved correctly in TASK 1. Therefore, you will not know whether you have won the tournament or not. If there is a tie for the first place, the winner will be selected randomly.

Which payment would you like to receive for your performance in TASK 1 ?

Please mark an X only in one of the options below. Your decision will not influence the payoff of the other participants as you will compete against their past performance.

\begin{tabular}{|c|l|c|}
\hline Option & \multicolumn{1}{|c|}{ Payment } & $\begin{array}{c}\text { Your decision } \\
\text { (mark an X in one option) }\end{array}$ \\
\hline Individual Pay & $\begin{array}{l}500 \text { ariary for each correctly } \\
\text { solved matrix }\end{array}$ & \\
\hline $\begin{array}{c}\text { Tournament against the } \\
\text { performance of the people in }\end{array}$ & $\begin{array}{l}\text { If you win: } 2.000 \text { ariary for each } \\
\text { correctly solved matrix } \\
\text { If your group in TASK 1 }\end{array}$ & \\
\hline
\end{tabular}




\section{TASK 5}

Instructor: Now, will start TASK 5. In this TASK you will have the opportunity to choose the payment that you would like to have in case TASK 5 is randomly selected for payment at the end of the workshop. You can either decide to have an individual pay rate of 500 ariary for each matrix that you solve correctly or to enter into tournament against yourself.

If you choose to enter into tournament against yourself, your performance in this TASK 5 will be compared with the number of matrices that you solved correctly in TASK 2 .

We will not provide you with the information of the score that you have to beat. We will just remind you about the number of matrices that you believed you solved correctly in TASK 2.

Before you make a decision, we will explain how each of the payment choices work:

Individual Pay: You will be paid 500 ariary for each matrix that you solve correctly in this TASK 5, meaning circling and finding the correct number of 1 's in the matrix, during the 3 minutes time limit.

Tournament against your TASK 2 performance: You will be competing against yourself in a tournament. In TASK 2 you might have solved certain number of matrices correctly and in this tournament against yourself you will have the possibility to improve your score.

If you solve more correct matrices in TASK 5 than in TASK 2 you will win the tournament against yourself and therefore you will be paid 2,000 ariary for each matrix that you solve correctly in this TASK 5 . If you have the same or less correct matrices in TASK 5 than in TASK 2 you will not win the tournament against yourself and therefore you will receive nothing. Like in the tasks before, you will not know whether you have won the tournament or not.

Before performing the TASK you first have to decide which of the two payment choices you would prefer to have for this TASK. Please mark an X only in one of the options. Now, our enumerators will start distributing the decision sheet for the TASK 5. 


\section{Decision sheet TASK 5}

In the paper you have just received, you will find your belief of the correct matrices that you have solved in TASK 2. Please have a look at it before answering the question below.

Now you will have the opportunity to choose the payment that you would like to have for this TASK 5. You can either decide to have an individual pay rate of 500 ariary for each matrix that you solve correctly in this task, or to enter into tournament against yourself.

If you choose to enter into tournament and compete against yourself, your performance in this TASK 5 will be compared with the number of matrices that you solved correctly in TASK 2.

We will not provide you with the information of the score that you have to beat. The payment choices are the following:

Individual Pay: You will be paid 500 ariary for each matrix that you solve correctly in TASK 5, meaning circling and finding the correct number of 1's in the matrix, during the 3 minutes time limit.

Tournament against your TASK 2 performance: You will be competing against yourself in a tournament. In TASK 2 you might have solved certain number of matrices correctly and in this tournament against yourself you will have the possibility to improve your score.

If you solve more correct matrices in TASK 5 than in TASK 2 you will win the tournament against yourself and therefore you will be paid 2,000 ariary for each matrix that you solve correctly in this TASK 5 . If you have the same or less correct matrices in TASK 5 than in TASK 2 you will not win the tournament against yourself and therefore you will receive nothing. Like in the tasks before, you will not know whether you have won the tournament or not.

Which payment do you prefer for TASK 5 ?

Please mark an X only in one of the options below.

\begin{tabular}{|c|l|l|}
\hline Option & \multicolumn{1}{|c|}{ Payment } & $\begin{array}{c}\text { Your decision } \\
\text { (mark an X in one option) }\end{array}$ \\
\hline Individual Pay & $\begin{array}{l}500 \text { ariary for each correctly } \\
\text { solved matrix }\end{array}$ & \\
\hline \multirow{2}{*}{ Tournament against yourself } & $\begin{array}{l}\text { If you win: 2,000 ariary for each } \\
\text { correctly solved matrix } \\
\text { If you do not win: 0 ariary }\end{array}$ & \\
\hline
\end{tabular}


Instructor: Now, our enumerators will start distributing the papers for TASK 5. In this TASK you chose already which payment option you would like to have for your performance in this TASK in case it is randomly selected for payment at the end of the workshop.

As you can see there are many matrices and you have the chance to solve as many as you can, one after the other. Please start with Matrix 1 and continue with Matrix 2, 3, etc. Please follow the given order.

Once everybody has received the papers we will blow a whistle so you know that you can turn around the papers with the matrices and start the TASK.

We will blow a whistle again for you to know that the time is up. Once the whistle sounds after the three minutes please put your pen aside. Please remain quiet and in your seat. Our enumerators will be collecting the papers. Do not discuss your performance with anyone else.

\section{— MATRICES —}

Instructor: Please stop counting and writing. Our enumerators will collect the TASK 5 now. Before continuing, please answer the question that our enumerators are distributing at the moment.

\section{TASK 5-a}

Now please answer the following question. If your guess is correct you will be paid 1,000 ariary.

How many matrices do think you have solved correctly during the 3 minutes time in this TASK 5 ?

— END OF TASKS —

Instructor: Before finishing this activity, we will distribute some question to you now. With each question that you solve correctly you will earn 1,000 ariary.

Please answer the following questions. For each correct answer you are going to be paid 1,000 ariary.

1. When you think of TASK 1 where you were payed for each correctly solved matrix 500 ariary. Which rank do you believe you had in comparison to the other 3 people in 
your group? 1 is the best performing student in your group of 4 people and 4 is the worst performing student in the same group of people.

I ranked out of 4

2. When you think of TASK 2 where you competed against the other persons in your group. Which rank do you believe you had in comparison to the other 3 people in your group? 1 is the best performing student in your group of 4 people and 4 is the worst performing student in the same group of people.

I ranked out of 4

3. On average, how many matrices do you think that the others in your session (all participants in the room) solved correctly in the different tasks?
1
2
3
4
5
6
7
8
9
10

4. How many people in your group of 4 do you think chose to compete in TASK 3 ?
0
2
3

1 


\section{End}

Instructor: Now, in order to select which activity will be used as your payment, one of you will take out one card of this non-transparent bag. According to the name written on the card we will pay each of you the earnings of that activity according to the decisions you made. For example if the name "Activity Triangle" comes up, we will pay you what you earned in that activity, if the name "Activity Rhombus" comes up, then we will pay what you earned in that activity. Same with "Activity Circle". As mentioned before, Activity Square will not be paid and thus will not be included in the bag.

If the result of the bag is Activity Rhombus, then we will use an extra bag to decide which TASK will be used to calculate the earnings of that activity. Remember that in Activity Rhombus we had 5 different tasks; however, only one of them will be paid. Therefore, the same person that comes to the front will randomly select the TASK that we will be using to calculate your earnings. In this other bag there are 5 small and equal papers. Each paper has a number from 1 to 5 written on it. This will guarantee that only one TASK will be picked for the payment calculation of Activity Rhombus in case it is selected. Please remember that you can receive also nothing, for example, if the TASK selected is TASK 2 and you lost the competition in this TASK.

In addition to the amount you earn from the Activity selected, each of you will receive 2,000 ariary as a bonus for your participation today. As we mentioned in the beginning, today you will receive the 2,000 ariary and in one week we will come back to give you the money that you possibly earned in the Activity selected.

In the name of Diversity Turn, I want to thank you very much for your time and collaboration today.

While we prepare the bonus payment, please fill the questionnaire my colleagues are giving to you at the moment. Once you have finished you will receive the bonus payment for your participation today. 


\section{Experimental Survey}

G- GEORG-AuguSt-universität GÖTTINGEN

Diversity Turn in Land Use Science

\section{Participant No.}

Hello! We are researchers from the University of Goettingen and we are investigating about vanilla production and the decisions students make under different incentive schemes in the SAVA region. Today, we kindly ask for your cooperation by filling this questionnaire. The answers you will provide here are completely anonymous and will only be used for academic purposes. This means that neither your name, nor any other names, will be mentioned at any time. Nobody will be able to identify that you gave this information. This is not a test; therefore there are no right or wrong answers. The answers should only correspond to your reality or your opinion. In name of the University we thank you very much for your time and collaboration.

1. Did you have difficulties in answering one or more of the activities you did today? Please mark your answer with an X.

Yes

No

If yes, in which one(s)?

2. Did you understand the instructions of the activity?

Please mark your answer with an $\mathrm{X}$.

Yes

No

3. Did you get exhausted as time in the experiment went by, so that you could concentrate less?

Please mark your answer with an X.

Yes

Yes, a little

No

4. Which track are you studying?

Please mark your answer with an $\mathrm{X}$.

A1

A2

$\mathrm{C}$

$\mathrm{D}$ 
5. Which occupation do you want to have in the future? Please indicate:

6. In how many years do you expect you will achieve to work in your desired occupation? YEARS

7. How likely is it that you will work in your desired occupation?

Please mark your answer with an X.

\begin{tabular}{|c|c|c|c|c|}
\hline 1 & 2 & 3 & 4 & 5 \\
Very unlikely & Unlikely & 50 percent likely & Likely & Very likely \\
\hline
\end{tabular}

8. How likely is it that you go to university?

Please mark your answer with an $\mathrm{X}$.

\begin{tabular}{|c|c|c|c|c|}
\hline 1 & 2 & 3 & 4 & 5 \\
Very unlikely & Unlikely & 50 percent likely & Likely & Very likely \\
\hline
\end{tabular}

9. How likely is it that destiny, good or bad luck or other people affect your chances to work in your desired occupation?

Please mark your answer with an $\mathrm{X}$.

\begin{tabular}{|c|c|c|c|c|}
\hline 1 & 2 & 3 & 4 & 5 \\
Very unlikely & Unlikely & 50 percent likely & Likely & Very likely \\
\hline
\end{tabular}

10. What is the highest school degree your mother has?

Please mark your answer with an X.

$\square$ No education

Primary education

$\square$ Secondary education

$\square$ University degree

11. What is the highest school degree your father has?

Please mark your answer with an $\mathrm{X}$.

$\square$ No education

$\square$ Primary education

$\square$ Secondary education

$\square$ University degree

12. At which age would you like to get married? YEARS 
13. How often do you meet other people who are not at your school and who are not from your family?

Please mark your answer with an X.

\begin{tabular}{|c|c|c|c|c|}
\hline 1 & 2 & 3 & 4 & 5 \\
Never & Once a year & Once a month & Once a week & Every day \\
\hline
\end{tabular}

14. How often do you use a smartphone?

Please mark your answer with an X.

\begin{tabular}{|c|c|c|c|c|}
\hline 1 & 2 & 3 & 4 & 5 \\
Never & Once a year & Once a month & Once a week & Every day \\
\hline
\end{tabular}

15. Do you have a person you look up to?

Please mark your answer with an X.

Yes

No
(a) If yes, specify the gender:
$\square$ Female $\quad \square$ Male
(b) If yes, specify the location where she/he lives:
(c) If no, go to question 16 .

16. On a scale from 1 to 5 , where 1 is strongly disagree and 5 is strongly agree, how much you agree or disagree with the following sentences. Please mark your answer with an X.

16.1. "To follow a career is more typical for men."

\begin{tabular}{|c|c|c|c|c|}
\hline 1 & 2 & 3 & 4 & 5 \\
Strongly disagree & Disagree & Neither agree nor disagree & Agree & Strongly agree \\
\hline
\end{tabular}

16.2. "Women can generally achieve their occupational goals."

\begin{tabular}{|c|c|c|c|c|}
\hline 1 & 2 & 3 & 4 & 5 \\
Strongly disagree & Disagree & Neither agree nor disagree & Agree & Strongly agree \\
\hline
\end{tabular}

16.3. "Men are typically performing better in competitive tasks."

\begin{tabular}{|c|c|c|c|c|}
\hline 1 & 2 & 3 & 4 & 5 \\
Strongly disagree & Disagree & Neither agree nor disagree & Agree & Strongly agree \\
\hline
\end{tabular}

16.4. "Men are better at counting 1's in matrices."

\begin{tabular}{|c|c|c|c|c|}
\hline 1 & 2 & 3 & 4 & 5 \\
Strongly disagree & Disagree & Neither agree nor disagree & Agree & Strongly agree \\
\hline
\end{tabular}


16.5. "Men believe that women are less able to count 1's in matrices."

\begin{tabular}{|c|c|c|c|c|}
\hline 1 & 2 & 3 & 4 & 5 \\
Strongly disagree & Disagree & Neither agree nor disagree & Agree & Strongly agree \\
\hline
\end{tabular}

16.6. How do you like to be in competition with somebody else? Please tick a box on the scale, where the value 1 means: "I do not like this" and the value 5 means: "I like it very much":

\begin{tabular}{|c|c|c|c|c|}
\hline 1 & 2 & 3 & 4 & 5 \\
I do not like this & & & & I like it very much \\
\hline
\end{tabular}

17. Are you generally willing to take risks, or do you try to avoid risks? Please mark your answer with an X. In the scale the value 1 means: "Not willing to take a risk" and the value 10 means "fully prepared to take risks".

\begin{tabular}{|c|c|c|c|c|c|c|c|c|c|}
\hline $\begin{array}{c}1 \\
\text { Not willing } \\
\text { to take a risk }\end{array}$ & 2 & 3 & 4 & 5 & 6 & 7 & 8 & 9 & $\begin{array}{c}10 \\
\text { Fully prepare } \\
\text { to take risks }\end{array}$ \\
\hline
\end{tabular}

18. Suppose you were given the choice between receiving some money today or some money in one year. We will present to you three different situations. For each of these situations we would like to know which option you would choose. These situations are hypothetical. Please mark your answer with an X.

18.1. Would you rather receive 100,000 ariary today or 150,000 ariary in 1 year?

$$
\text { Today }
$$

In one year

18.2. Would you rather receive 100,000 ariary today or 125,000 ariary in 1 year?

Today

In one year

18.3. Would you rather receive 100,000 ariary today or 105,000 ariary in 1 year?

Today

In one year

19. Imagine a coin is flipped six times. Before each time, a lottery is offered to you and you could decide whether you want to accept or reject it. The amount that could be won is the same in all lotteries, while the amount that could be lost increases. Please decide whether you would accept or reject each of the following lotteries. As the amount that could be lost increases along the lotteries, you can only switch from "Accept" to "Reject" once. Please mark your answer with an X. 


\begin{tabular}{|c|c|c|}
\hline Hypothetical Lottery & Accept & Reject \\
\hline $\begin{array}{l}\text { \#1. If the coin turns head up, then you would lose } 1,000 \text { ariary; } \\
\text { if the coin turns up tails, you would win } 3,000 \text { ariary }\end{array}$ & & \\
\hline $\begin{array}{l}\# 2 \text {. If the coin turns head up, then you would lose } 1,500 \text { ariary; } \\
\text { if the coin turns up tails, you would win } 3,000 \text { ariary }\end{array}$ & & \\
\hline $\begin{array}{l}\# 3 \text {. If the coin turns head up, then you would lose } 2,000 \text { ariary; } \\
\text { if the coin turns up tails, you would win } 3,000 \text { ariary }\end{array}$ & & \\
\hline $\begin{array}{l}\text { \#4. If the coin turns head up, then you would lose } 2,500 \text { ariary; } \\
\text { if the coin turns up tails, you would win } 3,000 \text { ariary }\end{array}$ & & \\
\hline $\begin{array}{l}\# 5 \text {. If the coin turns head up, then you would lose } 3,000 \text { ariary; } \\
\text { if the coin turns up tails, you would win } 3,000 \text { ariary }\end{array}$ & & \\
\hline $\begin{array}{l}\text { \#6. If the coin turns head up, then you would lose } 3,500 \text { ariary; } \\
\text { if the coin turns up tails, you would win } 3,000 \text { ariary }\end{array}$ & & \\
\hline
\end{tabular}

20. Rate your degree of confidence by writing down a number from 1 to 10 using the scale given below.

\begin{tabular}{|c|c|c|c|c|c|c|c|c|c|}
\hline $\begin{array}{c}1 \\
\begin{array}{c}\text { Cannot do } \\
\text { at all }\end{array}\end{array}$ & 2 & 3 & 4 & 5 & 6 & 7 & 8 & 9 & $\begin{array}{c}10 \\
\text { Highly certain } \\
\text { can do }\end{array}$ \\
\hline
\end{tabular}

Confidence (1-10)

20.1 Learn general mathematics

20.2 Learn biology

20.3 Learn reading, writing, and language skills

20.4 Learn to use computers

20.5 Learn science

20.6 Learn a foreign language

20.7 Learn social studies

21. Please rate the truthfulness of the following statements, according to how you see yourself. On the scale, 1 means "not true of myself" and 5 means "true of myself". Please mark your answer with an X.

21.1 I can always manage to solve difficult problems if I try hard enough.

\begin{tabular}{|c|c|c|c|c|}
\hline 1 & 2 & 3 & 4 & 5 \\
Not true of myself & Slightly true of myself & Half true of myself & Mostly true of myself & True of myself \\
\hline
\end{tabular}


21.2 If someone opposes me, I can find the means and ways to get what I want.

\begin{tabular}{|c|c|c|c|c|}
\hline 1 & 2 & 3 & 4 & 5 \\
Not true of myself & Slightly true of myself & Half true of myself & Mostly true of myself & True of myself \\
\hline
\end{tabular}

21.3 It is easy for me to stick to my aims and accomplish my goals.

\begin{tabular}{|c|c|c|c|c|}
\hline 1 & 2 & 3 & 4 & 5 \\
Not true of myself & Slightly true of myself & Half true of myself & Mostly true of myself & True of myself \\
\hline
\end{tabular}

21.4 I am confident that I could deal with unexpected events.

\begin{tabular}{|c|c|c|c|c|}
\hline 1 & 2 & 3 & 4 & 5 \\
Not true of myself & Slightly true of myself & Half true of myself & Mostly true of myself & True of myself \\
\hline
\end{tabular}

21.5 Thanks to my resourcefulness, I know how to handle unforeseen situations.

\begin{tabular}{|c|c|c|c|c|}
\hline 1 & 2 & 3 & 4 & 5 \\
Not true of myself & Slightly true of myself & Half true of myself & Mostly true of myself & True of myself \\
\hline
\end{tabular}

21.6 I can solve most problems if I invest the necessary effort.

\begin{tabular}{|c|c|c|c|c|}
\hline 1 & 2 & 3 & 4 & 5 \\
Not true of myself & Slightly true of myself & Half true of myself & Mostly true of myself & True of myself \\
\hline
\end{tabular}

21.7 I can remain calm when facing difficulties because I can rely on my abilities to reduce stress.

\begin{tabular}{|c|c|c|c|c|}
\hline 1 & 2 & 3 & 4 & 5 \\
Not true of myself & Slightly true of myself & Half true of myself & Mostly true of myself & True of myself \\
\hline
\end{tabular}

21.8 When I have problems, usually think of a solution

\begin{tabular}{|c|c|c|c|c|}
\hline 1 & 2 & 3 & 4 & 5 \\
Not true of myself & Slightly true of myself & Half true of myself & Mostly true of myself & True of myself \\
\hline
\end{tabular}

21.9 If I am in trouble, I can usually think of a solution.

\begin{tabular}{|c|c|c|c|c|}
\hline 1 & 2 & 3 & 4 & 5 \\
Not true of myself & Slightly true of myself & Half true of myself & Mostly true of myself & True of myself \\
\hline
\end{tabular}

21.10 I can usually handle whatever comes on my way.

\begin{tabular}{|c|c|c|c|c|}
\hline 1 & 2 & 3 & 4 & 5 \\
Not true of myself & Slightly true of myself & Half true of myself & Mostly true of myself & True of myself \\
\hline
\end{tabular}


22. In the following you will be presented with a pair of two statements: A and B. Please state for each pair with which statement you agree most.

Please mark your answer with an X.

22.1. A: Many of the unhappy things in people's lives are partly due to bad luck.

B: People's misfortunes result from the mistakes they make.

\begin{tabular}{|c|c|c|c|}
\hline 1 & 2 & 3 & 4 \\
\hline $\begin{array}{c}\text { I agree much more } \\
\text { with } \mathrm{A}\end{array}$ & $\begin{array}{c}\text { I agree slightly more } \\
\text { with A }\end{array}$ & $\begin{array}{c}\text { I agree slightly more } \\
\text { with B }\end{array}$ & $\begin{array}{c}\text { I agree much more } \\
\text { with B }\end{array}$ \\
\hline
\end{tabular}

22.2. A: In the case of the well prepared student there is rarely if ever such a thing as an unfair test.

B: Many times exam questions tend to be so unrelated to course work that studying is really useless.

\begin{tabular}{|c|c|c|c|}
\hline $\begin{array}{c}1 \\
\text { I agree much more } \\
\text { with } \mathrm{A}\end{array}$ & $\begin{array}{c}2 \\
\text { I agree slightly more } \\
\text { with A }\end{array}$ & $\begin{array}{c}3 \\
\text { I agree slightly more } \\
\text { with B }\end{array}$ & $\begin{array}{c}4 \\
\text { I agree much more } \\
\text { with B }\end{array}$ \\
\hline
\end{tabular}

22.3. A: Becoming a success is a matter of hard work, luck has little or nothing to do with it.

B: Getting a good job depends mainly on being in the right place at the right time.

\begin{tabular}{|c|c|c|c|}
\hline $\begin{array}{c}1 \\
\text { I agree much more } \\
\text { with } \mathrm{A}\end{array}$ & $\begin{array}{c}2 \\
\text { I agree slightly more } \\
\text { with A }\end{array}$ & $\begin{array}{c}3 \\
\text { I agree slightly more } \\
\text { with B }\end{array}$ & $\begin{array}{c}4 \\
\text { I agree much more } \\
\text { with B }\end{array}$ \\
\hline
\end{tabular}

22.4. A: When I make plans, I am almost certain that I can make them work.

B: It is not always wise to plan too far ahead because many things turn out to be a matter of good or bad fortune anyhow.

\begin{tabular}{|c|c|c|c|}
\hline 1 & 2 & 3 & 4 \\
$\begin{array}{c}\text { I agree much more } \\
\text { with A }\end{array}$ & $\begin{array}{c}\text { I agree slightly more } \\
\text { with A }\end{array}$ & $\begin{array}{c}\text { I agree slightly more } \\
\text { with B }\end{array}$ & $\begin{array}{c}\text { I agree much more } \\
\text { with B }\end{array}$ \\
\hline
\end{tabular}


22.5. A: Sometimes I can't understand how teachers arrive at the grades they give.

B: There is a direct connection between how hard I study and the grades I get.

\begin{tabular}{|c|c|c|c|}
\hline 1 & 2 & 3 & 4 \\
$\begin{array}{c}\text { I agree much more } \\
\text { with A }\end{array}$ & $\begin{array}{c}\text { I agree slightly more } \\
\text { with A }\end{array}$ & $\begin{array}{c}\text { I agree slightly more } \\
\text { with B }\end{array}$ & $\begin{array}{c}\text { I agree much more } \\
\text { with B }\end{array}$ \\
\hline
\end{tabular}

22.6. A: What happens to me is my own doing.

B: Sometimes I feel that I don't have enough control over the direction my life is taking.

\begin{tabular}{|c|c|c|c|}
\hline 1 & 2 & 3 & 4 \\
$\begin{array}{c}\text { I agree much more } \\
\text { with A }\end{array}$ & $\begin{array}{c}\text { I agree slightly more } \\
\text { with A }\end{array}$ & $\begin{array}{c}\text { I agree slightly more } \\
\text { with B }\end{array}$ & $\begin{array}{c}\text { I agree much more } \\
\text { with B }\end{array}$ \\
\hline
\end{tabular}

23. With how many people in your group are you friends with?

Please mark your answer with an X.
$\square 0$
1
2
3

24. In which year were you born?

25. Where have you been raised?

Please mark your answer with an X.

In a big city

In the rural area

26. What is your gender?

Please mark your answer with an X.

Female

Male

27. How many brothers do you have?

Please write how many.

28. How many sisters do you have?

Please write how many. 
29. Please indicate your economic situation on a scale from 1 to 5 , where 1 means "poor" and 5 "wealthy".

Please mark your answer with an X.

\begin{tabular}{|c|c|c|c|c|}
\hline 1 & 2 & 3 & 4 & $\begin{array}{c}5 \\
\text { Wealthy }\end{array}$ \\
\hline
\end{tabular}

30. Do you have a job?

Please mark your answer with an X.

Yes

$\square$ No

31. How many hours a week do you work? hours per week

32. Does your family cultivate vanilla?

Please mark your answer with an $\mathrm{X}$.

Yes

No

33. How often do you go to the market to buy food?

Please mark your answer with an X.

\begin{tabular}{|c|c|c|c|c|}
\hline 1 & 2 & 3 & 4 & 5 \\
Never & Once a year & Once a month & Once a week & Every day \\
\hline
\end{tabular}

34. What is your name:

Thank you very much for your participation! 


\section{Field Experiment Instructions — Job Announcement}

[Researcher enters the room and communicates the following]

Thank you very much for your participation today! Before you go, I would like to share with you some information about a job opening in our research project. In my work I visit different villages from the SAVA region and I am in contact with vanilla farmers. For my next visit, I am looking for assistants and a coordinator to work with me. The job will be starting this year in November to December [starting next year in July to August]. In this paper that I will distribute to all of you, you can find more information about the jobs and application process. 


\section{JOB ANNOUNCEMENT - PUBLIC Decision Sheet}

Before finishing the workshop of today, we would like to inform you about a job opening at our research project. Our project works with vanilla farmers in the SAVA region. We are looking for assistants and a coordinator who help us with our data collection starting this year in November to December [starting next year in July to August]. During the data collection we will do different workshops with the farmers. The job of the assistant consists in helping with the organization of the workshops and to fill in questionnaires with different farmers once the workshop is finished. The job of the coordinator is to visit the villages and plan the workshops in advance with the village chief. As the coordinator has more responsibilities than the assistant, the salary of the coordinator is 13 percent higher. The candidates for each position should be motivated to work in rural areas, be good team members and have good communications skills. Fluency in French or English is ideal but not a must.

If you are interested in applying for the job and want to know more about it please mark in the box below that you are interested. Once we have collected the decisions of all the people in the room we will call your name out loud to confirm that you are interested in applying for the job. If you mark that you are not interested, your name will not be called. Please remain in your seat and don't discuss your decision with the people around you.

Are you interested in applying for the job?

\section{I am interested}

I am not interested

If you are interested in the job, for which position exactly?

\section{Assistant}

\section{Coordinator}

For those who are interested, we will collect your name, E-Mail address and/or phone number and when we come back next week to give you your additional earnings of the workshop, you will have to fill in a job application. If you mark that you are not interested you will not have to fill in a job application next week. Your name, E-mail and/or telephone numbers will only be used for the job selection process. If you are interested in applying, please write down your name, E-Mail address/ telephone number here:

Name:

Email/telephone number:

Your name, E-mail and/or telephone numbers will only be used for the job selection process. 


\section{JOB ANNOUNCEMENT - PRIVATE Decision Sheet}

Before finishing the workshop of today, we would like to inform you about a job opening at our research project. Our project works with vanilla farmers in the SAVA region. We are looking for assistants and a coordinator who help us with our data collection starting this year in in November to December [starting next year in July to August]. During the data collection we will do different workshops with the farmers. The job of the assistant consists in helping with the organization of the workshops and to fill in questionnaires with different farmers once the workshop is finished. The job of the coordinator is to visit the villages and plan the workshops in advance with the village chief. As the coordinator has more responsibilities than the assistant, the salary of the coordinator is 13 percent higher. The candidates for each position should be motivated to work in rural areas, be good team members and have good communications skills. Fluency in French or English is ideal but not a must.

If you are interested in applying for the job and want to know more about it, please mark in the box below that you are interested. If you are not interested please mark in the box below that you are not interested. Your decision will not be shared with anybody in the room. Please remain in your seat and don't discuss your decision with the people around you.

Are you interested in applying for the job?

$\square$ I am interested

I am not interested

If you are interested in the job, for which position exactly?

Assistant

Coordinator

For those who are interested, we will collect your name, E-Mail address and/or phone number and when we come back next week to give you your additional earnings of the workshop, you will have to fill in a job application. If you mark that you are not interested you will not have to fill in a job application next week. If you are interested in applying, please write down your name, E-Mail address/ telephone number here:

Name:

Email/telephone number:

Your name, E-mail and/or telephone numbers will only be used for the job selection process. 
[After students have filled one of the decision sheets, the researcher tells them the following:]

Thank you for your time. As we mentioned before, in exactly one week we will be here at the same time to distribute the earnings of activity $\mathrm{X}$ [activity randomly selected for payment]. In addition, for those who expressed their interest in any of the job positions, we will bring the application forms on that day so you can fill them with your personal information. It is important that you bring one photo of you, as we will attached it to the application form. Please do not forget to bring the photo, otherwise your application will not be taken into account for the selection process. Now, please make a line at the front so each of you can receive the 2,000 ariary for your participation today. 


\section{Job Application Form}

\section{Diversity Turn
in Land Use Science}

\begin{tabular}{|c|c|}
\hline Full Name: & \\
\hline Date of Birth: & --------------------- \\
\hline Phone number: & --------------------------------------------- \\
\hline Email Address: & -------------------------------------- \\
\hline Where do you live? & --------------------------------------------------- \\
\hline $\begin{array}{l}\text { Would you be able to find accommodation } \\
\text { in Sambava for this job? }\end{array}$ & ------------------------------------------ \\
\hline Date Available to Start: & -------------------------------------------------- \\
\hline Track of study: & ------------------------------------------------- \\
\hline Average grade Terminal (last year of school): & -------------------------------------------- \\
\hline \multirow{2}{*}{ Language skills: } & English: Very good Good So so Not good \\
\hline & French: Very good Good So so Not good \\
\hline $\begin{array}{l}\text { Did you hear about the project before we } \\
\text { visited you school? }\end{array}$ & Yes No \\
\hline What are your salary expectations? & -------------------------------------------------- \\
\hline Do you like working in a team? & Yes $\quad$ No \\
\hline $\begin{array}{l}\text { Do you have health problems that might } \\
\text { impede you to travel by car or moto? }\end{array}$ & $\begin{array}{l}\text { Yes No } \\
\text { If yes, which ones? }\end{array}$ \\
\hline Have you worked in the past? & Yes No \\
\hline \multirow[t]{2}{*}{ Where have you worked before and for how long? } & $\begin{array}{l}\text { Place: } \\
\text { Duration of work: }\end{array}$ \\
\hline & $\begin{array}{l}\text { Place: } \\
\text { Duration of work: }\end{array}$ \\
\hline \multirow{3}{*}{ Please list three references and their contract information } & $\begin{array}{l}\text { Name: } \\
\text { Telephone number: } \\
\text { Relation to you: }\end{array}$ \\
\hline & $\begin{array}{l}\text { Name: } \\
\text { Telephone number: } \\
\text { Relation to you: }\end{array}$ \\
\hline & $\begin{array}{l}\text { Name: } \\
\text { Telephone number: } \\
\text { Relation to you: }\end{array}$ \\
\hline
\end{tabular}




\subsubsection{Appendix C — Video Scripts}

\section{Female Role Model Video: "Marie's story of achievement"}

Narrator: "This is Marie Rolande. She is 27 years old. Originally she is from Antsahanoro, but she has been living in Antalaha since 1991. Her goal was to become a research teacher of environmental conservation. At the moment she is teaching in CURSA (Centre Universitaire Régional de la SAVA) and at the same time she started her $\mathrm{PhD}$ with University of Mahajanga in cooperation with a University in Germany. Marie Rolande will tell us her story of how she achieved her goal:"

Marie Rolande: "During my Bachelor studies I always dreamed of becoming a research teacher, somebody who is important and respected by most of the people in the society I live in. I knew that in order to fulfill my goal, I have to exert a lot of effort by continuing my education. Working as a research teacher requires having minimum a Degree of Master 2."

Narrator: "Acquiring a Master 2 Degree in Madagascar encompasses a long journey. People need to study for many years and in the rst place they need to have the nancial resources to fund it."

Marie Rolande: "My parents supported me for my studies during primary and secondary school. However, for my university studies their help was not enough. To fully fund my studies, I received help from the Malagasy government which was not easy to obtain as they support only the best students. But this did not keep me from trying. During the time of my studies I studied very hard, always giving my best to be able to get the financial aid."

Narrator: "After 1 year of studying hard, Marie succeeded and received a grant from the government to fund her second and third year of her Bachelor studies."

Marie Rolande: "I was very happy and surprised when I received the news of my grant. Especially because I consider myself an average student and I knew many students, some way better than me, were applying for it. I think that what helped me to succeed was the commitment to my goal and my courage to keep going."

Narrator: "Apart from receiving a grant from the Malagasy government, Marie Rolande also found other sources of nancial support that gave her the opportunity to start her Master 2 Degree Program. After she nished her Bachelor, Marie Rolande started searching for different international programs where she could obtain her Master 2 Degree. She found a suitable program in Forest Management at the University of Kinshasa in Republic of Congo. It was a big step for Marie to do her Master 2 abroad, especially coming from 
a country where it is not common that a woman her age keeps on studying instead of marrying, starting a family or cultivating vanilla. However, most of Marie Rolande's family did not understand why she kept studying so much and not focusing on having a family. Also, other people started questioning her decision on not cultivating vanilla and told her that studying for so long was not worth it. She has been feeling this pressure for 5 years now."

Marie Rolande: "I am aware that some people, especially in my village, don't agree with the decisions I have made in my life. But my dream of becoming a research teacher was my priority and having a family just didn't t at that moment. I can still start a family or plant vanilla in the future but now I want to focus on my teaching and on my research.

Narrator: "After obtaining her Master2 Degree she was condent enough to apply for a research teacher position at CURSA. After some months of waiting, she nally got a positive response and got the dream job that she always wanted. Succeeding was not easy, it took her many years of studying and endurance until she was prepared to apply for the position."

Marie Rolande: "I am very happy to work for CURSA. Now I can nally focus on sharing the knowledge I have with my students and also doing research in my favorite eld of study."

Narrator: "Besides achieving her goal, this job at CURSA has opened many doors for Marie. For example she started in 2016 a PhD with the University of Mahjanga in cooperation with a University in Germany. Furthermore, she has had the opportunity to work in other projects with international students that have visited the SAVA region."

Marie Rolande: "Becoming a research teacher at CURSA has opened me many doors and I am sure that there are more projects to come. Also, my family has played a key role in the last years. Especially, I wouldn't have achieved all this without the help of my mother and grandfather. They have been very important to me because they have supported me to continue my dreams all the time."

Mother of Marie Rolande: "I am very proud of my daughter and I know that with her commitment and strength she has a great future ahead. You know, she was like any other kid but as years passed by she started imaging something dierent for her life. I know how difficult it was for her and all the obstacles she had to face, but at the end she succeeded. Now, she can tell her story to others and help them to overcome their fears."

Narrator: "Some people think that she is losing her time with that job; however, her students and colleagues see her with other eyes. They see her as a person that follows her objectives and who is ready to make sacrices along the way to achieve them." 
Friend of Marie Rolande: "Some people in the village think that she should be doing something different, like having children and planting vanilla, but there are also people like me that see her life dierent and who admire her decision to keep on studying, to follow her dream. I was very happy when I got to know that she got the job at CURSA because I knew how much she wanted that job."

Colleague of Marie Rolande: "She is a great role model for all of our students. I have heard several times that they would like to be like her. She also tells her students that when she was young, she was like them and that if they want to succeed they need to have condence in themselves and study hard."

Narrator: "The story of Marie Rolande shows that if one aims at doing something and works towards it, it is possible to achieve it. She imagined a dierent life than most of her friends and family have, and even though the journey was long and with many obstacles, she was able to make that imagination a reality." 


\section{Male Role Model Video: "Fulgence's story of achievement"}

Narrator: "This is Fulgence. He is 33 years old. Originally he is from from Antsahamanena but he has been living in Antalaha since 2015. His goal was to become a research teacher in zoology. At the moment he is teaching at CURSA (Centre Universitaire Régional de la SAVA) and at the same time he started his $\mathrm{PhD}$ with University of Antananarivo in cooperation with a University in Germany. Fulgence will tell us his story on how he achieved his goal:"

Fulgence: "During my Bachelor studies I always dreamed of becoming a research teacher, somebody who is important and respected by most of the people in the society I live in. I knew that in order to fulll my goal, I have to exert a lot of effort by continuing my education. Working as a research teacher requires having minimum a Degree of Master."

Narrator: "Acquiring a Master 2 Degree in Madagascar encompasses a long journey. People need to study for many years and in the rst place they need to have the nancial resources to fund it."

Fulgence: "My family supported me for my studies during primary and secondary school. However, for my university studies their help was not enough. To fully fund my studies, I received help from the Malagasy government which was not easy to obtain as they support only the best students. But this did not keep me from trying. During the time of my studies I studied very hard, always giving my best to be able to get the nancial aid."

Narrator: "After 1 year of studying hard, Fulgence succeeded and received a grant from the government to fund his second and third year of his Bachelor studies."

Fulgence: "I was very happy and surprised when I received the news of my grant. Especially because I consider myself an average student and I knew many students, some way better than me, were applying for it. I think that what helped me to succeed was the commitment to my goal and my courage to keep going."

Narrator: "Apart from receiving a grant from the Malagasy government, Fulgence got support from his older brother who decided to work in his place so that he could continue studying. After he nished his Bachelor, Fulgence started searching for different programs where he could obtain his Master 2 Degree. He found a suitable program in Science at the University of Mahajanga. It was a big step for Fulgence to do his Master 2 in another region of Madagascar, especially as he is coming from a rural area that is located far away from that University. However, some people from Fulgence family did not understand why he kept studying so much and not focus on cultivating vanilla instead. They think that 
studying for so long was not worth it."

Fulgence: "I am aware that some people, especially in my village, don't agree with the decisions I have made in my life. But my dream of becoming a research teacher was my priority and cultivating vanilla before just didn't $t$ at that moment. I can still plant vanilla in the future but now I want to focus on my teaching and on my research."

Narrator: "After obtaining his Master 2 Degree he was condent enough to apply for a research teacher position at CURSA. After some months of waiting, he nally got a positive response and got the dream job that he always wanted. Succeeding was not easy, it took him many years of studying and endurance until he was prepared to apply for the position."

Fulgence: "I am very happy to work for CURSA. Now I can nally focus on sharing the knowledge I have with my students and also doing research in my favorite eld of study."

Narrator: "Besides achieving his goal, this job at CURSA has opened many doors for Fulgence. For example he started in 2016 a PhD with the University of Tana in cooperation with a University in Germany. Furthermore, he has had the opportunity to get in contact with international researchers that have helped him to improve his research."

Fulgence: "Becoming a research teacher at CURSA has opened me many doors and I am sure that there are more projects to come. Also, my family has played a key role in the last years. Especially, I wouldn't have achieved all this without the help of my mother, my father and my aunt. They have been very important to me because they have supported me to continue my dreams all the time."

Mother of Fulgence: "I am very proud of my son and I know that with his commitment and strength he has a great future ahead. You know, he was like any other kid but as years passed by he started imaging something dierent for his life. I know how dicult it was for him and all the obstacles he had to face, but at the end he succeeded. Now, he can tell his story to others and help them to overcome their fears."

Narrator: "Some people think that he is losing his time with that job; however, his students and colleagues see him with other eyes. They see him as a person that follows his objectives and who is ready to make sacrices along the way to achieve them."

Friend of Fulgence: "Some people in the village think that he should be doing something different, like planting vanilla, but there are also people like me that see his life different and who admire his decision to keep on studying, to follow his dream. I was very happy 
when I got to know that he got the job at CURSA because I knew how much he wanted that job."

Colleague of Fulgence: "He is a great role model for all of our students. I have heard several times that they would like to be like him. He also tells his students that when he was young, he was like them and that if they want to succeed they need to have condence in themselves and study hard."

Narrator: "The story of Fulgence shows that if one aims at doing something and works towards it, it is possible to achieve it. He imagined a dierent life than most of his friends and family have, and even though the journey was long and with many obstacles, he was able to make that imagination a reality." 


\section{Placebo Video: "Rural and Urban Life in the SAVA Region"}

Narrator: "Life in cities is very attractive for young people. They often migrate to cities like Antalaha to find a job. There they find opportunities they do not have in the villages they come from. Marie Rolande is a young woman who left her village and came to the city to study and then work as a research teacher at CURSA, the Centre Universitaire Régional de la SAVA. Here she is teaching students in environmental conservation and at the same time she is doing her Phd with University of Mahajanga in cooperation with a University in Germany."

Marie Rolande: "Originally I am from Antsahanoro. However I have been living here in Antalaha since 1991. I think that the urban life is not the same as the life in villages. In the villages people mostly earn their living with farming. This also is reected in their clothing. Farmers wear long shirts and trousers that protect them from injuries and mosquito bites. In the cities, clothing is different. Here people like to wear short clothes due to the warm climate."

Narrator: "Fulgence is a young man who lives in Antalaha. As Marie, he is also a research teacher at CURSA. He is teaching students in zoology. He is doing his $\mathrm{PhD}$ with University of Antananarivo in cooperation with a University in Germany, too."

Fulgence: "I have been living in bigger cities for the course of my studies. The life in a city like Antalaha is different than in rural areas. First the city is more developed as the rural area. Here you have more shops, markets; better infrastructure in general. Also lifestyle is different. Here people enjoy going out; watching films and dancing in discos. In the rural area this is different; there you have fewer opportunities even though some people have solar panels which enable them to watch videos."

Fulgence: "Not only rural and urban life differ in many aspects, but also the cities among each other. The rst difference is the climate. Antalaha and Sambava have the same climate, but not Vohemar and Andapa. The second difference lies in the ethnicity. In Sambava for example we can find all ethnicities. Here in Antalaha the biggest ethnicity is the "Bezimzaraka."

Marie Rolande: "Some people of my family still live in Antsahanoro, where I come from. I visit them often; especially when there are traditional ceremonies in the village. For weddings for example, they invite not only the family of the woman and the man but all people in the village who want to come. And they prepare a big party for that: They kill a Zebu, they prepare a lot of rice and a lot of good things to eat, and they have beautiful music. City weddings are smaller; not so much people are invited." 
Narrator: "Rural and urban life is connected through farming and breeding livestock. Many occupations in the urban area depend on the cultivation that takes place in the rural area. Most products that are sold on markets in the city are usually from fields outside the cities, such as vanilla and rice. But there is also trade in the other direction. Products from Tana or from Tamatav are imported to the cities and sold in the rural areas."

Marie Rolande: "This is Antsahanoro. Here I spent many days of my life. Here, life is slower than in Antalaha and you know everybody in the village. When I am 60 years old, I will need some tranquility and a calm place, so I think I will return to the village. But, I am not really sure about the others, but me, I really like environment, nature."

Narrator: "Fulgence comes from Antsahamanena a village that is located in a remote area. The fastest way of reaching it, is to go by pirogue. Here most of the people cultivate vanilla. They spent most of their days in the eld. As the do not have electricity there, they hear radio with batteries while they are working. The radio does not only serve as entertainment, but also as information source; so they know what is happening in the region."

Fulgence: "This is the village I come from. I really like coming here for traditional ceremonies, when we have Zebu meat. Here in the villages Zebu is more valuable than in the cities, so people are used to have Zebu for celebrations."

Narrator: "In Antalaha, if you don't have enough money, people just buy some meat or some chicken in the market, instead of having a Zebu. In Fulgence's family it is his mother who prepares the Zebu for traditional ceremonies, while Fulgence's father takes care of the vanilla."

Fulgence's mother: "Yes, Zebu is our traditional meal. Usually we eat it with rice and romazava. Everybody from our big family joins for special ceremonies, which means that I have to prepare a lot. Here in the villages it is normal for people to have very big families."

Marie's mother: "Families here are very big and they are getting bigger with every generation. But the land stays the same, so that there is often not enough land for young people. They need to move away into the big cities just to discover another way to conduct their lives. And maybe often they want to move away because they are just lazy to live like a farmer."

Narrator: "Most of the friends of Marie and Fulgence also did not want to become a farmer. At the moment they live in Antalaha and some are working as teachers, too. But as a teacher you do not necessarily have to live in the big city." 
Fulgence's female friend: "I know many young people that try to nd a job in the city. Most young people try to make it by working in the vanilla business. At the moment the vanilla prices are very high and this is very attractive for young people, but maybe in some years it will not be like that anymore."

Colleague of Marie: "Another dierence between rural and urban areas is that only in big cities you can nd public schools where students can nish their secondary education. Because of this, many students have to move to the cities to continue studying."

Narrator: "Living in the city has advantages and disadvantages, same as in the rural area. However, this diversity makes the SAVA region a beautiful place to live." 


\section{Bibliography}

Abbink, K., \& Herrmann, B. (2011). The moral costs of nastiness. Economic Inquiry, 49(2), 631-633. doi: 10.1111/j.1465-7295.2010.00309.x

Abeler, J., Falk, A., Goette, L., \& Huffman, D. (2011). Reference points and effort provision. American Economic Review, 101(2), 470-492. doi: 10.1257/aer.101.2.470

Aimone, Ball, S., \& King-Casas, B. (2015). The Betrayal Aversion Elicitation Task: An Individual Level Betrayal Aversion Measure. PLoS ONE, 10(9), 1-12. Retrieved from http://journals.plos.org/plosone/article/file?id=10.1371/journal. pone .0137491\&type=printable doi: 10.1371/journal.pone.0137491

Aimone, \& Houser, D. (2012). What you don't know won't hurt you: a laboratory analysis of betrayal aversion. Exp Econ, 15, 571-588. Retrieved from https://link.springer.com/ content/pdf/10.1007\%2Fs10683-012-9314-z.pdf doi: 10.1007/s10683-012-9314-z

AlAzzawi, S. (2014). Trade liberalization, industry concentration and female workers: the case of egypt. IZA Journal of Labor Policy, 3(1), 20.

Algan, B. Y., \& Cahuc, P. (2010). Inherited Trust and Growth. American Economic Review, 100 (December), 2060-2092.

Allcott, H. (2011). Social norms and energy conservation. Journal of Public Economics, 95 (910), 1082-1095. Retrieved from http://dx.doi.org/10.1016/j.jpubeco.2011.03.003 doi: $10.1016 /$ j.jpubeco.2011.03.003

Allcott, H., \& Rogers, T. (2014). The short-run and long-run effects of behavioral interventions: Experimental evidence from energy conservation. American Economic Review, 104(10), 3003-3037. doi: 10.1257/aer.104.10.3003

Alpizar, F., Carlsson, F., \& Johansson-Stenman, O. (2008). Anonymity, reciprocity, and conformity: Evidence from voluntary contributions to a national park in Costa Rica. Journal of Public Economics, 92(5-6), 1047-1060. doi: 10.1016/j.jpubeco.2007.11.004 
Andersen, S., Ertac, S., Gneezy, U., List, J. A., \& Maximiano, S. (2013). Gender, competitiveness, and socialization at a young age: Evidence from a matrilineal and a patriarchal society. Review of Economics and Statistics, 95(4), 1438-1443. doi: 10.1162/REST_a_00312

Anderson, M. L. (2008). Multiple inference and gender differences in the effects of early intervention: A reevaluation of the Abecedarian, Perry Preschool, and Early Training Projects. Journal of the American Statistical Association, 103(484), 1481-1495. doi: $10.1198 / 016214508000000841$

Andreoni, J. (1990). Impure Altruism and Donations to Public Goods: A Theory of Warm-Glow Giving. The Economic Journal, 100(401), 464-477.

Andreoni, J., \& Miller, J. (2002). Giving According to GARP : An Experimental Test of the Consistency of Preferences for Altruism. Econometrica, 70(2), 737-753.

Andriamalala, G., \& Gardner, C. J. (2010). L'utilisation du dina comme outil de gouvernance des ressources naturelles : leçons tirés de Velondriake, sud-ouest de Madagascar. Mongabay.com Open Access Journal - Tropical Conservation Science, 3(4), 447-472. Retrieved from http://journals.sagepub.com/doi/pdf/10.1177/194008291000300409

Appadurai, A. (2004). The Capacity to Aspire: Culture and the Terms of Recognition. In V. Rao \& M. Walton (Eds.), Culture and public action (pp. 59-84). Palo Alto, California: Stanford University Press.

Arbache, J. S., Kolev, A., \& Filipiak, E. (2010). Why Study Gender Disparities in Africa's Labor Markets? In J. S. Arbache, A. Kolev, \& E. Filipiak (Eds.), Gender disparities in africa's labor market. The International Bank for Reconstruction and Development. doi: https://doi.org/10.1596/978-0-8213-8066-6

Ashraf, N., Bohnet, I., \& Piankov, N. (2006). Decomposing trust and trustworthiness. Experimental Economics, 9(3), 193-208. doi: 10.1007/s10683-006-9122-4

Balafoutas, L., Davis, B. J., \& Sutter, M. (2016). Affirmative action or just discrimination? A study on the endogenous emergence of quotas. Journal of Economic Behavior and Organization, 127, 87-98. Retrieved from http://dx.doi.org/10.1016/j.jebo.2016 .04 .015 doi: $10.1016 /$ j.jebo.2016.04.015

Bandura, A. (1977). Social Learning Theory. New Jersey, Englewood Cliffs: Prentice-Hall.

Bandura, A. (1997). Self-Efficacy: The Exercise of Control. New York: Freeman.

Bandura, A. (2004). Social cognitive theory for personal and social change by enabling media. In A. Singhal, M. J. Cody, E. M. Rogers, \& M. Sabido (Eds.), Entertainmenteducation and social change: History, research, and practice (pp. 75-96). Mahwah, New Jersey: Lawrence Erlbaum Associates. 
Bandura, A. (2006). Guide for Constructing Self-Efficacy Scales. In T. Urdan \& F. Pajares (Eds.), Self-Efficacy Beliefs of Adolescents (Vol. 5, pp. 307-337). Greenwhich, Connecticut: IAP Information Age Publishing, Inc.

Beaman, L., Duflo, E., Pande, R., \& Topalova, P. (2012). Female Leadership Raises Aspirations and Educational Attainment for Girls: A Policy Experiment in India. Science, 335 (6068), 582-586.

Becker, G. S. (1968). Crime and Punishment: An Economic Approach. Journal of Political Economy, 76, 169-217. doi: 10.1002/9780470752135.ch25

Becker, G. S. (1976). Altruism, Egoism, and Genetic Fitness: Economics and Sociobiology. Journal of Economic Literature, 14(3), 817-826.

Bellows, J., \& Miguel, E. (2009). War and local collective action in Sierra Leone. Journal of Public Economics, 93(11-12), 1144-1157. Retrieved from http://dx.doi.org/10.1016/ j.jpubeco.2009.07.012 doi: 10.1016/j.jpubeco.2009.07.012

Bénabou, R., Falk, A., \& Tirole, J. (2019). Narratives, Imperatives, and Moral Reasoning.

Benabou, R., \& Tirole, J. (2006). Incentives and Prosocial Behavior. The American Economic Review, 96(5), 1652-1678. Retrieved from http://pubs.aeaweb.org/doi/ pdfplus/10.1257/aer.96.5.1652

Ben-Ner, A., \& Putterman, L. (2001). Trusting and trustworthiness. Boston University Law Review, 81, 523-551.

Berg, J., Dickhaut, J., \& McCabe, K. (1995). Trust, Reciprocity, and Social History. Games and Economic Behavior, 10, 122-142.

Bernard, T., Dercon, S., Orkin, K., \& Taffesse, A. S. (2014). The Future in Mind: Aspirations and Forward-Looking Behaviour in Rural Ethiopia (Working Paper No. 10224). London, UK. Retrieved 2020-07-10, from http://www.ssrn . com/abstract $=2514590$

Bernard, T., Dercon, S., \& Taffesse, A. S. (2012). Beyond fatalism: An empirical exploration of self-efficacy and aspirations failure in Ethiopia. ESSP Working Papers Seies(46). Retrieved from https://ideas.repec.org/p/fpr/esspwp/46.html

Bernard, T., \& Taffesse, A. S. (2014). Aspirations: An Approach to Measurement with Validation Using Ethiopian Data. Journal of African Economies, 23(2), 189-224. doi: $10.1093 /$ jae/ejt030

Besley, T., Fetzer, T., \& Mueller, H. (2015). The welfare cost of lawlessness: Evidence from Somali Piracy. Journal of the European Economic Association, 13(2), 203-239. doi: $10.1111 /$ jeea. 12114

Besley, T., \& Ghatak, M. (2010). Property rights and economic development. In Handbook of development economics (1st ed., Vol. 5, pp. 4525-4595). Elsevier BV. Retrieved from 
http://dx.doi.org/10.1016/B978-0-444-52944-2.00006-9 doi: 10.1016/B978-0-444 $-52944-2.00006-9$

Billon, P. L. (2008). Diamond Wars? Conflict Diamonds and Geographies of Resource Wars. , 2(98), 345-372. doi: 10.1080/00045600801922422

Blau, F. D., \& Kahn, L. (2017). The Gender Wage Gap: Extent, Trends, and Explanations. Journal of Economic Literature, 55(3), 789-865. doi: 10.2307/j.ctt1tm7gsm.15

Bohnet, I., Greig, F., Herrmann, B., \& Zeckhauser, R. (2008). Betrayal aversion: Evidence from Brazil, China, Oman, Switzerland, Turkey, and the United States. American Economic Review, 98(1), 294 - 310. doi: 10.1257/aer.98.1.294

Bohnet, I., \& Zeckhauser, R. (2004). Trust, risk and betrayal. Journal of Economic Behavior Organization, 55, 467-484. Retrieved from https://www.hks.harvard.edu/ fs/rzeckhau/trust_risk_and_betrayal.pdf doi: 10.1016/j.jebo.2003.11.004

Bolton, \& Ockenfels, A. (2006). Inequality Aversion, Efficiency, and Maximin Preferences in Simple Distribution. The American Economic Review, 96 (5), 1906-1911.

Bolton, G., Brandts, J., \& Ockenfels, A. (2005). Fair procedures: Evidence from games involving lotteries. Economic Journal, 115(506), 1054-1076. doi: 10.1111/j.1468-0297 $.2005 .01032 . \mathrm{x}$

Bornhorst, F., Ichino, A., Kirchkamp, O., Schlag, K. H., \& Winter, E. (2010). Similarities and differences when building trust: The role of cultures. Experimental Economics, 13(3), 260-283. doi: 10.1007/s10683-010-9240-x

Bowles, S. (1998). Endogenous Preferences: The Cultural Consequences of Markets and other Economic Institutions. Journal of Economic Literature, 36 (1), 75-111.

Bowles, S. (2008). Policies designed for self-interested citizens may undermine "The moral sentiments": Evidence from economic experiments. Science, 320(5883), 1605-1609. doi: 10.1126/science. 1152110

Brañas-Garza, P. (2007). Promoting helping behavior with framing in dictator games. Journal of Economic Psychology, 28(4), 477-486. doi: 10.1016/j.joep.2006.10.001

Brandts, J., \& Charness, G. (2003). Truth or consequences: An experiment. Management Science, 49(1), 116-130. doi: 10.1287/mnsc.49.1.116.12755

Breda, T., Grenet, J., Monnet, M., \& Van Effenterre, C. (2020). Do Female Role Models Reduce the Gender Gap in Science? Evidence from French High Schools (IZA DP No. 13163). IZA Institute of Labor Economics. Retrieved from http://ftp.iza.org/ dp13163.pdf

Brown, Meer, J., \& Williams, J. F. (2019). Why do people volunteer? An experimental analysis of preferences for time donations. Management Science, 65(4), 1455-1468. doi: $10.1287 /$ mnsc. 2017.2951 
Brown, M. (2009). Madagascar's Cyclone Vulnerability and the Global Vanilla Economy. In E. C. Jones \& A. D. Murphy (Eds.), The political economy of hazards and disasters (pp. 241-264). Lanham: AltaMira Press.

Bruner, J. (1991). The Narrative Construction of Reality. Critical Inquiry, 18(Autumm), 1-21. Retrieved from http://www. semiootika.ee/sygiskool/tekstid/bruner.pdf

Bursztyn, L., Fujiwara, T., \& Pallais, A. (2017). 'Acting wife': Marriage market incentives and labor market investments. American Economic Review, 107(11), 3288-3319. doi: $10.1257 /$ aer.20170029

Cadot, O., Dutoit, L., \& de Melo, J. (2009). The elimination of Madagascar's Vanilla Marketing Board, 10 years on. Journal of African Economies, 18(3), 388-430. doi: $10.1093 /$ jae/ejn025

Caisse Nationale de Prévoyance Sociale Madagascar. (2015). Retrieved 2020-07-28, from http://www.cnaps.mg/en/index.php

Cappelen, A. W., Sørensen, E. Ø., \& Tungodden, B. (2013). When do we lie? Journal of Economic Behavior and Organization, 93, 258-265. doi: 10.1016/j.jebo.2013.03.037

Cardenas, J. C., \& Carpenter, J. (2008). Behavioural Development Economics: Lessons from Field Labs in the Developing World. Journal of Development Studies, 44(3), 311-338. doi: $10.1080 / 00220380701848327$

Carpenter, J., Frank, R., \& Huet-Vaughn, E. (2018). Gender differences in interpersonal and intrapersonal competitive behavior. Journal of Behavioral and Experimental Economics, 77, 170-176. doi: 10.1016/j.socec.2018.10.003

Carpenter, J., Matthews, P. H., \& Schirm, J. (2010). Tournaments and Office Politics: Evidence from a Real Effort Experiment. American Economic Review, 100(1), 504-517. doi: $10.1257 /$ aer.100.1.504

Cassar, A., Grosjean, P., \& Whitt, S. (2013). Legacies of violence: Trust and market development. Journal of Economic Growth, 18(3), 285-318. doi: 10.1007/s10887-013 $-9091-3$

Cassar, A., Healy, A., \& von Kessler, C. (2017). Trust, Risk, and Time Preferences After a Natural Disaster: Experimental Evidence from Thailand. World Development, 94 , 90-105. doi: 10.1016/j.worlddev.2016.12.042

Castillo, M., \& Carter, M. (2011). Behavioral Responses to Natural Disasters (Working Paper No. 1026). Retrieved from https://ideas.repec.org/p/gms/wpaper/1026.html

Charities Aid Foundation, C. (2017). CAF World Giving Index 2017: A global view of giving trends. Retrieved 2020-10-12, from https://www. cafonline.org/docs/default -source/about-us-publications 
Charness, G., \& Dufwenberg, M. (2006). Promises and Partnership. Econometrica, 74(6), 1579-1601. Retrieved from http://www.jstor.org/stable/4123084http:// about.jstor.org/terms

Charness, G., Masclet, D., \& Villeval, M. C. (2014). The Dark Side of Competition for Status. Management Science, 60(1), 38-55. doi: 10.1287/mnsc.2013.1747

Cheema, A., Khwaja, A. I., Naseer, F., \& Shapiro, J. N. (2019). Glass walls: Experimental evidence on access constraints faced by women (Tech. Rep.). Mimeo, Harvard University.

Chlaß, N., Güth, W., \& Miettinen, T. (2019). Purely procedural preferences - Beyond procedural equity and reciprocity. European Journal of Political Economy, 59(February), 108-128. doi: 10.1016/j.ejpoleco.2019.02.005

Chlaß, N., \& Riener, G. (2015). Lying, Spying, Sabotaging: Procedures and Consequences. DICE Discussion Papers(November), 1-44.

Chong, A., \& Ferrara, E. L. (2009). Television and divorce: Evidence from Brazilian novelas. Journal of the European Economic Association, 7(2-3), 458-468.

Clot, S., Grolleau, G., \& Ibanez, L. (2014). Smug Alert! Exploring self-licensing behavior in a cheating game. Economics Letters, 123, 191-194. Retrieved from http://dx.doi.org/ 10.1016/j.econlet.2014.01.039 doi: 10.1016/j.econlet.2014.01.039

Cobb-Clark, D. A. (2015). Locus of control and the labor market. IZA Journal of Labor Economics, 4(1), 1-19.

Cobo-Reyes, R., Dominguez, J. J., García-Quero, F., Grosskopf, B., Lacomba, J. A., Lagos, F., ... Pearce, G. (2020). The development of social preferences. Journal of Economic Behavior and Organization, 179, 653-666. Retrieved from https://doi.org/10.1016/ j.jebo.2019.01.018 doi: 10.1016/j.jebo.2019.01.018

Cox, J. C. (2004). How to identify trust and reciprocity. Games and Economic Behavior, 46, 260-281. doi: 10.1016/S0899-8256(03)00119-2

Cuberes, D., \& Teignier, M. (2016). Aggregate effects of gender gaps in the labor market: A quantitative estimate. Journal of Human Capital, 10(1), 1-32.

Cubitt, R., Gächter, S., \& Quercia, S. (2017). Conditional cooperation and betrayal aversion. Journal of Economic Behavior Organization, 141, 110-121. doi: 10.1016/ j.jebo.2017.06.013

Dahlstrom, M. F. (2014). Using narratives and storytelling to communicate science with nonexpert audiences. PNAS, 111(4), 13614-13620. Retrieved from http://www.pnas .org/content/111/Supplement_4/13614.full.pdf doi: 10.1073/pnas.1320645111

Dal Bó, E., \& Dal Bó, P. (2014). Do the right thing: The effects of moral suasion on cooperation. Journal of Public Economics, 117, 28-38. 
Dalton, P. S., Ghosal, S., \& Mani, A. (2014). Poverty and Aspirations Failure. The Economic Journal, 126(590), 165-188. doi: 10.1111/ecoj.12210

De Dominicis, S., Schultz, P. W., \& Bonaiuto, M. (2017). Protecting the environment for self-interested reasons: Altruism is not the only pathway to sustainability. Frontiers in Psychology, 8(JUN), 1-13. doi: 10.3389/fpsyg.2017.01065

De Groot, W. T., \& Zwaal, N. (2007). Storytelling as a medium for balanced dialogue on conservation in Cameroon. Environmental Conservation, 34(1), 45-54. doi: 10.1017/ S0376892907003682

Dellavigna, S., \& Gentzkow, M. (2010). Persuasion: Empirical Evidence. Annual Review of Economics, 2, 643-669. Retrieved from https://eml.berkeley.edu/\{ $\}$ sdellavi/wp/ PersuasionAERDellaVignaGentzkowProofsJun10.pdf doi: 10.1146/annurev.economics .102308 .124309

Dellavigna, S., List, J. A., \& Malmendier, U. (2012). Testing for altruism and social pressure in charitable giving. Quarterly Journal of Economics, 127(1), 1-56. doi: 10.1093/qje/qjr050

Dewatripont, M., \& Tirole, J. (2005). Modes of Communication. Journal of Political Economy, 113(6), 1217-1238.

Dold, M., \& Khadjavi, M. (2017). Jumping the queue: An experiment on procedural preferences. Games and Economic Behavior, 102, 127-137. Retrieved from http:// dx.doi.org/10.1016/j.geb.2016.12.002 doi: 10.1016/j.geb.2016.12.002

Dubois, D., Rucker, D. D., \& Galinsky, A. D. (2016). Dynamics of Communicator and Audience Power: The Persuasiveness of Competence versus Warmth. Journal of Consumer Research, 43, 68-85. doi: 10.1093/jcr/ucw006

Duflo, E. (2003). Grandmothers and Granddaughters: Old-age Pensions and Intrahousehold Allocation in South Africa. The World Bank Economic Review, 17(1), 1-25. doi: $10.1093 /$ wber /lhg013

Duflo, E. (2012). Women empowerment and economic development. Journal of Economic Literature, 50(4), 1051-1079. doi: 10.1257/jel.50.4.1051

Dyer, J. (2020). The Fruits (and Vegetables) of Crime: Protection from Theft and Agricultural Development. Retrieved from http://individual.utoronto.ca/julian _dyer/JDyer_WatchmanExperiment_Draft.pdf

Eckel, C. C., \& Wilson, R. K. (2004). Is trust a risky decision? Journal of Economic Behavior and Organization, 55(4), 447-465. doi: 10.1016/j.jebo.2003.11.003

Engel, C. (2011). Dictator games: A meta study. Experimental Economics, 14, 583-610. doi: $10.1007 / \mathrm{s} 10683-011-9283-7$ 
Epstein, G., Heintz, J., Ndikumana, L., \& Chang, G. (2010). Employment, poverty and economic development in Madagascar: A macroeconomic framework (No. 58). Geneva.

Evans, L., Maio, G. R., Corner, A., Hodgetts, C. J., Ahmed, S., \& Hahn, U. (2013). Self-interest and pro-environmental behaviour. Nature Climate Change, 3(February), 1-4. doi: $10.1038 /$ nclimate1662

Fafchamps, M., \& Minten, B. (2009). Insecurity and Welfare : Evidence from County Data. Journal of Development Studies, 45(6), 831-863. doi: 10.1080/00220380902802206

Fafchamps, M., \& Moser, C. (2003). Crime , Isolation and Law Enforcement University of Oxford and Cornell University. Journal of African Economies, 12(4), 625-671.

Fairtrade International. (2019). Living Income Reference Price for Vanilla from Uganda and Madagascar. Retrieved from https://files.fairtrade.net/publications/Fairtrade _Vanilla_LivingIncomeRefPrice_fullreport.pdf

Falk, A., Becker, A., Dohmen, T., Enke, B., Huffman, D., \& Sunde, U. (2018). GLOBAL EVIDENCE ON ECONOMIC PREFERENCES. Quarterly Journal of Economics, 133(4), 1645-1692. doi: 10.1093/qje/qjy013.Advance

FAO. (2020). FAOSTAT. Retrieved from http://www.fao.org/faostat/en/home

Fehr, E. (2009). On the economics and biology of trust. Journal of the European Economic Association, 7(2-3), 235-266.

Fehr, E., \& Fischbacher, U. (2002). Why Social Preferences Matter - The Impact of Non-Selfish Motives on Competition, Cooperation and Incentives. The Economic Journal, 112(478), C1-C33.

Fehr, E., \& Gächter, S. (1998). Reciprocity and economics: The economic implications of Homo Reciprocans. European Economic Review, 42, 845-859. doi: 10.1016/S0014 -2921(97)00131-1

Fehr, E., \& Schmidt, K. M. (1999). A theory of fairness, competition, and cooperation. The Quarterly Journal of Economics, 114, 817-868.

Fernández-Llamazares, Á., \& Cabeza, M. (2018). Rediscovering the Potential of Indigenous Storytelling for Conservation Practice. Conservation Letters, 11(3), 1-12. doi: 10.1111/ conl.12398

Ferraro, P. J., \& Price, M. K. (2013). Using nonpecuniary strategies to influence behavior: Evidence from a large-scale field experiment. Review of Economics and Statistics, 95(1), 64-73. doi: 10.1162/REST_a_00344

Fetchenhauer, D., \& Dunning, D. (2012). Betrayal aversion versus principled trustfulness - How to explain risk avoidance and risky choices in trust games. Journal of Economic Behavior and Organization, 81, 534-541. doi: 10.1016/j.jebo.2011.07.017 
Field, E., Pande, R., Rigol, N., Schaner, S., \& Moore, C. (2019). On her own account: How strengthening women's financial control impacts labor supply and gender norms. Yale University Economic Growth Center Discussion Paper(1068).

Flanagan, O. (1993). Consciousness reconsidered. Bradford Book.

Frazier, B. (2018). Blood Avocados: Cracking Down on Cartels. Retrieved 2020-0320, from https://brownpoliticalreview.org/2018/04/blood-avocados-cracking -cartels/

Fritz-Vietta, N., Tahirindraza, H. S., \& Stoll-Kleemann, S. (2017). Local people's knowledge with regard to land use activities in southwest Madagascar - Conceptual insights for sustainable land management. Journal of Environmental Management, 199, 126-138. doi: $10.1016 /$ j.jenvman.2017.05.034

Fritz-vietta, N. V. M., Ferguson, H. B., \& Stoll-kleemann, S. (2011). Conservation in a Biodiversity Hotspot: Insights from Cultural and Community Perspectives in Madagascar. In Biodiversity hotspots (pp. 209-233). doi: 10.1007/978-3-642-20992-5

Genicot, G., \& Ray, D. (2017). Aspirations and Inequality. Econometrica, 85(2), 489-519. Retrieved from https://www.econometricsociety.org/doi/10.3982/ECTA13865 doi: 10.3982/ECTA13865

Gino, F., Krupka, E. L., \& Weber, R. A. (2013). License to Cheat : Voluntary Regulation and Ethical Behavior. Management Science, 59(10), 2187-2203.

Ginther, D. K., Currie, J. M., Blau, F. D., \& Croson, R. T. A. (2020). Can Mentoring Help Female Assistant Professors in Economics? An Evaluation by Randomized Trial. AEA Papers and Proceedings, 110, 205-209. doi: 10.1257/pandp.20201121

Glick, P., Handy, C., \& Sahn, D. E. (2015). Schooling, marriage, and age at first birth in Madagascar. Population Studies, 69(2), 219-236.

Gneezy, U. (2005). Deception: The Role of Consequences. American Economic Review, 95 (1), 384-394. doi: 10.1257/0002828053828662

Gneezy, U., Leonard, K. L., \& List, J. A. (2009). Gender Differences in Competition: Evidence From a Matrilineal and a Patriarchal Society. Econometrica, 77(5), 1637-1664. doi: 10.3982 ECTA6690

Gneezy, U., Niederle, M., \& Rustichini, A. (2003). Performance in Competitive Environments: Gender Differences. The Quarterly Journal of Economics, 118(3), 1049-1074. doi: $10.1162 / 00335530360698496$

Gravert, C. (2013). How luck and performance affect stealing. Journal of Economic Behavior and Organization, 93, 301-304. doi: 10.1016/j.jebo.2013.03.026 
Grillo, I. (2020). Boycotting Avocados Won't Hurt Cartels. Retrieved 2020-0320, from https://www.nytimes.com/2020/03/02/opinion/avocados-drug-cartels -mexico.html

Groenewald, S. F., \& Bulte, E. (2013). Trust and livelihood adaptation: Evidence from rural Mexico. Agriculture and Human Values, 30(1), 41-55. doi: 10.1007/s10460-012-9383-9

Haaland, I., Roth, C., \& Wohlfart, J. (2020). Designing Information Provision Experiments. CESifo Working Paper, 8406, 1-53.

Hänke, H., Barkmann, J., Blum, L., Franke, Y., Martin, D. A., Niens, J., ... Wurz, A. (2018). Socio-economic, land use and value chain perspectives on vanilla farming in the SAVA region (north-eastern Madagascar): the Diversity Turn Baseline Study (DTBS) (Tech. Rep. No. October). Goettingen: University of Goettingen.

Harbring, C., \& Irlenbusch, B. (2011). Sabotage in Tournaments: Evidence from a Laboratory Experiment. Management Science, 57(4), 611-627. doi: 10.1287/mnsc.1100 .1296

Harbring, C., Irlenbusch, B., Kräkel, M., \& Selten, R. (2007). Sabotage in Corporate Contests - An Experimental Analysis. International Journal of the Economics of Business, 14 (3), 367-392. doi: 10.1080/13571510701597445

Harrison, G. W., \& List, J. A. (2004). Field Experiments. Journal of Economic Literature, 42(4), 1009-1055.

Havkin-Frenkel, D., \& Belanger, F. (2018). Handbook of vanilla science and technology. Wiley.

Henrich, B. J., Boyd, R., Bowles, S., Camerer, C., Fehr, E., Gintis, H., \& Mcelreath, R. (2001). In Search of Homo Economicus : Behavioral Experiments in 15 Small-Scale Societies. The American Economic Review, 91(2), 73-78.

Herrera, C., Sahn, D. E., \& Villa, K. M. (2019, jun). Teen fertility and female employment outcomes: Evidence from Madagascar. Journal of African Economies, 28(3), 277303. Retrieved from https://academic.oup.com/jae/article/28/3/277/5364072 doi: 10.1093/jae/ejy024

Herrera Almanza, C., Fred, A., Marchetta, F., Pelissier, A., Rajemison, H., Rakotomanana, F., ... Villa, K. (2017). Madagascar Young Adult Transitions Survey (GLM|LIC Working Paper No. 26). Growth in Labour Markets in Low Income Countries Programme. Retrieved 2020-09-22, from https://g2lm-lic.iza.org/wp-content/uploads/2017/ 04/glmlic-wp026.pdf

Hillenbrand, A., \& Verrina, E. (2018). The Differential Effect of Narratives. SSRN Electronic Journal, 1-46. doi: 10.2139/ssrn.3303744 
Ho, T., Nie, Z., Alpizar, F., Carlsson, F., \& Nam, P. K. (2020). Celebrity Endorsement in Promoting Pro-Environmental Behavior. (CeCAR Working Paper Series No. 8) doi: 10.1016/j.ajodo.2020.09.006

Hong, K., \& Bohnet, I. (2007). Status and distrust: The relevance of inequality and betrayal aversion. Journal of Economic Psychology, 28, 197-213. Retrieved from www.elsevier.com/locate/joep doi: 10.1016/j.joep.2006.06.003

Houser, D., Schunk, D., \& Winter, J. (2010). Distinguishing trust from risk: An anatomy of the investment game. Journal of Economic Behavior Organization, 74, 72-81. doi: 10.1016/j.jebo.2010.01.002

Houser, D., Vetter, S., \& Winter, J. (2012). Fairness and cheating. European Economic Review, 56, 1645-1655. doi: 10.1016/j.euroecorev.2012.08.001

Hsieh, C.-T., Hurst, E., Jones, C. I., \& Klenow, P. J. (2019). The allocation of talent and us economic growth. Econometrica, 87(5), 1439-1474.

Ibanez, Marcela, Khan, S., Minasyan, A., Sahoo, S., \& Balasubramanian, P. (2017). Women's economic empowerment on human development in low and middle-income countries. Campbell Systematic Reviews 2018.

Ibanez, \& Riener, G. (2018). Sorting through Affirmative Action: Three Field Experiments in Colombia. Journal of Labor Economics, 36 (2), 437-478. doi: 10.1086/694469

ILO. (2020). World Employment and Social Outlook. Madagascar. Retrieved 2020-08-08, from https://www.ilo.org/wesodata

International Labour Organization. (2018). Global wage report 2018/19: What lies behind gender pay gaps. Retrieved from https://www.ilo.org/global/publications/books/

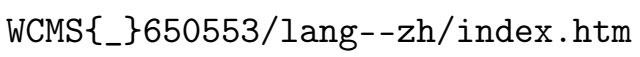

IPBES. (2018). Land Degradation and Restoration (Tech. Rep. No. July 2018).

Irlenbusch, B., \& Ruchala, G. K. (2008). Relative rewards within team-based compensation. Labour Economics, 15, 141-167. doi: 10.1016/j.labeco.2007.02.003

Jacobsen, C., Reinholt Fosgaard, T., \& Pascual-Ezama, D. (2017). Why do we lie? A practical guide to the dishonesty literature. Journal of Economic Surveys, 00(0), 1-31. doi: $10.1111 /$ joes.12204

Jacquet, J., Hagel, K., Hauert, C., Marotzke, J., Röhl, T., \& Milinski, M. (2013). Intraand intergenerational discounting in the climate game. Nature Climate Change, 3(12), 1025-1028. Retrieved from http://dx.doi.org/10.1038/nclimate2024 doi: 10.1038/ nclimate2024

Jaime Torres, M. M., \& Carlsson, F. (2018). Direct and spillover effects of a social information campaign on residential water-savings. Journal of Environmental Economics and Management, 92, 222-243. doi: 10.1016/j.jeem.2018.08.005 
Janzen, S. A., Magnan, N. P., Sharma, S., \& Thompson, W. M. (2017). Aspirations failure and formation in rural Nepal. Journal of Economic Behavior and Organization, 139, 1-25. doi: 10.1016/j.jebo.2017.04.003

Jayachandran, S. (2015). The Roots of Gender Inequality in Developing Countries. Annual Review of Economics, 7(1), 63-88. doi: 10.1146/annurev-economics-080614-115404

Jayachandran, S. (2020). Social Norms as a Barrier to Women's Employment in Developing Countries. NBER Working Paper, 27449. Retrieved from https://www.nber.org/ papers/w27449

Jensen, R. (2012). Do labor market opportunities affect young women's work and family decisions? Experimental evidence from India. Quarterly Journal of Economics, 127(2), 753-792. doi: 10.1093/qje/qjs002

Jensen, R., \& Oster, E. (2009). The Power of TV: Cable Television and Women's Status in India. Quarterly Journal of Economics, 124(3), 1057-1094. doi: 10.1162/ qjec.2009.124.3.1057

Jerusalem, M., \& Schwarzer, R. (1995). Generalized Self-Efficacy scale. In J. Weinman, S. Wright, \& M. Johnston (Eds.), Measures in health psychology: A user's portfolio. causal and control beliefs (pp. 35-37). Windsor, UK: NFER-NELSON.

Johnson, N. D., \& Mislin, A. A. (2011). Trust games: A meta-analysis. Journal of Economic Psychology, 32, 865-889. doi: 10.1016/j.joep.2011.05.007

Jones, J., Andriamarovololona, M., \& Hockley, N. (2008). The Importance of Taboos and Social Norms to Conservation in Madagascar. Conservation Biology, 22(4), 976-986. doi: 10.1111/j.1523-1739.2008.00970.x

Karlan, \& List, J. (2007). Does price matter in charitable giving? Evidence from a large-scale natural field experiment. American Economic Review, 97(5), 1774-1793. doi: $10.1257 /$ aer.97.5.1774

Karlan, D. S. (2005). Using Experimental Economics to Measure Social Capital and Predict Financial Decisions. The American Economic Review, 95(5), 1688 - 1699. doi: $10.1257 / 000282805775014407$

Katz, D., Grinstein, A., Kronrod, A., \& Nisan, U. (2016). Evaluating the effectiveness of a water conservation campaign: Combining experimental and field methods. Journal of Environmental Management, 180, 335-343. doi: 10.1016/j.jenvman.2016.05.049

Keizer, K., Lindenberg, S., \& Steg, L. (2008). The Spreading of Disorder. Science, 322(5908), 1681-1685.

Kellum, J., Randrianarimanana, H., Andrianaivosoa, L. M., \& Telingator, S. (2020). Madagascar Gender Analysis for the 2020 - 2025 Country Development (Tech. Rep.). USAID. 
Knack, S., \& Keefer, P. (1997). Does Social Capital Have an Economic Payoff? A Cross-Country Investigation. The Quarterly Journal of Economics, 112(4), 1251-1288.

Kolev, A., \& Sirven, N. (2010). Gender Disparities in Africa's Labor Markets: A CrossCountry Comparison Using Standardized Survey Data. In J. S. Arbache, A. Kolev, \& E. Filipiak (Eds.), Gender disparities in africa's labor market (chap. 1). The International Bank for Reconstruction and Development.

Komarek, A. M. (2010). Crop diversification decisions: The case of vanilla in Uganda. Quarterly Journal of International Agriculture, 49(3), 227-242.

Koppel, L., Andersson, D., \& Västfjäll, D. (2017). The (Null) Effect of Affective Touch on Betrayal Aversion, Altruism, and Risk Taking. Frontiers in Behavioral Neuroscience, 11, 1-11. doi: 10.3389/fnbeh.2017.00251

La Ferrara, E., Chong, A., \& Duryea, S. (2012). Soap Operas and Fertility: Evidence from Brazil. American Economic Journal: Applied Economics, 4(4), 1-31.

Landry, C. E., Lange, A., List, J. A., Price, M. K., \& Rupp, N. G. (2006). Toward an Understanding of the Economics of Charity: Evidence from a Field Experiment. Quarterly Journal of Economics, 121(2), 747-782.

Laney, R., \& Turner, B. L. (2015). The persistence of self-provisioning among smallholder farmers in northeast Madagascar. Human Ecology, 43(6), 811-826. doi: 10.1007/ s10745-015-9791-8

Lindenberg, S., \& Steg, L. (2007). Normative, Gain and Hedonic Goal Frames Guiding Environmental Behavior. Journal of Social Issues, 63(1), 117-137.

Liu, E. M., \& Huang, J. K. (2013). Risk preferences and pesticide use by cotton farmers in China. Journal of Development Economics, 103(1), 202-215. doi: 10.1016/j.jdeveco .2012 .12 .005

Llopis, J. C., Diebold, C. L., Schneider, F., Harimalala, P. C., Patrick, L., Messerli, P., \& Zaehringer, J. G. (2020). Capabilities Under Telecoupling: Human Well-Being Between Cash Crops and Protected Areas in North-Eastern Madagascar. Frontiers in Sustainable Food Systems, 3(January), 1-20. doi: 10.3389/fsufs.2019.00126

Lubega, P., Nakakawa, F., Narciso, G., Newman, C., \& Kityo, C. (2018). Inspiring women: Experimental evidence on sharing entrepreneurial skills in Uganda (Working Paper No. TRiSS-WPS-03-2018). Retrieved 2020-07-10, from https://www.tcd.ie/triss/assets/ PDFs/wps/triss-wps-03-2018.pdf

Lybbert, T., \& Wydick, B. (2018). Poverty, Aspirations, and the Economics of Hope. Economic Development and Cultural Change, 66(4), 709-753. 
Martin, D. A., Andriafanomezantsoa, R., Dröge, S., Osen, K., Rakotomalala, E., Wurz, A., ... Kreft, H. (2020). Bird diversity and endemism along a land-use gradient in Madagascar: The conservation value of vanilla agroforests. Biotropica(April 2020), 179-190. doi: 10.1111/btp.12859

McKelway, M. (2020). Women's Employment in India: Intra-Household and Intra-Personal Constraints. Retrieved from https://drive.google.com/file/d/ 1Fi8Y8A0o4j-NwqOmROowAVOkLcuCC1Ai/view

Meier. (2007). Do Subsidies Increase Charitable Giving in the Long Run? Matching Donations in a Field Experiment. Journal of the European Economic Association, 5(6), 1203-1222. doi: 10.2139/ssrn.960959

Meier, Niessen-Ruenzi, A., \& Ruenzi, S. (2020). The Impact of Role Models on Women's Self-Selection in Competitive Environments (Working Paper). Retrieved 2020-09-22, from https://papers.ssrn.com/sol3/papers. cfm?abstract_id=3087862

Michalopoulos, S., \& Meng Xue, M. (2021). Folklore. (NBER Working Paper Series No. 25430)

Mullainathan, S., \& Shleifer, A. (2005a). The Market for News. The American Economic Review, 95(4), 1031-1053.

Mullainathan, S., \& Shleifer, A. (2005b). Persuasion in Finance. Business Week(October), 1-48. doi: 10.1017/CBO9781107415324.004

Myers, N., Mittermeier, R. A., Mittermeier, C. G., da Fonseca, G. A. B., \& Kent, J. (2000). Biodiversity hotspots for conservation priorities. Nature, 403(6772), 853-858. doi: $10.1038 / 35002501$

Neimark, B., Osterhoudt, S., Blum, L., \& Healy, T. (2019). Mob justice and 'The civilized commodity'. Journal of Peasant Studies, 0(0), 1-20. Retrieved from https://doi.org/ 10.1080/03066150.2019.1680543 doi: 10.1080/03066150.2019.1680543

Niederle, M., Segal, C., \& Vesterlund, L. (2013). How Costly Is Diversity? Affirmative Action in Light of Gender Differences in Competitiveness. Management Science, 59(1), $1-16$.

Niederle, M., \& Vesterlund, L. (2007). Do Women Shy Away From Competition? Do Men Compete Too Much? The Quarterly Journal of Economics, 122(3), 1067-1101. doi: 10.1162/qjec.122.3.1067

Niederle, M., \& Vesterlund, L. (2011). Gender and Competition. Annual Review of Economics, 3(1), 601-630.

Nordman, C. J., Rakotomanana, F., \& Robilliard, A.-S. (2010). Gender Disparities in the Malagasy Labor Market. In J. S. Arbache, A. Kolev, \& E. Filipiak (Eds.), 
Gender Disparities in Africa's Labor Market (pp. 87-144). The International Bank for Reconstruction and Development.

Nunn, N., \& Wantchekon, L. (2011). The slave trade and the origins of Mistrust in Africa. American Economic Review, 101(7), 3221-3252. doi: 10.1257/aer.101.7.3221

Osborne, T., Belghith, N., Bi, C., Thiebaud, A., Mcbride, L., \& Jodlowski, M. (2016). Shifting fortunes and enduring poverty in Madagascar : recent findings. Retrieved 2020-04-15, from http://documents.worldbank.org/curated/en/413071489776943644/Shifting -fortunes-and-enduring-poverty-in-Madagascar-recent-findings

Osterhoudt, S. (2020). "Nobody wants to kill": Economies of affect and violence in Madagascar's vanilla. American Ethnologist, 47(3), 1-15. doi: 10.1111/amet.12911

Ostry, M. J. D., Alvarez, J., Espinoza, M. R. A., \& Papageorgiou, M. C. (2018). Economic gains from gender inclusion: New mechanisms, new evidence. International Monetary Fund.

Porter, C., \& Serra, D. (2020). Gender Differences in the Choice of Major: The Importance of Female Role Models. American Economic Journal: Applied Economics, 12(3), 226-254. doi: 10.1257 app.20180426

Qian, N. (2008). Missing Women and the Price of Tea in China: The Effect of Sex-Specific Earnings on Sex Imbalance. Quarterly Journal of Economics, 123(3), 1251-1285. doi: $10.1162 /$ qjec.2008.123.3.1251

Quercia, S. (2016). Eliciting and measuring betrayal aversion using the BDM mechanism. Journal of the Economic Science Association, 2(1), 48-59.

Ray, D. (2006). Aspirations, Poverty and Economic Change. In A. V. Banerjee, R. Benabou, \& D. Mookherjee (Eds.), Understanding poverty (pp. 409 - 421). New York, NY: Oxford University Press.

Reddy, S. M., Wardropper, C., Weigel, C., Masuda, Y. J., Harden, S., Ranjan, P., ... Prokopy, L. S. (2020). Conservation behavior and effects of economic and environmental message frames. Conservation Letters(May), 1-5. doi: 10.1111/conl.12750

Riley, E. (2018). Role models in movies: the impact of Queen of Katwe on students' educational attainment. Retrieved from http://www.csae.ox.ac.uk/materials/papers/ csae-wps-2017-13

Rode, J. (2010). Truth and trust in communication: Experiments on the effect of a competitive context. Games and Economic Behavior, 68, 325-338. doi: 10.1016/ j.geb.2009.05.008

Rotter, J. (1966). Generalized expectancies for internal and external locus of reinforcement. Psychological Monographs: General and Applied, 80(1), 1-28. doi: 10.1017/CBO9781107415324.004 
Roy, S., Morton, M., \& Bhattacharya, S. (2018). Hidden human capital: Self-efficacy, aspirations and achievements of adolescent and young women in India. World Development, 111, 161-180. doi: 10.1016/j.worlddev.2018.07.002

Ruhinduka, R. D., Alem, Y., Eggert, H., \& Lybbert, T. (2020). Smallholder rice farmers' post-harvest decisions: Preferences and structural factors. European Review of Agricultural Economics, 47(4), 1587-1620. doi: 10.1093/erae/jbz052

Schechter, L. (2007). Theft, Gift-Giving and Trustworthiness: Honesty is its own reward in Rural Paraguay. The American Economic Review, 97(5), 1560-1582.

Schier, U. K. (2020). Female and male role models and competitiveness. Journal of Economic Behavior and Organization, 173, 55-67. doi: 10.1016/j.jebo.2020.03.001

Schultz. (2001). The structure of environmental concern: Concern for self, other people, and the biosphere. Journal of Environmental Psychology, 21(4), 327-339. doi: 10.1006/ jevp.2001.0227

Schultz, W., \& Zelezny, L. (2003). Reframing Environmental Messages to be Congruent with American Values. Human Ecology Review, 10(2), 126-136. doi: 10.1111/j.1439 $-037 \mathrm{X} .2011 .00478 . \mathrm{x}$

Schwieren, C., \& Weichselbaumer, D. (2010). Does competition enhance performance or cheating? A laboratory experiment. Journal of Economic Psychology, 31, 241-253. doi: 10.1016/j.joep.2009.02.005

Sen, A. (1977). Rational Fools: A Critique of the Behavioral Foundations of Economic Theory. Philosophy Public Affairs, 6(4), 317-344.

Sen, A. (1997). Maximization and the Act of Choice. Econometrica, 65(4), 745-779.

Shleifer, A. (2004). Does Competition Destroy Ethical Behavior? AEA PAPERS AND PROCEEDINGS, 94(2), 414-418.

Skjortnes, M., \& Zachariassen, H. H. (2010). 'Even with higher education you remain a woman': a gender perspective on higher education and social change in the Toliara region of Madagascar. Gender and Education, 22(2), 193-207.

Soares, R. R. (2015). Welfare costs of crime and common violence. Journal of Economic Studies, 42(1), 117-137. doi: 10.1108/JES-05-2012-0062

Steg, L., Bolderdijk, J. W., Keizer, K., \& Perlaviciute, G. (2014). An Integrated Framework for Encouraging Pro-environmental Behaviour: The role of values, situational factors and goals. Journal of Environmental Psychology, 38, 104-115. doi: 10.1016/j.jenvp.2014.01 .002

Steg, L., Perlaviciute, G., van der Werff, E., \& Lurvink, J. (2014). The Significance of Hedonic Values for Environmentally Relevant Attitudes, Preferences, and Actions. Environment and Behavior, 46 (2), 163-192. doi: 10.1177/0013916512454730 
Steg, L., \& Vlek, C. (2009). Encouraging pro-environmental behaviour: An integrative review and research agenda. Journal of Environmental Psychology, 29(3), 309-317. doi: 10.1016/j.jenvp.2008.10.004

Stifel, D., \& Rakotomanana, F. H. (2007). Assessing Labor Market Conditions in Madagascar, 2001-2005 (Africa Region Working Paper Series No. 105). World Bank Group. Retrieved 2020-09-22, from http://documents1.worldbank.org/curated/en/ 207511468270305133/pdf/418910MG0LaborOmarkets0wp10501PUBLIC1 . pdf

Stocker, M., Razafimanantsoa Harivelo, F. N., Desponts, C., \& Lalaina, M. (2019). Madagascar Economic Update: A New Start? (Tech. Rep.). Washington, D.C.: World Bank Group. Retrieved 2020-09-22, from https://openknowledge.worldbank.org/ handle/10986/32636

Stout, J. G., Dasgupta, N., Hunsinger, M., \& McManus, M. A. (2011). STEMing the Tide: Using Ingroup Experts to Inoculate Women's Self-Concept in Science, Technology, Engineering, and Mathematics (STEM). Journal of Personality and Social Psychology, $100(2), 255-270$.

Styger, E., Rakotondramasy, H. M., Pfeffer, M. J., Fernandes, E. C. M., \& Bates, D. M. (2007). Influence of slash-and-burn farming practices on fallow succession and land degradation in the rainforest region of Madagascar. Agriculture, Ecosystems $\& 6$ Environment, 119, 257-269. doi: 10.1016/j.agee.2006.07.012

Sutherland, E. (1960). Principles of criminology. 6th Edition. Philadelphia: J. B. Lippincott Co.

Trautmann, S. T. (2009). A tractable model of process fairness under risk. Journal of Economic Psychology(30), 803-813 Contents. doi: 10.1016/j.joep.2009.07.002

UNESCO Institute of Statistics. (2020). Madagascar education and literacy (Tech. Rep.). Retrieved from http://uis.unesco.org/en/country/mg

UNFPA. (2015). Madagascar sees a new generation of women leaders. Retrieved 202004-16, from https://www.unfpa.org/news/madagascar-sees-new-generation-women -leaders

UNICEF. (2018). Challenges and opportunities for children in Madagascar (Tech. Rep.). United Nations Children's Fund. Retrieved 2020-09-22, from https://www .unicef .org/ madagascar/en/reports/challenges-and-opportunities-children-madagascar

UNICEF. (2020). Early childhood development - development status. Retrieved 2020-07-29, from https://data.unicef .org/resources/dataset/early-childhood-development -development-status/

Vitz, P. C. (1990). The use of stories in moral development: New psychological reasons for an old education method. American Psychologist, 45(6), 709-720. doi: 10.1037/ 0003-066X.45.6.709 
Voors, M. J., Nillesen, E. E., Verwimp, P., Bulte, E. H., Lensink, R., \& Van Soest, D. P. (2012). Violent conflict and behavior: A field experiment in Burundi. American Economic Review, 102(2), 941-964. doi: 10.1257/aer.102.2.941

Waeber, P. O., De Grave, A., Wilmé, L., \& Garcia, C. (2017). Play, learn, explore: grasping complexity through gaming and photography. MADAGASCAR CONSERVATION AND DEVELOPMENT, 1-7.

Waeber, P. O., Wilmé, L., Mercier, J.-r., Camara, C., \& Lowry, P. (2016). How Effective Have Thirty Years of Internationally Driven Conservation and Development Efforts Been in Madagascar? PLoS ONE, 1-13. doi: 10.1371/journal.pone.0161115

Welch, M. R., Rivera, R. E. N., Conway, B. P., Yonkoski, J., Lupton, P. M., \& Giancola, R. (2005). Determinants and Consequences of Social Trust. Sociological Inquiry, 75 (4), $453-473$.

Wilson, J., \& Kelling, G. (1982). Broken windows. Retrieved from https://www .theatlantic.com/magazine/archive/1982/03/broken-windows/304465/

World Bank. (2019). World Development Indicators. Retrieved 2019-09-10, from https:// data. worldbank. org

World Bank. (2020). World Development Indicator. Retrieved 2020-12-29, from https:// databank. worldbank. org/home

World Economic Forum. (2019). The Global Gender Gap Report (Tech. Rep.). Cologny/Geneva, Switzerland: World Economic Forum. Retrieved 2020-09-22, from https://www. weforum.org/reports/gender-gap-2020-report-100-years-pay -equality

Wozniak, D., Harbaugh, W. T., \& Mayr, U. (2014). The Menstrual Cycle and Performance Feedback Alter Gender Differences in Competitive Choices. Journal of Labor Economics, 32(1), 161-198.

Zak, P. J., \& Knack, S. (2001). Trust and Growth. The Economic Journal, 111 (April), 295-321. 